\title{
Ontology of Designing
}
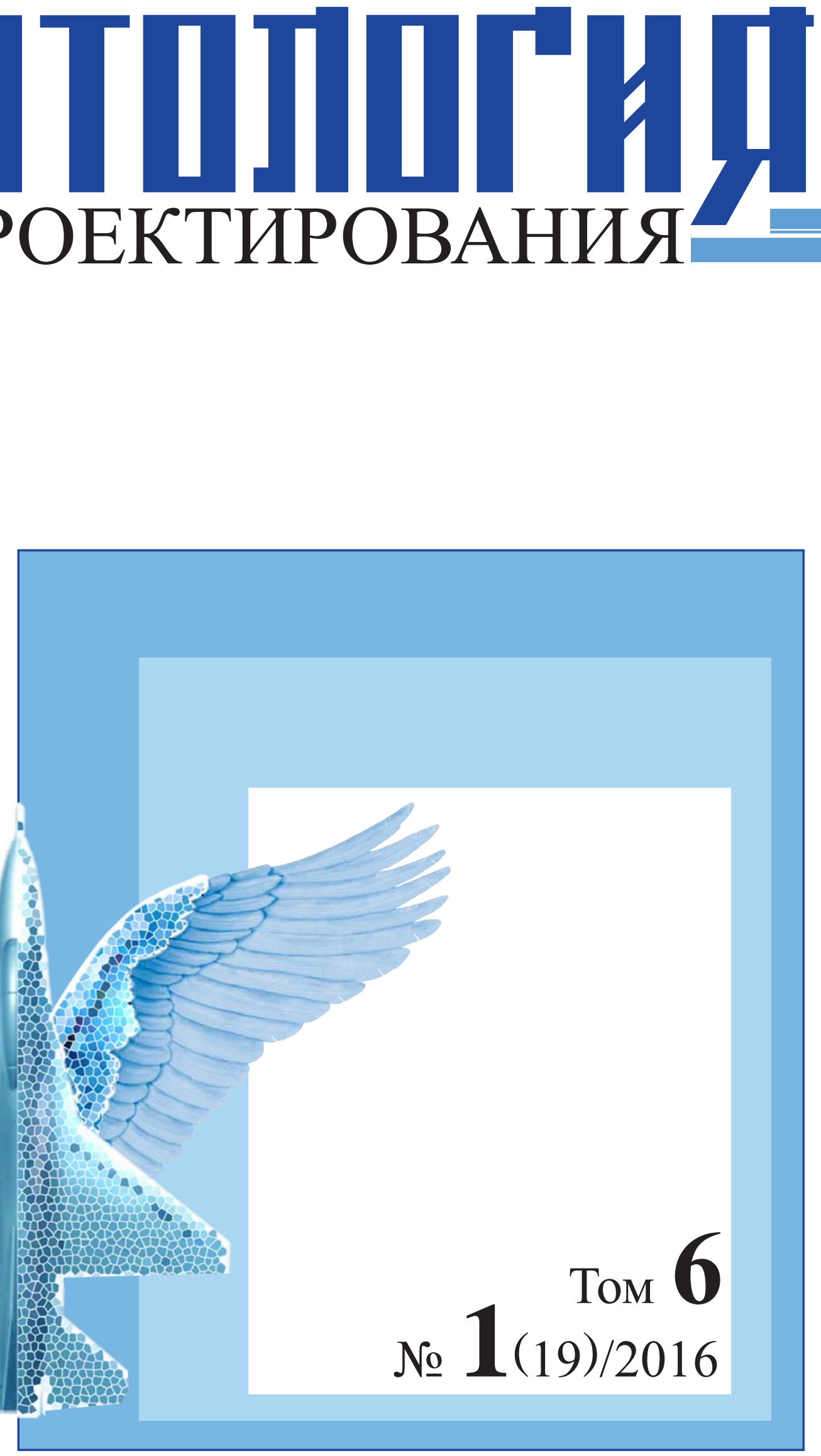


\section{Ontology of Designing}

\section{ㅁТ미ㅁㅐㅐ \\ ПРОЕКТИРОВАНИЯ}

Научный журнал

Том 6

№ 1(19)

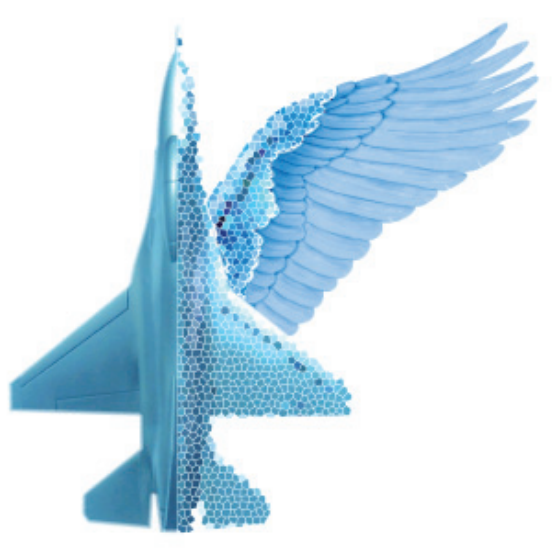


ISSN 2223-9537 (Print)

ISSN 2313-1039 (Online)
«ОНТОЛОГИЯ ПРОЕКТИРОВАНИЯ»

том 6 № 1(19)/2016

DOI:10.18287/2223-9537-2016-6-1

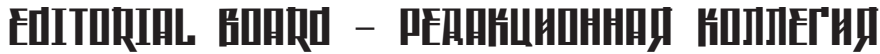

Anatoly I. Belousov

Nikolay M. Borgest

Yuri R. Valkman

Stanislav N. Vasiliev

Vladimir A. Vittikh

Vladimir V. Golenkov

Vladimir I. Gorodetsky

Alexander S. Kleshchev

Valery A. Komarov

Sergey M. Krylov

Victor M. Kureichik

Lyudmila V. Massel

Dmitry A. Novikov

Semyon A. Piyavsky

Yury M. Reznik

George Rzevski

Peter O. Skobelev

Sergey V. Smirnov

Peter I. Sosnin

Dzhavdet S. Suleymanov

Robert I. Tuller

Boris E. Fedunov

Altynbek Sharipbay

Boris Ya. Shvedin
Белоусов Анатолий Иванович, д.т.н., профессор, СГАУ, г. Самара

Боргест Николай Михайлович, к.т.н., профессор СГАУ, член IАОА, г. Самара

Валькман Юрий Роландович, д.т.н., профессор, МНУЦ ИТиС НАН и МОН Украины, г. Киев

Васильев Станислав Николаевич, академик РАН, ИПУ РАН, г. Москва

Виттих Владимир Андреевич, д.т.н., профессор, ИПУСС РАН, г. Самара

Голенков Владимир Васильевич, д.т.н., профессор, БГУИР, г. Минск

Городецкий Владимир Иванович, д.т.н., профессор, СПИИРАН, г. Санкт-Петербург

Клещёв Александр Сергеевич, д.ф.-м.н., профессор, ИАПУ дВО РАН, г. Владивосток

Комаров Валерий Андреевич, д.т.н., профессор, СГАУ, г. Самара

Крылов Сергей Михайлович, д.т.н., профессор, СамГтУ, г. Самара

Курейчик Виктор Михайлович, д.т.н, профессор, Технологический институт ЮФУ, г. Таганрог

Массель Людмила Васильевна, д.т.н., профессор., ИСЭМ СО РАН, г. Иркутск

Новиков Дмитрий Александрович, член-корреспондент РАН, ИПУ РАН, Г. Москва

Пиявский Семён Авраамович, д.т.н., профессор, СГАСУ, г. Самара

Резник Юрий Михайлович, д.филос.н., проф., Институт философии РАН, г. Москва

Ржевский Георгий, профессор, Открытый университет, г. Лондон

Скобелев Петр Олегович, д.т.н., НПК «Разумные решения», г. Самара

Смирнов Сергей Викторович, д.т.н., ИПУСС РАН, г. Самара

Соснин Петр Иванович, д.т.н., профессор, УлГтУ, г. Ульяновск

Сулейманов Джавдет Шевкетович, академик, вице-президент АН РТ, г. Казань

Таллер Роберт Израилевич, д.филос.н., профессор, СГАУ, г. Самара

Федунов Борис Евгеньевич, д.т.н., профессор, ГосНИИ Авиационных систем, г. Москва

Шарипбай Алтынбек, д.т.н., профессор, Институт искусственного интеллекта, г. Астана

Шведин Борис Яковлевич, к.психол.н., ООО «Дан Роуз», член IАОА, г. Ростов-на-Дону

\section{Executive Editorial Board - Исполнительная редакция}

Chief Editor Smirnov S.V.

Executive Editor Borgest N.M. Editor Kozlov D.M.

Editor Krylov S.M.

Technical Editor Simonova A.U.

Translation Editor Korovin M.D. Secretary Shustova D.V.

\section{ИПУСС РАН}

443020, Самара, ул. Садовая, 61

тел./факс.: +7 (846) 3332770

$\mid \begin{aligned} & \text { Главный редактор } \\ & \text { Выпускающий редактор } \\ & \text { Редактор } \\ & \text { Редактор } \\ & \text { Технический редактор } \\ & \text { Редактор перевода } \\ & \text { Секретарь }\end{aligned}$

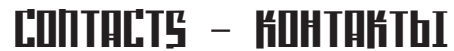

Смирнов С.В.

Боргест H.M.

Козлов Д.М.

Крылов С.M.

Симонова А.Ю

Коровин М.Д.

Коровин М.Д
Шустова Д.В. зам. директора ИПУСС РАН

директор изд-ва «Новая техника» профессор СГАУ

профессор СамГТУ

редактор изд-ва «Новая техника» аспирант СГАУ

инженер ИПУСС РАН

\section{СГАУ}

443086, Самара, Московское шоссе 34, корп. 10, кафедра КиПЛА

тел.: +7 (846) 26746 47, факс.: +7 (846) 2674646

Смирнов С.В.

smirnov@iccs.ru

Боргест H.M.

borgest@yandex.ru

\section{Издательство «Новая техника»}

443010, Самара, ул.Фрунзе, 145, тел.: +7 (846) 33267 84, факс: +7 (846) 3326781

The journal has been successfully evaluated in the evaluation procedure for the ICI Journals Master List 2014 and journal received the ICV (Index Copernicus Value) of $\mathbf{6 7 . 4 6}$ points.

Журнал включён в перечень рецензируемых научных изданий, в которых должны быть опубликованы основные научные результаты диссертаций на соискание учёной степени кандидата наук, на соискание учёной степени доктора наук (Письмо Департамента аттестации научных и научно-педагогических работников Минобрнауки РФ от 01.12.2015 № 13-6518). Журнал включён в Российский индекс научного цитирования (РИНЦ). Номер контракта 64-03/2012.

Импакт-фактор РИНЦ с учётом цитирования из всех источников 0,742 (2013 г.), 0,960 (2014г.)

Журнал зарегистрирован в Федеральной службе по надзору в сфере связи, информационных технологий и массовых коммуникаций (Роскомнадзор). Свидетельство ПИ № ФС 77-46447 от 7.09.2011 г.
http://agora.guru.ru/scientific_journal/
Отпечатано в издательстве «Новая техника»
(C) Все права принадлежат авторам публикуемых статей
Подписано в печать 24.03.2016. Тираж 300 экз.
(C) Издательство «Новая техника», 2011-2016
(C) ИПУСС РАН, 2015-2016
(C) СГАУ, 2015-2016 


\section{ОТ РЕДАКЦИИ}

ИЗУЧАЯ НАСТОЯЩЕЕ, ПРОЕКТИРУЕМ БУДУЩЕЕ

\section{ПРИКЛАДНЫЕ ОНТОЛОГИИ ПРОЕКТИРОВАНИЯ}

М.В. Гришин, С.Н. Ларин, П.И. Соснин

С.М. Крылов

МАТЕМАТИЧЕСКИЕ ОСНОВЫ ОНТОЛОГИИ ПРОЕКТИРОВАНИЯ БИНАРНЫХ СИСТЕМ ОБРАБОТКИ ИНФОРМАЦИИ

\section{МЕТОДЫ И ТЕХНОЛОГИИ ПРИНЯТИЯ РЕШЕНИЙ}

Г.П. Виноградов, Н.Г. Виноградова

\section{ИНЖИНИРИНГ ОНТОЛОГИЙ}

О.П. Кузнецов, В.С. Суховеров ОНТОЛОГИЧЕСКИЙ ПОДХОД К ОЦЕНКЕ ТЕМАТИКИ НАУЧНОГО ТЕКСТА

С.В. Микони

О КЛАССЕ, КЛАССИФИКАЦИИ И СИСТЕМАТИЗАЦИИ

\section{ФИЛОСОФСКИЕ АСПЕКТЫ ПРОЕКТНОЙ ДЕЯТЕЛЬНОСТИ}
Е.М. Кочнева СОПОСТАВЛЕНИЕ ПОНЯТИЙ ПРОЕКТ, ПРОЕКТИРОВАНИЕ И ПРОЕКТИРОВОЧНАЯ ДЕЯТЕЛЬНОСТЬ: ИСТОРИЧЕСКИЙ, ЭТИМОЛОГИЧЕСКИЙ И ГНОСЕОЛОГИЧЕСКИЙ АСПЕКТЫ

И.С. Заяц

ДВИЖЕНИЕ КАК КАТЕГОРИЯ АРХИТЕКТУРЫ

М.P. Арпентьева ЭВЕРГЕТИКА И ОНТОЛОГИИ УПРАВЛЕНИЯ

РЕКОМЕНДАЦИИ АВТОРАМ ЖУРНАЛА 


\section{[CIIITEII}

\section{FROM THE EDITORS}

STUDYING THE PRESENT, DESIGNING THE FUTURE

\section{APPLIED ONTOLOGY OF DESIGNING}

M.V. Grishin, S.N. Larin, P.I. Sosnin

ONTOLOGY OF DESIGNING INDUSTRIAL EQUIPMENT

WITHIN THE AVIATION PRODUCTION

S.M. Krylov

MATHEMATICAL FOUNDATION OF BINARY SYSTEM ONTOLOGY

FOR DATA PROCESSING

\section{METHODS AND TECHNOLOGIES OF DECISION MAKING}

G.P Vinogradov, N.G Vinogradova

SELF-ORGANIZING NETWORK EXPERT SYSTEMS ENVIRONMENT

IN PRINCIPLE ENDOGENOUS TARGET DESIGNATION

\section{ONTOLOGY ENGINEERING}

O.P. Kuznetsov, V.S. Sukhoverov

A ONTOLOGICAL APPROACH TO DETERMINING THE SUBJECT MATTER OF SCIENTIFIC TEXT

S.V. Mikoni

ABOUT THE CLASS, CLASSIFICATION AND SYSTEMATIZATION

\section{PHILOSOPHICAL AND LINGUISTIC ASPECTS OF DESIGNING}

E.M. Kochneva

COMPARISON OF CONCEPT DESIGN, DESIGNING AND PROJECT

ACTIVITY: HISTORICAL, ETYMOLOGICAL AND

EPISTEMOLOGICAL ASPECTS

I.S. Zayats MOVEMENT AS A CATEGORY OF ARCHITECTURE

M.R. Arpentieva

EVERGETIC AND ONTOLOGIES OF MANAGEMENT

RECOMMENDATIONS FOR AUTHORS OF JOURNAL 


\section{PERПIÍLHН}

\section{ИЗУЧАЯ НАСТОЯЩЕЕ, ПРОЕКТИРУЕМ БУДУЩЕЕ STUDYING THE PRESENT, DESIGNING THE FUTURE}

Дело умных предвидеть беду, пока она не пришла... ... Трудно быть хорошим [для всех]

Питтак

\section{Дорогой наш читатель, уважаемые авторы и члены редакционной коллегии!}

Начало года, первая его четверть для нашего журнала были так же насыщены событиями, как и все предыдущие годы его продвижения в медийном пространстве.

13-15 января в Москве Гайдаровский форум «Россия и мир: взгляд в будущее» («Russia and the World: Looking to the future»), на котором наш журнал был аккредитован как СМИ, а в завершающий день форума последний выпуск журнала был презентован ректору РАНХиГС при Президенте РФ Владимиру Александровичу Мау.

Затронутые на форуме проблемы во многом близки научному направлению «Онтология проектирования», т.к. сущностный анализ предметной области, целеполагание, критерии и принципы распределения ограниченных ресурсов, методы принятия решений и многое другое, о которых шла речь на форуме, бесспорно, относятся к области научных исследований, результаты которых публикуются в нашем журнале. Теперь мы в ожидании материалов с научными достижениями из пограничных проектных областей, где объектом исследований выступают сообщества субъектов, где задействованы мотивационные механизмы, где воздействие информации может доминировать над материальным фактором, где моделирование поведения экземпляров классов существенно отличается от моделирования самих классов. Пока же, по словам министра экономического развития РФ А.В. Улюкаева, «..ответы на вызовы.. остаются в области академических упражнений, советов, рекомендаций и плохо имплементируются в жизнь. ...если теория противоречит фактам, значит, надо теорию пересмотреть, надо развиваться». Вот этим и займёмся!

Здесь же по нашей традиции стоит вспомнить греческий опыт и, в частности, одного из семи мудрецов Древней Греции Питтака из Митилены (651-569 до н.э.). Наряду с известными моделями демократии, автократии, олигархии и другими их разновидностями Аристотель на примере Питтака показал такой вид правления как эсимнетия или «выборная тирания». Эсимнетия - это единоличное правление, когда народ как носитель верховной власти сам добровольно вручает власть одному человеку на определённый срок или для решения определённых задач. Эсимнет, или иногда историки, да и современники, именуют его тираном, мог единолично принимать самые ответственные решения, но в рамках существующих законов ${ }^{2}$. Приписываемые Питтаку законы следует рассматривать не как

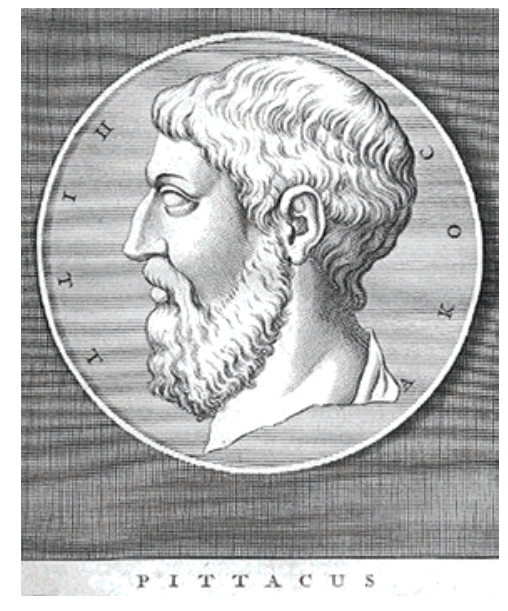

\footnotetext{
${ }^{1}$ Таково же и одноимённое название юбилейных Гайдаровских чтений, прошедших в Москве осенью 2015 года, и вышедших в начале 2016 года материалов, посвящённых 25-летию Института Гайдара (ISBN 978-5-93255-442-5).

${ }^{2}$ Пальцева Л.А. Питтак Митиленский (к вопросу об эсимнетии в архаической Греции) / Античное государство. Политические отношения и государственные формы в античном мире. Сборник научных статей под редакцией проф. Э.Д. Фролова. Санкт-Петербург, 2002. - http://centant.spbu.ru/centrum/publik/kafsbor/20021/palz.htm
} 
антиаристократические, а как одно из проявлений объективного процесса постепенного укрепления коллективного начала в политической структуре в противовес аристократическому индивидуализму. При этом Питтак, как «примерный эсимнет», не может считаться «народным вождем», так как правление в Митиленах до конца V в. до н.э. оставалось олигархическим, и демос не получил никакой существенной власти ${ }^{3} \ldots$ Оставив за кадром онтологию власти, нельзя не вспомнить мудрый совет Питтака, который на вопрос о том, что же лучше всего, ответил: «Хорошо делать, что делаешь». При этом признался, что если потребуется отыскать дельного человека и «если искать с пристрастием, то такого и не найти». Завершить воспоминания о Питтаке стоит его многозначными изречениями «пользуйся мерой» и «знай всему пору», что в проектной деятельности всегда является определяющим.

18-20 февраля в Минске прошла очередная VI Международная научно-техническая конференция «Open Semantic Technologies for Intelligent Systems»(OSTIS-2016), информационную поддержку которой традиционно уже который год оказывает наш журнал.

24-28 февраля Челябинский государственный университет провел V Международную научную конференцию «Информационные технологии и системы» (ИТиС-2015), на которой был заслушан пленарный доклад Боргеста Н.М. «Информационная поддержка издательской деятельности на примере выпуска научного журнала «Онтология проектирования».

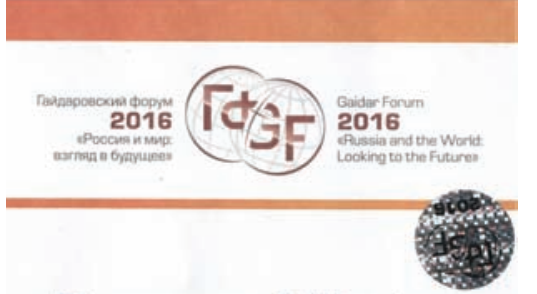

\section{Borgest Nikolay}

"Ontology of Designing" scientific journal
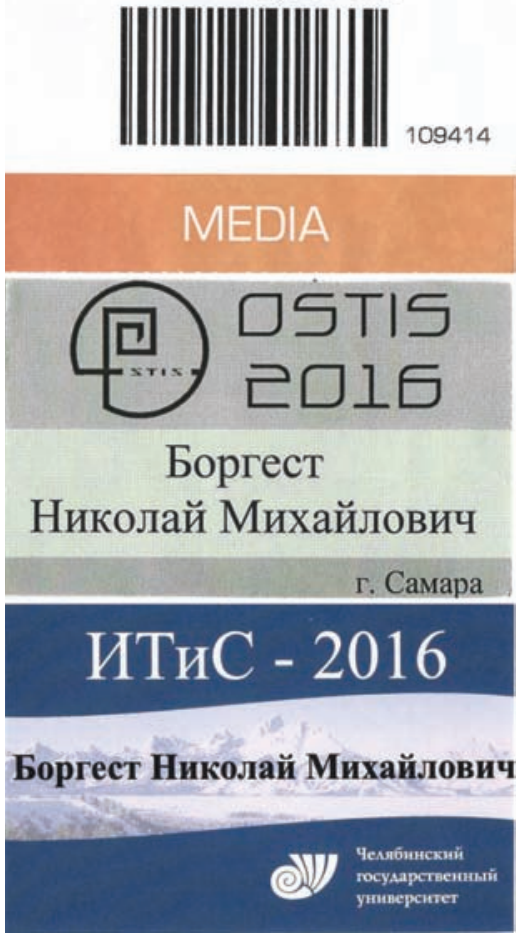

В разделе «Рекомендуемые научные конференции» этого номера журнала приводятся данные о международных научных конференциях, которые будут проходить в 2016 году и, надеемся, могут представлять интерес для нашего читателя.

Уважаемый читатель!

В этом номере журнала вы найдёте статьи новых ещё не публиковавшихся у нас учёных и специалистов, а также уже известных нашему читателю авторов из Москвы, СанктПетербурга, Нижнего Новгорода, Самары, Твери, Калуги и Ульяновска.

Отрадно отметить внимательное прочтение нашими авторами других статей в нашем журнале. Так, профессор С.В. Микони уже не первый раз оперативно реагирует на призыв редакции к освещению возникающих проблем и поддерживает «градус научной дискуссии» на страницах нашего журнала. Доцент Е.М. Кочнева из Мининского университета поддерживая идею, высказанную в статье Н.М. Боргеста, предложила расширить словник разрабатываемого толкового словаря проектанта. Доктор наук М.Р. Арпентьева из Калужского университета им. К.Э. Циолковского развивает идеи В.А. Виттиха об эвергетике, рассматривая её с позиций онтологии управления.

Следующий выпуск нашего журнала - 20-й юбилейный! И мы надеемся порадовать наших читателей новыми результатами и опытом формализации знаний проектной деятельности в различных предметных областях. Мы уверены, что «перекрёстное опыление» гуманитарных и технических научных знаний даст свои всходы и плоды!

Ontologists and designers of all countries and subject areas, join us!

${ }^{3}$ Соломатина Е.И. Питтак Митиленский: народный диктатор или вождь аристократов? «Studia historica». Vol. III. Москва, 2003. - C. 19-37. - http://ancientrome.ru/publik/article.htm?a=1382620479 


\title{
УДК 658.512:004
}

\section{ОНТОЛОГИИ ПРОЕКТИРОВАНИЯ ШАБЛОННОЙ ОСНАСТКИ В АВИАЦИОННОМ ПРОИЗВОДСТВЕ}

\author{
М.В. Гришин ${ }^{1}$, С.Н. Ларин ${ }^{2}$, П.И. Соснин ${ }^{3}$ \\ ${ }^{1}$ Ульяновское конструкторское бюро приборостроения, Ульяновск, Россия \\ likani7@mail.ru \\ ${ }^{2}$ Научно-производственное объединение «МАРС», Ульяновск, Россия \\ larinmars@ rambler.ru \\ ${ }^{3}$ Ульяновский государственный технический университет, Ульяновск, Россия \\ sosnin@ulstu.ru
}

\begin{abstract}
Аннотация
Целью данной работы является совершенствование процессов проектирования шаблонной оснастки в условиях авиационных производств за счёт разработки средств онтологической поддержки. В статье в состав инструментально-технологических средств проектирования шаблонов предлагается включить средства онтологического сопровождения, обеспечивающие: контролируемое накопление опыта разработок шаблонов в форме моделей прецедентов, подготовленных к повторному использованию; систематизацию моделей шаблонов, в основу которой положено интерактивное классифицирование и связывание с использованием механизмов систематизации в онтологиях; контролируемое использование лексики, включая понятия, в документах, разрабатываемых в процессе работ. Важной особенностью предлагаемых средств является то, что они опираются на результаты экспериментов, которые проводились с семантическими моделями шаблонов и моделями программ числового программного управления, использующихся в их производстве. Для проведения экспериментов, создания онтологии и средств онтологического сопровождения предложено использовать вопросно-ответную моделирующую среду WIQA, средства которой были адаптированы к инструментальной поддержке жизненного цикла шаблонов.
\end{abstract}

Ключевые слова: онтология проектирования, классификатор, воздушное судно, шиаблонная оснастка, WIQA.

Цитирование: Гришин М.В. Онтологии проектирования шаблонной оснастки в авиационном производстве / М.В. Гришин, С.Н. Ларин, П.И. Соснин // Онтология проектирования. - 2016. - Т.6, №1(19). - C. 7-28. - DOI: 10.18287/2223-9537-2016-6-1-7-28.

\section{Введение}

За последние семьдесят лет развития отечественной авиационной отрасли в области технологической подготовки производства (ТПП) предприятий-изготовителей воздушных судов накопился немалый запас знаний в части проектирования и изготовления технологической оснастки (ТО), служащей для изготовления различной номенклатуры деталей.

В процессе ТПП новых изделий трудоёмкость проектирования и изготовления ТО (шаблоны, форм-блоки, контрольно-доводочные плазы, штампы и т.д.) может доходить в среднем до $50 \%$ от общей стоимости одного или нескольких образцов изделия.

Учитывая важность ТО для подготовки производства новых наукоёмких изделий, на отечественных авиационных предприятиях к знаниям и опыту относятся как к исключительно полезным ресурсам. Большая часть информации, вложенной в такие ресурсы, представлена в виде электронных моделей деталей (ЭМД), электронных чертежей, технологических процессов, а также текстах различных регламентов, стандартов предприятия, технологических инструкций, ГОСТ, ОСТ и т.п. 
Всё это аккумулировалось в течение долгого времени, прошло апробацию и согласование на практике. Как следствие, для подобных больших объёмов разнородных инженерных знаний возникает потребность в переработке для подтверждения необходимости использования одних и отказа от других знаний, оказавшихся устаревшими. При этом естественно использовать известные методы систематизации и классификации, переработки и сохранения, а также принципы повторного использования.

В тоже время, проектирование ТО - это творческий процесс, состоящий из набора событий и связанных с ним состояний и действий пользователя. В рамках этих событий происходит логическое развитие конструкции от технического задания или условий поставки, до готового решения в виде электронной модели оснастки и далее вплоть до изготовления ТО «в металле» [1]. Здесь также следует отметить тот факт, что для изготовления одной детали требуется несколько единиц ТО, обслуживающих различные этапы жизненного цикла конструкций. Важно и то, что перенос знаний в компьютерную среду, как правило, изменяет характер деятельности лиц, вовлечённых в процесс проектирования, по сравнению с профессиональной активностью в рамках твердотельных систем автоматизированного проектирования (САПР), так как компьютеризованные знания оказываются необходимыми и используются в различных и разнообразных «точках» производственного процесса.

В статье с ориентацией на проектирование шаблонной оснастки авиационных деталей предлагается унифицированная версия систематизации знаний, в основу которых положена онтология проектирования, реализованная в инструментальной моделирующей среде WIQA (Working In Questions and Answers) [2]. К специфике этого инструментария относится возможность нормативного отображения освоенного опыта проектирования на специализированную семантическую память. В число этих норм включены унифицированные модели понятий и модели прецедентов (деятельностных единиц повторного использования), что определило решение применить онтологическую систематизацию для интеграции знаний.

Предлагаемая версия онтологической систематизации доведена до практического применения как на этапах формирования и развития онтологии, так и на этапах использования шаблонов в изготовлении деталей, их контроле и взаимоувязке, причём в контексте сокращения времени и повышения качества проектирования ТО на основе повторного использования накопленных знаний и опыта.

\section{1 Онтология как средство поддержки процессов проектирования}

Реальность такова, что на современных российских машиностроительных предприятиях онтологические формы представления опыта и знаний практически не применяются, однако анализ ряда работ отечественных учёных в этом направлении говорит о положительной динамике интеграции прикладных онтологий как в производственный цикл изделий, так и в информационные системы предприятий. Одним из основных факторов, способствующих продвижению этой области, является то обстоятельство, что на предприятиях авиационной отрасли имеется острая нехватка инженеров среднего возраста. Возрастной разрыв специалистов инженерно-технического состава составляет от двадцати до двадцати пяти лет, и в тоже время старшее поколение покидает стены завода, унося колоссальный запас опыта и знаний с собой. Следует отметить, что особо опасна потеря опыта проектирования.

Другим принципиальным фактором внедрения онтологий в производственные процессы является их расширяющаяся информатизация, которая требует особого контроля интеграции этих процессов в единое и согласованное целое. На более детальных уровнях онтологическое сопровождение способствует повышению степени автоматизации действий специалистов в их коллективной и персональной деятельности, особенно там, где профессиональная дея- 
тельность носит творческий характер. В первую очередь это относится к рабочим местам специалистов, которые вовлечены в проектную деятельность, для концептуальной систематизации которой оказываются полезными онтологии проектирования.

Под онтологией проектирования понимается формализованное описание знаний субъектов проектирования о прочессе проектирования новых или модернизаций уже известных артефактов, включая знания о самом объекте проектирования и близких к нему по свойствам артефактов, а также тезаурус предметной области [3] (рисунок 1).

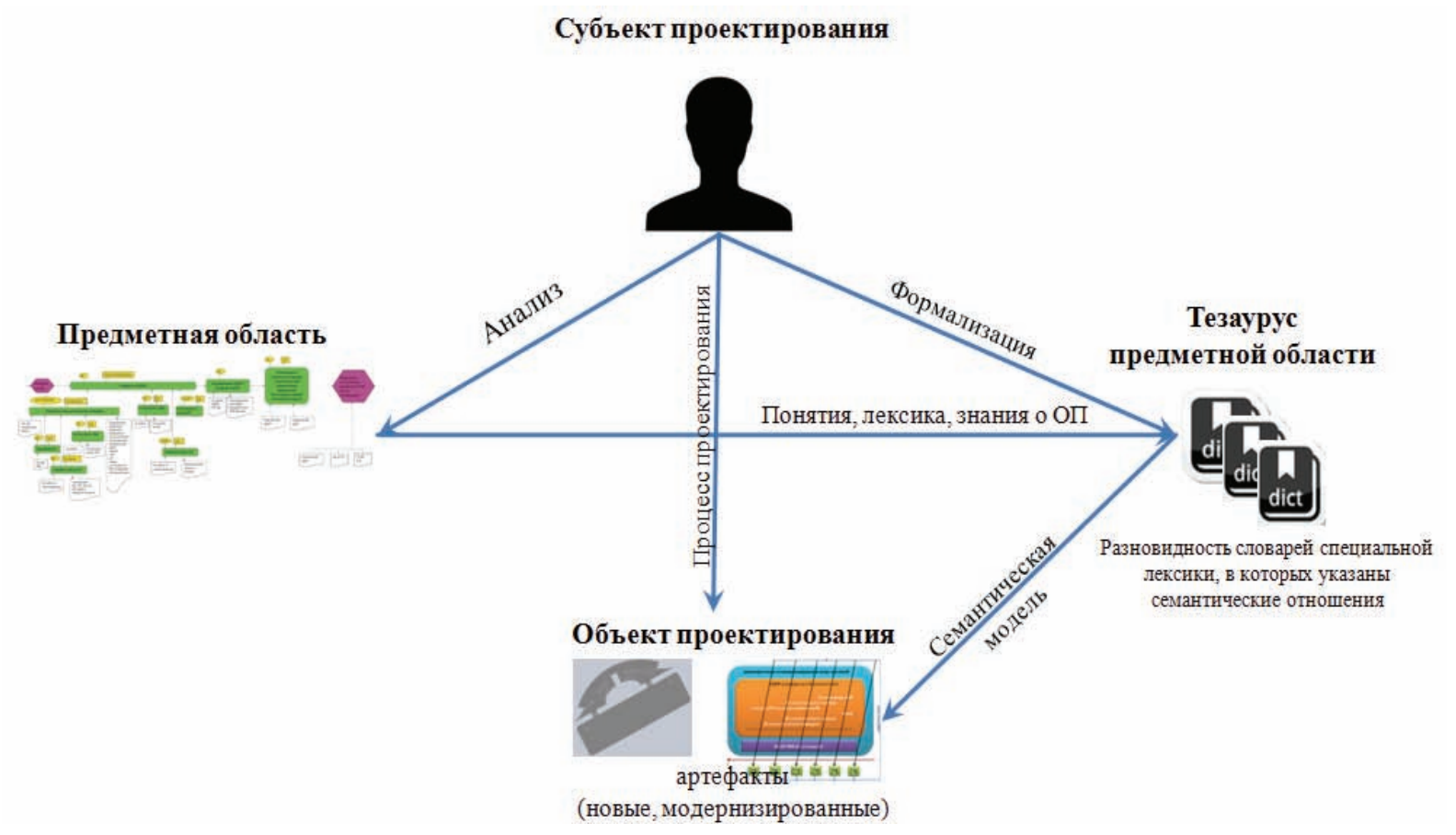

Рисунок 1 - Представление структурной схемы онтологии проектирования

Как видно из рисунка 1, онтология проектирования позволяет шире и детальнее представить процесс проектирования (в рассматриваемом случае шаблонной оснастки), оперируя понятиями и знаниями предметной области. Она позволяет не только сохранять и аккумулировать опыт, но также и экспериментировать с моделями шаблонов, создавая принципиально новые проектные решения и оценивать их «удачность» и «рациональность» применительно к производственным технологическим процессам. В качестве примера на рисунке 2 представлен вариант нового проектного решения, полученного в ходе экспериментов с проектной онтологией, рабочее название которому можно дать как комбинированный шаблон или комбинированный шаблон обрезки и кондуктор (ШОК). Следует отметить, что согласно [4] каждый тип шаблона независим сам по себе и их позиционирование друг относительно друга осуществляется либо по технологическим рискам, либо по базовым отверстиям (БО). Минусами такого подхода является то, что если проектировщиком будет допущена ошибка хотя бы в 2 мм, конечная деталь может получиться бракованной, а в случае, представленном на рисунке 2, введены дополнительные конструктивные элементы - шпильки, фиксирующиеся посредством шпилечных отверстий (ШО). В этом случае достигается достаточное базирование между ШОК (верхний), который контролирует выштамповку детали, и ШОК (нижний), служащим для контроля нижнего контура и его обрезки по шаблону.

Достоинством онтологического подхода является то, что ранние этапы проектирования осуществляются с активным применением естественно-профессионального языка, включа- 
ющего специализированные термины, способствующие унификации понимания в порождаемых текстах и используемых рассуждениях.

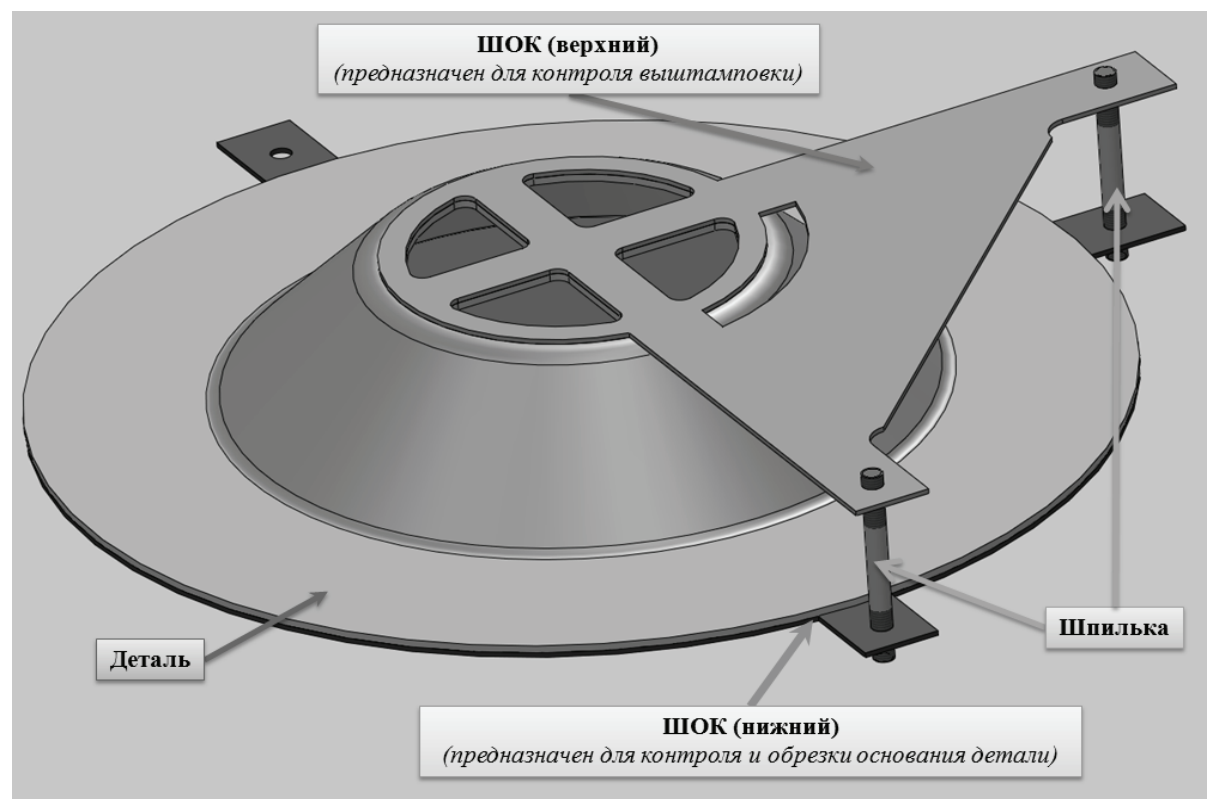

Рисунок 2 - Пример нового проектного решения «Комбинированный шаблон обрезки и кондуктор»

\section{2 Применение проектной онтологии к жизненному циклу шаблонов в условиях авиационного предприятия}

Несмотря на то, что на данный момент использование плазов в машиностроительном производстве практически сведено к нулю, а ЭМД используется как первоисточник информации для получения моделей и электронных документов системы бесплазовой подготовки производства, значительную часть шаблонов всё равно придётся делать (бесплазовое — не значит бесшаблонное), поскольку изготовление и контроль элементов конструкции на первых порах осуществляется по традиционной технологии. Отказ от шаблонов возможен только после переоснащения всех этапов производства (включая сборку) новым поколением программно-управляемого оборудования [5]. Более того, изготовление части деталей, особенно профилей жёсткости, стрингеров, лонжеронов, (составляющей до 40\% номенклатуры изделий) экономически целесообразнее делать по традиционной технологии, нежели на станках с числовым программным управлением (ЧПУ).

Поэтому на сегодняшний день в авиастроительном производстве для изготовления, контроля и сборки деталей фюзеляжа, крыльев и элерона, включая детали их обшивки, широко используется шаблонное оснащение, в состав которого входят десятки тысяч шаблонов разной степени сложности и назначения. Этот факт обусловлен такими особенностями деталей названного класса, как сложность их геометрических форм, малая жёсткость, большие габариты, высокие требования точности изготовления и точности сопряжения. Кроме того, для увязки деталей, входящих в каждое плоское сечение конструкции самолёта, необходима система жёстких носителей, фиксирующих контуры внутренних деталей, входящих в состав данного сечения. Например, большие по величине детали приходится увязывать на листовых металлических контрольно-контурных шаблонах (ККШ). Отмеченные особенности неявно и обобщенно отражены на рисунке 3, на котором приведён и обозначен ряд шаблонов.

Исходя из сказанного, можно считать, что шаблон является не только носителем геометрии и формы детали, но также включает конструктивные и технологические базы, контуры и 
оси внутренних деталей, попавших в данное сечение, различные конструктивные и технологические отверстия. Кроме того на шаблоны наносятся различная надписи: название шаблона, шифр и номер чертежа изделия, марка и толщина материала и др.

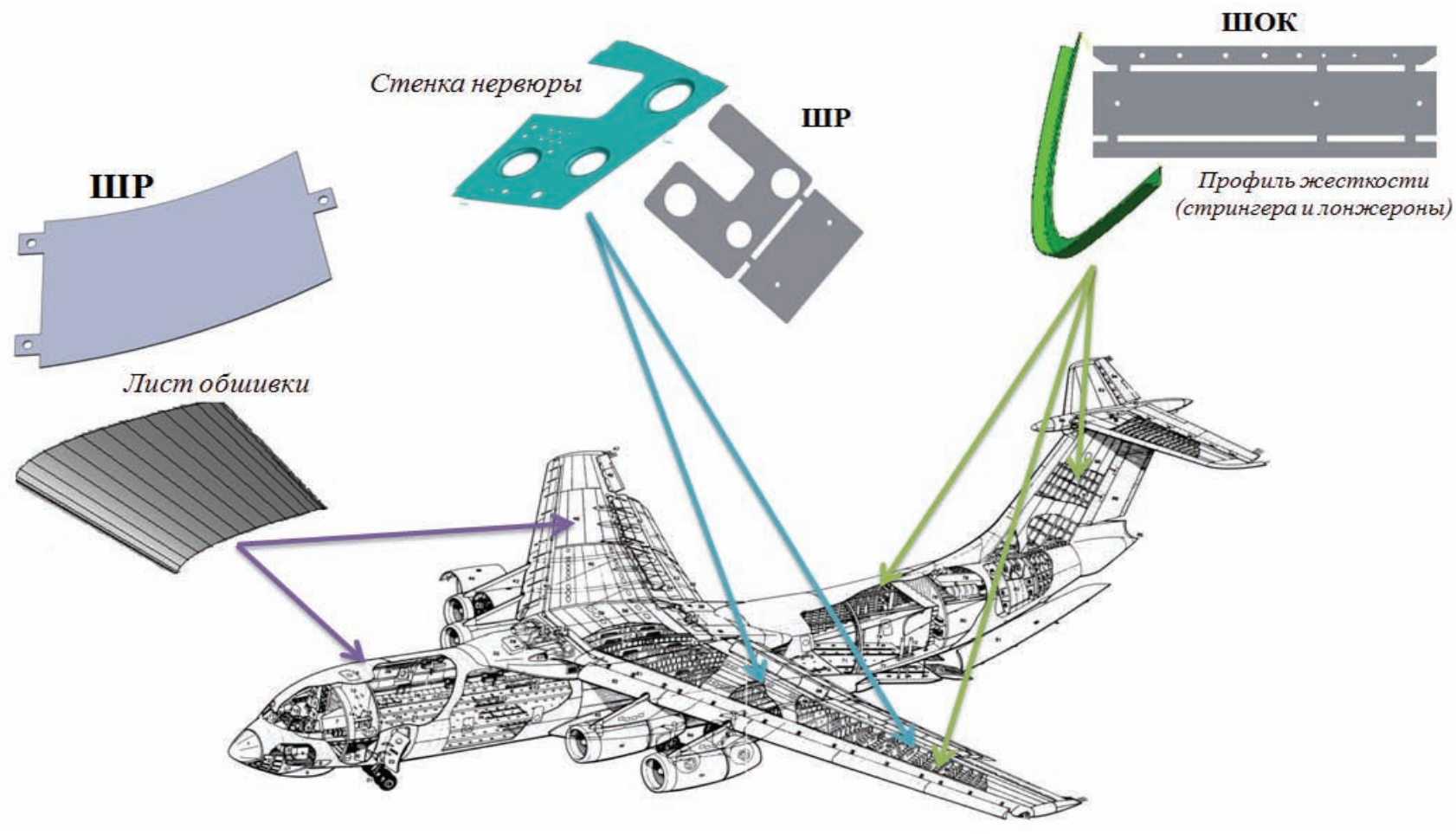

Рисунок 3 - Схема взаимосвязей деталей и шаблонов на примере Ил-76МД-90А

Геометрия любого конфигурируемого шаблона сложнее геометрии детали, для работы с которой он создан. Выбор и реализация той части структуры шаблона, которая дополняет включённую в шаблон форму (и размеры) определённого сечения детали, выводит на ряд проектных задач, допускающих альтернативные решения, причём на разных этапах жизненных циклов деталей и соответствующих им шаблонов. Такую особенность учитывает совокупность представленных средств структурного проектирования шаблонов. Схема комплексирования таких средств (в контексте жизненного цикла шаблона) приведена на рисунке 4.

При переходе к производству нового самолета шаблонную оснастку приходится создавать заново, используя освоенные шаблоны, модифицируя их, и разрабатывая новые. Такое положение дел указывает на целесообразность включения экспериментов (не с шаблонами, а с их моделями) в жизненный цикл проектирования шаблонов.

Для обеспечения онтологической поддержки процесса, любой шаблон представляется моделью прецедентного типа, в которой нормативно накапливается и интегрируется в единое целое то, что в проектировании шаблона будет полезным и удобным для повторного использования такой модели. Центральное место в ней занимает нормативная структура, составляющие которой заполняются предметным образом, а информационное содержание извлекается и оперативно используется в процессе проектирования соответствующего шаблона [6]. Для рационализации жизненного цикла шаблона действия по проектированию шаблона должны осуществляться в соответствии со стандартом [4]. Отличие лишь в том, что все эти действия выполняются под управлением (псевдокодовых) программ действий проектировщика в среде WIQA, причём отображения детали и исходной версии шаблона исполняют роль входных данных для осуществления действий непосредственно в моделирующей среде. 


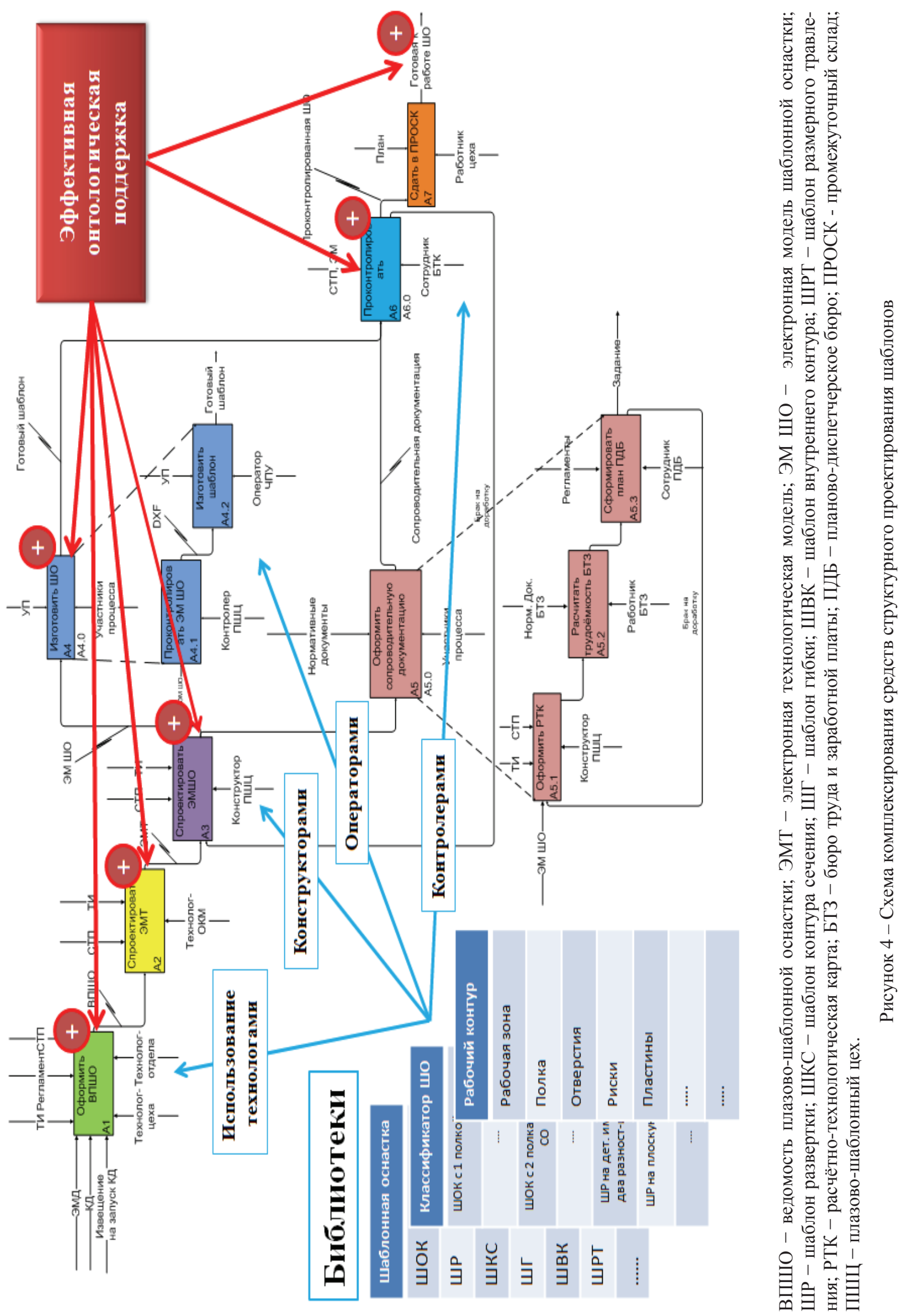




\section{1 Обзор редакторов онтологий}

Онтологии как форма представления знаний используются в программировании. Наиболее широкое применение они нашли в построении семантической паутины, системах искусственного интеллекта, экспертных системах (в частности, медицинских) и прочих областях, где знаниями оперируют в близких онтологиям формате.

Количество общедоступных редакторов онтологий уже давно превысило 100. Широко используются, например, редакторы онтологий: Ontolingua, Protege, Magenta, OntoSaurus, OntoEdit, WebODE и др. (рисунок 5) [3].

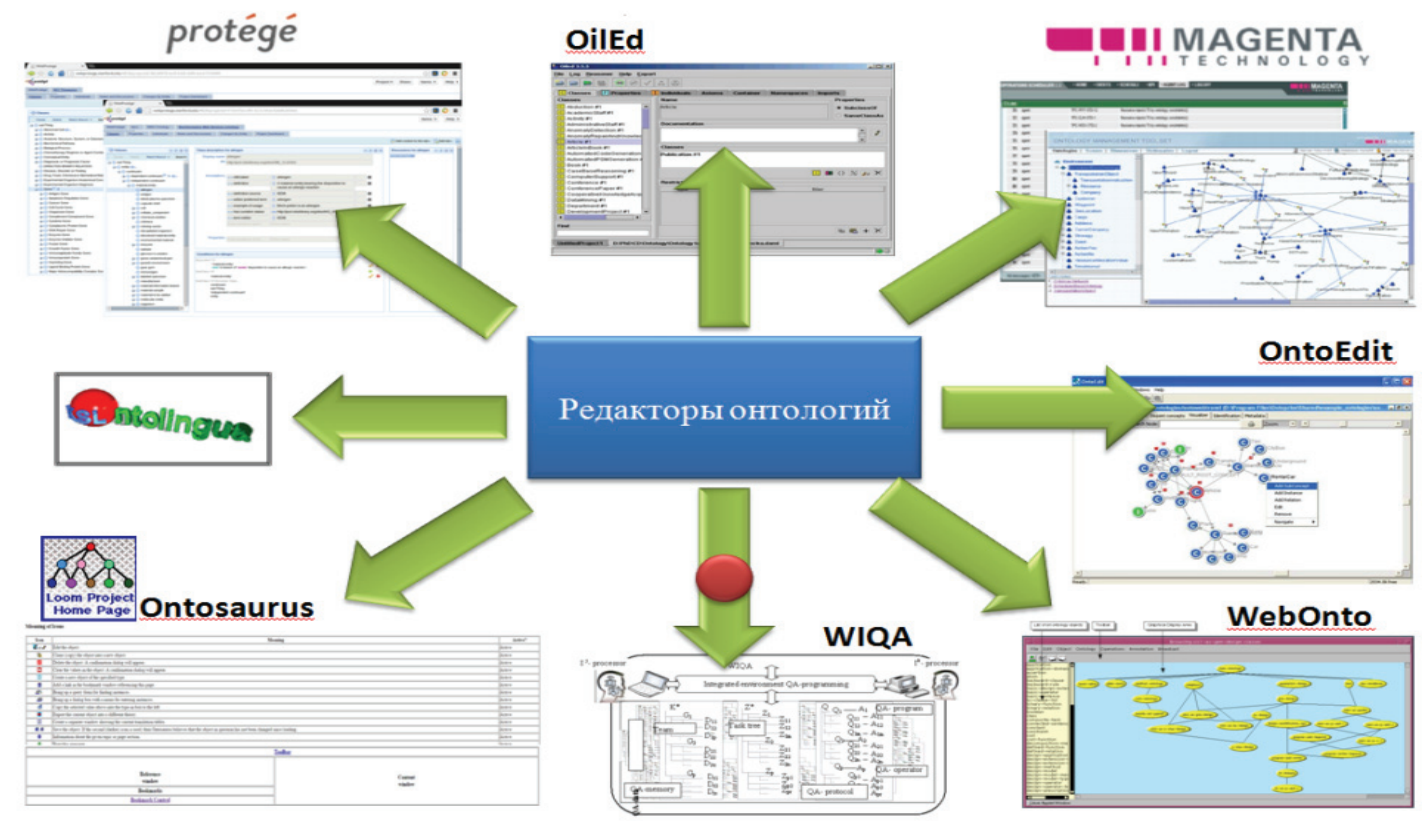

Рисунок 5 - Примеры редакторов онтологий

Большинству используемых в настоящее время редакторов онтологий присущи схожие недостатки, возникшие из-за стремления разработчиков к обеспечению кроссплатформенности своих приложений - с помощью использования соответствующих языков программирования, подобным языку Java, либо с помощью исполнения приложений в виде веб-сервисов и надстроек к уже существующим интегрированным средам разработки, таким как Eclipse [7].

Среди таких недостатков, в первую очередь, выделим следующие:

- отсутствие контекстной помощи в руководствах пользователя;

- отсутствие русифицированных руководств и интерфейсов онторедакторов;

- сложность процесса разработки в условиях обеспечения кроссплатформенности.

В целях устранения отмеченных недостатков в состав моделирующей среды WIQA включены онтологические средства, которые позволили существенно расширить потенциал онтологической систематизации и средства представления аксиоматики, дополнив её типовыми моделями прецедентов.

\section{2 Отображение процесса проектирования на семантическую память}

В соответствии с исходными установками предлагаемого подхода, созданная «онтология проектирования» предназначена для систематизации моделей шаблонов, которые разработаны и используются в производстве авиационных деталей [8]. 
В спецификациях «онтологии» и её материализации принципиальное место занимает вопросно-ответная память (QA-память) инструментария WIQA, обобщённо представленная на рисунке 6.

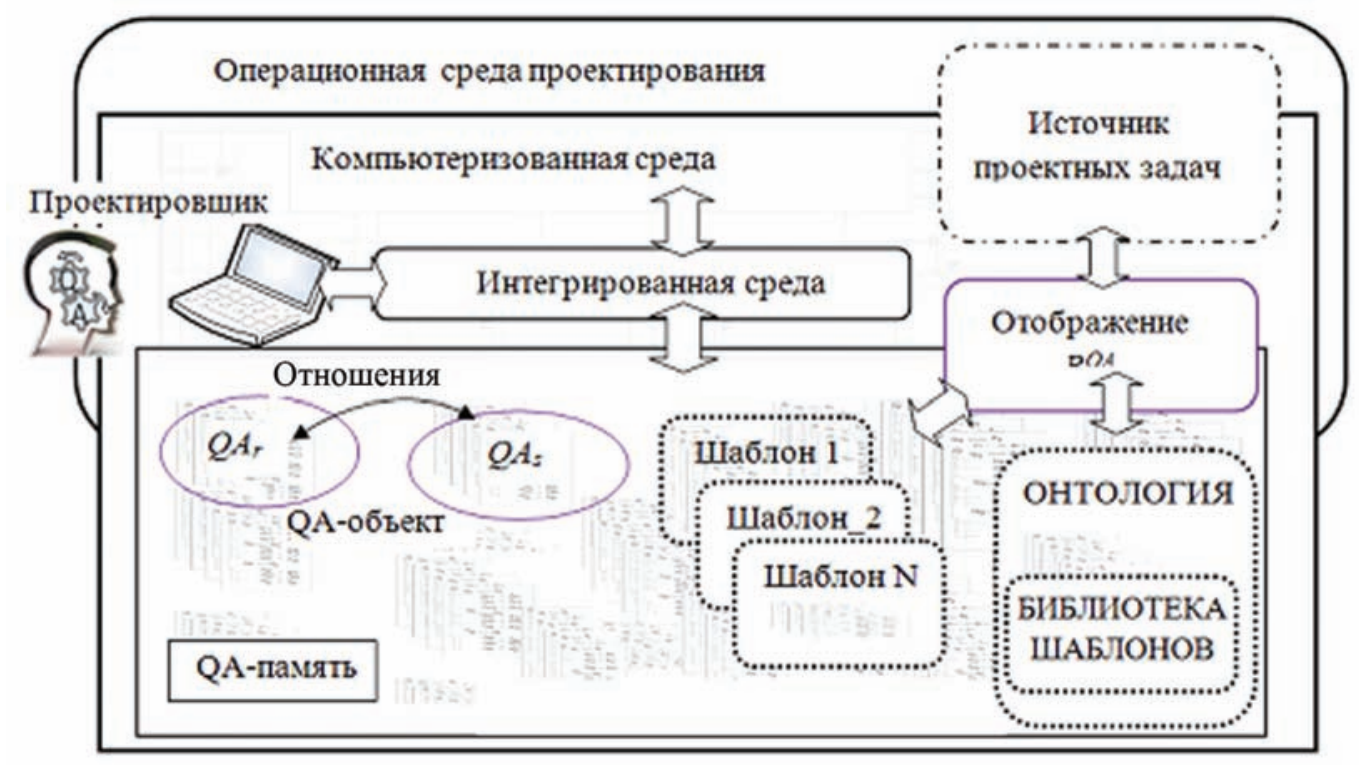

Рисунок 6 - Отображение процесса проектирования шаблонов на семантическую память моделирующей среды WIQA

QA-память - это подсистема инструментария WIQA, предназначенная для семантического моделирования составляющих процесса проектирования в решении задач. Конкретная вопросно-ответная модель (QА-модель) объекта загружается в ячейки QA-памяти, каждая из которых используется для хранения спецификации или совокупности спецификаций объекта моделирования. Типовая ячейка памяти приведена на рисунке 7 [8].

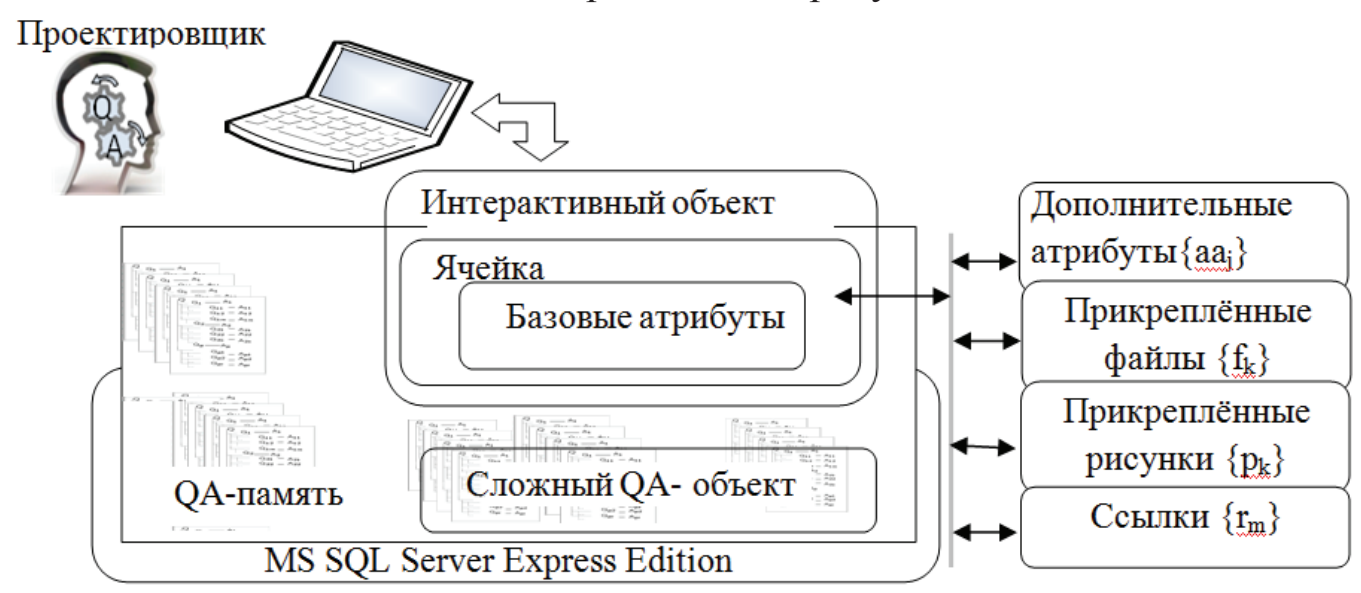

Рисунок 7 - Структура ячейки QA-памяти моделирующей среды WIQA

В число базовых атрибутов ячейки QА-памяти включены: уникальное имя модели (тип и индекс, приписываемый автоматически), например Q1.1.2, способное выполнять роль адреса ячейки; идентификатор создателя модели, то есть имя I; знаковая модель Q или А, в форме символьной строки; момент времени создания или модификации; имя проекта и другие атрибуты. Версия ячейки QА-памяти, адаптированная к регистрации составляющих онтологии, приведена на рисунке 8 [8]. 


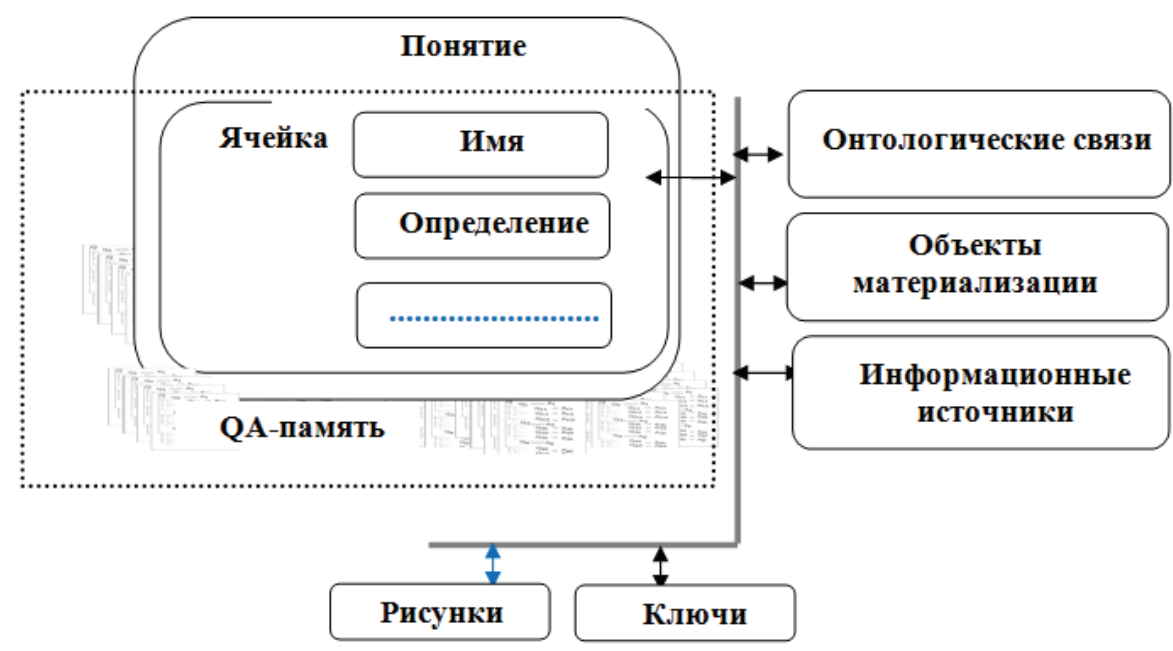

Рисунок 8 - Версия ячейки QА-памяти

С учётом структуры и семантики ячеек памяти и их настройки на онтологию предметной области проектирования шаблонов реализована и модель прецедента, схема которого приведена на рисунке 9.

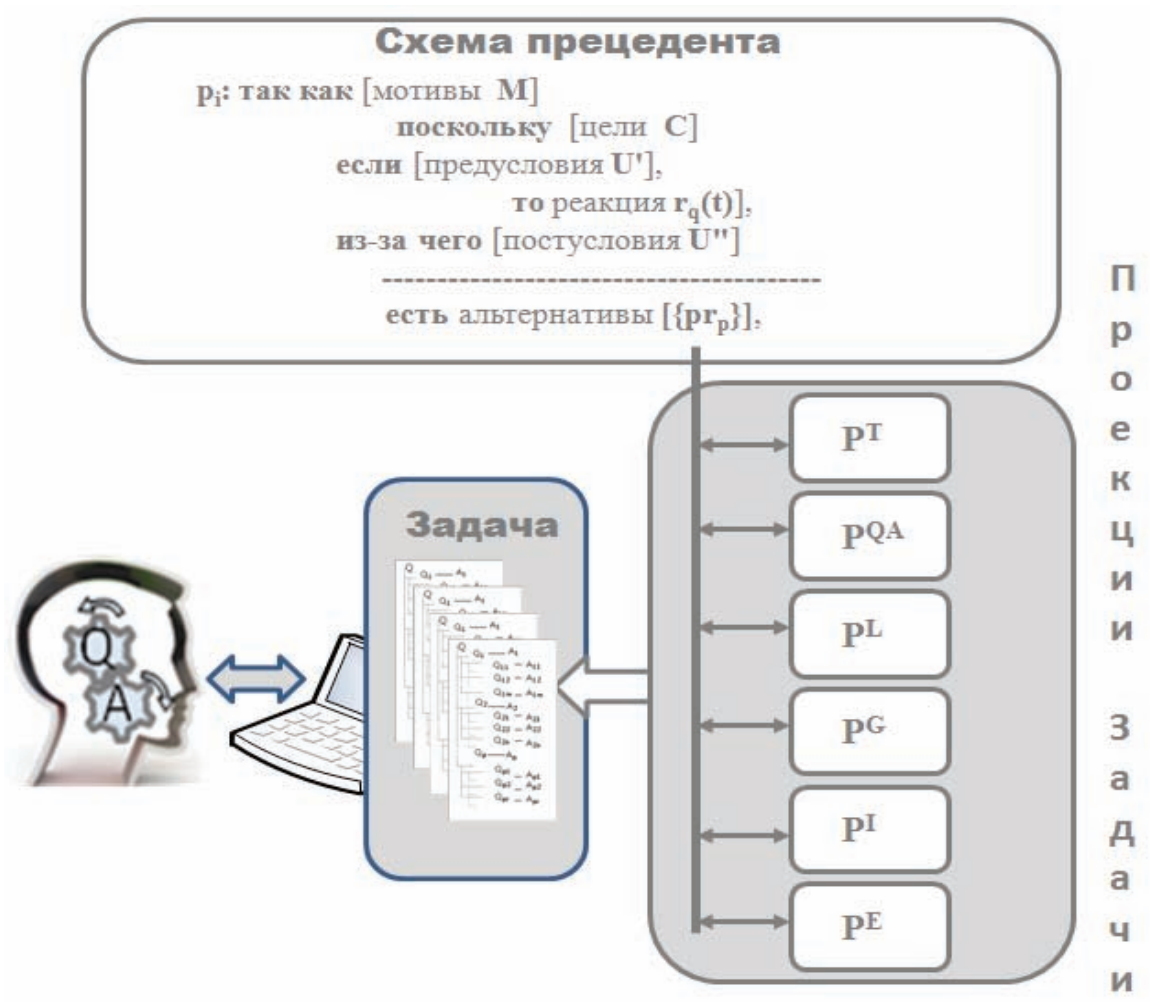

Рисунок 9 - Модель прецедента

Модель конкретного прецедента $\mathrm{P}_{\mathrm{k}}$ включает: текстовую составляющую $\mathrm{P}^{\top}$, в виде постановки задачи; логическую составляющую $\mathrm{P}_{k}{ }_{k}$, формула которой представлена на рисунке 9; вопросно-ответную модель $P^{Q A}{ }_{k}$ задачи $Z_{k}$; графическое представление прецедента $P^{G}$; исходный псевдокод $\mathrm{P}_{\mathrm{k}}$ и исполняемый код $\mathrm{P}_{\mathrm{k}}$.

Нормативная модель прецедента построена таким образом, чтобы она раскрывала концептуальное содержание задачи и представляла её концептуальное решение (псевдокод ре- 
шения). По этой причине в модели принципиальное место занимают конструкции на естественно-профессиональном языке $L_{p}$ предметной области $\left\{Z_{k}\right\}$. Основными из этих конструкций являются текст $T_{\mathrm{k}}$ постановки задачи $\mathrm{P}^{\top}{ }_{\mathrm{k}}$ и предложения $\left\{\Pi_{\mathrm{ik}}\right\}$ в модели $\mathrm{P}^{\mathrm{QA}}$, , регистрирующей вопросно-ответный анализ этой задачи, в результате которого на все важные вопросы по её решению получены ответы, достаточные для построения логической схемы $\mathrm{P}_{\mathrm{k}}{ }_{\mathrm{k}}$ и концептуально-алгоритмического решения $\mathrm{P}_{\mathrm{k}}[9]$.

\section{3 Разработка классификатора шаблонной оснастки}

\section{1 Исходные предпосылки}

На текущий момент времени одним из узких мест в обеспечении проектирования и изготовления шаблонной оснастки является нормативно-техническая и организационная документация - стандарты предприятия, инструкции, положения, директивы и т.П., - основными недостатками которой можно считать:

- моральное устаревание (большинство документов имеют редакцию времен СССР);

- наличие в стандартах видов оснастки, которая не используется;

- отсутствие адаптации под современные средства информационных технологий;

- отсутствие классификации шаблонов по подтипам (имеется только общий, поверхностный классификатор видов шаблонов);

- отсутствие классификации элементов шаблонной оснастки.

Поэтому в ходе проектирования электронной модели шаблона возникают ситуации, когда один и тот же шаблон на одну и ту же деталь может иметь несколько вариантов исполнения. На рисунке 10 представлены возможные вариации исполнения шаблонов ШОК и ШКС на уголковый профиль с отверстиями под заклепки.

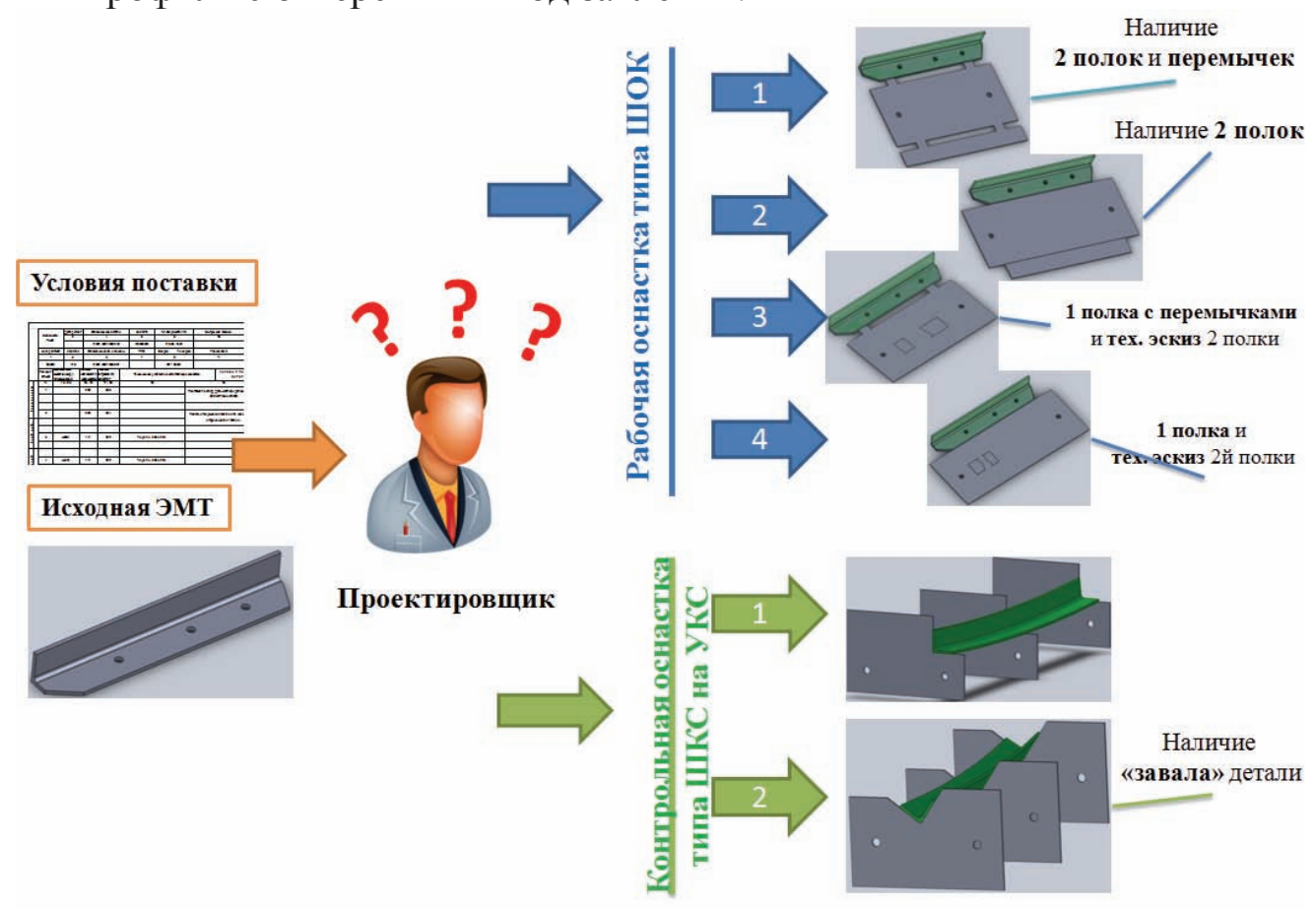

Рисунок 10 - Возможные вариации исполнения шаблонов к детали

Следует отметить, что все вариации исполнения шаблона на представленную деталь приемлемы, однако не все они удачны с точки зрения эксплуатации, металлоёмкости и трудоём- 
кости исполнения. Например, когда одна полка детали имеет простой контур и не имеет отверстий, то целесообразно с целью экономии металла и машинного времени станка с ЧПУ на котором изготавливается шаблон, дать её в виде технологического эскиза на добавке. Аналогично поступают и с перемычками на шаблоне, когда контур рабочей полки прост и нет необходимости в дополнительных смотровых окнах, то добавок «вливается» в зону рабочей полки шаблона.

Основываясь на изложенных положениях, не нашедших своё отражение ни в стандартах, ни в технологических инструкциях, разработан технологический классификатор шаблонной оснастки на основе существующего классификатора, описанного в [4].

\section{2 Цели разработки классификатора и решение задач ТПП}

Классификатор исполняет роль информационной основы для разработки комплекса программ автоматизированного проектирования шаблонной и объёмной технологической оснастки в авиационной промышленности $[10,11]$. Его использование нацелено на:

- создание единого информационного языка для автоматизированных систем проектирования и тематического поиска изделий и конструкторско-технологических документов, предотвращзая разработку аналогичных;

- определение объектов, процессов и направлений унификации и стандартизации; использование различными предприятиями и организациями электронной конструкторскотехнологической документации, разработанной другими предприятиями, без её переоформления, при проектировании, производстве, эксплуатации и ремонте;

- повышения уровня автоматизации проектно-конструкторских работ;

- применение кодов оснастки по классификатору технологической оснастки как опережающей информации при решении задач ТПП;

Применение классификатора в условиях ТПП создаёт предпосылки для решения следующих задач:

- анализ номенклатуры плоской шаблонной и объёмной оснастки по их конструкторскотехнологическим признакам;

- группирование оснастки по конструкторско-технологическому подобию для разработки прикладного программного обеспечения нацеленного на автоматизацию проектных работ в части проектирования электронной документации на оснастку;

- унификация и стандартизация оснастки и процессов её проектирования;

- автоматизация проектирования электронных моделей оснастки и технологических процессов её изготовления.

\section{3 Раскрытие древа классификатора}

Классификатор построен по смешанному методу, основанному на дедуктивном логическом делении классифицируемого множества. Этим методом достигается конкретизация признаков классификации оснастки на каждой последующей ступени классификации [10-12].

Разработка классификатора основана на следующих логических правилах:

- деление множества оснастки на классификационные группировки произведено на каждой ступени классификации по одному и тому же признаку или их сочетанием;

- на каждой ступени классификации исчерпывается объём делимого множества;

- деление множества произведено последовательно, однако имеются пропуски очередной (-ых) ступеней классификации в тех случаях, когда оснастка не имеет признака классификации, удовлетворяющего данной ступени. 
Для того чтобы при классификации исчерпывался объём делимого множества, в классификаторе предусмотрена группировка под наименованием «Элементы». Такие группировки, как правило, использованы на последних стадиях классификации.

К группировкам «Элементы» относятся составные, структурированные по конструкторско-технологическим признакам элементы оснастки. В связи с тем, что их наличие или отсутствие обусловлено конкретным типом детали, открывать для них новые группировки нецелесообразно из-за возможного огромного количества вариаций.

Все множество изделий в классификаторе принадлежит к одному суперклассу «Оснастка». Этот класс считается высшим в иерархии и имеет нулевой уровень классификации. Исходя из того, что суперкласс уникален по своей природе, его обозначение в классификационной составляющей опускается.

Все множество оснастки разделено в классификаторе на следующие группы классов: Рабочая и Контрольная.

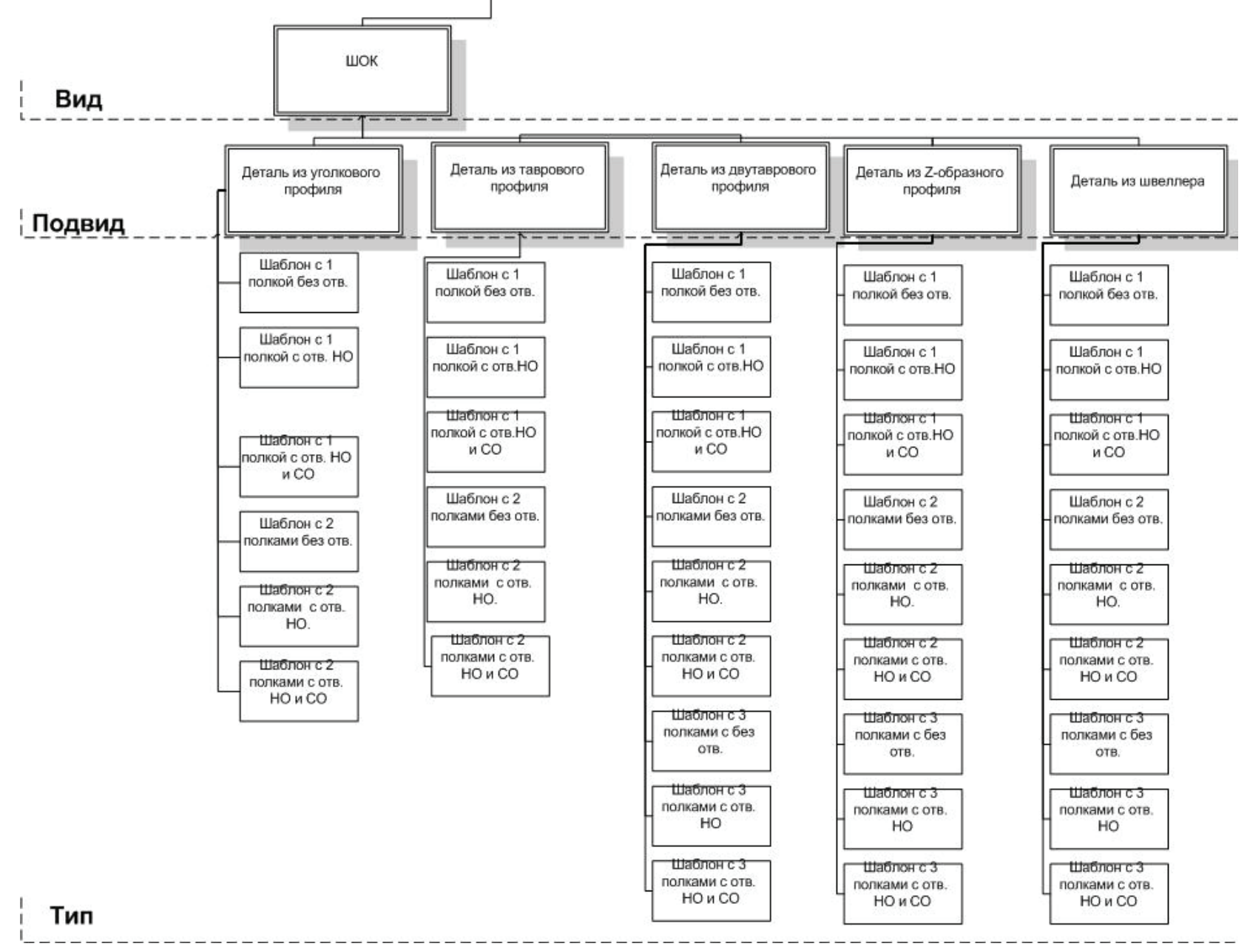

Рисунок 11 - Представление нижних уровней классификатора шаблонной оснастки

На первом уровне классификации при формировании классов «Рабочая оснастка» и «Контрольная оснастка» использован функциональный признак. Этот признак даёт представление об оснастке и отличает её от других классов изделий. Наименования, присвоенные классам по этому признаку, непосредственно отражают номенклатуру включённых в них типов оснастки. Наиболее общие признаки, использованные на верхних уровнях классификации, конкретизируются на последующих уровнях. Далее множество изделий классов, опре- 
делённых по функциональному признаку подразделяется на подклассы, выделяемые по признаку геометрической формы (рисунок 11).

Признак «геометрическая форма» шаблона конкретизируется на последующих уровнях классификации следующим атрибутами: параметрический, конструктивный и наименование оснастки. Каждый подкласс состоит из нескольких групп, каждая группа - из подгрупп, подгруппа включает себя несколько видов, вид - множество подвидов, подвид определён несколькими типами, каждый тип состоит из группы комплексных элементов.

Результаты, полученные в разработке классификатора, послужили исходным информационным контентом, вложенным в представляемую версию онтологии проектирования шаблонов. Кроме того, было принято решение о включении классификатора в состав онтологии как её компонента, который интегрально представляет родовидовую систематизацию с учётом систематизации «часть-целое».

\section{4 Разработка модели онтологии проектирования шаблонной оснастки}

\section{1 Структуризация онтологии проектирования шаблонов}

Для реализации средств и обеспечения поддержки процесса проектирования моделей шаблонной оснастки была построена, проверена и использована концептуальная схема онтологии, которая обобщённо представлена на рисунке 12.

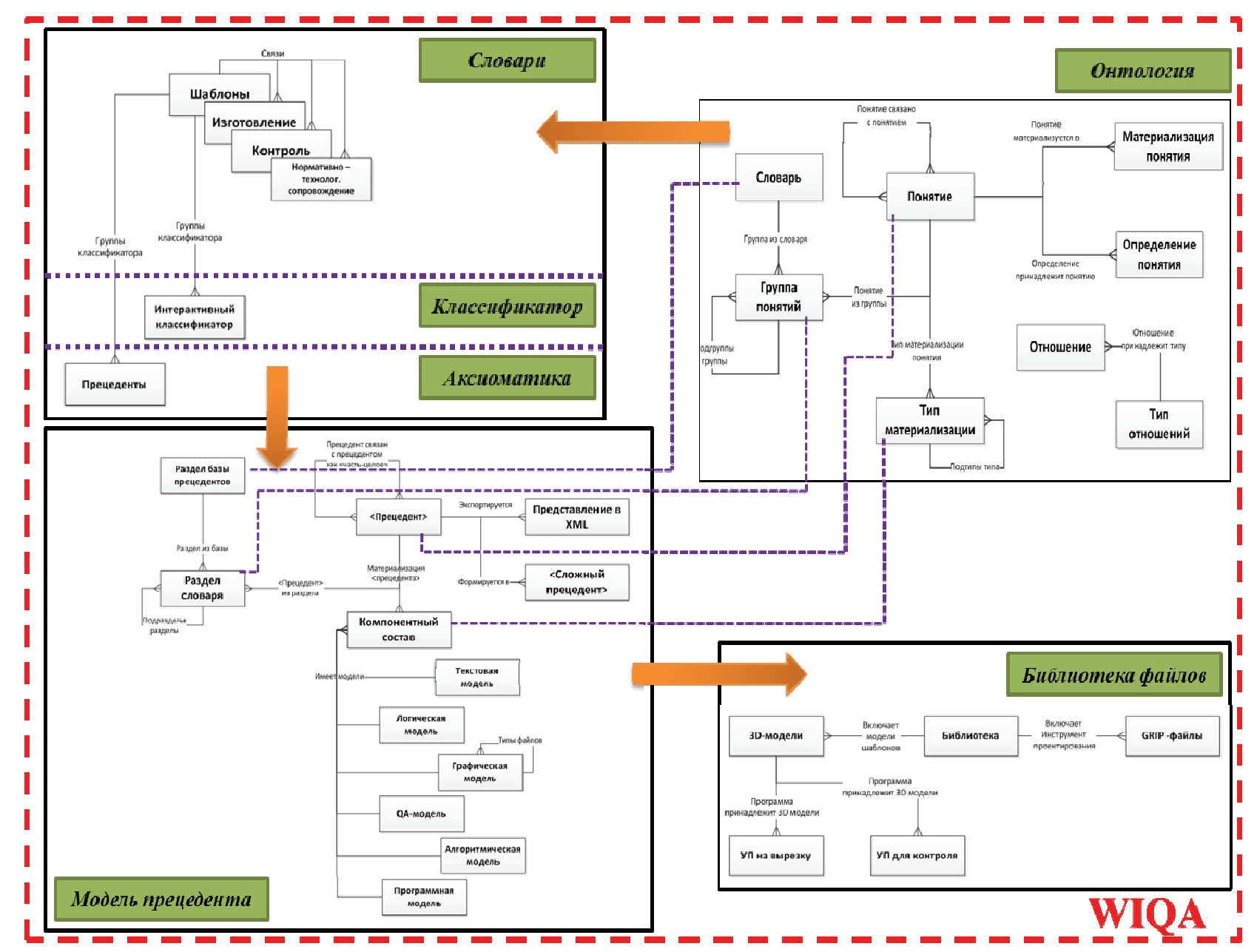

Рисунок 12 - Концептуальная схема онтологии проектирования шаблонной оснастки 
В схеме выделены следующие разделы (секции) контролируемых понятий.

- Шаблоны - словарь, включающий в себя изготавливаемые в производстве шаблоны. На основе данных шаблонов формируется углублённый классификатор шаблонной оснастки. В данном словаре имеется возможность не только использовать известные образцы шаблонов, но и создать принципиально новые, не стандартизированные проектные решения.

- Изготовление - в данный словарь включены термины, относящиеся к изготовлению как самих шаблонов, так и деталей, в которых шаблонная оснастка выступает в качестве инструмента изготовления или контроля. Здесь секция «Детали» структурирована по типам полуфабрикатов «Профиль» и «Лист».

- Контроль - словарь, отвечающий за контроль изготавливаемой оснастки.

- Нормативно-техническая документация - секция, в которой собраны технологические инструкции и другие производственные регламенты, отвечающие за то, как изготавливать и как использовать шаблонную оснастку.

Раздел «Аксиоматика» включает в себя модели прецедентов шаблонов и их проекции.

В комплексе средств онтологической поддержки предусмотрена «Библиотека файлов», по своей сути являющаяся материализацией прецедентов в необходимой для конечного пользователя форме. Здесь хранятся 3D-модели шаблонов, а также программы, необходимые для их проектирования, изготовления и контроля.

Для реализации прецедентов и их использования в онтологии используются контекстные связи между понятиями по определённым признакам, таким как: часть-целое, наследование, ассоциация и пр. В общем виде связи представлены на рисунке 13.

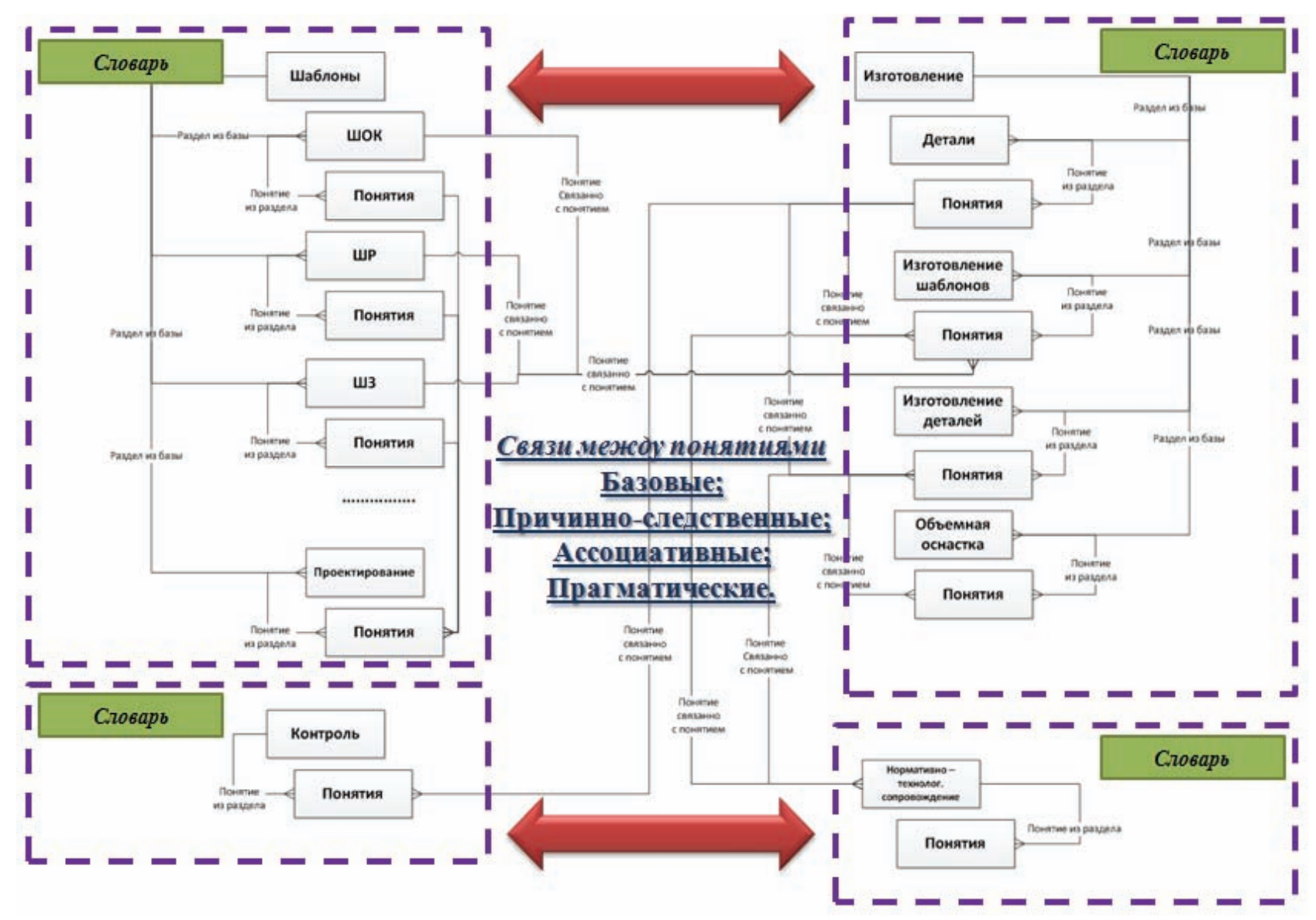

Рисунок 13 - Представление связей в онтологии проектирования шаблонной оснастки 
Для представляемой онтологии принципиален поиск, обслуживающий автоматизированное взаимодействие с её содержимым. Поскольку в среднем для производства одного самолета требуется до 100 тыс. ед. шаблонной оснастки, то актуален вопрос о релевантном поиске среди образцов, зарегистрированных в онтологии. При обращении к поисковой системе пользователь должен иметь возможность получить в ответ ресурсы, релевантные смыслу запроса, и их поиск должен быть семантически ориентированным [13]. Другими словами, в таком поиске важна работа с семантическими описаниями шаблонов, раскрывающими действия и результаты по его созданию, что в конечном итоге выводит на их представления с помощью моделей прецедентов.

\section{2 Представление шаблона в виде модели прецедента}

Среда WIQA ориентирована на концептуальное моделирование в процессах решения проектных задач, в основу которого положено псевдокодовое программирование активности проектировщиков, что переносится и на программный доступ к составляющим онтологии, включая доступ по ссылкам к концептуальным моделям шаблонов [13].

Для представления каждого шаблона выбрана модель M (Zj) задачи Zj его повторного использования проектировщиком, оказавшимся в определенной проблемной ситуации. Первая реакция проектировщика в проблемной ситуации «Обратиться к опыту и попытаться найти в нём подходящий прецедент» [13]. С каждым прецедентом связывают определённое типовое поведение в определённых условиях по образцу поведения, оказавшемуся (многократно) полезным в прошлом.

Независимо от того, что прецеденты разнообразны как по структуре, так и по содержанию, у шаблонов прецедентов существует подобная логика доступа, которая (в общем случае) приводит к логической модели прецедента $\mathrm{P}$, представленной на рисунке 14.

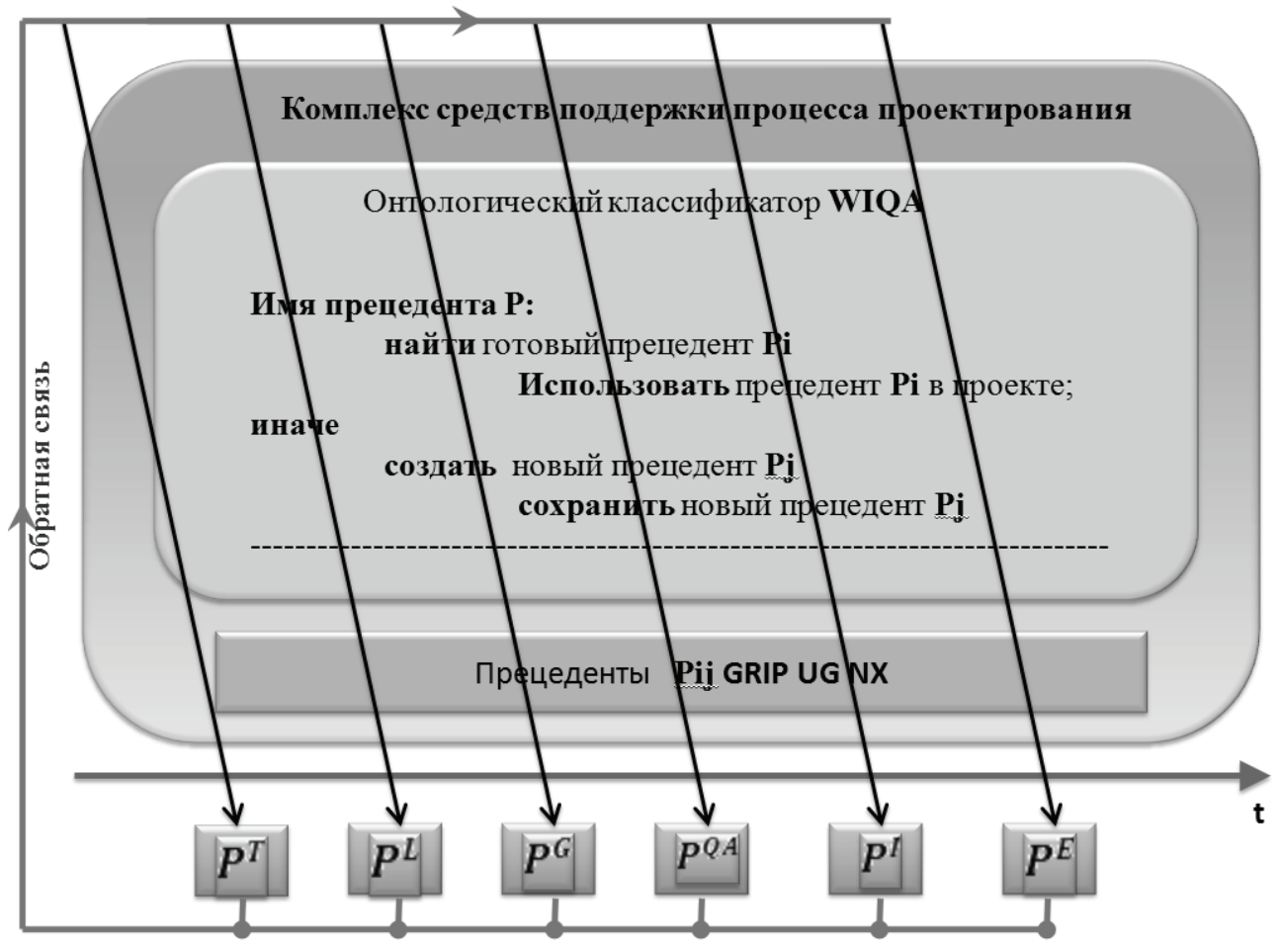

Рисунок 14 - Логическая модель прецедента 
Логическая модель прецедента (шаблона) используется для его представления в среде WIQA. Модель привязана к жизненному циклу построения прецедента (шаблона) и его освоения, по ходу чего создаются следующие специализированные модели.

- Текстовая модель $\mathrm{P}^{\top}$, представляющая постановку задачи $\mathrm{Z}\left(\mathrm{P}_{\mathrm{i}}\right)$, в результате решения которой создан образец прецедента (шаблона) как определённый результат интеллектуального освоения реального прецедента. Так, при проектировании шаблона типа ШОК первичным становится его отображение в текстовой модели $\mathrm{P}^{\top}$ в форме текстового запроса на проектирование шаблона, доставляющего основные исходные данные, например, «спроектировать шаблон обрезки и кондуктора на Z-образный профиль с тремя рабочими полками и отверстиями, без подсечек, с учётом добавочного материала».

- Логическая модель $\mathrm{P}^{\mathrm{L}}$, конкретизирующая типовые модели в виде формулы логики предикатов, записанной на языке постановки задач $\mathrm{P}^{\top}$.

- Графическая модель прецедента (шаблона) $\mathrm{P}^{\mathrm{G}}$, представляющая его материализацию в различных вариациях (рисунок 15).

- Вопросно-ответная модель прецедента $P^{Q A}$, соответствующая задаче $Z\left(P_{i}\right)$.

В качестве примера рассмотрим вопросно-ответную модель с учётом разработанной классификации проектирования ШОК, упомянутого выше, для задачи Z( $\left.\mathrm{P}_{\mathrm{i}}\right)$. Определим список (фрагмент) вопросов и ответов:

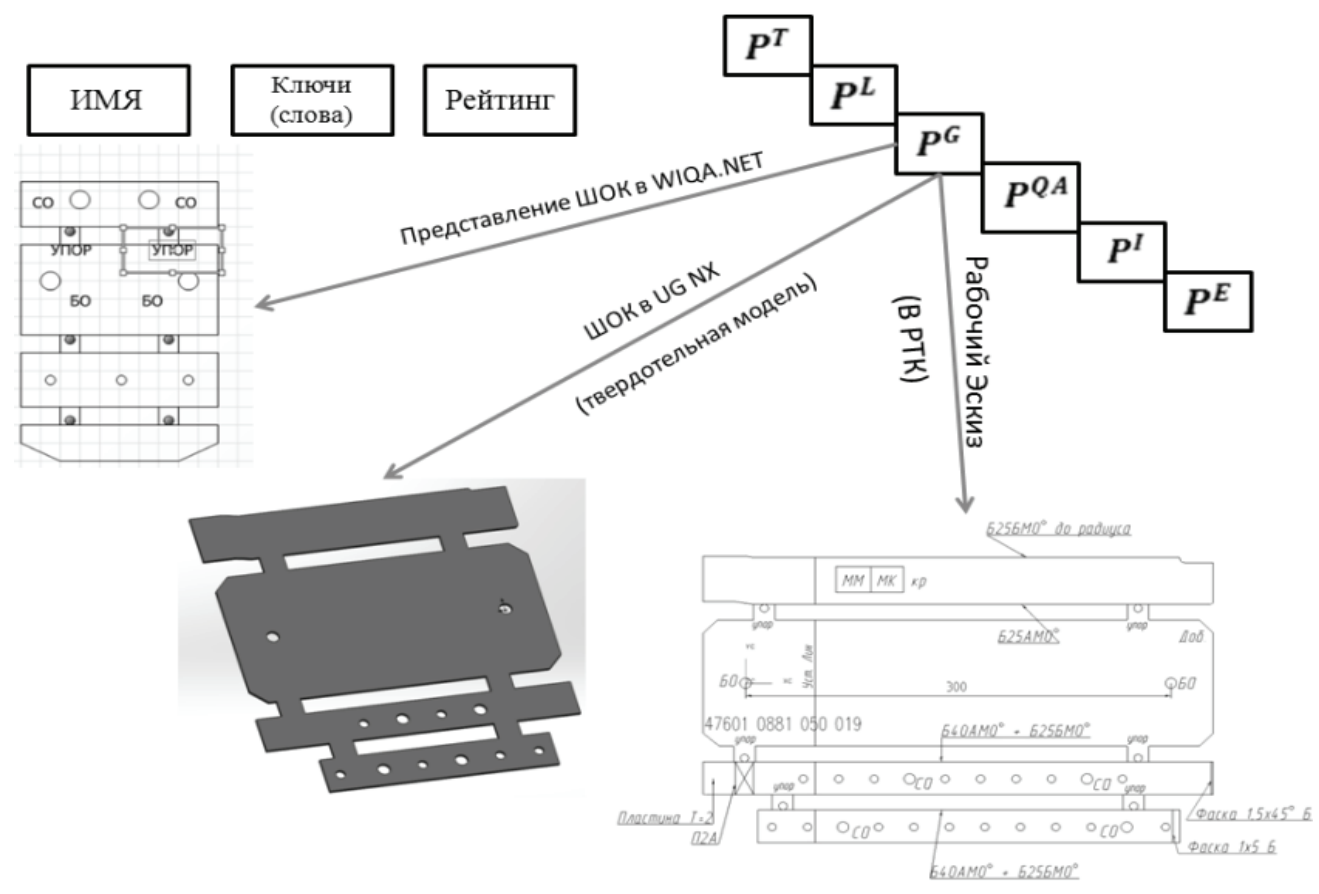

Рисунок 15 - Преставление графической модели прецедента

Q1. Какой необходим шаблон?

А1. Шаблон обрезки и кондуктор.

Q2. Шаблон цельный?

А2. Да // Исходя из габаритов детали.

Q3. На деталь из какого профиля?

A3. Z-образный профиль.

Q4. Сколько рабочих полок?

А4. Три рабочие полки. 
- Модель $\mathrm{P}^{\prime}$, представляющая вложенное в шаблон (прецедент) поведение в форме исходного кода его программы. Приведём для примера часть исходного кода исполнения задачи $\mathrm{Z}\left(\mathrm{P}_{\mathrm{i}}\right)$ написанного в вопросно-ответной среде WIQA:

// Создание первой полки рабочего контура.

DD_CreateLine("Polyline", "ShapeName=PL1", "X=100", "Y="50", "X=100", "Y="100")

DD_CreateLine("Polyline", "ShapeName=PL1", "X=100", "Y="100", X=200", *"Y="100")

DD_CreateLine("Polyline", "ShapeName=PL1", "X=200", "Y="100", "X=200", "Y="50")

DD_Createline("Polyline", "ShapeName=PL1", "X=200", "Y="50", "X=100", "Y="50")

// Вскрытие отверстий на первой полке рабочего контура.

DD_Create ("Elipse", "ShapeName=S01", "X=125", "Y="75", "Diametr=8")

DD_Create ("Elipse", "ShapeName=S02", "X=175", "Y="75", "Diametr=8").

- Модель $\mathrm{P}^{\mathrm{E}}$, выводящая на исполняемый код программы, реализующей образец шаблона (прецедента);

- Интегральная модель прецедента $\mathrm{P}^{S}$ в виде схемы, объединяющей все специализированные модели прецедента в единое целое.

С интегральной моделью прецедента, которая представлена на рисунке 16, связывается материальная форма образца прецедента, размещённая в онтологии прецедентов, разработанной в комплексе WIQA.

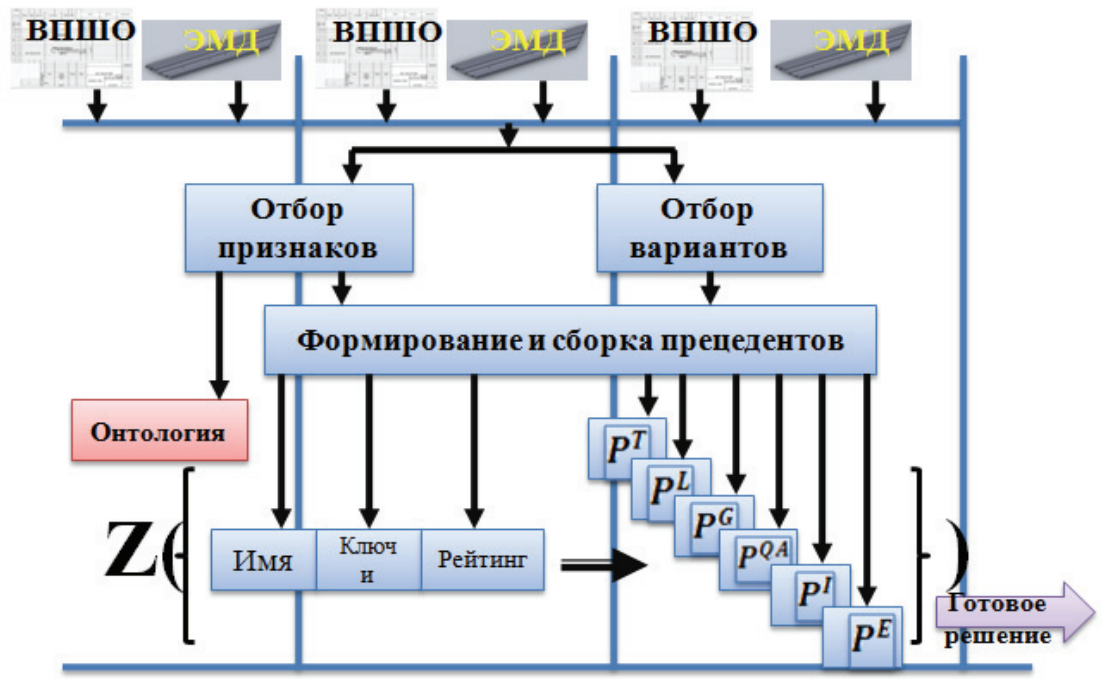

\section{Прецедентьи}
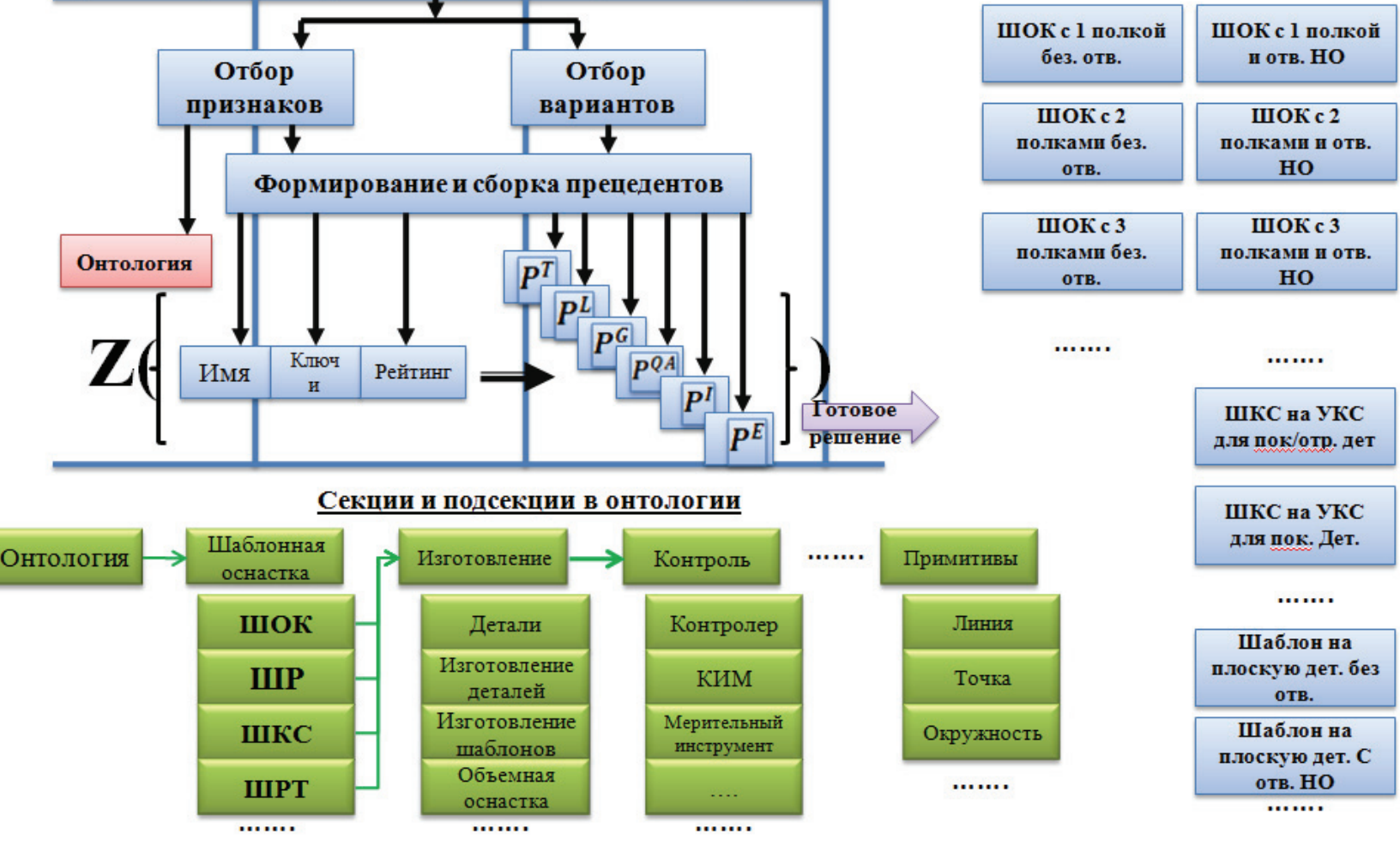

Рисунок 16 - Интегральная модель прецедента

Отметим, что специализированная модель может быть представлена исходным кодом того языка программирования, который используется при создании программного обеспечения. Однако для расширения возможностей повторного использования моделей типа $\mathrm{P}^{\prime}$ целесообразно использование псевдокодового языка L WIQA $[13]$. 


\section{5 Реализация средств поддержки процесса проектирования шаблонов B WIQA}

Центральное место в онтологии проектирования шаблонов, как и в любой другой онтологии, порождаемой в среде WIQA, занимает «Словарь», в структуре которого выделены разделы для представления основных видов шаблонов. Статьи разделов содержат не только определения шаблонов, но также ссылки на модели шаблонов и ключи для поиска по оперативным запросам (рисунок 17).

Среда WIQA ориентирована на концептуальное моделирование в процессах решения проектных задач [12], в основу которого положено псевдокодовое программирование активности проектировщиков [13], что переносится и на программный доступ к составляющим онтологии, включая доступ по ссылкам к концептуальным моделям шаблонов.

Благодаря инструментарию WIQA имеется возможность полного описания необходимой оснастки в онтологии словаря. На основе классифицированного шаблона и его составляющих элементов создаются связи для формализации шаблона по признакам «часть-целое» (т.к. в него входят определяющие его элементы), «наследование» (т.к. в большинстве случаев у шаблона имеется родитель или предок) и заполняются слоты необходимых атрибутов (рисунки 18 и 19).

Отметим, что отношениям можно не только приписать имена, выводящие на их семантику, но и прокомментировать. Такая возможность особо полезна для прагматических отношений, в частности, инструментального типа (связывающего шаблон с инструментами для его обработки или процесс механической обработки со средствами его реализации).

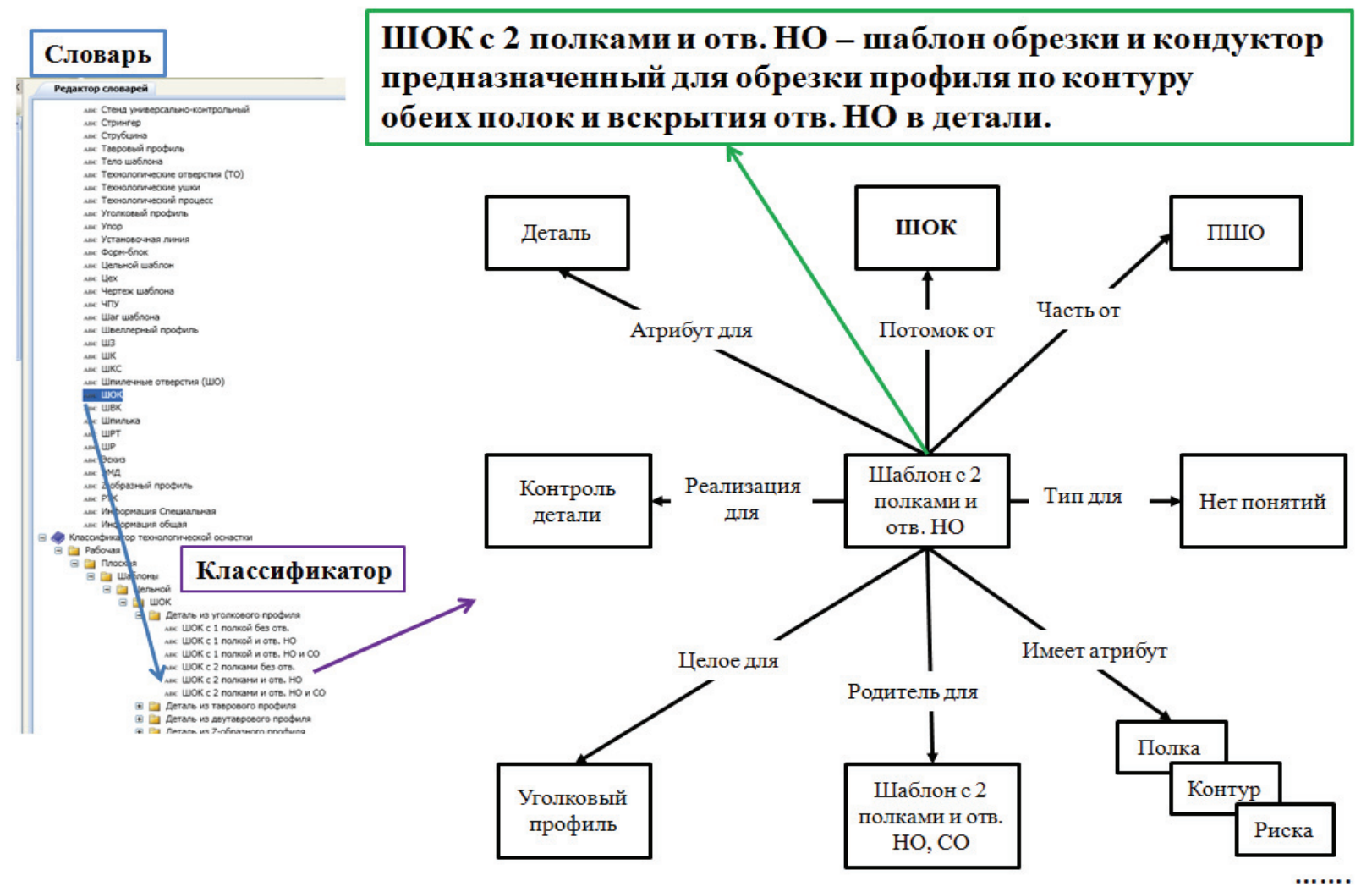

Рисунок 17 - Онтологический словарь в WIQA 


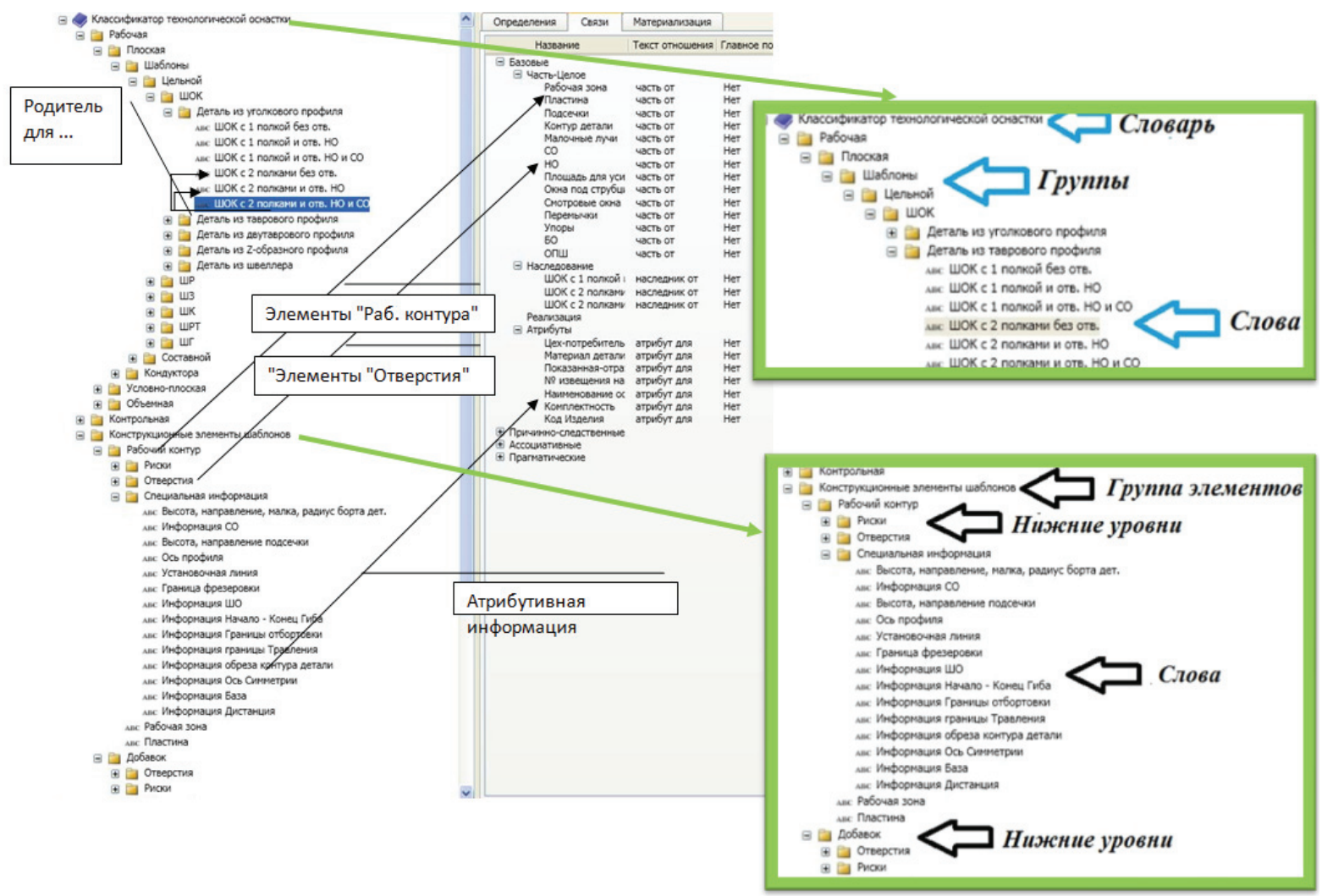

Рисунок 18 - Реализация классификатора шаблонной оснастки в WIQA

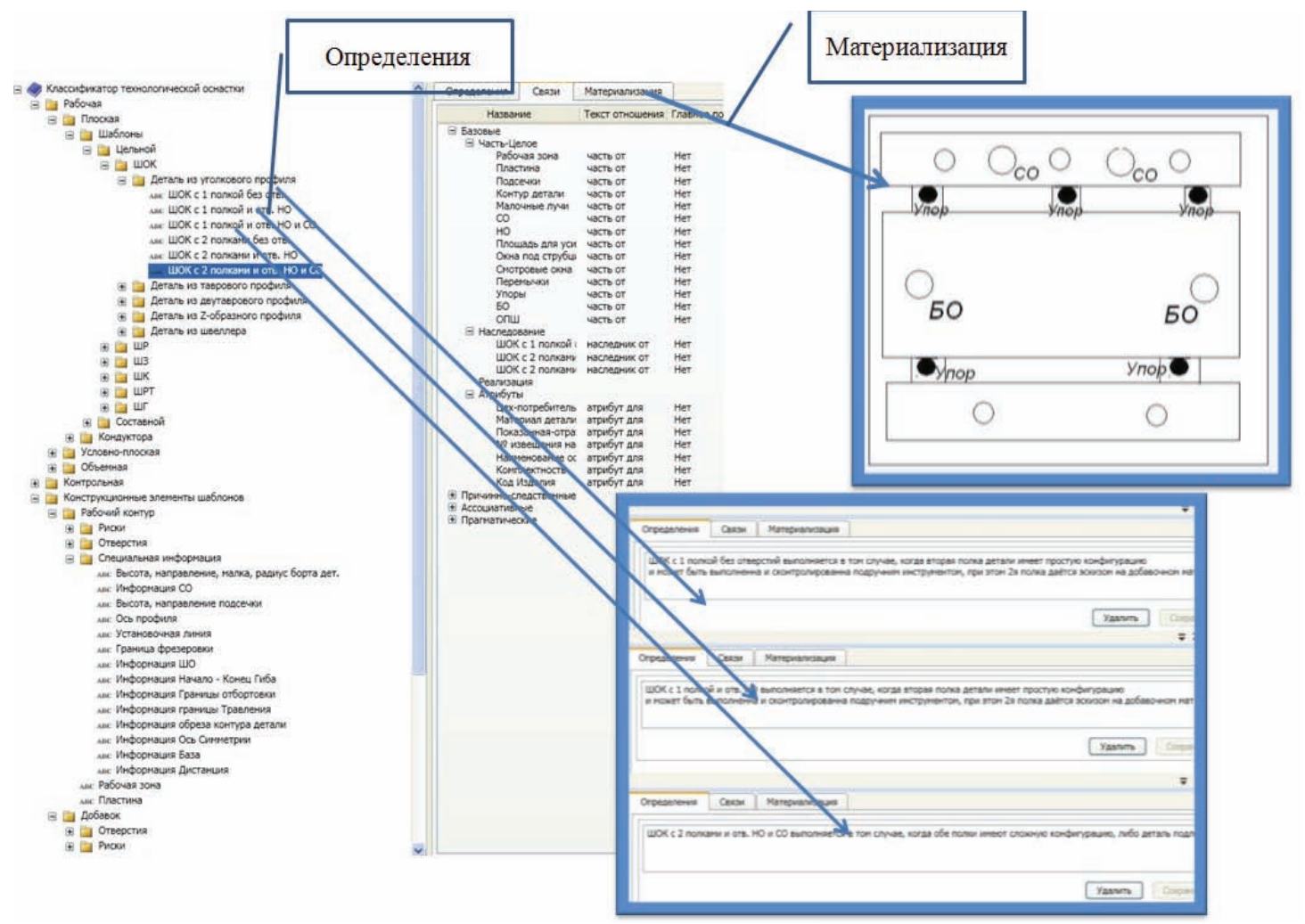

Рисунок 19 - Реализация определений и материализации в классификаторе шаблонной оснастки 


\section{Заключение}

В статье представлен подход к созданию онтологии проектирования шаблонной технологической оснастки с помощью инструментария WIQA. Использование средств WIQA обеспечивает моделирование не только имеющихся шаблонов, но и создание новых шаблонов, с возможностью спецификации и аккумуляции их моделей в онтологическом словаре.

Модельное представление шаблонов полезно для их повторного использования в задачах, когда модели приходится адаптировать к изменившимся условиям производства, например, при создании новых образцов авиационной техники. Интерактивная версия классификатора в виде проектной онтологии с программным доступом к её составляющим способствует повышению степени автоматизации проектно-конструкторской деятельности в разработке шаблонной оснастки.

Внедрение средств онтологической поддержки проектирования шаблонной оснастки обеспечивает:

- возможность повторного использования проектных решений;

- материализацию проектных решений как в онтологии, так и в CAD-системе;

- создание под нужды производства принципиально новых проектных решений (прецедентов), не предусмотренных стандартами;

- аккумулирование и передачу опыта по проектным решениям в онтологии;

- быстрое обучение пользователя в процессе работы.

\section{Благодарности}

Авторы выражают благодарность доценту кафедры «Самолетостроения» УлГТУ А.В. Лебедеву и инженеру-конструктору АО «УКБП» В.В. Плутахину за оказанную помощь и консультации по формированию классификатора технологической оснастки.

\section{Список источников}

[1] Рыбаков, $\boldsymbol{A}$.В. Проектирование технологической оснастки на основе системы автоматизированной поддержки информационных решений / А.В. Рыбаков, С.А. Евдокимов, А.А. Краснов // Информационные технологии. - 2001. - №10. - С. 15-21.

[2] Соснин, П.И. Вопросно-ответное программирование человеко-компьютерной деятельности / П.И. Соснин. - Ульяновск : УлГТУ, 2010. - 240 с.

[3] Боргест, Н.M. Онтология проектирования. Теоретические основы. Ч. 1. Понятия и принципы / Н.М. Боргест. - Самара: СГАУ, 2010. - 91 с.

[4] СТП 687.07.0873-2004. Система качества. Технологическая подготовка производства. Изготовление и применение плазово-шаблонной оснастки. - Ульяновск: ЗАО «Авиастар-СП», 2004. - 168 с.

[5] Самсонов, О.С. Бесплазовое производство авиационной техники: проблемы и перспективы / О.С. Самсонов, Ю.Е. Тарасов // САПР и Графика. - 2000. - № 9. - С. 33-38.

[6] Соснин, П.И. Структурное проектирование конфигурируемых шаблонов авиационных деталей / П.И. Соснин, О.Э. Чоракаев // Автоматизация процессов управления. - 2014. - №2 (36). - С. 99-107.

[7] Гончаренко, А.B. Информационная система редактирования онтологий / А.В. Гончаренко, Б.С. Добронец // Молодежь и наука: Материалы VIII Всероссийской н.-т. конф. студентов, аспирантов и молодых ученых, посвященной 155-летию со дня рождения К.Э. Циолковского. Отв. ред.: О.А. Краев. - Красноярск: Сибирский федеральный университет, 2012. - http://conf.sfu-kras.ru/sites/mn2012/section12.html

[8] Гришин, M.B. Онтология как средство проектирования шаблонной оснастки в условиях подготовки наукоемкого производства / М.В. Гришин, С.Н. Ларин, В.И. Кочергин // Автоматизация процессов управления. 2015. - №1(39). - C. 89-98.

[9] Sosnin, P. Pseudo-Code Simulation of Designer Activity in Conceptual Designing of Software Intensive Systems / P. Sosnin // Proc. of the 27th European Conference on Modelling and Simulation ECMS 2013, 2013, 85-92.

[10] ОК 012-93 Классификатор ЕСКД. Введение. $1.79 .100 \quad$ (с изменениями) http://docs.cntd.ru/document/1200000470 (Дата обращения: 20.09.2015). 
[11] Ширялкин, $\boldsymbol{A . \Phi . ~ О с н о в ы ~ ф о р м и р о в а н и я ~ м н о г о у р о в н е в ы х ~ к л а с с и ф и к а ц и и ̆ ~ е с т е с т в е н н о г о ~ т и п а ~ д л я ~ с о з д а н и я ~}$ эффективных производственных сред в машиностроении / А.Ф. Ширялкин - Ульяновск: УлГТУ, 2009. 298 c.

[12] Соснин, П.И. Концептуальное моделирование компьютеризованных систем / П.И. Соснин. - Ульяновск: УлГТУ, 2008. - 198 с.

[13] Маклаев, B.A. Создание и использование автоматизированной базы опыта проектной организации / В.А. Маклаев, П.И. Соснин. - Ульяновск: УлГТУ, 2012. - 360 с.

\title{
ONTOLOGY OF DESIGNING INDUSTRIAL EQUIPMENT WITHIN THE AVIATION PRODUCTION
}

\author{
M.V. Grishin ${ }^{1}$, S.N. Larin ${ }^{2}$, P.I. Sosnin ${ }^{3}$ \\ IJ SC U lyanovsk instrument manufacturing design bureau, Ulyanovsk, Russia \\ likani7@mail.ru \\ ${ }^{2}$ FRPC OJ SC «RPA «M ars», Ulyanovsk, Russia \\ larinmars@ rambler.ru \\ ${ }^{3}$ U lyanovsk state technical university, Ulyanovsk, Russia \\ sosnin@ulstu.ru
}

\begin{abstract}
The aim of this work is to improve the process of designing the template snap within the aviation industry by the development of tools for the ontological support. The offered means of the ontological support provide: the controlled accumulating the experience of templates' development in the form of precedent models prepared for the reuse; the systematization of templates' models with the use of the interactive classification and means that embeds in the ontology of designing; the controlled use of lexis, including the concept, in documents, developed in the process of the work. Means of the ontological support has been developed in the environment of the toolkit WIQA, that has been adopted the subject area of designing the template snap used in the aviation industry.
\end{abstract}

Key words: ontology design, classifier, aircraft, patterned accessories, WIQA.

Citation: Grishin M V, Larin SN, Sosnin PI. Ontology of designing industrial equipment within the aviation production. O ntology of designing. 2016; 6(1): 7-28. DOI: 10.18287/2223-9537-2016-6-1-7-28.

\section{References}

[1] R ybakov AV, E vdokimov SA, Krasnov AA. Proektirovanie tehnologicheskoj osnastki na osnove sistemy avtomatizirovannoj podderzhki informacionnyh reshenij [Tooling Design based automated support system information solutions]. Informacionnye technologii [Information Technology]. - 2001. - №10: 15-21. (In Russian).

[2] Sosnin PI. Voprosno-otvetnoe programmirovanie cheloveko-komp'juternoj dejatel'nosti [Question-response programming human-computer activities]. - Ulyanovsk : U1STU, 2010. - 240 p. (In Russian).

[3] B orgest N M. Ontologija proektirovanija. Teoreticheskie osnovy. Ch. 1. Ponjatija i principy. [Ontology of designing. Theoretical basis. Part 1. Concepts and principles] - Samara : SSAU, 2010. - 91 p. (In Russian).

[4] STP 687.07.0873-2004. Systema kachestva. Tehnologicheskaja podgotovka proizvodstva. Izgotovlenie i primenenie plazovo-shablonnoj osnastki. [Quality system. Technological preparation of production. Production and use of lofting template tooling] - Ulyanovsk: JSC «Aviastar-SP», 2004. - 168 p. (In Russian).

[5] Samsonov OS, Tarasov U E. Besplazovoe proizvodstvo aviacionnoj tehniki: problemy i perspektivy [Unlofting production of aviation equipment: problems and prospects]. SAPR i Grafika [CAD and Graphics]. - 2000. - № 9: 33-38. (In Russian).

[6] Sosnin PI, Chorakaev $\boldsymbol{O}$ E . Strukturnoe proektirovanie konfiguriruemyh shablonov aviacionnyh detalej [Structural design of configurable templates aircraft parts]. Avtomatizacija processov upravlenija [Automation of control processes]. - 2014. - №2 (36): 99-107. (In Russian).

[7] G oncharenko $A \mathbf{V}$, D obronec BS. Informacionnaja sistema redaktirovanija ontologij [Information system ontology editing] / Molodezh' i nauka: Materialy VIII Vserossiyskoy. n.-t. konf. studentov, aspirantov i molodyh uchenyh, posvjashhennoj 155-letiju so dnja rozhdenija K.Je. Ciolkovskogo [Youth and science: Proc. of VIII All-Russian 
scientific and engineering. conf. students, graduate students and young scientists in the sacred 155-th anniversary of the birth of K.E. Tsiolkovsky] / Ed.: O.A. Kraev. - Krasnoyarsk: Siberian Federal University, 2012. (In Russian).

[8] Grishin $\boldsymbol{M} \mathbf{V}$, Larin SN, Kochergin VI. Ontologija kak sredstvo proektirovanija shablonnoj osnastki v uslovijah podgotovki naukoemkogo proizvodstva [Ontology as a design template tooling in a preparation of high-tech manufacturing] / Avtomatizacija processov upravlenija [Automation of control processes]. - 2015. - №1(39): 89-98. (In Russian).

[9] Sosnin PI. Pseudo-Code Simulation of Designer Activity in Conceptual Designing of Software Intensive Systems / Proc. of the 27th European Conference on Modelling and Simulation ECMS 2013. 2013, 85-92.

[10] OK 012-93 Klassifikator ESKD. Vvedenie. 1.79.100 [OC 012-93 Qualifier ESKD. Introduction. 1.79.100 (Amended)] - http://docs.cntd.ru/document/1200000470 (Valid on: 20.09.2015). (In Russian).

[11] Shiryalkin $\boldsymbol{A F}$. Osnovy formirovanija mnogourovnevyh klassifikacij estestvennogo tipa dlja sozdanija jeffektivnyh proizvodstvennyh sred $\mathrm{v}$ mashinostroenii [Bases of formation of multi-level classification of the natural type to create efficient production environment in engineering] - Ulyanovsk: UlSTU, 2009. - 298 p. (In Russian).

[12] Sosnin PI. Konceptual'noe modelirovanie komp'juterizovannyh sistem [Conceptual modeling of computerized systems] / P.I. Sosnin. - Ulyanovsk: UlSTU, 2008. - 198 p. (In Russian).

[13] Maklaev V $\boldsymbol{A}$, Sosnin PI. Sozdanie i ispol'zovanie avtomatizirovannoj bazy opyta proektnoj organizacii [Creation and use of an automated experience of the design organization] - Ulyanovsk: UISTU, 2012. - 360 p. (In Russian).

\section{Сведения об авторах}

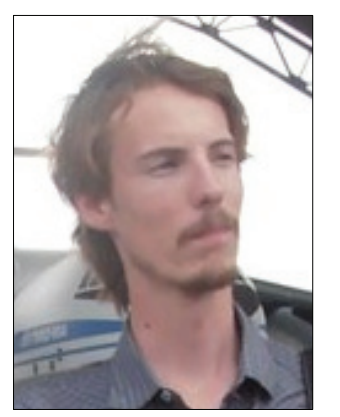

Грииин Максим Вячеславович, 1990 г. рождения. Окончил Институт авиационных технологий и управления УлГТУ в 2011 г., к.т.н. (2015). Инженер-конструктор АО «Ульяновское конструкторское бюро приборостроения». В списке научных трудов более 15 работ в области автоматизации проектирования технологической подготовки производства и прикладных онтологий.

Grishin Maxim Vyacheslavovich (b.1990) graduated from the Institute of Aviation Technology and Management UISTU in 2011, PhD (2015). He is design engineer at JSC Ulyanovsk instrument manufacturing design bureau. He is co-author more 15 scientific articles and abstracts in the field of CAD and ontology.

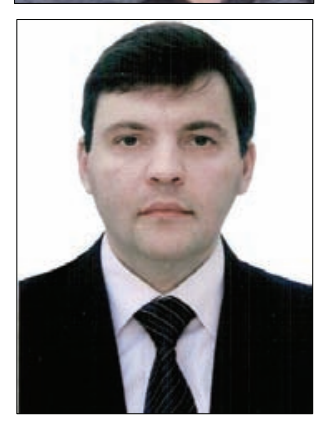

Ларин Сергей Николаевич, 1978 г. рождения. Окончил Институт авиационных технологий и управления УлГТУ в 2002 г., к.т.н. (2006). Заместитель начальника производственно-технологического комплекса АО «НПО «МАРС». В списке научных трудов более 80 статей в области автоматизации проектирования технологической подготовки производства.

L arin Sergey Nikolaevich (b. 1978) graduated from the Institute of Aviation Technology and Management UISTU in 2002, PhD (2006). He is Deputy Chief of industrial-technological complex FRPC OJSC «RPA «Mars». He is co-author more 80 scientific articles and abstracts in the field of CAD.

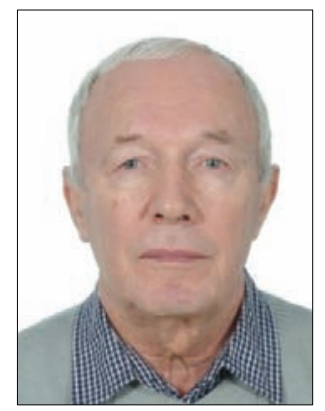

Соснин Петр Иванович, 1945 г. рождения. Окончил Ульяновский политехнический институт в 1968 г., д.т.н. (1994), профессор (1995), зав. кафедрой «Вычислительная техника» (с 1980 г.) Ульяновского государственного технического университета. В списке научных трудов более 400 статей, 12 монографий в области искусственного интеллекта и его приложений к автоматизации проектирования.

Sosnin Petr Ivanovich (b. 1945) graduated from the Ulyanovsk Polytechnic Institute (1968). His employment experience included the Ulyanovsk Polytechnic Institute and Ulyanovsk State Technical University. His special field of interests includes AI applications for computer aided design. P. Sosnin defended doctor degree in Moscow Aviation Institute (1994). He is the author of eight books and more than four hundred articles, including 12 books. 


\title{
УДК 510.8
}

\section{МАТЕМАТИЧЕСКИЕ ОСНОВЫ ОНТОЛОГИИ ПРОЕКТИРОВАНИЯ БИНАРНЫХ СИСТЕМ ОБРАБОТКИ ИНФОРМАЦИИ}

\author{
С.М. Крылов \\ Самарский государственный технический университет, Самара, Россия \\ s_m_krylov@mail.ru
}

\begin{abstract}
Аннотация
В статье рассматриваются теоретические предпосылки для достижения булевской функциональной полноты простейших гетерогенных и гомогенных бинарных функциональных блоков и систем из них, предназначенных для логической обработки информации. Информация в таких системах может быть представлена различными (разнородными) физическими параметрами, кодирующими разные состояния физических объектов. Анализируются простейшие типы функциональных зависимостей выходных сигналов (параметров) таких блоков от входных, обеспечивающие полноценную логическую обработку. Рассматриваются схемы типовых устройств и систем, гарантирующих подобную обработку. Показано, что гомогенные и гетерогенные бинарные системы обработки информации могут быть построены на основе общей (универсальной) базовой онтологии, рассматривающей любые физические объекты как функциональные, преобразующие один набор некоторых физических параметров (физических свойств в самом широком смысле) в другой.
\end{abstract}

Ключевые слова: булевские функиии, функциональная полнота, гетерогенные и гомогенные системы обработки информации, онтология бинарных систем обработки информащии, общая формальная технология, свойства объектов, функииональности объектов.

Цитирование: Крылов, С.М. Математические основы онтологии проектирования бинарных систем обработки информации / С.М. Крылов // Онтология проектирования. - 2016. - Т. 6, № 1(19). - C. 29-38. - DOI: 10.18287/2223-9537-2016-6-1-29-38.

\section{Введение}

В работе [1], посвященной анализу различных вопросов, связанных с современными онтологиями проектирования сложных технических систем и, в частности, формализации знаний в таких системах, облегчающих их автоматическую алгоритмическую обработку, отмечается, что «...проблема перевода имеющихся знаний в форму, пригодную для машинной обработки, все ещё актуальна и зачастую препятствует практической реализации систем интеллектуальной поддержки» (задач проектирования). На важность математики в исследовании различных аспектов прикладных онтологий обращал также внимание В. Г. Черняков [2]. В работе [3] рассмотрен ряд особенностей, связанных с математическими основами онтологии проектирования гетерогенных электронных систем обработки информации на базе нового направления общей теории систем (ОТС), получившего название «Общая формальная технология» (ОФТ). ОФТ изучает формальные алгоритмы над реальными объектами или их достаточно адекватными математическими моделями, а также поведение самих таких моделей на основе реализуемых ими функциональных взаимодействий объектов между собой $[3,4]$. Предлагаемый на основе подобных ОФТ-концепций подход позволяет, во-первых, ввести единообразные математически-обоснованные модели, объясняющие функционирование как гомогенных, так и гетерогенных систем обработки двоичной (бинарной) информации, и, во-вторых, существенно расширить пространство потенциально-полезных схемотех- 
нических решений за счёт использования для реализации нужных вычислительных функций опять же не только гомогенных, но и разнотипных (гетерогенных) сигналов, включая гетерогенные (разнородные) параметры различных электронных компонентов и функциональных блоков (ФБ). Например, в [3] показано, что для двухвходовых ФБ с гетерогенными входными и выходными сигналами или параметрами пространство таких потенциально-полезных схемотехнических решений при проектировании электронных бинарных систем можно увеличить примерно в 3000 раз.

С другой стороны, в [5] на основе этого же подхода предпринята попытка объяснить логику обработки информации в системах «химического типа», т.е. в системах различных химических реакций, широко используемых природой для реализации самых разнообразных процессов контроля и управления, а также в процессах синтеза и анализа нужных молекул в биологических организмах. Для обоснования булевской функциональной полноты таких систем использован классический метод сведения различных химических преобразований к традиционным двоичным функционально-полным наборам логических функций. В то же время в работе [4] показано, что уже в самом простом формальном варианте описаний различных бинарных преобразований сигналов из пяти теоретически-возможных гомогенных и гетерогенных взаимодействий обычной, классической (т.е. гомогенной) логике соответствует только один. Каковы же самые общие критерии функциональной полноты именно таких гетерогенных систем обработки информации - при различных, желательно максимально простых (или наиболее очевидных, наиболее «естественных») функциональных зависимостях выходных сигналов (параметров) от входных?

Чтобы разобраться в этих вопросах, напомним некоторые особенности ОФТ-подхода к представлению различных физических объектов и их функциональностей. Согласно ему, любой физический объект $0_{\text {i в }}$ ОФТ формально представляется в виде двух конечных множеств-списков:

$$
0_{i}=\left\langle\gamma_{i}, \mathbf{M}_{i}\right\rangle=\left\langle\left\{\gamma_{11}, \gamma_{12}, \ldots, \gamma_{i n}\right\},\left\{\gamma_{i j}=\varphi_{i j}\left(\gamma_{s k}, \gamma_{1}, \ldots, \gamma_{s m}\right) ; \ldots\right\}\right\rangle,
$$

где $\gamma_{i}$ - множество (список) интересующих нас свойств объекта, или параметров (обозначенных символами типа $\gamma_{1 k}$ ), включая, например, геометрические свойства, описывающие форму объекта, его положение в пространстве и даже (при необходимости) направление, скорость движения и, к примеру, массу и/или цвет; $\mathbf{M}_{\text {i }}$ множество (список) интересующих нас функциональностей $\varphi_{\text {ij }}$ объекта $O_{i}$ (эти функциональности могут быть записаны в любой удобной форме - в виде функций, физических законов, алгоритмических процедур и т.д.); n - число параметров (свойств), используемых в данном представлении объекта $0_{i} ; j, l \in\{1, \ldots, n\} ; k, m$ - номера (вторые индексы) тех свойств и функциональностей, которые актуальны для анали-

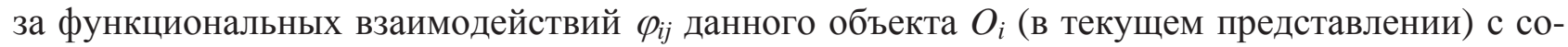
седними (или удалёнными - если речь идёт о взаимодействии, например, через поле) объектами типа $\mathrm{O}_{s}$, причём в общем случае значение некоторого параметра (свойства) $\gamma_{\text {j }}$ объекта

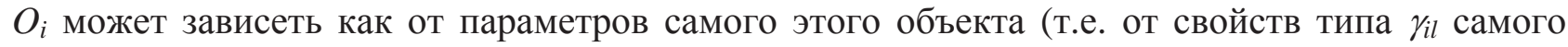
объекта $0_{i}$ ), так и от параметров (свойств) $\gamma_{s k}$ других объектов типа $0_{s}$, контактирующих с данным объектом $0_{i}$ или удалённых от него (точнее - удалённо-взаимодействующих с $0_{i}$ ). Подчеркнём, что функциональных зависимостей $\varphi_{\mathrm{j} j}$ в списке функциональностей $\mathbf{M}_{\mathrm{i}}$ объекта

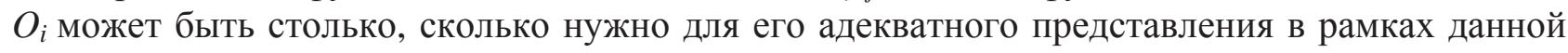

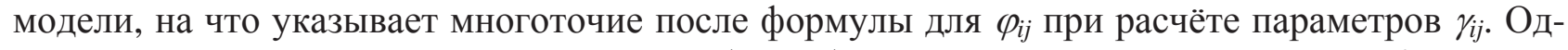

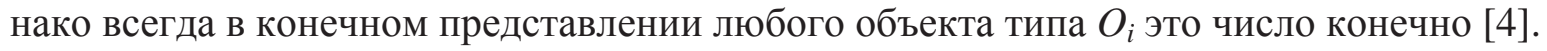




\section{1 Предварительные замечания}

В соответствии с рассмотренным выше подходом формальное представление какоголибо двухвходового логического элемента (например, типа «2И-НЕ») может быть записано следующим образом:

$$
0_{2 \text { И-НЕ }}=\left\langle\gamma_{2 \text { И-НЕ }}, \mathbf{M}_{2 \text { И-НЕ }}\right\rangle=\left\langle\left\{\gamma_{1}, \gamma_{2}, \gamma_{3}\right\},\left\{\gamma_{3}=\varphi_{2 и-H Е}\left(\gamma_{1}, \gamma_{2}\right)=-\left(\gamma_{1} \wedge \gamma_{2}\right)\right\}\right\rangle,
$$

где символ «-» (минус) означает инверсию результата операции в скобках, «^» - символ конъюнкции, $\gamma_{1}, \gamma_{2}, \gamma_{3} \in\{0,1\}$, а нижние индексы обозначают тип того логического элемента, к которому относится данное множество (элементов, свойств или функциональностей).

Используя обозначения, принятые в [4], тип формальных функциональных преобразований, использованный в (2), можно записать следующим образом:

$$
\left(\gamma_{1}\right)_{\mathrm{i}}^{2 \mathrm{~L}-\mathrm{HE}} *\left(\gamma_{2}\right)_{\mathrm{i}}^{2 \mathrm{U}-\mathrm{HE}} \rightarrow\left(\gamma_{3}\right)_{\mathrm{i}}^{2 \text { 2U-HE }},
$$

где нижний индекс і означает, что все три параметра в скобках $\left(\gamma_{1}\right),\left(\gamma_{2}\right)$ и $\left(\gamma_{3}\right)$ (соответствующие текущим значениям двух входных логических сигналов $\gamma_{1}, \gamma_{2}$ и одному выходному - $\left.\gamma_{3}\right)$ относятся к одному и тому же виду их физических носителей или параметров, то есть гомогенны; верхние индексы (символы « $\left.{ }^{2 И-\mathrm{HЕ}} \gg\right)$ просто обозначают сам тип объекта (логического элемента «2И-НЕ»), к которому относится данный параметр, символ звездочки «*» обозначает некое (в общем случае - любое) функциональное взаимодействие двух входных параметров $\gamma_{1}$ и $\gamma_{2}$, стрелка « $\rightarrow$ указывает направление функциональных преобразований, а последний компонент «( $/ 3)_{j}^{2 И-\mathrm{HE}_{\Perp}}$ в (3) - их результат (в виде значения параметра $\left.\gamma_{3}\right)$. С некоторой долей условности можно считать, что параметры $\gamma_{1}, \gamma_{2}, \gamma_{3}$ есть некие физические свойства логических элементов типа «2И-НЕ», в совокупности определяющие его состояние [4]. Схематически такое взаимодействие двух входных параметров-сигналов $\gamma_{1}, \gamma_{2}$, формирующих в итоге этого (взаимодействия) значение некоего выходного параметра-сигнала $\gamma_{3}$, для соответствующего объекта с двумя входами и одним выходом $0_{2-1}$, можно представить так, как это показано на рисунке 1.

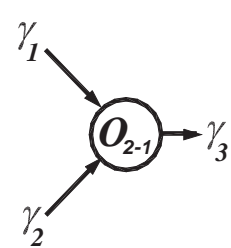

Рисунок 1 - Условное обозначение функционирования некоего объекта с двумя входами и одним выходом

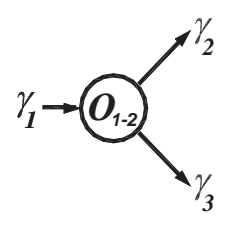

Рисунок 2 - Функция разветвителя в самом общем виде

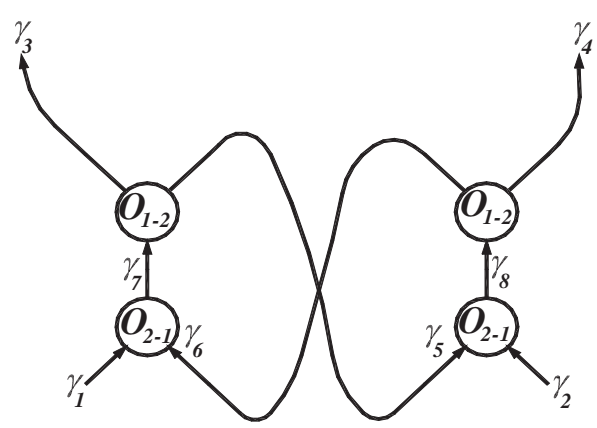

Рисунок 3 - Общая схема гетерогенного бинарного триггера

Для удобства и простоты сопоставления с реальными логическими элементами можно считать, что физическими носителями этих параметров могут быть, например, два уровня напряжений, соответствующих нулю и единице, или два уровня тока, или два уровня частоты сигнала и т.п. Обозначая аналогично все возможные типы функциональных преобразований, можно, согласно [4], для объектов типа $0_{2-1}$, (т.е. для объектов с двумя условновходными физическими параметрами $\gamma_{1}$ и $\gamma_{2}$, и одним условно-выходным параметром $\gamma_{3}$ ) записать: 


$\begin{array}{ll}(4.1) & \left(\gamma_{1}\right)_{\mathrm{i}}{ }^{0} *\left(\gamma_{2}\right)_{\mathrm{i}}{ }^{0} \rightarrow\left(\gamma_{3}\right)_{\mathrm{i}}{ }^{0} \\ \text { (4.2) } & \left(\gamma_{1}\right)_{\mathrm{i}} \mathrm{i}^{0} *\left(\gamma_{2}\right)_{\mathrm{k}}{ }^{0} \rightarrow\left(\gamma_{3}\right)_{\mathrm{i}}{ }^{0} \\ \text { (4.3) } & \left(\gamma_{1}\right)_{\mathrm{k}}{ }^{0} *\left(\gamma_{2}\right)_{\mathrm{i}}{ }^{0} \rightarrow\left(\gamma_{3}\right)_{\mathrm{k}}{ }^{0} \\ (4.4) & \left(\gamma_{1}\right)_{\mathrm{i}}{ }^{0} *\left(\gamma_{2}\right)_{\mathrm{k}}{ }^{0} \rightarrow\left(\gamma_{3}\right)_{\mathrm{s}}{ }^{0} \\ (4.5) & \left(\gamma_{1}\right)_{\mathrm{i}}{ }^{0} *\left(\gamma_{2}\right)_{\mathrm{i}}{ }^{0} \rightarrow\left(\gamma_{3}\right)_{\mathrm{k}}{ }^{0}\end{array}$

где различные нижние индексы i, $\mathrm{k}, \mathrm{s}$ соответствуют различныл, то есть не зависимым друг от друга, а, следовательно, с математической точки зрения ортогональным друг к другу, физическим параметрам.

Ещё раз отметим, что тип функционального взаимодействия, использованный в функционировании бинарных гомогенных логических элементов вида (2), соответствующий общему выражению (3), реализуется только в выражении (4.1) системы (4), тогда как остальные 4 типа функциональных взаимодействий (4.2)-(4.5) относятся, во-первых, к взаимодействиям гетерогенного типа, а, во-вторых, в случае симметричности двух входных физических параметров і и k, выражения (4.2) и (4.3) описывают фактически один и тот же их тип.

\section{2 Новые результаты}

Какую же простейшую математическую зависимость должны носить функциональные

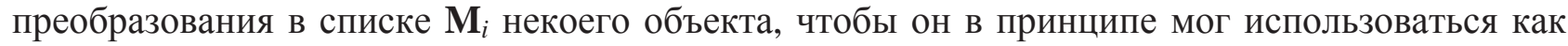
базовый объект для формирования функционально-полных систем логических функций подобно логическим элементам типа «2И-НЕ»? Как известно [3], эти логические элементы могут обеспечить функциональную полноту набора логических функций вместе с константами «0» (или «1»), и в совокупности с ещё одним функциональным блоком, названным в $[3,5]$ «разветвителем» (сигналов или параметров) - см. рисунок 2.

Заметим, что в отличие от «разветвителей» в работах $[3,5]$, «разветвитель сигналов (параметров)» на рисунке 2 не обязательно генерирует на выходе два эквивалентных сигнала (параметра). Это могут быть в принципе любые гетерогенные сигналы-параметры или даже разные физические объекты [5]. Обозначим соответствующий ФБ как объект типа $0_{\text {1-2. }}$

С учётом наиболее простых конкретных вариантов реализации функций (функциональностей) разветвителя один из них можно математически записать следующим образом:

$$
\text { Если } \gamma_{1}>\gamma_{1 \mathrm{c}} \text {, то }\left(\gamma_{2}>>\gamma_{2 c}\right) \&\left(\gamma_{3}>>\gamma_{3 c}\right) \text {, иначе }\left(\gamma_{2}<<\gamma_{2 c}\right) \&\left(\gamma_{3}<<\gamma_{3 c}\right) \text {, }
$$

где $\gamma_{1 c}, \gamma_{2 c}, \gamma_{3 c}$ - некоторые «пороговые» значения («константы») для параметров $\gamma_{1}, \gamma_{2}$ и $\gamma_{3}$ соответственно.

Другой вариант:

$$
\text { Если } \gamma_{1}>\gamma_{1 \mathrm{c}} \text {, то }\left(\gamma_{2}>\gamma_{2 \mathrm{c}}\right) \&\left(\gamma_{3}>\gamma_{3 \mathrm{c}}\right) \text {, иначе }\left(\gamma_{2} \approx \varnothing\right) \&\left(\gamma_{3} \approx \varnothing\right),
$$

где $\varnothing$ - символ отсутствующего («пустого» или «близкого к нулю») параметра (собственно,

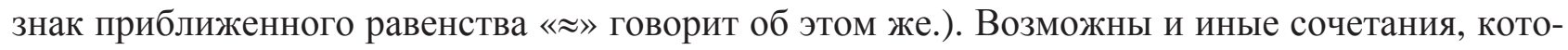
рые мы ввиду их практически одинакового смысла пока рассматривать не будем.

Если вновь обратиться к внутренней сущности правой части формулы (2) в контексте

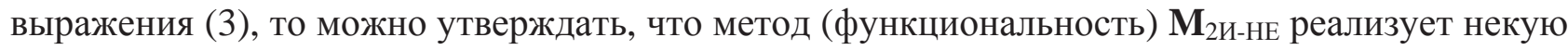
разновидность «инвертированной пороговой функциональности». Действительно, при традиционном толковании всех выражений в (4) если каждый из входных параметров $\left(\gamma_{1}\right)_{\mathrm{i}}$ и $\left(\gamma_{2}\right)_{\mathrm{i}}$ превышает некоторый фиксированный уровень, условно соответствующий «1», то только в этом случае выходной параметр $\left(\gamma_{3}\right)$ i становится равным «нулю» (или просто отсутствует). В противоположном случае «выход» $\left(\gamma_{3}\right)$; остается «активным», т.е. «генерирует» уровень параметра $\left(\gamma_{3}\right)$ i, условно соответствующий «единице» (что обычно связывается с наличием дан- 
ного параметра на «выходе» объекта). Таким образом, получается, что суммарная (итоговая) функциональность для (2) легко формируется последовательной композицией двух более простых функциональностей - чисто «пороговой» для двух входных параметров и чисто «инвертирующей» - для выходного. Заметим при этом, что «инверсию» значения некоторого

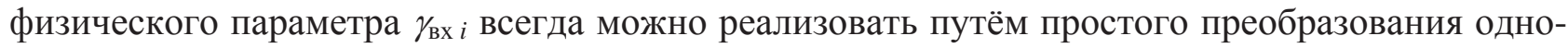
го уровня одного параметра в другой по следующей схеме:

$$
\gamma_{\text {вых }}=\left\{\begin{array}{l}
\gamma_{\text {вых.1 }}, \text { если } \gamma_{\text {вх } і}>\gamma_{\text {с і }} \\
\gamma_{\text {вых.2 }}, \text { иначе },
\end{array}\right.
$$

где $\gamma_{\mathrm{ci}}$ - некоторое (обычно не крайнее) значение некоторого физического параметра из области допустимых значений для $\gamma_{\text {вх }}$, а $\gamma_{\text {вых1 и }} \gamma_{\text {вых2 }}$ - аналогичные допустимые (но не обяза-

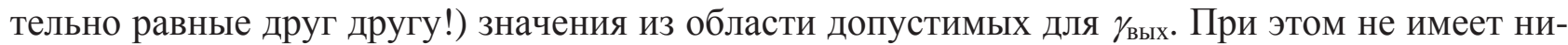

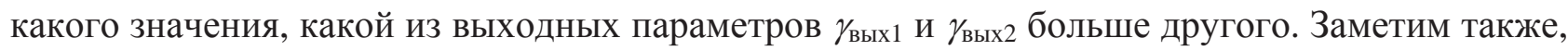

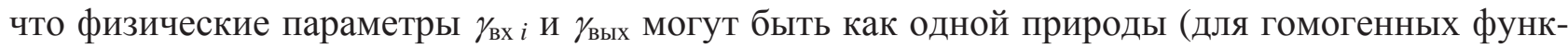
циональных преобразований), так и разной (для гетерогенных), а само выражение (7) с очевидностью описывает всё ту же «пороговую функциональность» для некоего гипотетического «одновходового (с одним выходом)» объекта $0_{1-1}$. Ясно, что такой объект легко реализовать на основе любого «двухвходового» объекта $0_{2-1}$, входящего в систему различных типов функциональных преобразований (4) - если сделать один из входных «сигналов-параметров» какого-либо объекта в ней постоянным (то есть константой). Сама же функциональность двухвходового порогового элемента $0_{2-1}$ для рассматриваемого случая может быть записана так:

$$
\gamma_{3}=\left\{\begin{array}{l}
\gamma_{3-1}, \text { если }\left(\gamma_{1}>\gamma_{1 c}\right) \wedge\left(\gamma_{2}>\gamma_{2 c}\right) \\
\gamma_{3-2}, \text { если }\left(\gamma_{1}<\gamma_{1 c}\right) \vee\left(\gamma_{2}<\gamma_{2 c}\right) ;
\end{array}\right.
$$

где $\gamma_{3-1}, \gamma_{3-2}$ - различные значения (например, уровни) выходного параметра $\gamma_{3}$, а $\gamma_{1 c}$ и $\gamma_{2 c}$ - по прежнему некоторые пороговые значения для входных параметров $\gamma_{1}$ и $\gamma_{2}$. Нетрудно видеть, что в общем случае возможны также смена типа выходного параметра $/ 3$ - формула (9), или его полное «выключение» - формула (10):

$$
\begin{aligned}
& \gamma_{3}=\left\{\begin{array}{l}
\gamma_{3-1}, \text { если }\left(\gamma_{1}>\gamma_{1 \mathrm{c}}\right) \wedge\left(\gamma_{2}>\gamma_{2 \mathrm{c}}\right) \\
\gamma_{4}, \text { если }\left(\gamma_{1}<\gamma_{1 \mathrm{c}}\right) \vee\left(\gamma_{2}<\gamma_{2 \mathrm{c}}\right) ;
\end{array}\right. \\
& \gamma_{3}=\left\{\begin{array}{l}
\gamma_{3-1}, \text { если }\left(\gamma_{1}>\gamma_{1 \mathrm{c}}\right) \wedge\left(\gamma_{2}>\gamma_{2 \mathrm{c}}\right) \\
\varnothing, \text { если }\left(\gamma_{1}<\gamma_{1 \mathrm{c}}\right) \vee\left(\gamma_{2}<\gamma_{2 \mathrm{c}}\right) ;
\end{array}\right.
\end{aligned}
$$

где $\varnothing$ - символ пустого (отсутствующего, «выключенного») выходного параметра $\gamma_{3}$.

С другой стороны, легко заметить, что в отношении самих параметров $\gamma_{1}$ и $\gamma_{2}$ все три выражения (8)-(10) описывают логическую функцию типа «И». Действительно, только при наличии и первого, и второго входных параметров $\gamma_{1}$ и $\gamma_{2}$ со значениями, превышающими пороговые, на выходе $0_{2-1}$ формируется выходной сигнал-параметр $\gamma_{3}$. Другие возможные типы логических взаимодействий по этим входным параметрам (например, «ИЛИ», «Исключающее ИЛИ» и т.д.) представляются более сложно устроенными, поэтому пока не рассматриваются.

С учётом «инверсии» типа (7) можно заключить, что при определённых условиях практически любое выражение системы (4) для «двухвходовых с одним выходом» функциональ- 
ных объектов может служить базовым, делающим в принципе возможным достижение булевской функциональной полноты [5]. Ограничивающим условием здесь служит только факт существования объектов, которые могут связываться по своим выходным и входным параметрам-сигналам друг с другом в соответствующие сети. Например, сеть таких гетерогенных объектов, соответствующая схеме обычного двоичного гетерогенного триггера, с учётом вышесказанного, может условно изображаться как показано на рисунке 3.

Легко проверяется, что триггер (см. рисунок 3) работает при любой из приведённых выше интерпретаций функциональностей объектов $0_{2-1}(8)-(10)$ и разветвителей $0_{1-2}$. (5)-(6).

Кроме того, все восемь параметров $\left(\gamma_{1}-\gamma_{8}\right)$, необходимые для работы такого триггера, могут быть различными по своей физической сути, т.е. гетерогенными, однако это условие не является жёстким, обязательным. Некоторые из них вполне могут быть и гомогенными, например, $\gamma_{1}$ и $\gamma_{2}, \gamma_{3}$ и $\gamma_{6}$, и даже $\gamma_{1}, \gamma_{4}$ и $\gamma_{5}$, включая все $\gamma_{1}-\gamma_{8}$.

Аналогичным образом могут быть сконструированы трёх-стабильные триггеры, и вообще - любые n-стабильные запоминающие устройства, где $n$ - любое (конечное) целое число. Правда, для их реализации потребуются объекты с большим числом входов: от типа $0_{3-1}$ до типа $O_{(n+1)-1}$ и соответствующие разветвители. Впрочем, как показано в $[3,5]$, разветвители (с функциональностями «порогового» типа) на любое количество выходов, как и многовходовые схемы совпадения наличия параметров на любое конечное их число, могут быть реализованы каскадным включением соответствующих объектов типа $0_{1-2}$ и $0_{2-1}$ (рисунок 4).

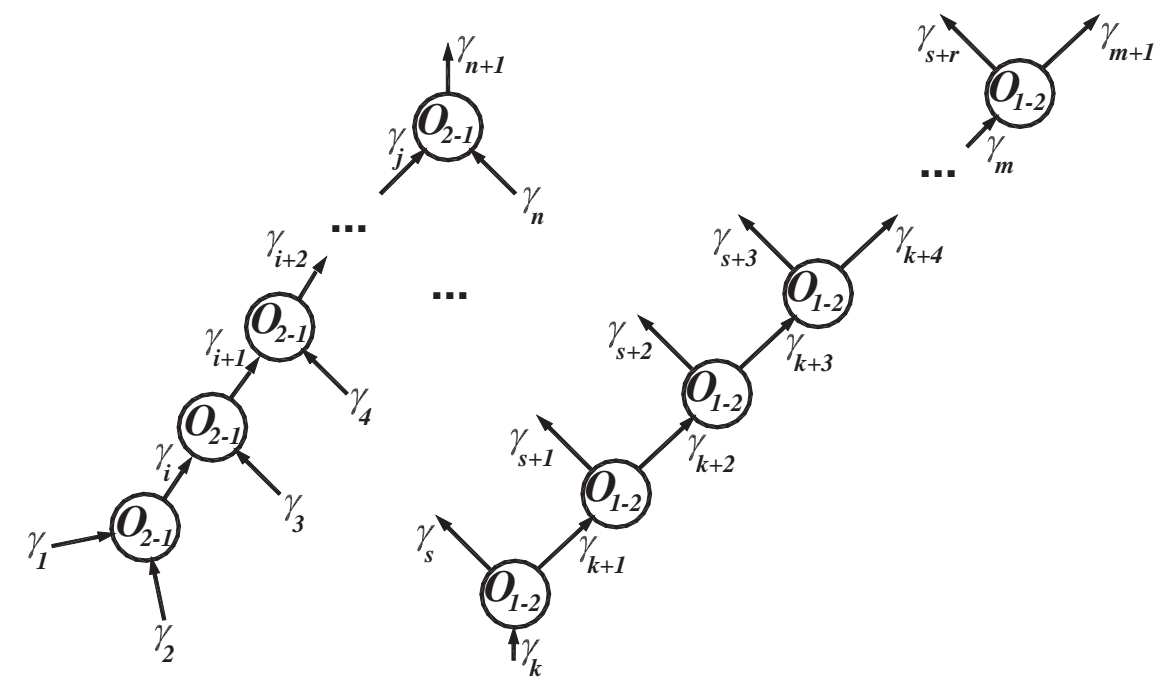

Рисунок 4 - Многовходовая схема совпадения (слева) и разветвитель (справа) на любое конечное число входов и выходов

\section{3 Основные теоремы}

Рассмотренные выше особенности различных компонентов бинарных систем обработки информации с максимально широким диапазоном физических реализаций позволяют сформулировать следующие базовые теоремы, называемые далее утверждениями.

Утверждение 1. Любая конечная булева функция (бинарная комбинационная схема) может быть реализована подходящей конечной сетью функциональных объектов типа $0_{2-1}$ и $0_{1-2}$ с функциональностями «порогового» типа, связанными между собой по индивидуальным уникальным входным-выходным параметрам (сигналам). 
Доказательство. Действительно, любая конечная булева функция может быть реализована в виде дизъюнктивной нормальной формы (ДНФ), представляющей собой конечную дизъюнкцию конечных же конъюнкций [6]. Представим все конъюнкции, входящие в соответствующую ДНФ, в виде подходящих сетей функциональных объектов типа $0_{2-1}$ и $O_{1-2}$, связанных надлежащим образом между собой по индивидуальным уникальным входнымвыходным параметрам (сигналам) - см. рисунок 4. Сопоставим каждый уникальный индивидуальный выходной параметр соответствующей схемы совпадения (типа приведённой на рисунке 4 слева) с тем выходным сигналом, за который отвечает соответствующая конъюнкция ДНФ, а все входящие в эту конъюнкцию двоичные переменные - с соответствующими входными параметрами нашей схемы совпадения. Это всегда можно сделать, поскольку по условиям утверждения 1 мы всегда можем назначать нашим входным и выходным параметрам входящих в сеть объектов «индивидуальные уникальные имена», а с помощью сетей типа «разветвителей» (рисунок 4) получить столько реплик исходных физических параметровсигналов, сколько необходимо.

В итоге мы получим сеть, на выходах которой будут формироваться именно те выходные параметры, которые соответствуют логическим единицам на выходах соответствующих конъюнкций при наличии требуемого набора их входных логических переменных, т.е. сеть, эмулирующую нашу ДНФ. Таким образом, утверждение доказано.

Справедливость утверждения 1 вместе с рассмотренной ранее возможностью реализовать в аналогичных сетях многоустойчивые элементы памяти позволяет сформулировать также следующее.

Утверждение 2. Любой детерминированный конечный автомат (обработки информации) может быть реализован подходящей конечной сетью функциональных объектов типа $\mathrm{O}_{2-1}$ и $\mathrm{O}_{1-2}$ с функциональностями «порогового» типа, связанными между собой по индивидуальным уникальным входным-выходным параметрам (сигналам).

Доказательство. Детерминированный конечный автомат может быть реализован либо как автомат Мили, либо как автомат Мура [7]. Поскольку оба автомата эквивалентны, рассмотрим в качестве основного автомат Мили. Он содержит конечный набор триггеров (память состояний) и комбинационную схему, реализующую функции переходов и выходов, т.е. переключение состояний в зависимости от текущего состояния и кода входного символа, и формирующую коды выходных символов в зависимости от этих же параметров (рисунок 5). Оба этих конечных функциональных блока вполне реализуемы в рамках рассмотренных выше функциональностей (рисунки 1-4). Утверждение доказано.

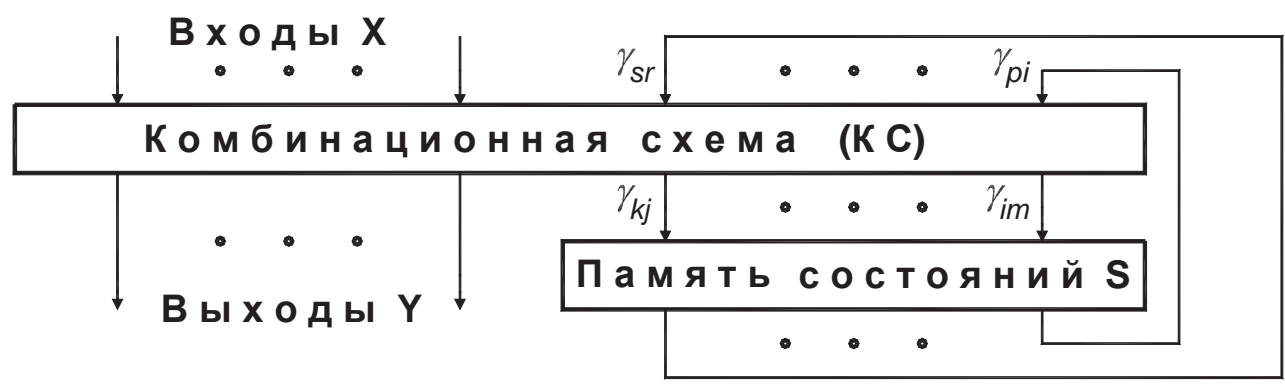

Рисунок 5 - Структурная схема автомата Мили 


\section{4 Обсуждение}

Очевидно, что рассмотренные в утверждениях 1 и 2 гетерогенные бинарные системы обработки информации (ГБСОИ) являются функционально-полными с точки зрения класса булевских функций, несмотря на то, что они не содержат в явном виде никакие классические функционально-полные (под)классы таких функций.

Самое неожиданное свойство рассмотренных ГБСОИ - то, что для достижения булевской функциональной полноты им не нужна логическая инверсия. Аналогичная особенность отмечалась и в преобразованиях «химического типа» при исследовании вопросов их функциональной полноты $[4,5]$. Роль инверсии в ГБСОИ выполняет либо конкретный и уникальный уровень выходного параметра (сигнала), либо смена типа самого этого параметра. Выше уже отмечалось, что разные типы таких параметров с точки зрения математики следует рассматривать, как ортогональные. Таким образом, необходимая для достижения булевской функциональной полноты функция логической инверсии реализуется здесь в многомерном пространстве ортогональных физических свойств (параметров) путём некоего (функционального) отображения параметра одного типа на параметр другого (ортогонального) типа.

Другой интересный аспект рассматриваемых ГБСОИ - возможная интерпретация необходимости уникальных индивидуальных физических свойств-параметров, связывающих объекты-элементы в сети и выполняющих роль уникальных (индивидуальных) сигналов. В работах по ОФТ отмечалось [4], что с формально-технологической точки зрения такими уникальными индивидуальными физическими параметрами объектов могут быть, во-первых, их пространственное положение (в двухмерном, а лучше - в трёхмерном пространстве), вовторых - форма и структура (состав) объектов (например, физико-химический). Вторая интерпретация приводит к выводу о том, что с представленной точки зрения соответствующие цепочки химических реакций также могут обладать булевской функциональной полнотой и, естественно, поэтому могут кодировать сложные процессы обработки информации химического типа $[4,5]$, в которых входные и выходные символы-сигналы представляют собой те или иные химические вещества - молекулы. Как известно, этот вариант широко используется природой для своих самых необычных и самых сложных конструкций - живых существ [8].

Если же воспользоваться первым вариантом интерпретации, то приходим к более гомогенным структурам - в частности, к структурам, близким к структуре головного мозга [9]. В них роль уникальных физических параметров-сигналов, как уже отмечалось выше, играют уникальные пространственные (обычно трёхмерные) физические координаты элементарных объектов обработки информации - клеток-нейронов. При этом надобность в гетерогенных типах самих сигналов отпадает, что делает структуру мозга более простой с точки зрения её физической реализации. Кстати - те же самые причины (простота) заставляют и нас использовать для реализации своих систем обработки информации аналогичные (гомогенные по типам сигналов) подходы.

Заметим, что даже мозг ребенка уже изначально содержит структуры, аналогичные упомянутым в утверждениях 1 и 2 [10]. То есть уже изначально структура мозга состоит из многоустойчивых элементов памяти и комбинационных схем. Другое дело, что в процессе обучения (настройки) этой начальной структуры на конкретные важные объекты и события некоторые из уже имеющихся первоначальных связей оказываются не нужными. Такие связи со временем деактивируются, то есть разрываются. При этом скорость такой деактивации оказывается довольно высокой - примерно до 12,5 триллионов связей в год или более 34 миллиардов в день (то есть в среднем чуть менее 400 тысяч связей в секунду). Однако перед этим - в раннем возрасте (до 3-х лет) устанавливаются новые - полезные - связи со скоростью до примерно 2 миллиона в секунду [10]! 


\section{Заключение}

Таким образом, прикладная онтология проектирования самых различных бинарных систем обработки информации действительно имеет в своей основе общую математическую базу, подтверждающую эффективность использования математики при онтологическом анализе таких систем.

Рассмотренный подход к оценке структур и типов функциональностей для реализации как гомогенных, так и гетерогенных бинарных систем обработки информации и их компонентов на основе предложенной в ОФТ концепции формального представления любых объектов в виде (1), показал свою эффективность и состоятельность, что подтверждает факт целесообразности использования метаматематического аппарата ОФТ при исследовании различных физических и интеллектуальных процессов окружающего мира, включая потенциальные возможности самой математики. Оказалось, что с позиций ОФТ привычные нам гомогенные системы обработки информации на основе булевской логики и часто используемые в живой природе гомогенные (опять же по типам информационных сигналов) структуры типа нейросетей, и даже различные цепочки гетерогенных химических реакций, оказываются вполне равноправными по своим информационно-функциональным возможностям, сопоставимыми с аналогичными возможностями функционально-полных наборов булевских функций. Это позволяет подойти к разработке и проектированию самых разнообразных, в том числе гетерогенных, систем обработки информации с принципиально новых, несколько непривычных и неожиданных позиций $[3,4]$.

\section{Список источников}

[1] Боргест, Н.М. Робот-проектант: на пути к реальности / Н.М. Боргест, С.А. Власов, Ал.А. Громов, Ан.А. Громов, М.Д. Коровин, Д.В. Шустова //Онтология проектирования. - 2015. - №4 (18). - С. $429-449$. doi: 10.18287/2223-9537-2015-5-4-429-449.

[2] Черняков, $\boldsymbol{A}$. Г. Онтология как математика: Бадью, Гуссерль, Плотин. / А.Г. Черняков. - Философский портал "philosophy2.ru" - http://philosophy2.ru/library/chernyakov/chern_ontol_math.pdf (Актуально на 1.03.2016).

[3] Крылов, С.М. Онтология проектирования гетерогенных электронных систем / С.М. Крылов, Е.Н. Гребенщиков // Онтология проектирования. - 2012. - № 1(3). - С. 65-72.

[4] Крылов, С.М. Метаматематические основы науки будущего / С.М. Крылов. - Самара: СамГТУ, 2014. - 247с. - http://vt.samgtu.ru/images/pdf/krylov/metamath.pdf (Актуально на 1.03.2016).

[5] Гребенщцков, E.H. Системный анализ гетерогенных слабоструктурированных автоматов. II. Переход от преобразований «химического типа» к логическим схемам и обратно / Е.Н. Гребенщиков, С.М. Крылов // Вестник Самарского государственного технического университета. Серия технические науки. - 2012. №2(34). - С. 65-71.

[6] Яблонский, С.В. Введение в дискретную математику / С.В. Яблонский. - М.: Наука, 1986. - 384 с.

[7] Кузнецов, О.П. Дискретная математика для инженера / О.П. Кузнецов, Г.М. Адельсон-Вельский. - М.: Энергия, 1980.- 344 с.

[8] Николаев, А.Я. Биологическая химия / А.Я. Николаев. - М.: Высш. школа, 1989. - 495 с.

[9] Блум, Ф. Мозг, разум и поведение / Ф. Блум, А. Лейзерсон, Л. Хофстедтер - М.: Мир, 1988. - 248 с.

[10] Шириова, Л. Чем мозг ребёнка отличается от взрослого? - https://newtonew.com/discussions/post-skartinkami-chem-mozg-rebenka-otlichaetsja-ot-vzroslogo (Актуально на 1.03.2016).

\section{MATHEMATICAL FOUNDATION OF BINARY SYSTEM ONTOLOGY FOR DATA PROCESSING}

\section{Krylov S.M.}

Samara State Technical U niversity, Samara, Russia

S_m_krylov@mail.ru 


\begin{abstract}
The paper deals with theoretical principles that guarantee Boolean functional completeness of some primitive types of heterogeneous and homogeneous binary operational units designed for a logical data processing. Information in such units can be represented by various (different) physical parameters coding different states of physical objects. Simplest functionalities that define output "signals" ("output" parameters) as primitive functions of input "signals" ("input" parameters) are analyzed. It is shown that heterogeneous and homogeneous binary systems for data processing can be constructed on the basis of a general concept using proper object models based on General Formal Technological approach. It is shown that the homogeneous and heterogeneous binary information processing systems can be constructed based on the total (universal) basic ontology, which considers all physical objects as functional convert a certain set of physical parameters (physical properties in its broadest sense) in the other.
\end{abstract}

Key words: boolean functions, functional completeness, homogeneous and heterogeneous systems for data processing, ontology of binary systems for data processing, G eneral F ormal Technology, object properties, object functionalities.

Citation: Krylov SM. Mathematical foundation of binary system ontology for data processing. O ntology of designing. 2016; 6(1): 29-38. DOI: 10.18287/2223-9537-2016-6-1-29-38.

\title{
References
}

[1] B orgest N M, Vlasov SA, Gromov AIA, Gromov AnA, Korovin M D, Shustova DV. Robot-Designer: on the Road to Reality. Ontology of Designing. 2015; 4 (18): 429-449. doi: 10.18287/2223-9537-2015-5-4-429-449 (In Russian).

[2] Chernjakov AG. Ontology as mathematics: Badiou, Husserl, Plotin. - Philosophical portal "philosophy2.ru" - 19 p. - http://philosophy2.ru/library/chernyakov/chern_ontol_math.pdf (valid for 1.03.2016) (In Russian).

[3] Krylov SM, Grebenschikov EN. Ontology of heterogeneous electronics system design. Ontology of Designing. 2012; 1(3): 65-72. (In Russian).

[4] Krylov SM. Mathematical Foundations of Future Science - Samara: SamGTU Publisher; 2014.247 p. http://vt.samgtu.ru/images/pdf/krylov/metamath.pdf (valid for 1.03.2016) (In Russian).

[5] Grebenschikov E N, Krylov SM. System analysis of heterogeneous semi-automatic machines. II. The transition from the transformation of "chemical type" to the logic circuits and back / Bulletin of the Samara State Technical University. A series of technical science. - 2012. - №2(34): 12-25. (In Russian).

[6] Yablonsky SV. Introduction to discrete mathematics. - Moscow: Nauka. 1986. - 384 p. (In Russian).

[7] Kuznetsov OP, Adelson-B elsky G M. Discrete mathematics for the engineer. - Moscow: Energy. 1980. - 344 p. (In Russian).

[8] Nikolaev AY, Biological Chemistry. - Moscow: Higher School. 1989. - 495 p. (In Russian).

[9] B loom F E, L azerson A, H ofstadter L. Brain, Mind, and Behavior. - New York: W. H. Freeman and Co. 1985.

[10] Shirshov L. The brain child different from an adult? - https://newtonew.com/discussions/post-s-kartinkami-chemmozg-rebenka-otlichaetsja-ot-vzroslogo (valid for 1.03.2016) (In Russian).

\section{Сведения об авторе}

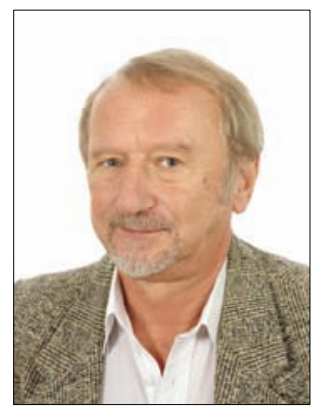

Сергей Михайлович Крылов, 1948 г. рождения. Окончил Куйбышевский политехнический институт в 1973 г. Доктор технических наук, профессор кафедры вычислительной техники Самарского государственного технического университета. Автор более 150 работ, включая 7 монографий в области точной философии, общей теории систем, формальной технологии, метаматематики, метафизики и многоцелевых программируемых систем для различных технологий.

Sergey Mikhailovich Krylov (b. 1948) graduated from Kuibyshev polytechnic institute in 1973. D. Sc. (Eng.), professor of Computer Department in Samara State Technical University. Hi is the author and co-author of more than 150 publications, including 7 monographs, in the field of exact philosophy, General System Theory, General Formal Technology, meta-mathematics, metaphysics, and multipurpose programmable systems for various technologies. 


\title{
УДК 519.21
}

\section{САМООРГАНИЗУЮЩИЕСЯ СЕТЕВЫЕ ЭКСПЕРТНЫЕ СРЕДЫ В СИСТЕМАХ С ЭНДОГЕННЫМ ПРИНЦИПОМ ЦЕЛЕУКАЗАНИЯ}

\author{
Г.П. Виноградов ${ }^{1}$, Н.Г. Виноградова ${ }^{2}$ \\ Тверской государственный технический университет, Тверь, Россия \\ 1'wgp272ng@ mail.ru, ²n-nataly08@mail.ru
}

\begin{abstract}
Аннотация
В статье обсуждается проблема построения модели функционирования социально-экономической системы, использующей механизмы информационного взаимодействия её участников. Центральным моментом такого взаимодействия является формирование согласованных представлений о целях, ограничениях, потребностях, возможностях и направлениях развития. Модель позволяет не только определить заказчиков и потребителей товаров и услуг, требования к объёмам и показателям качества, но и формировать их представления о собственных потребностях. Это позволяет считать, что механизмы формирования согласованных представлений и способов действия участников системы являются более эффективными, чем, например, рыночные или командноиерархические. Показано, что наиболее перспективной формой информационного взаимодействия при решении задач поиска, производства нового знания и определения направления его использования становятся саморазвивающиеся сетевые экспертные среды. Элементарной частью такой среды является эксперт-профессионал, владеющий современными телекоммуникационными технологиями. Интеграция в сетевой структуре естественных интеллектов образует коллективный стратегический субъект, который является средством синергии знаний и действий в процессе развития. Рассматривается проблема построения самоорганизующихся сетевых экспертных сред для обеспечения инновационного развития производств, выпускающих высокотехнологичную, наукоёмкую продукцию и услуги.
\end{abstract}

Ключевые слова: экспертная среда, самоорганизаџия, сетевые технологии, согласование представлений, инновачионное развитие.

Цитирование: Виноградов, Г.П. Самоорганизующиеся сетевые экспертные среды в системах с эндогенным принципом целеуказания / Г.П. Виноградов, Н.Г. Виноградова // Онтология проектирования. - 2016. - Т. 6, № 1(19). - С. 39-54. - DOI: 10.18287/2223-9537-2016-6-1-39-54.

\section{Введение}

В XXI веке развитие организационных систем во все большей степени переходит от эволюционного типа к проектному. Управление этим процессом предполагает сочетание казуального подхода (причинно-следственного) с телеологическим (целевая детерминация). Движущей силой развития становится деятельность, представленная множеством институциональных построений, ориентированных, прежде всего, на развитие инноващионной деятельности $[1,2]$ путём совершенствования видов информационных взаимодействий в функционировании социально-экономических систем, в частности сетевой экономики. Информационные взаимодействия предоставляют более широкие возможности развития по сравнению с рыночными и иерархическими взаимодействиями, так как они создают предпосылки и являются средством формирования в сознании агентов согласованной информационной модели среды их жизнеобитания. Существуют определённые ограничения на информационные взаимодействия, которые связаны с параметрами распространения информационных потоков в системе. Институциональные структуры могут делать процесс и результат 
информационных взаимодействий управляемым и согласованным. В этом смысле рыночные и иерархические взаимодействия являются частным случаем информационных взаимодействий, перенесённых в рамки определённых институциональных структур. Простейшая модель социально-экономической системы, функционирующая на базе информационных взаимодействий, включает пять типов объектов:

- макротехнология;

- информационное пространство;

- институциональные структуры;

- коллективные модели среды;

- люди, как действующие лица системы.

Такой подход означает, что наиболее перспективной формой информационного взаимодействия при решении задач поиска, производства нового знания и определения направления его использования становятся саморазвивающиеся сетевые экспертные среды. Элементарной частью такой среды является эксперт-профессионал, владеющий современными телекоммуникационными технологиями, средствами Интернета. Интеграция в сетевой структуре естественных интеллектов образует коллективный стратегический субъект, который является средством синергии знаний и действий в процессе развития.

Это позволяет считать проблематику организации саморазвивающихся инновационных сред, составной частью которых являются самоорганизующиеся сетевые экспертные среды, одним из важных направлений в теории управления. Необходима разработка методологических основ организации подобных сред и управления ими. Центральным аспектом в этом становится оценка субъектами (в дальнейшем агенты) ценности, полезности нового знания и технологий, оценка рисков, определение механизма их исключения, соотнесения нового знания с целями и задачами развития. Это требует, в свою очередь, новых моделей управления процессом формирования представлений агентов о предметной области (ПрО) при определении направления развития.

Предлагаемый подход может быть применён для формализации экспертных знаний, основой которой являются онтологии различных уровней. Возможность их расширения за счёт, например, информационного управления самоорганизацией экспертных сред позволяет выполнять задачи:

- классификации получаемой информации;

- интеграции разнородной и разного качества информации;

- интерпретации и оценки полезности полученных сведений;

- получения релевантной информации от носителей соответствующего знания;

- согласования субъективных онтологий предметных областей у носителей знаний.

Полученные онтологии особенно для динамичных, плохо формализуемых и слабо структурированных ПрО на основе самоорганизующихся сетевых экспертных сред позволяет существенно расширить возможности систем поддержки принятия решений, в том числе и при проектировании сложных систем.

\section{1 Принципы создания и применения систем управления эволюцией организационно-технологической системы}

Пусть организационно-технологическая система (ОТС) состоит из центра и $\mathrm{n}$ подчинённых ему агентов, обладающих свойствами активности, целеустремлённости и интеллектуальности. Состояние ОТС рассматривается как целеустремлённое состояние, а результат принятия решения - это результат компромисса между целеустремлёнными выборами агентов и центра в ситуации целеустремлённого состояния с учётом воздействия на систему 
управляющих воздействий и возмущений внешней среды. Это позволяет под эволюцией ОТС понимать последовательность смены ситуаций целеустремлённого состояния, происходящих в результате целеустремлённого выбора, с целью её адаптации и самоорганизации по результатам функционирования.

Информация о состоянии активных элементов системы, получаемая центром в процессе управления, используется им для настройки механизма функционирования ОТС, который включает в себя процедуры:

- ормирования данных о резервах;

- планирования;

- стимулирования;

- обучения;

- регулирования и т.п.

Особенность производства, использующего наукоёмкие технологии, связана со специализацией знаний и повышением степени интеллектуализации труда персонала, распределением центров принятия решений и ответственности. Это делает зависимым качество этой информации от результатов выбора агентов и как результат приводит к различной степени эффективности использования производственного, интеллектуального, финансового и другого потенциалов ОТС. Поэтому одной из важнейших проблем для центра является повышение эффективности ОТС путём повышения эффективности функционирования активных агентов, путём развития их способности видения и учёта перспективы, а также последствий принимаемых решений, влияния изменений во внешней среде и случайных факторов. Решение её возможно на основе соответствующих информационных технологий и средств автоматизации обработки информации. Их внедрение должно позволять согласовывать в целевом состоянии интересы агентов и центра и их оценок ценности ситуации целеустремлённого состояния на каждом периоде функционирования системы для поддержания соответствующего уровня мотивации и единого понимания задач персоналом. В этом смысле развитие ОТС становится ориентированным на реализацию согласованных интересов, осуществляется за счёт использования эндогенных факторов целеполагания, в определённом смысле путём целенаправленного воздействия на состояние окружения системы, а не только путём своей настройки на экзогенно заданную цель.

Основные положения и методы создания и функционирования системы управления эволюцией ОТС при таком подходе отражают специфику построения и применения процессов согласования интересов и оценок ситуации целеустремлённого состояния путём учёта субъективных представлений агентов и активизации их творческого потенциала, построения эффективных схем согласования интересов. К ним относятся принципы:

- активного окружения;

- создания коалиций с целью согласования интересов всех движущих сил, определяющих развитие;

- согласования и согласованной оптимизации на множестве компромиссных решений, принятых на основе субъективных представлений;

- моделирования (интеграция на базе теории активных систем, методов и средств моделирования, включая алгоритмический подход, структурное проектирование, моделирование на основе теории многоагентных систем, игровое имитационное моделирование);

- гибкости для аппаратно-программных и информационных технологий, обеспечивающих процессы выработки решений;

- применения субъективных представлений агентов в информационных технологиях;

- поэтапного внедрения для оценки результатов выполнения и обучения пользователей на каждом этапе; 
- визуализации при построении пользовательского интерфейса для обеспечения процессов анализа и согласования информации о вариантах и результатах решений и определения направлений в пространстве экономических показателей, выбора шагов в пространстве решений, останова процесса.

\section{Принцип активного окружения}

Основными элементами внешней среды для организационно-технологической системы являются поставщики сырья, энергоресурсов, полуфабрикатов, потребители выпускаемой продукции, представители экологических служб, отвечающих за безопасность окружающей среды и т.п. Для понимания ситуации целеустремленного состояния системы надо рассматривать как минимум следующую цепочку: поставщик - производитель - потребитель (глубина рефлексии - два). Такой подход к структуризации окружения ОТС позволяет поставить в соответствие трёхуровневую активную многоагентную систему.

Поставщики, конкурирующие между собой, образуют группу агентов низшего уровня, и их цель состоит в удовлетворении желаний потребителей, расширение на этой основе доли контролируемого рынка и росте прибыли. Агенты-производители образуют второй уровень активной системы. Их основная цель состоит в приобретение сырья, полуфабрикатов и услуг возможно более высокого качества, снижение издержек и выпуск конкурентоспособной продукции. Третий уровень образуют потребители конечных продуктов, их основной целью является либо получение реального экономического эффекта за счёт приобретения продуктов от агентов второго уровня, либо удовлетворение потребностей. Характерной чертой такой системы является взаимозависимость, возникающая на основе взаимных интересов.

Одной из возможностей для повышения эффективности этой трёхуровневой активной системы является анализ производства у поставщиков и производителей продукции и, по возможности, у потребителя, кому поставляется продукция. Соответственно поставщик и потребитель должны обладать подобным знанием. Такого рода знание создаёт предпосылки определения желаемых состояний в пространстве экономических показателей за счёт появления идей улучшения организации производства, выбора шагов решений в этом пространстве с одновременной трансляцией усовершенствований потребителю. Это позволяет не только учитывать пожелания клиента, но сформировать его потребности, что создаёт направление дальнейших нововведений.

\section{Принцип создания коалиций}

Этот принцип заключается в образовании при разработке и внедрении системы управления эволюцией ОТС ответственной группы, включающей в себя поставщиков информационных технологий, разработчиков системы, пользователей и руководителей, осуществляющих финансирование работ, для согласования и подтверждения факта выявления резервов за счёт предлагаемых методов совершенствования и управления технологического процесса. Такая коалиция осуществляет проработку и принятие решений по всем стадиям создания системы управления эволюцией ОТС: по объёмам финансирования, по срокам и этапам работ, оценке достигаемых результатов и т.д.

\section{Принцип моделирования}

Вследствие распределения знания о свойствах технологического процесса и ограниченных когнитивных возможностей человека особенностью построения и использования системы управления эволюцией ОТС является активизация творческого потенциала производственного персонала, что обуславливает использование процедур согласования и согласованной оптимизации. Их цель - формирование представлений на всех уровнях о возможных 
состояниях системы и окружения. Получение подобной информации вызывает необходимость создания на стадиях создания и эксплуатации системы управления эволюцией ОТС совокупности моделей (концептуальных, функциональных, информационных, структурных, алгоритмических, эвристических, математических, имитационных и др.) человекомашинных процессов принятия согласованных решений. Они должны описывать различные функциональности системы, использовать как количественную, так и качественную информацию и образовывать интегрированный комплекс, соответствующий точкам принятия решений. Их интеграция должна быть выполнена на основе теории многоагентных систем, теории интеллектуальных организаций, теории активных систем, методов и средств моделирования, включая алгоритмический подход, структурное проектирование, на основе синергетического принципа дополнительности [3, 4].

\section{Принцип гибкости}

Система управления эволюцией ОТС должна реализовывать технологию выявления и построения моделей поведения агентов, согласования решений с помощью разработанных и применяемых информационных и программных продуктов с развитым интерфейсом для формирования состояния убеждённости у агентов за счёт информационного управления с учётом ограничений на их информационную культуру. Она должна обеспечить применение методов и моделей построения представлений пользователей о ПрО на всех уровнях, и их согласование, согласованной оптимизации на множестве компромиссных решений, принятых на основе субъективных представлений, при использовании современных обеспечивающих информационных технологий (хранилищ данных, экспертных систем, средств выявления знаний, предметно ориентированных программных систем и т.д.). Она должна также обеспечить решение задач управления при изменении структуры ПрО, модернизации методов и моделей, программных и технических средств.

\section{Принцип применения}

Средства выявления и моделирования формирования субъективных представлений агентов и принятия на их основе решений, процессы управления представлениями, согласование и согласованная оптимизация должны быть составной частью информационных технологий на всех уровнях ОТС и обеспечить методическую, математическую и информационную поддержку деятельности агентов. Они должны быть встроены в естественный процесс управления процессом функционирования, а также в функциональности в организационноэкономической составляющей ОТС на основе средств автоматизации для придания им желаемых свойств.

\section{Принцип поэтапного внедрения}

Эффект от разработки и внедрения автоматизированных систем управления различного назначения, по зарубежному опыту, лишь в $30 \%$ случаев соответствует ожиданиям. Основная причина в этом состоит в различии представлений о целях, задачах, применяемых средств и т.п. у пользователей и разработчиков. Дело в том, что их разработка и внедрение осуществляются в изменяющейся активной экономической среде, точное описание которой получить в принципе невозможно или нецелесообразно. Поэтому для сокращения сроков и получения реального эффекта от внедрения системы управления эволюцией ОТС необходимо использовать принцип поэтапного внедрения. Он должен реализовываться на всех стадиях создания системы, начиная от предпроектного обследования до внедрения. Для оценки эффективности решений необходимо проведение комплексных экспериментальных работ 
для оценки предлагаемых средств и решений, проводимых в форме игрового имитационного моделирования с учётом основных свойств объектов управления.

\section{Принцип визуализации}

Его использование при построении пользовательского интерфейса для обеспечения процессов анализа и согласования информации направлено на формирования образа как вырабатываемого, так и принятого решения. Это даёт возможность пользователям выполнять оценку как собственной деятельности, так и качества решений при создании системы управления ОТС. Такая оценка может быть выполнена на базе автоматизированной технологии оценки качества программной продукции путём применения модифицированной методики экспертной оценки качества промышленной продукции [5]. Для этого должны использоваться оценки состояния системы в пространстве показателей, соответствующем ПрО агента, определения им направления движения в пространстве этих показателей, выбора шагов продвижения в выбранном направлении, правил останова процесса, скорости сходимости согласования представлений и решений. При этом используется методика оценки эффективности, предложенная в [6] и модифицированная в [7].

\section{2 Механизм самоорганизации сетевых экспертных систем}

Саморазвитие предполагает вовлечение через использование сетевых технологий продвинутых потребителей товаров и услуг в инновационный процесс совершенствования потребительских свойств товаров и услуг, получения идей или контента путём обращения к их креативным способностям в обмен на вознаграждение, соответствующее вкладу. В Советском Союзе такое решение проблем называлось движением новаторов. На Западе оно было несколько расширено, модифицировано и названо краудсорсингом ${ }^{1}$. Для его реализации разработаны соответствующие технологии [8]. Однако их прямая реализация без учёта принципа активного окружения приводит к значительному росту трудоёмкости при поиске и обработки большого количества информации. Поэтому необходима система, обеспечивающая направление поиска решений и идей, а также фильтрацию, обобщение информации, определение её ценности и перспективности. Способом повышения краудсорсинговых решений является синтез технологий краудсорсинга, сетевой экспертизы и методологии теории активных систем (рисунок 2).

По сравнению с традиционными технологиями поиска новых решений такой подход для формирования согласованных представлений обладает следующими преимуществами $[8,9]$.

- Самоорганизащия. Открытое активное окружение позволяет привлечь для формирования идей, предложений по совершенствованию продукции и услуг практически неограниченное число экспертов. Мотивацией для этого может служить, например, система грантов.

- Независимость. Возможность получения информации, отражающей различные точки зрения с объяснением позиции.

- Целенаправленность. Субъекты, составляющие активное окружение и участвующие в информационном взаимодействии, как правило, связаны общими целями, поскольку ощутимого результата можно добиться совместными усилиями. Принцип согласования уровня вознаграждения в зависимости от вклада каждого в общий результат позволяет поддерживать творческие усилия на требуемом уровне.

\footnotetext{
${ }^{1}$ Краудсо́рсинг (англ. crowdsourcing, crowd — «толпа» и sourcing — «использование ресурсов») — привлечение к решению тех или иных проблем инновационной производственной деятельности широкого круга лиц для использования их творческих способностей, знаний и опыта на добровольных началах. Прим.ред.
} 
- Соревновательность. Управляемый процесс обмена точками зрения центром приводит к повышению общего уровня качества предложений, способствует образованию коалиций субъектов.

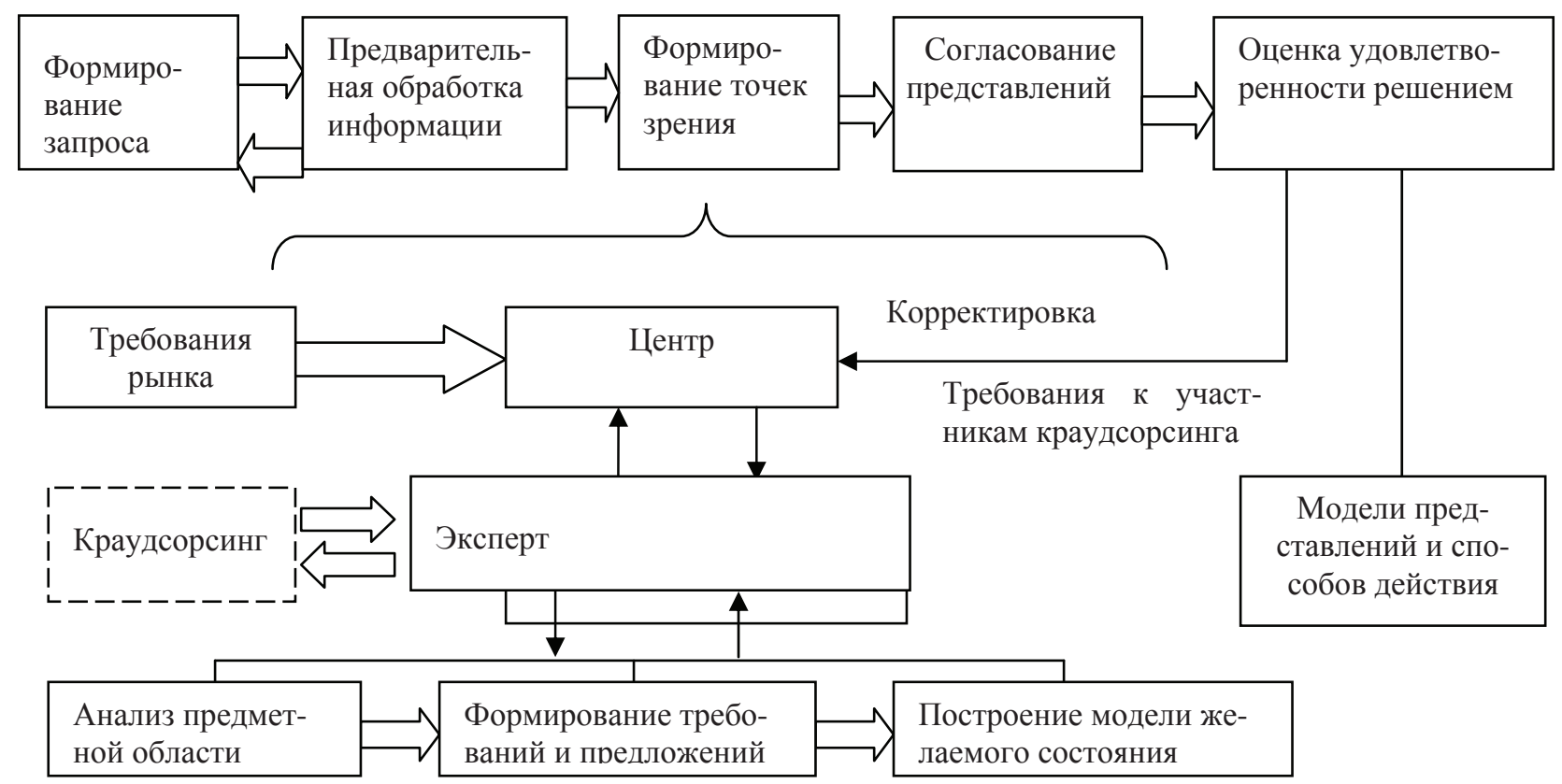

Рисунок 2 -Формирование согласованных представлений на основе краудсорсинга

В отличие от традиционных способов использований технологий краудсорсинга предлагается рассматривать процесс извлечения новых идей и знаний как активную систему с неоднородными агентами со встречным способом сообщения информации и активным воздействием центра в форме запросов для получения рефлексивных оценок. Средства краудсорсинга в этом случае используются для решения задачи по извлечению информации, очистки и предварительной обработки (выделению признаков, семантическая кластеризация, построение онтологий и т.п.), что значительно ускоряет процесс построения согласованной модели выбора в сетевой экспертизе и её трансляции в окружение ОТС.

Центр формирует запросы, оформляет их дизайн, дорабатывает семантическую кластеризацию и онтологию ПрО. Цикл взаимодействия центра с экспертами будет продолжаться до тех пор, пока вклад новой информации в рост оценки полезности сформированных представлений станет несущественным. Полученная модель представлений ПрО используется для формирования модели способа действия. Анализ удовлетворённости от принятого решения позволяет корректировать как модель представлений, так и модель способа действия (решения).

Способы описания структуры представлений субъектов активного окружения, условия их идентичности, регулярности, правильности, различий в информированности субъектов, а также условия существования динамического информационного равновесия, модели согласования представлений в процессе коммуникации приведены в [10]. 


\section{3 Математическая постановка и описание задачи принятия согласованных решений}

Пусть иерархическая структура производства и потребления наукоёмкой продукции задана перечислением входящих в неё агентов, описанием их прав и интересов, в соответствии с которыми они принимают решения. Кроме того, пусть определена регламентация процедур доступа, обработки и передачи информации. Будем считать, что возможности и права агентов в системе не одинаковы (что позволяет говорить об их неоднородности [9]). Неоднородность проявляется в различной степени влияния агентов друг на друга.

Для целей анализа будем рассматривать базовую модель иерархической системы, состоящей из центра (агент верхнего уровня) и агентов нижнего уровня. Согласно [11] цели верхнего уровня условно разделим на следующие группы:

- определение и согласование целей выживания и развития системы в целом в условиях неопределённости и динамики рынка;

- формирование согласованного восприятия внешней и внутренней среды системы;

- формирование согласованного представления о ситуации целеустремленного состояния;

- разработка согласованного плана действий, учитывающего интересы всех подсистем;

- оптимизация по возможности обобщенных показателей эффективности функционирования системы, представляющих собой функции от параметров всех подсистем (агентов). Решение последних двух задач может быть записано следующим образом:

$$
(\mathrm{u}, \mathrm{v}) \in \Omega \text {, }
$$

где $\mathrm{u}$ - управление центра, $\mathrm{v}=\left(\mathrm{v}_{1}, \mathrm{v}_{2}, \ldots, \mathrm{v}_{\mathrm{n}}\right)$ - вектор управлений подсистем, $\Omega$ - множество таких управлений, которые переводят систему в одно из состояний множества $X(X-$ область желаемых состояний системы).

Условие (1) может быть выполнено лишь на основе некоторой совокупности предположение о поведении и информированности всех агентов системы. Примем следующие предположения.

1) центр может сформулировать желаемое состояние системы в виде некоторого набора обобщённых показателей, которые являются функциями параметров агентов. Конкретные зависимости центру в общем случае неизвестны, но для их определения он может использовать данные прошлых периодов функционирования системы, информацию о результатах, полученных конкурентами в данном сегменте рынка и результаты сетевой экспертизы. Такое предположительное знание будем называть представлениями центра о возможностях агентов и направлении развития системы.

2) на основе представлений о возможностях агентов и желаемых состояниях центр определяет свое управление (план действий и информационный запрос) $u \in U$ и сообщает его агентам.

3) при известном управлении $\mathrm{U}_{i}$-й агент выбирает свое управление $v_{i} \in V\left(u_{i}\right)$, которое переводит его в состояние $y_{i} \in Y_{i}$, где $Y_{i}$ - множество возможных состояний. Будем считать, что агенты взаимозависимы по выбору своих состояний. Это предполагает при выборе учёт глобальных ограничений Ү $2 л$. Следовательно, при выполнении условия (1) система может находиться в одном из следующих состояний $Y=Y^{2 л} \cap\left(\prod_{i=1}^{n} Y_{i}\right.$. Здесь $\prod_{i=1}^{n} Y_{i}-$ это множество, определяемое локальными ограничениями, например, по объёму выпуска, качеству, затратам и т.д. 
4) пусть поведение агента соответствует гипотезе рационального поведения. Тогда выбор агента будет сделан так, чтобы максимизировать свой субъективно понимаемый критерий эффективности $\mathrm{G}_{\mathrm{i}}\left(\mathrm{U}, \mathrm{v}_{\mathrm{i}}\right)$.

5) центр, в общем случае, приблизительно знает пространство управлений и критерии эффективности агентов, поэтому для создания представлений о желаемых состояниях агентов он должен организовать с ними обмен информацией. Для этого центр запрашивает у агентов оценки качества продукции и услуг u и желаемые состояния $\mathrm{y}_{\mathrm{i}}$, уточняет их интересы в окрестности полученного решения в обмен на стимулирование за получение встречной информации.

6) получив новую информацию, центр пересчитывает решение и задает новые вопросы агентам до тех пор, пока не будет получено точное или близкое к нему решение.

7) при наличии неопределённости факторов центр стремится в соответствии с принципом детерминизма снизить её уровень за счёт применения процедур, повышающих степень полезности своих представлений [12].

Описанная модель формирования плана развития производства предполагает, что агенты, как управляющие своими подсистемами, так и использующие её на уровне своих представлений, хорошо «знают» и «чувствуют» свои объекты управления и могут с достаточной степенью точности ответить на запросы центра.

Эти предположения позволяют определить множество допустимых управлений центра следующим образом:

$$
U^{0}=\left\{u \in U \mid V(u)=\prod_{i=1}^{n} v_{i}(u) \neq \varnothing,(u, v) \in \Omega, \forall v \in R(u)=\prod_{i=1}^{n} R_{i}(u)\right\},
$$

где $R_{i}(u)=\operatorname{Arg} \max _{v_{i} \in V_{i}(u)} G_{i}\left(u, v_{i}\right)$.

Если у центра имеется критерий эффективности $F(u, v)$, то оптимальным гарантирующим управлением является такое $\mathrm{u}^{0} \in \mathrm{U}^{0}$, что

$$
F^{0}=\sup _{u \in U} \inf _{v \in R(u)} F(u, v) .
$$

Общность интересов центра и агентов определяется условиями на суммарное вознаграждение

$$
\sum_{i=1}^{n} G\left(u_{i}, v_{i}\right)+F^{0} \leq C(\bar{Y})
$$

где $\bar{Y}$ - доход от выполнения заказов, $C(\cdot)$ - фонд материального поощрения.

Таким образом, при согласовании модели развития производства товаров и услуг в системе с не противоположными интересами необходимо рассматривать интеграционный тип возможного компромисса, поскольку величина распределяемого ресурса согласно (4) является величиной переменной, зависящей от их суммарных усилий. Поэтому цель согласования состоит в достижении суммарного выигрыша, и он может быть получен путём сообщения достоверной информации и совместным решением проблем. В системах, где агенты связаны общими интересами и целью, справедлив принцип «запрета эгоизма», так как какой-либо агент может нанести ущерб системе, только если при этом он наносит ущерб себе. 
Пусть объект управления і-го агента описывается уровнем затрат $y_{i}^{B x}$, уровнем выпуска $\mathrm{y}_{\mathrm{i}}^{\text {Bblx }}$ и набором режимных параметров $\mathrm{z}_{\mathrm{i}}$, с помощью которых агент может влиять на ход процесса в своей ПрО. Тогда множество возможных состояний і-го агента можно определить следующим образом

$$
Y_{i}=\left\{y_{i} \mid \underline{y}_{i}^{B x} \leq y_{i}^{b x} \leq \bar{y}_{i}^{b x}, y_{i}^{B b l x}=w_{i}\left(y_{i}^{B x}, z_{i}\right) \in Y_{i}^{b b l x}, z_{i} \in z_{i}\right\} .
$$

Задача (1-5) является задачей поиска максимина со связанными ограничениями.

Обозначим через $\mathrm{y}_{i}^{b b l x}=\mathrm{w}_{\mathrm{i}}^{*}\left(\mathrm{y}_{\mathrm{i}}^{B x}, \mathrm{z}_{\mathrm{i}}\right) \in \mathrm{Y}_{\mathrm{i}}^{B b l x}$ представление агента о функционировании объекта управления, тогда

$$
\mathrm{Y}_{\mathrm{i}}^{*}=\left\{\mathrm{y}_{\mathrm{i}} \mid \underline{y}_{\mathrm{i}}^{b x} \leq \mathrm{y}_{\mathrm{i}}^{B x} \leq \bar{y}_{\mathrm{i}}^{b x}, \mathrm{y}_{\mathrm{i}}^{B b l x}=\mathrm{w}_{\mathrm{i}}^{*}\left(\mathrm{y}_{\mathrm{i}}^{B x}, \mathrm{z}_{\mathrm{i}}\right) \in \mathrm{Y}_{\mathrm{i}}^{b b l x}, \mathrm{z}_{\mathrm{i}} \in \mathrm{z}_{\mathrm{i}}\right\}
$$

можно рассматривать как субъективные представления агента о множестве возможных состояний. Очевидно, оно определяется его знанием, опытом.

В свою очередь центр может иметь собственное представление о возможностях агентов в виде

$$
\mathrm{Y}_{\mathrm{i}}^{u}=\left\{\mathrm{y}_{\mathrm{i}} \mid \underline{\mathrm{y}}_{\mathrm{i}}^{B x} \leq \mathrm{y}_{\mathrm{i}}^{B x} \leq \bar{y}_{\mathrm{i}}^{B x}, \mathrm{y}_{\mathrm{i}}^{B b l x}=\mathrm{w}_{\mathrm{i}}^{u}\left(\mathrm{y}_{\mathrm{i}}^{B x}, \mathrm{z}_{\mathrm{i}}\right) \in \mathrm{Y}_{\mathrm{i}}^{b b l x}, \mathrm{z}_{\mathrm{i}} \in \mathrm{z}_{\mathrm{i}}\right\} .
$$

В случае эффективных производств можно с достаточной степенью точности предположить выполнение гипотезы о полной информированности центра о возможностях, желаемых состояниях агентов и их продуктивности с точностью до параметров. Это означает, что центр располагает всей необходимой информацией о моделях $\mathrm{V}_{\mathrm{i}}, \mathrm{i}=\overline{1, n}$ агентов, но не знает выбор агентов. В этом случае, как показано в [13], центр, используя это знание, рассчитывает управление $u^{0} \in \mathrm{U}^{0}$, а агент делает только один ход, выбирая своё состояние $\mathrm{y}_{\mathrm{i}}$ и управление $v_{i}$ из множества допустимых состояний $B_{i}\left(u_{i}\right)=Y_{i}\left(u_{i}\right) \cap Y_{i}$, пытаясь при этом максимизировать значение своей целевой функции

$$
G_{i}\left(u_{i}, v_{i}\right)_{v_{i} \in B_{i}}\left(u_{i}\right) \text { max. }
$$

Тогда результат выбора всех агентов определяется в этом случае как множество R(D) всех ситуаций, где $D=Y^{2 л} \cap \amalg^{n} B_{i}\left(u_{i}\right)$ множество возможных состояний всей системы. Ва$i=1$

рьируя управление $u=\left\{u_{i}, i=\overline{1, n}\right\}$, центр может проигрывать возможные сценарии поведения системы.

\section{4 Алгоритм построения агентом множества согласованных состояний}

Агент, обладая более детализированной информацией, может при создании центром более привлекательных условий $u_{k}$ путём решения задачи (8) определять для себя такой вектор 
$x_{k}^{(h)}$, который позволяет расширить множество $x_{k}^{(h)}$ представлений центра о его возможностях, $\mathrm{h}$ - шаг итерационного процесса.

Обозначим через $\omega_{k}=\left\{\omega_{k}^{(h)}, h=\overline{1, H}\right\} \in A_{k}$ - вектор параметров состояния, определяющий значения вектора действий $x_{k}^{(h)}=\left\{x_{k j}^{(h)}, j \in\left[\overline{1, m_{k}}\right]\right\} \in X_{k}^{(h)}$. Можно считать, что этот вектор описывает знание агента возможностей контролируемого им объекта управления. Здесь $A_{k}-$ множество возможных значений вектора состояния. Будем считать, что агент обладает способностями, знаниями, которые гарантируют существование $\Psi_{k}: A_{k} \rightarrow X_{k}^{(h)}$.

Доступный агенту уровень знаний о конструктивных особенностях потребляемой продукции и услуг делают справедливым предположение о существовании для К-го агента предельного множества параметров состояния.

Обозначим через $0_{k}^{*}=\left\{0_{k}^{*} \mid o_{k}\left(x_{k}\right), x_{k} \in X{ }_{k}^{(h)}\left(\omega_{k}^{(h)}\right), \omega_{k}^{(h)} \in A_{k}\right\}-$ множество достижимости или множество предельных возможностей.

Будем предполагать, что агент за счёт своих креативных способностей, в том числе способности к самообучению и поиску новой информации, при соответствующем стимулирующем воздействии центра способен определять такие состояния $\omega_{k}^{(1)} \in A_{k}$ и $\omega_{k}^{(2)} \in A_{k}$, что возможно $\omega_{\mathrm{k}}^{(2)} \succ \omega_{\mathrm{k}}^{(1)}$, где символ $\succ$ означает «более значимо» и при этом $\mathrm{X}_{\mathrm{k}}^{(1)}\left(\omega_{\mathrm{k}}^{(1)}\right) \subseteq \mathrm{X}_{\mathrm{k}}^{(2)}\left(\omega_{\mathrm{k}}^{(2)}\right) . \quad$ Следовательно, существует такая последовательность $\omega_{k}^{(1)}, \omega_{k}^{(2)}, \omega_{k}^{(3)}, \ldots$, что $\lim _{h \rightarrow \infty} 0_{k}^{(h)}\left(x_{k}^{(h)}\left(\omega_{k}^{(h)}\right)\right)=0_{k}^{*}$.

То есть агент путём изучения объекта управления способен определить его предельные возможности для достижения желаемого состояния. Последовательность $\omega_{k}^{(1)}, \omega_{k}^{(2)}, \omega_{k}^{(3)}, \ldots$ будем называть последовательностью вскрытия резервов от потенциальных конструктивных решений за счёт их доработки и упрощения в обслуживании.

Такая способность агента формировать расширяющееся множество способов действия позволяет определить следующие свойства целевой функции агента и областей достижимости:

$$
\forall \omega_{k}^{(1)}, \omega_{k}^{(2)} \in A_{k^{\prime}} \omega_{k}^{(2)} \succ \omega_{k}^{(1)}, X_{k}^{(1)}\left(\omega_{k}^{(1)}\right) \subseteq X_{k}^{(2)}\left(\omega_{k}^{(2)}\right) \mapsto E \varphi_{k}\left(x_{k}^{(2)}\right)>E \varphi_{k}\left(x_{k}^{(1)}\right) .
$$

Это условие означает, что поведение агента при выполнении принципа рациональности соответствует закону повышающихся потребностей, который в литературе по психологии поведения определяет мотивацию и целеустремлённость агента.

В реальных условиях агент при превышении некоторого порога значимости $\Delta=\mathrm{E} \varphi_{\mathrm{k}}\left(\mathrm{x}_{\mathrm{k}}^{(2)}\right)-\mathrm{E} \varphi_{\mathrm{k}}\left(\mathrm{x}_{\mathrm{k}}^{(1)}\right)$ изменения ценности ситуации целеустремлённого состояния по результату способен идентифицировать предпочтительные способы действия и видит открывающиеся возможности при изменении структуры своей информированности (знания).

Выработка решения при таком подходе заключается в реализации совокупности последовательных процедур, предназначенных для поиска промежуточных решений, на основании 
которых агент уточняет свои возможности и формирует окончательное решение. Полный цикл его формирования k-м агентом состоит в выполнении следующих шагов на этапе $h$.

1) формирование множеств $A_{\mathrm{k}}$ и $\mathrm{X}_{\mathrm{k}}^{(\mathrm{h})}$ на основе знаний, опыта, интуиции и располагаемой информации о параметрах состояния $\omega_{\mathrm{k}}^{(\mathrm{h})}$. Просмотр множества $A_{\mathrm{k}}$ и формирование точки $0_{k}^{(h)^{*}}=\left\{0_{k}^{(h) *} \mid o_{k}^{(h) *}\left(x_{k}^{(h)}\right), x_{k}^{(h)} \in X_{k}^{(h)}\left(\omega_{k}^{(h)}\right), \omega_{k}^{(h)} \in A_{k}\right\}$. Проверка, существует ли $x_{k}^{(h)^{*}}$ такое, что $0_{k}^{(h)}\left(x_{k}^{(h)^{*}}\right)=0_{k}^{(h)^{*}}$. Если - да, то $x_{k}^{(h)^{*}}$ - это компромиссное решение, a $\mathrm{o}_{\mathrm{k}}^{(\mathrm{h})^{*}}$ - прогнозируемая ситуация, в противном случае переход к п. 2.

2) решение задачи поиска потенциально-предпочтительного набора действий $x_{k}^{(h)^{*}} \in X_{k}^{(h)}\left(\omega_{k}^{(h)}\right)$, позволяющего сформировать вектор $0_{k}^{-(h)}$ предельных значений критериев при использовании имеющегося на данный момент знания о правиле $\Psi_{\mathrm{k}}^{(\mathrm{h})}$ и структуре множества $A_{\mathrm{k}}$. Так как компоненты ${ }_{\mathrm{ki}}^{-(\mathrm{h})}, \mathrm{i}=\overline{1, \mathrm{~N}}$ порознь достижимы, а вместе - нет, то делается попытка найти компромиссное решение. Если агент не согласен попытаться найти компромиссное решение за счёт компенсаторных уступок по каждому критерию, которые несколько хуже решения ${ }_{\mathrm{k}}^{-(\mathrm{h})}$, то переход к п. 3, иначе к п. 5.

$3)$ исследование направлений возможного расширения множества $A$, организация процедур поиска новой информации (знания) о $\omega_{\mathrm{k}}^{(\mathrm{h})} \in \mathrm{A}_{\mathrm{k}}$ и правиле $\Psi_{\mathrm{k}}: \mathrm{A}_{\mathrm{k}} \rightarrow \mathrm{X}_{\mathrm{k}}^{(\mathrm{h})}$.

4) если расширение множества $A_{\mathrm{k}}$ возможно, то переход к п. 1 , иначе фиксация ситуации, что компромиссное решение не может быть найдено при выбранном векторе $0_{\mathrm{k}}^{(h) *}$.

5) получение от агента сведений, достаточных для определения вектора $\underline{o}_{k}^{(h)} \prec 0_{k}^{(h)^{*}}$, где $\underline{0}_{k}^{(h)}$ - минимальные требования агента к принимаемым им во внимание результатам.

6) выполнение процедуры поиска минимально-предпочтительной точки в пространстве критериев по направлению предпочтения $\underline{0}_{k}^{(h)}, 0_{k}^{(h)^{*}}$, определение вектора $\omega_{k}^{(h)^{*}} \in A_{k}$ и $\underline{x}_{k}^{(h)^{*}} \in X_{k}^{(h)}\left(\omega_{k}^{(h)^{*}}\right)-$ минимального значения плановых показателей, соответствующих значениям компонент вектора $\underline{0}_{-k}^{(h)}$.

7) если полученные значения для $\underline{x}_{k}^{(h) *}, \underline{o}_{k}^{(h) *}$ принимаются как компромиссное решение, то процедура останавливается, в противном случае переход к п. 8.

8) для ограничений на $\underline{o}_{k}^{(h)}$ определяется приоритетная координата $i \in\left[\overline{1, N_{k}}\right]$, по которой делается расширение множеств $A_{k}$ и $X_{k}^{(h)}$, так чтобы $0_{k}^{(h)}\left(x_{k}^{(h)}\right)=0 \underset{k}{(h)}+\Delta_{k}^{(h)}$, 
где $\Delta_{k}^{(\mathrm{h})}$ - минимально возможное улучшение, которое является значимым для агента и определяется по его высказываниям о «гибкости» ограничения на основе выполнения процедур поиска дополнительной информации. Переход к п. 1.

Описанный алгоритм использует три типа механизмов, применение которых порождает интерактивный процесс для построения компромиссного решения.

C помощью механизм анализа агент в момент $r$ обрабатывает сведения, полученные на шаге $r$ - 1 для построения множеств $P_{k}$ и $X_{k}$ с целью определения $x_{k}, y^{0^{*}}, c^{*}, z^{*}$. Здесь сопоставляются результаты, полученные на момент $r$ с результатами на шаге $r$ - 1 , формируется представление о значениях вектора $0^{*}$ и значений уступок по его компонентам. Строится предварительное представление о желательных значениях показателей $\mathrm{E} \varphi_{\mathrm{k}}\left(\mathrm{o}\left(\mathrm{y}^{0^{*}}\right)\right)$ и $\mathrm{EE}_{\mathrm{k}}\left(\mathrm{o}\left(\mathrm{y}^{0^{*}}\right)\right)$.

С помощью механизма целеполагания по результатам анализа определяются условия возможности достижения желательных значений $\mathrm{x}_{\mathrm{k}}, \mathrm{y}^{0^{*}}, \mathrm{c}^{*}, \mathrm{z}^{*}, \quad \mathrm{E} \varphi_{\mathrm{k}}\left(0\left(\mathrm{y}^{0^{*}}\right)\right)$, $\mathrm{E}_{\mathrm{k}}\left(\mathrm{o}\left(\mathrm{y}^{0^{*}}\right)\right)$. Рассчитывается идеальная точка в пространстве оценок 0, связанная с множествами $P_{k}$ и $X_{k}-$ это точка $\overline{0}^{*}$, имеющая координаты $0^{*} i=\max 0_{j}(x(p)), i=\overline{1, L}$. То есть $\overline{0}^{*}$

$$
p \in P_{k}, x \in X_{k}
$$

- наибольшее значение оценки по координате i, которое может быть получено с помощью намеченных действий. Эта точка образует центр области поиска предпочтительных состояний. Если при найденном значении координат точки $0^{*}$ ограничения не выполняются, то агент рассматривает возможность расширения множеств $P_{k}, X_{k}$ и $C_{k}$ за счёт включения дополнительных переменных, осуществления структурных изменений и т.п. для ослабления наиболее жёстких ограничений так, чтобы выполнялось включение $P_{k}(r) \subseteq P_{k}(r+1)$ и $X_{k}(r) \subseteq X_{k}(r+1)$. Если это невозможно, то формируются сведения о координатах $\underline{0}_{i}<0^{*}$ точки $\underline{0}_{j} \neq \overline{0}^{*}$ i, которая была бы достижимой и лучшим компромиссом в окрестности точки $\overline{0}^{*}$. Путём минимизации потерь $\sum_{i=1}^{L}\left|0_{i}-0_{i}{ }^{*}\right|$ определяются величины $p_{i}=0_{i}-0_{i} 0^{*} \neq 0$ примерно эквивалентные, небольшие и значащие для агента.

Благодаря механизму самоорганизащии формируются знания о правилах $\Delta$ и $\Psi$ для расширения множеств $P_{k}, X_{k}$ и $C_{k}$. Механизм может иметь различные формы:

- проведение экспериментальных исследований на объекте с целью улучшения своего представления о его функционировании;

- анализ обстановки $v_{-k}$;

- привлечение экспертов для подготовки рекомендаций по улучшению режимов ведения процесса;

- процедуры опроса персонала;

- процедуры голосования и т.п. 


\section{Заключение}

В статье представлен результат построения механизма управления инновационной деятельностью, основанный на управляемом информационном взаимодействии участников. Такой подход рассматривается как альтернатива рыночным механизмам, так как он является средством построения:

- согласованных представлений о ситуации целеустремленного состояния участниками взаимодействия (понимаемой в смысле [13]);

- согласованной системы целей и способов их достижения участниками, связанными общими не противоположными интересами, в общем случае не совпадающими.

Рассмотрены принципы построения системы управления развитием организационнотехнологической системы, активно использующей инновации. На их основе предложен механизм самоорганизации сетевых экспертных систем, использующий сетевые технологии для вовлечения поставщиков, производителей и потребителей товаров и услуг в инновационный процесс.

Реализацию такого механизма предложено осуществлять на основе синтеза технологий краудсорсинга, сетевой экспертизы, современных сетевых и телекоммуникационных технологий, методологии теории активных систем. Это позволяет реализовывать не только рефлексию нулевого уровня, но и рефлексии более высоких уровней, а также сделать процесс и результат рефлексии управляемым, например, путём построения открытых развивающиихся онтологий ПрО. Такой подход означает также активное использование различных средств информационного управления для создания соответствующих информационных структур у участников информационного взаимодействия.

Предложен алгоритм построения агентом множества согласованных состояний, использующий механизмы анализа, целеполагания и самоорганизации.

\section{Благодарности}

Данная работа выполнена при частичной финансовой поддержке РФФИ в рамках проекта 14-01-00328\14.

\section{Список источников}

[1] Gubanov, D. E-Expertise: Modern Collective Intelligence / D. Gubanov, N. Korgin, D. Novikov, A. Raikov // Springer Series: Studies in Computational Intelligence. - 2014. - Vol. 558, XVIII. - 112 p.

[2] Bummux, B.A. Социогуманитарные и коммуникационные проблемы интерсубъективного управления инновационными процессами / В.А. Виттих, Т.В. Моисеева, С.В. Смирнов // Проблемы социогуманитарного обеспечения инновационных процессов на евразийском пространстве. Под ред. В.Е. Лепского. - М.: Когито-Центр, 2014. - С. 214-224.

[3] Городецкий, В.И. Теория, модели, инфраструктуры и языки спецификации командного поведения автономных агентов. Обзор (Часть 1) / В.И. Городецкий // Искусственный интеллект и принятие решений. 2011. - №2. - С. 19-30.

[4] Скобелев, П.О. Ситуационное управление и мультиагентные технологии: коллективный поиск согласованных решений в диалоге / П.О. Скобелев // Онтология проектирования. - 2013.- №2(8). - С. 26-48.

[5] Кузнецов, В.H. Эвристическая стратегия диагностики слабо формализуемых технологических систем / В.Н. Кузнецов // Элементы и системы оптимальной идентификации и управления технологическими процессами. - Тула: ТГТУ, 1993. - с. 29-35.

[6] Бурков, В.Н. Механизмы функционирования организационных систем / В.Н. Бурков, В.В. Кондратьев. М.: Наука, 1981. - 384 с.

[7] Новиков, Д.А. Рефлексия и управление: математические модели / Д.А. Новиков, А.Г. Чхартишвили. - М.: Физматлит, 2013. - 412 с. 
[8] Райков, А.Н. Конвергентное управление и поддержка решений / А.Н. Райков.// М.: Издательство ИКАР, 2009. - 245 c.

[9] Виноградов, Г.П. Моделирование поведения агента с учётом субъективных представлений о ситуации выбора / Г.П. Виноградов, В.Н. Кузнецов // Искусственный интеллект и принятие решений. - 2011 - №3. C. 58-72.

[10] Виноградов, Г.П. Формирование представлений агента о предметной области в ситуации выбора / Г.П. Виноградов, Г.П. Шматов, Д.А. Борзов // Программные продукты и системы. - 2015. - №2 (110). C. 83-94.

[11] Лепский, B.E. Эволюция представлений об управлении в контексте научной рациональности / В.Е. Лепский // Философия управления: методологические проблемы и проекты. Отв. ред: В.И. Аршинов, В.М. Розин. - М.: ИФРА, 2013. - с. 68-99.

[12] Новиков, Д.А. Математические модели формирования и функционирования команд / Д.А. Новиков - М.: Физматлит, 2008. - 184 с.

[13] Виноградов, Г.П. Методы и алгоритмы принятия решений в автоматизированных системах управления производствами с непрерывной технологией на основе субъективных представлений / Г.П. Виноградов. Тверь: ТГТУ, 2013. - 256 с.

\title{
SELF-ORGANIZING NETWORK EXPERT SYSTEMS ENVIRONMENT IN PRINCIPLE ENDOGENOUS TARGET DESIGNATION
}

\author{
G.P. Vinogradov ${ }^{1}$, N.G. Vinogradova ${ }^{2}$ \\ Tver State Technical U niversity, Tver, Russia \\ 1'wgp272ng@ mail.ru, 2n-nataly08@mail.ru
}

\begin{abstract}
The article discusses the problem of constructing a model of the functioning of the socio-economic system, using the mechanisms of information exchange participants. The central point of this interaction is the formation of coherent ideas about the purpose, limitations, needs, possibilities and directions of development. The model allows not only to identify customers and consumers of goods and services to the volume and quality of performance requirements, but also to form their perceptions of their own needs. This suggests that the mechanisms of formation of coherent ideas and ways of acting members of the system are more effective than, for example, market or command hierarchy. It is shown that the most promising form of information exchange in solving search problems, the production of new knowledge and determine the direction of its self-developing expert network environment. An elementary part of any environment is an expert professional, owning modern telecommunication technologies. Integration into the network structure of the natural intelligence forms is a subject of a collective strategy, which is a means of synergy of knowledge and actions in the process of building a self-organizing development. The article considers the problem of creation of media expert networks for the development of innovative industries that produce high-tech, high technology products and services.
\end{abstract}

Keywords: expert community, self-organization, networking, coordination of ideas, innovative development.

Citation: Vinogradov GP, Vinogradova NG. Self-organizing network expert systems environment in principle endogenous target designation. O ntology of Designing 2016; 6(1): 39-54. DOI: 10.18287/2223-9537-2016-6-1-39-54.

\section{References}

[1] Gubanov D, Korgin N, Novikov D., Raikov A. E-Expertise: Modern Collective Intelligence. Springer Series Studies in Computational Intelligence 2014 - Vol. 558, XVIII. - 112 p.

[2] Vittikh VA, M oiseeva TV, Smirnov SV. Socio-humanitarian and communication problems intersubjective management of innovation processes. Problems of social and humanitarian support for innovative processes in the Eurasian space. Edited by V.E. Lepsky. Mosccow: Cogito-Centr Publisher; 2014: 214-224. (In Russian).

[3] Gorodeckij VI. Teoriya, modeli, infrastruktury i yazyki specifikacii komandnogo povedeniya avtonomnyh agentov. Obzor (chast 1) [The theory, model, infrastructure and specification languages command behavior of autonomous 
agents. Review (Part 1)]. Iskusstvennyj intellekt i prinyatie reshenij [Artificial intelligence and decision making] 2011; N 2: 19-30. (In Russian).

[4] Skobelev PO. Situation-driven decision making and multi-agent technology: finding solutions in dialogue. Ontology of Designing 2013; 2(8): 26-48. (In Russian).

[5] Kuznecov VN. Evristicheskaya strategiya diagnostiki slabo formalizuemykh tekhnologicheskikh system. Ehlementy i sistemy optimalnoj identifikacii i upravleniya tekhnologicheskimi processami. [Heuristic strategy for diagnostics of hardly formalizable technological systems. Elements and systems of optimal identification and process control] Tula: TGTU Publisher, 1993: 29-35. (In Russian).

[6] B urkov VN, Kondrat ev VV. Mekhanizmy funkcionirovaniya organizacionnykh system. [Mechanisms of functioning of organizational systems] Moscow: Nauka Publisher, 1981. - 384 p. (In Russian).

[7] Novikov DA, Chkhartishvili AG. Refleksiya i upravlenie: matematicheskie modeli. [Reflection and management: mathematical models] Moscow: Fizmatlit Publisher, 2013. - 412 p. (In Russian).

[8] Rajkov AN. Konvergentnoe upravlenie i podderzhka reshenij [Convergent management and decision making support] Moscow: IKAR Publisher, 2009. - 245 p.(In Russian).

[9] Vinogradov GP, Kuznecov VN. Modelirovanie povedeniya agenta s uchetom sub"ektivnyh predstavlenij o situacii vybora. [Modeling the behavior of an agent based on subjective perceptions of a situation of choice] Iskusstvennyj intellekt i prinyatie reshenij [Artificial intelligence and decision making] 2011; 3: 58-72. (In Russian).

[10] Vinogradov G P, Shmatov GP, Borzov DA. Formirovanie predstavlenij agenta o predmetnoj oblasti v situacii vybora. [The formation of preception of the the agent of the domain in a situation of choice] Programmnye produkty $i$ sistemy [Software and System] 2015; 2(110): 83-94. (In Russian).

[11] Lepskij VE. Evolyuciya predstavlenij ob upravlenii v kontekste nauchnoj racionalnost. Filosofiya upravleniya: metodologicheskie problemy i proekty. [The evolution of ideas about how to manage in the context of scientific rationality] Eds.: Arshinov VI, Rozin VM. - Moscow: IFRA Publisher, 2013: 68-99. (In Russian).

[12] Novikov DA. Matematicheskie modeli formirovaniya i funkcionirovaniya komand. [Mathematical models of the formation and functioning of commands] Moscow: Fizmatlit Publisher, 2008. - 184 p. (In Russian).

[13] Vinogradov GP. Metody i algoritmy prinyatiya reshenij v avtomatizirovannykh sistemakh upravleniya proizvodstvami s nepreryvnoj tekhnologiej na osnove sub"ektivnykh predstavlenij [Methods and algorithms for decisionmaking in the automated control system with continuous technology based on subjective perceptions] Tver: TGTU Publisher, 2013. - 256 p. (In Russian).

\section{Сведения об авторах}

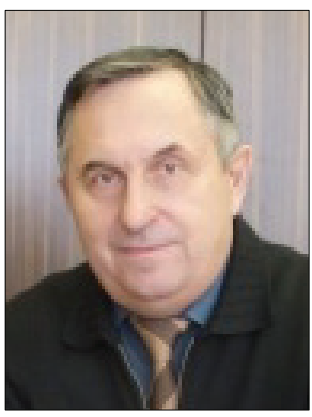

Виноградов Геннадий Павлович, 1948 г. рождения. Окончил в 1971 г. факультет химического машиностроения Калининского политехнического института, д.т.н. (2013). Профессор кафедры информатики и прикладной математики Тверского государственного технического университета, член Российской ассоциации искусственного интеллекта. В списке научных трудов более 200 работ в области теории принятия решений, многоагентных систем.

Vinogradov Gennadiy Pavlovich, 1948 b. He graduated in 1971 the Faculty of Chemical Engineering of the Kalinin Polytechnic Institute, Ph.D. (2013). Professor, Department of Computer Science and Applied Mathematics, Tver State Technical University; member of the Russian Association for Artificial Intelligence. The list of scientific works of more than 200 works in the field of decision theory, multi-agent systems.

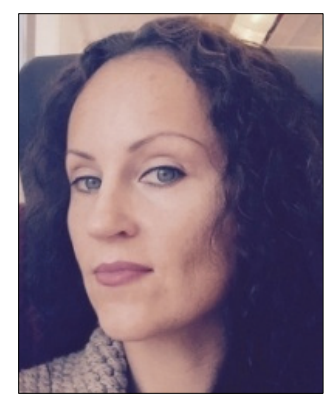

Виноградова Наталья Геннадьевна, 1979 г. рождения. Окончила Тверской государственный технический университет. Аспирант Тверского государственного технического университета. В списке научных трудов три публикации в области создания самоорганизующихся инновационных сред.

Vinogradova Natalia G., 1979 b. He graduated in the city of Tver State Technical University. Postgraduate Tver State Technical University. The list of scientific works of three publications in the field of self-organizing innovative environments. 


\title{
УДК 004
}

\section{ОНТОЛОГИЧЕСКИЙ ПОДХОД К ОЦЕНКЕ ТЕМАТИКИ НАУЧНОГО ТЕКСТА}

\author{
О.П. Кузнецов ${ }^{1}$, В.С. Суховеров ${ }^{2}$ \\ Институт проблем управления Российской академии наук, Москва, Россия \\ 1olkuznes@ipu.ru, 22suhoverv@ipu.ru
}

\section{Аннотация}

В работе предлагается подход к определению тематики научного текста, использующий онтологию предметной области. Излагается оригинальный принцип построения онтологий прикладных наук, при котором дерево онтологии содержит три обязательных ветви: «Фундаментальные теории», «Прикладные теории», «Области приложений», классами онтологии являются темы, а экземплярами классов - термины соответствующих тем. Описывается строение онтологии наук об управлении. Приводятся фрагменты онтологии управления и её словаря. Предполагается, что научный текст релевантен теме, если он содержит термины этой темы. Предлагается метод оценки степени релевантности научного текста различным темам, основанный на подсчёте числа вхождений в документ терминов этих тем. Результатом работы этого метода является «профиль документа» - вектор релевантностей документа темам онтологии. Описывается автоматическая система анализа тематики научных текстов из области теории и практики управления, разработанная на основании предложенного подхода. Обсуждаются лингвистические проблемы поиска терминов. Приведены некоторые статистические данные обработки тематических разделов журнала «Автоматика и телемеханика» и пример построения профиля для конкретной статьи журнала. Отмечаются возможные направления улучшения оценок релевантности.
\end{abstract}

Ключевые слова: онтология, компетентность, релевантность, тема, термин, профиль документа, теория управления.

Цитирование: Кузнецов,О.П. Онтологический подход к оценке тематики научного текста / О.П. Кузнецов, В.С. Суховеров // Онтология проектирования. - 2016. - Т.6, №1(19). - С. 55-66. DOI: 10.18287/2223-9537-2016-6-1-55-66.

\section{Введение}

Определение тематики документа обычно является первым и необходимым этапом для принятия решения относительно дальнейших действий с содержимым документа и, возможно, с его автором. Поскольку алгоритмические подходы к определению тематики как известные [1], так и предлагаемый - не анализируют качество содержания документа (корректность, новизну, актуальность, стиль и т.д.), то дальнейшие действия в значительной степени зависят от того, получил ли документ экспертную оценку (рецензию, экспертное заключение и др.) или нет. Наличие квалифицированной оценки качества документа (типичный случай - публикация в рецензируемых изданиях) означает, что он может служить свидетельством степени компетентности автора. Определение тематики таких документов помогает решать различные задачи управления персоналом в научных организациях - приём на работу, поручение наукоёмких заданий, подбор команды для работы над проектом и т.д. Неотрецензированный документ, как правило, требует формального или неформального рецензирования, экспертного заключения и т.д. Здесь типичный случай - рецензирование статей, поданных в научный журнал или докладов, присланных на конференцию. Определение тематики таких документов позволяет решать задачу назначения рецензентов. 
Заметим, что сама задача определения тематики может решаться независимо от наличия или отсутствия оценки качества документа; такая оценка играет роль для возможных приложений. В настоящей работе задача определения тематики документа решается для научных документов: статей, докладов и др.

\section{1 Автоматическая оценка тематики текста. Компетенция и компетентность}

Прикладные задачи, для решения которых нужна автоматическая оценка тематики научного текста, можно разбить на два больших класса: 1) информационные и 2) управленческие задачи.

Под информационными задачами мы понимаем задачи классификации ${ }^{1}$ и рубрикации. Решение такой задачи заключается в определении раздела информационного хранилища, куда следует поместить рассматриваемый документ. Об отклонении документа речь не идёт.

Управленческие задачи связаны с принятием решений, влияющих на дальнейшие действия с документом и взаимодействие с его автором. Здесь следует выделить два класса задач:

1) задачи, решаемые редколлегиями научных журналов, программными комитетами конференций, диссертационными советами: определение соответствия тематике журнала или конференции, выбор рецензентов и оппонентов;

2) задачи управления персоналом в научных организациях: приём на работу, поручение наукоёмких заданий.

В задаче 1 речь идёт о принятии решения по документу: принять или отклонить. При этом предполагается, что тексты не рецензированы, научное и литературное качество текста неизвестно; единственная задача автоматической оценки - отправить текст компетентному рецензенту. Решение о выборе рецензентов на основании автоматической оценки тематики принимает человек (ответственный секретарь редакции, председатель программного комитета и т.д.), которому известны компетенции рецензентов.

В задаче 2 речь идёт о принятии решения относительно научного работника по результатам оценки его компетентности на основании научных публикаций. Поскольку качество текста автоматически не оценивается, то рассматриваются тексты, качество которых уже было оценено, т.е. публикации в рецензируемых журналах. На основании установленной компетенции могут приниматься различные решения: о приёме на работу; о назначении экспертом по материалам, присланным на экспертизу; о выборе оппонентов и т.д. Если объединить обе задачи (оценку тематики текста и оценку компетентности сотрудника на основании его публикаций), то в дополнение к оценке тематики текста мы получаем оценку компетентности возможных рецензентов этого текста по набору их публикаций, что позволяет автоматизировать выбор рецензентов.

Уточним два понятия, которые в этой области постоянно используются: компетенция и компетентность. Компетенция - это понятие, в общем случае не связанное с конкретным лицом. В работе [2] компетенция описывается как совокупность следующих характеристик:

1) наименование компетенции;

2) категория или область, к которой принадлежит компетенция;

\footnotetext{
1 Читателей просим обратить внимание также на опубликованную в этом номере журнала статью Микони С.В., посвященную классификации. Классификация (и как результат, и как процесс) важна для построения онтологий в различных предметных областях, а полученный опыт представляет особый интерес для онтологии проектирования. Поэтому результаты исследований в этой области для редакции журнала будут всегда приоритетными. Прим. peд.
} 
3) описание компетенции, объясняющее, что может знать, уметь или делать обладатель компетенции;

4) свидетельства компетенции, по наличию которых можно определить, обладает ли сотрудник данной компетенцией.

В нашем случае п.2 (категория компетенции) - это область научного знания; в дальнейшем области знания будем называть темами. Как правило, это сформировавшиеся области, и п.3 можно опустить: описание компетенции предполагается известным. В качестве свидетельств компетенции рассматриваются публикации сотрудника.

Компетентность - это отношение человек-компетенция, означающее, что человек владеет данной компетенцией.

Отношение документ-компетенция будем называть релевантностью: документ релевантен некоторой теме, если в нём говорится об этой теме.

Такое понимание различий между компетенцией и компетентностью вполне традиционно (см., например, [3]).

Является ли документ, релевантный некоторой компетенции, свидетельством компетенции автора? Если документ - статья, опубликованная в рецензируемом журнале, то да, является. Если документ не отрецензирован (статья, поступившая в редакцию журнала, или доклад, присланный на конференцию), - нет, не является.

Очевидно, что отмеченные два отношения - компетентность и релевантность - не являются бинарными, поскольку важно оценить не только их наличие, но и уровень (степень) компетентности или релевантности в некоторой непрерывной шкале. Соответственно, и различные свидетельства компетенции могут обладать различной степенью убедительности.

\section{2 Оценка тематики текста и онтологии прикладных наук}

Задача определения тематики документа представляет собой позиционирование его тематики в некотором тематическом пространстве. Представление тематического пространства в виде онтологий рассматривалось в ряде работ, посвящённых управлению персоналом [4, 5]. Предлагаемый подход к автоматизированному решению этой задачи впервые был изложен в работе [6]. Он разбивается на три подзадачи.

- Описание тематического пространства как онтологии области научного знания с учётом специфики онтологий прикладных наук.

- Разработка метода позиционирования научного текста в заданной онтологии на основе поиска в нём терминов, характерных для определённых фрагментов онтологии.

- Разработка автоматизированной системы, реализующей предлагаемый метод для онтологии наук об управлении.

Прежде, чем заняться конкретным решением первой подзадачи - несколько слов о предлагаемом принципе построения онтологий прикладных наук.

Онтологии научных областей знаний обычно строятся по таксономическому принципу, т.е. традиционному принципу классификации. Классификатор - это ориентированное дерево, где корень соответствует области знания в целом, две смежные невисячие вершины находятся в отношении «класс-подкласс», а документ - это лист дерева (висячая вершина), который с единственной смежной с ней вершиной находится в отношении «экземпляркласс».

Важным принципом таксономической классификации является принцип однозначности: 
Каждый объект классификаиии (статья, книга, заявка на грант и т.д.) должен находиться ровно в одной вершине дерева. Чем дальше от корня находится объект, тем точнее (подробнее) он охарактеризован.

Так устроены универсальные классификаторы (УДК, классификаторы РНФ, РФФИ и др.). Таксономическая традиция возникла в естественных науках, где принцип однозначного отнесения природных объектов к какому-либо классу существует несколько столетий и, в общем, себя оправдывает. С классификацией текстов, о чём идет речь в данной работе, дело обстоит сложнее, поскольку в одном документе могут рассматриваться несколько тем. В ряде случаев однозначность классификации вынуждена: принятая статья может быть отнесена только к одной рубрике журнала, а принятый доклад включается в программу только одной секции конференции. Однако для принятия однозначного решения необходима информация обо всех возможных альтернативах.

В прикладных науках неоднозначность классификации научных текстов становится принципиальной. Статья, присланная на конференцию и посвящённая анализу данных, содержит определённый математический аппарат (например, методы математической статистики) и при этом говорит об использовании описанных результатов в различных прикладных областях: финансы, экология и т. д. Это означает, что для оценки данной статьи могут потребоваться три компетенции: в определённом разделе фундаментальной науки (математики, физики и т. д.), проблемной области (анализе данных) и в области приложений. Потребуются ли они в действительности - зависит от степени релевантности статьи этим компетенциям. Соответственно, задача автоматизированного выбора рецензентов должна заключаться в поиске наилучшего совпадения набора релевантностей документа с набором компетентностей рецензента.

С учётом этих соображений предлагается следующий подход к принципам построения онтологий прикладных наук.

- Строение онтологии в виде дерева в основном сохраняется (возможные локальные нарушения древовидности связаны с многозначностью терминов - см. ниже).

- С корнем дерева онтологии всегда смежны три вершины. Их имена всегда одинаковы: «фундаментальная наука», «прикладная теория» или «проблемная область», «область приложений». Эти вершины в дальнейшем будем называть главными вершинами, а поддеревья, корнями которых они являются, - главными поддеревьями.

- Все вершины дерева онтологии разбиваются на два вида: вершины-темы и вершинытермины. Вершины-темы образуют основной каркас дерева и связаны между собой отношением тема-подтема, имеющим все таксономические свойства отношений типа класс-подкласс. Вершина-термин связана с темой отношением термин-тема, которое является отношением экземпляр-класс. Все нижележащие вершины наследуют этот термин. Висячими вершинами являются все вершины-термины и только они.

- Экземплярами классов (висячими вершинами, листьями) являются термины, относящиеся к данному классу (тематическому разделу). Термин может принадлежать нескольким темам в разных ветвях дерева. В этом случае древовидность онтологии формально нарушается.

Сам документ в онтологии не хранится и экземпляром не является. При этом принцип однозначности отсутствует: в тематическом пространстве документ может относиться к разным ветвям дерева, т.е. принадлежать классам, находящимся на разных ветвях в разных поддеревьях, с разным весом, который отражает степень релевантности документа данному классу.

На рисунке 1 приведён малый фрагмент онтологии теории игр, где термины изображены пунктирными прямоугольниками, отношения тема-подтема - сплошными стрелками, а 
отношения тема-термин - пунктирными стрелками. Отметим, что термин в общем случае может принадлежать нескольким темам. Здесь возможны два семантически различных случая. В первом случае термин принадлежит темам из разных главных поддеревьев. Например, термин «Передача данных» принадлежит как фундаментальной теории «Теория информации», так и прикладной проблемной области «Передача и обработка сигналов». Во втором случае термин в разных контекстах имеет разный смысл. Таков, например, термин «устойчивость», который используется в разных прикладных теориях и фактически представляет собой множество разных терминов, названных одним и тем же словом. В обоих случаях нарушается однозначность принадлежности термина теме и, соответственно, древовидность онтологии.

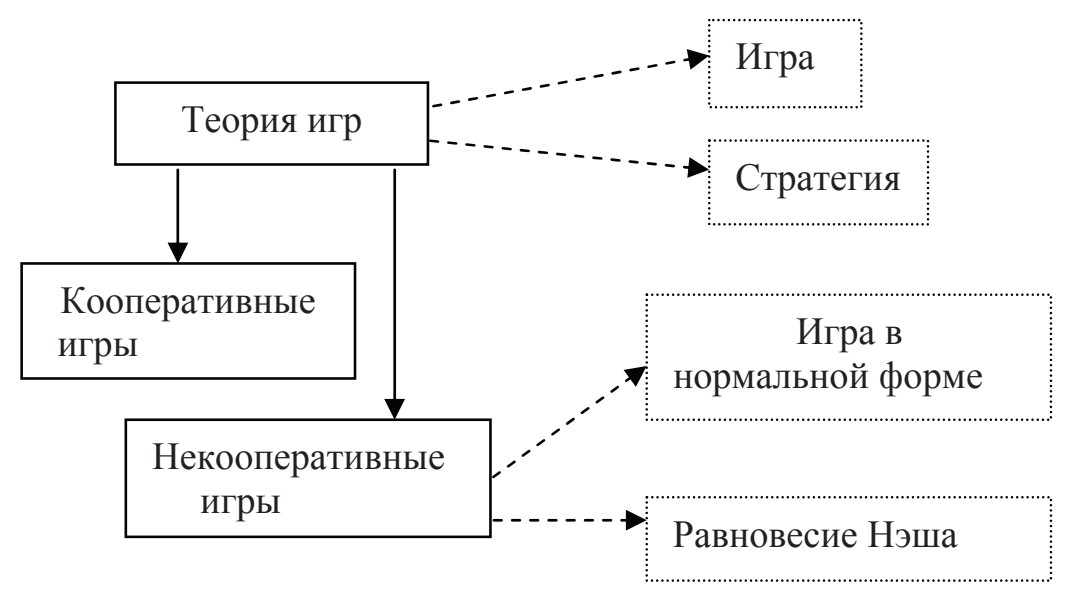

Рисунок 1 - Фрагмент онтологии теории игр

\section{3 Онтология наук об управлении}

Структуру создаваемой онтологии определяет круг задач, которые предполагается решать с её помощью. Онтологии, ориентированные на детальное описание предметной области (ПрО), имеют значительную глубину: длины путей от корня к листьям довольно велики. Разработанная в данной работе онтология наук об управлении предназначена для оценки тематики научных статей об управлении, присылаемых в журнал «Автоматика и телемеханика», с целью определения наиболее подходящих по компетентности кураторов этих статей - членов редколлегии, которые назначают рецензентов и принимают решения о судьбе статьи. Куратор не обязан иметь узкую компетенцию, совпадающую с тематикой статьи; однако он способен определить, кто из известных ему рецензентов этой компетенцией обладает, оценить аргументацию рецензентов и по итогам рецензирования принять решение о приёме или отклонении статьи. Для решения этой задачи большая глубина онтологии не нужна.

Построению онтологии предшествовало изучение архива статей журнала «Автоматика и телемеханика» за несколько последних лет. Сначала путём «ручного» извлечения терминов из статей журнала был создан словарь терминов, представляющий собой таблицу, столбцы которой соответствуют трём главным деревьям, описанным выше. Отнесение терминов к конкретным темам производилось экспертным образом. Фрагмент словаря приведён в таблице 1.

При формировании словаря важно было отбирать термины, специфические для конкретной темы, поэтому такие «безликие» термины, как «функция», «система», «уравнение», встречающиеся практически в каждой статье, бессмысленно включать в 
словарь в качестве однословных терминов. Эти слова должны входить в состав многословных терминов: «функция Ляпунова», «уравнение Лагранжа первого рода». Более тонкие ситуации, возникающие при поиске терминов, - это наличие слов, которые в одних контекстах являются терминами, а в других - нет. Примеры: «игра», «множество». Такие коллизии решаются, как правило, экспертным путём.

Таблица 1 - Фрагмент словаря терминов с привязкой их к теориям и сферам применения

\begin{tabular}{|c|c|c|c|}
\hline Термин & $\begin{array}{c}\text { Фундаментальные } \\
\text { теории }\end{array}$ & Прикладные теории & $\begin{array}{c}\text { Области } \\
\text { применения }\end{array}$ \\
\hline летательный аппарат & & Управление движением & Авиация \\
\hline $\begin{array}{l}\text { линейные матричные } \\
\text { неравенства }\end{array}$ & Линейная алгебра & $\begin{array}{l}\text { Теория автоматического } \\
\text { управления }\end{array}$ & \\
\hline орграф & Теория графов & & \\
\hline $\begin{array}{l}\text { отношения } \\
\text { предпочтения }\end{array}$ & $\begin{array}{l}\text { Теория множеств и } \\
\text { отношений }\end{array}$ & $\begin{array}{l}\text { Теория выбора и принятия } \\
\text { решений }\end{array}$ & \\
\hline передача данных & Теория информации & $\begin{array}{l}\text { Передача и обработка } \\
\text { сигналов }\end{array}$ & $\begin{array}{l}\text { Коммуникационные } \\
\text { системы и сети }\end{array}$ \\
\hline
\end{tabular}

В результате анализа словаря был получен список тем, который затем был преобразован в дерево онтологии. На рисунке 2 показан фрагмент верхней части дерева онтологии. Уже на третьем уровне иерархии нет возможности показать все вершины. Под «Прикладными теориями», кроме показанных на рисунке, располагаются вершины «Автоматизация проектирования», «Анализ данных», «Искусственный интеллект», «Передача и обработка сигналов» и др., под «Областями приложений» - вершины «Социально-экономические системы», «Бизнес и финансы», «Технологические процессы», «Робототехника», и др.

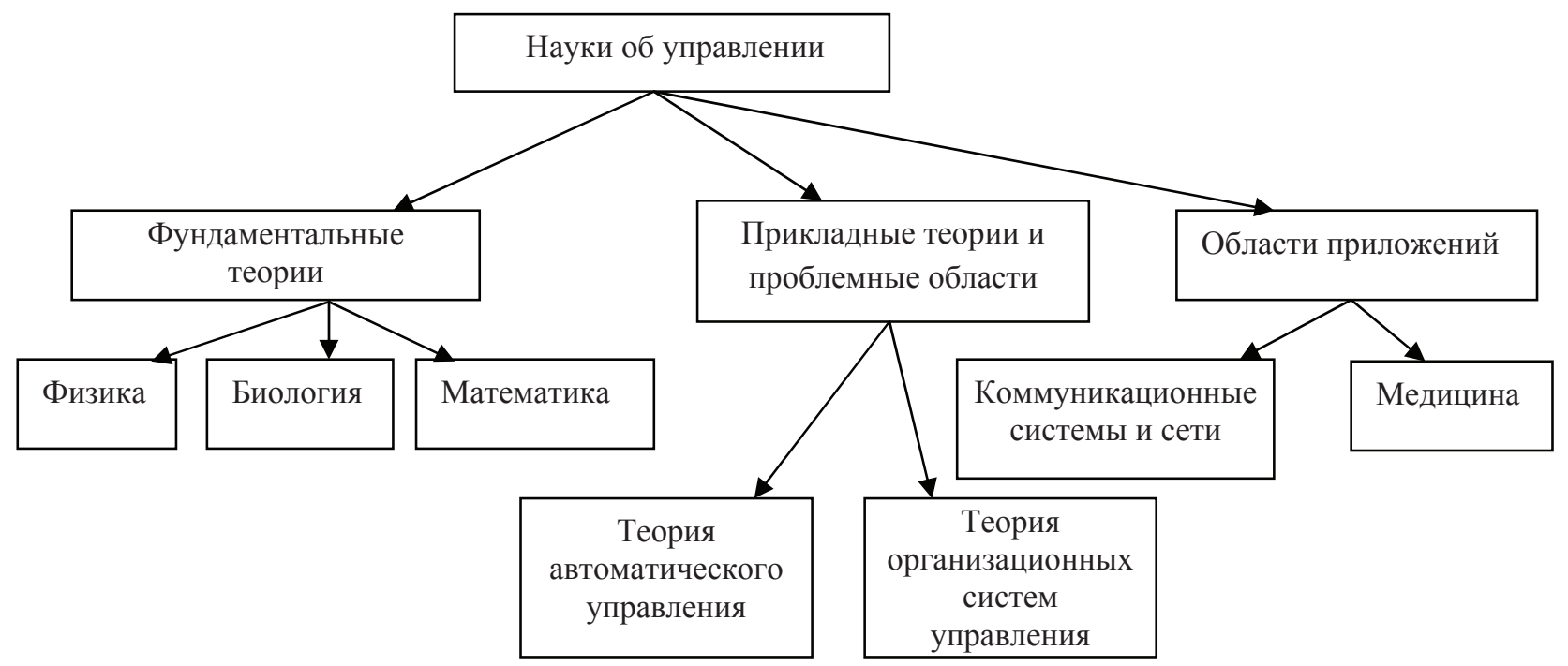

Рисунок 2 - Фрагмент верхней части дерева онтологии наук об управлении

В текущей версии нельзя говорить о полноте словаря и тематики: их расширение будет постоянно происходить в ходе опытной эксплуатации и по мере привлечения специалистов в отдельных областях. Кроме того, постоянно появляются новые теории, области приложений и соответствующая терминология. Поэтому как словарь, так и онтология должны в принципе быть постоянно открытыми к расширению и модификации. 


\section{4 Метод анализа тематики текста}

Предлагаемый метод анализа тематики научного текста на основе онтологии, организованной указанным образом, состоит из двух этапов.

Первый этап заключается в последовательном поиске всех терминов онтологии в анализируемом документе, подсчёте числа вхождений терминов с учётом их принадлежности различным темам онтологии. При этом приходится решать лексические проблемы, традиционные для систем обработки текстов естественного языка. Одна из таких проблем - это проблема морфологии, которая состоит в том, что в стандартных словарях слова представлены в лемматизированной, т.е. «нормальной» форме (существительные, прилагательные, причастия - именительный падеж, единственное число; глагол инфинитив), тогда как в текстах эти слова могут встречаться в различных словоформах. Эта проблема усложняется для многословных терминов типа «целочисленное линейное программирование».

В текущей версии системы эта проблема решается с помощью регулярных выражений формального языка для записи, поиска и манипуляций с подстроками текста [7]. Для каждого термина (однословного или многословного) формируется и записывается в словарь регулярное выражение, содержащее все его возможные словоформы.

Пример: трёхсловному термину «целочисленное линейное программирование» соответствует регулярное выражение, содержащее все его возможные словоформы:

(целочисленн ((ое)|(ого)|(ому)|(ым)|(ом))(\s|(\s\s))

линейн((ое)|(ого)|(ому)|(ым)|(ом))(\s|(\s\s))

программировани((е)|(я)|(ю)|(ем)|(и))).

На втором этапе на основе найденных терминов и их принадлежности темам формируется вектор релевантностей документа всем темам онтологии. Этот вектор называется профилем документа. Поскольку тем в онтологии много, а ненулевых релевантностей намного меньше, в качестве профиля документа можно рассматривать вектор ненулевых релевантностей. Профиль является результатом многомерной классификации документа.

Профиль сотрудника можно определить как профиль множества его публикаций. Вопрос о том, как конкретно формировать этот профиль из профилей публикаций, здесь не рассматривается.

Для описания алгоритма формирования профиля $\mathrm{P}(\mathrm{d})$ документа $\mathrm{d}$ введём ряд понятий. Будем считать, что онтология содержит $\mathrm{N}$ тем, которые имеют фиксированные номера; в документе найдено $K_{d}$ вхождений терминов; все они пронумерованы.

Значимость $\mathrm{S}_{\mathrm{m}}^{\mathrm{i}} \mathrm{i}$-го термина в $\mathrm{m}$-й теме определим следующим образом:

$s_{m}^{i}=0$, если $\mathrm{i}$-й термин не принадлежит $\mathrm{m}$-й теме; иначе

$s_{m}^{i}=1 / c_{i}$, где $c_{i}-$ число тем, которым принадлежит i-й термин.

Таким образом, принадлежность термина нескольким темам уменьшает его вероятность принадлежности $\mathrm{m}$-й теме и вносит неопределённость в его классификацию. Эта неопределённость будет разрешаться за счёт других терминов, возможно, экспертным путём.

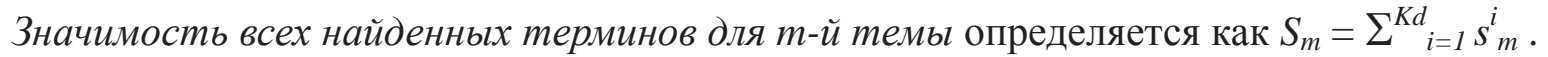

Суммарная значимость $\mathrm{S}_{\mathrm{d}}$ всех найденных терминов документа $\mathrm{d}$ для всех тем онтологии равна $\mathrm{S}_{\mathrm{d}}=\sum^{\mathrm{N}} \mathrm{j}=1_{\mathrm{j}} \mathrm{S}_{\mathrm{j}}$.

Тогда релевантность $\mathrm{R}_{\mathrm{m}}(\mathrm{d})$ документа $\mathrm{d}$ m-й теме определяется как сумма значимостей всех терминов $\mathrm{m}$-й теме, нормированная по $S_{d}$ :

Профиль $P(d)=\left(R_{1}(d), R_{2}(d), \ldots, R_{N}(d)\right)$.

$$
R_{m}(d)=S_{m} / S_{d}
$$


Проиллюстрируем приведённый алгоритм примером.

Пусть в документе $d$ найдено 15 терминов. Термины $\{1,2, \ldots, 10\}$ принадлежат теме 1 , термины $\{9, \ldots, 15\}$ принадлежат теме 2 . Термины $\{6,7, \ldots, 10\}$ повторились 4 раза; остальные - 2 раза.

$$
\begin{aligned}
& \text { Тогда } s_{1}{ }_{1}=\ldots=s^{8}{ }_{1}=1 ; s^{9}{ }_{1}=s^{10}{ }_{1}=1 / 2 ; s^{11}{ }_{1}=\ldots=s^{15}{ }_{1}=0 ; \\
& s^{1}=\ldots s^{7}{ }_{2}=s^{8}{ }_{2}=0 ; s^{9}{ }_{2}=s^{10}{ }_{2}=1 / 2 ; s^{11}{ }_{2}=\ldots=s^{15}{ }_{2}=1 . \\
& S_{1}=\left(s^{1}{ }_{1}+\ldots+s^{5}{ }_{1}\right) \cdot 2+\left(s^{6}{ }_{1}+\ldots+s^{10}{ }_{1}\right) \cdot 4=5 \cdot 2+3 \cdot 4+(0,5+0,5) \cdot 4=26 \\
& S_{2}=\left(s^{9}{ }_{1}+s^{10}{ }_{1}\right) \cdot 4+\left(s^{11}{ }_{1}+\ldots+s^{15}{ }_{1}\right) \cdot 2=(0,5+0,5) \cdot 4+5 \cdot 2=14 . \\
& R_{1}(d)=26 /(26+14)=0,65 ; R_{2}(d)=14 /(26+14)=0,35 ; P(d)=(0,65 ; 0,35 ; 0 ; \ldots ; 0) .
\end{aligned}
$$

При таком нормировании сумма релевантностей документа всегда равна 1. Однако полученные релевантности не нужно интерпретировать как вероятности принадлежности теме - напомним, что наша классификация многомерна, и предполагается, что документ может принадлежать разным темам. Величины релевантностей отражают предпочтительность компетенций предполагаемых рецензентов или экспертов.

\section{5 Программная реализация}

При разработке онтологии использовались программные средства Protégé [8]. Для представления онтологии в виде, удобном для совместной работы с программной системой, был выбран формат книги Excel, которая содержит таблицу-рубрикатор тем онтологии и таблицу-словарь терминов ПрО.

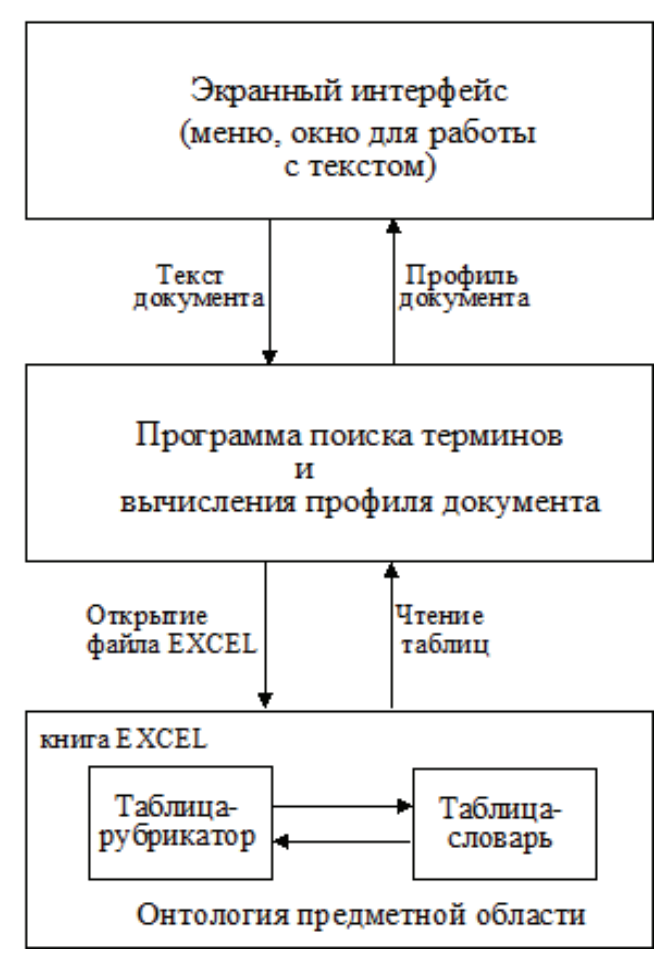

Рисунок 3 - Блок-схема программной системы определения профиля документа
Программный комплекс определения профиля документа содержит программу на языке Python, выполняющую поиск терминов в документе и вычисление количественной оценки тематики текста; экранный интерфейс пользователя и книгу Excel (рисунок 3).

Как уже отмечалось выше, словарь ПрО содержит лемматизированные термины на естественном языке, причём каждому из них соответствует единственное регулярное выражение [7], которое, в свою очередь, содержит все возможные словоформы термина (однословного или многословного).

Система тестировалась на текстовых вариантах файлов статей различных рубрик из архива журнала «Автоматика и телемеханика».

Одна из тестируемых рубрик - «Системы массового обслуживания». На рисунке 4 показано окно рабочей программы с результатом вычисления релевантностей (в процентах) текста статьи темам онтологии «Науки об управлении». 
C:/Work 2015/Practice/FindTermsExe/Эксперимент/Системы массового обслужИВанИЯ/СИСТЕМА ОБСЛУЖИВАНИЯ С ОДИНОЧНЫМ И СЕССИОННЫМ ПОСТУПЛЕНИЕМ ЗАПРОСОВ.txt

\section{ТЕМАТИКА ДОКУМЕНТА:}

Линейная алгебра, теория матриц $2.0 \%$

Теория вероятностей и математическая статистика $5.3 \%$

Теория случайных процессов $8.5 \%$

Теория графов $15.3 \%$

Теория информации $3.3 \%$

Сетевые и многоагентные структуры $3.0 \%$

Исследование операций $9.5 \%$

Передача и обработка сигналов $0.3 \%$

Теория автоматического управления $0.8 \%$

Теория оптимального управления $4.0 \%$

Теория выбора и принятия решений $0.5 \%$

Теория массового обслуживания $39.7 \%$

Техническая диагностика, надежность $6.5 \%$

Вычислительные и коммуникационные системы и сети $1.0 \%$

Экономика $0.3 \%$

\section{ВСЕГО НАЙДЕНО ТЕРМИНОВ: 199}

\section{Рисунок 4 - Окно рабочей программы с результатом вычисления релевантностей текста статьи заданным темам}

Жирным курсивом на рисунке выделены тематические разделы, для которых релевантность текста превышает $10 \%$.

Другая тестируемая рубрика - «Теория линейных систем». Она была выбрана не случайно: ей во многом соответствует терминология тематики онтологии «Теория автоматического управления», содержащая более 100 терминов. В тестовых примерах объёмом 16-62 kB количество найденных терминов обычно превышало 50 единиц (рисунок 5), а в некоторых случаях превосходило 100 при объёме словаря менее 700 терминов. Но были и исключения, когда документ содержал менее 50 терминов; при этом в нём превалировали математические выкладки и рисунки-схемы.

В среднем прослеживается тенденция роста числа найденных терминов с увеличением объёма текста, хотя количество найденных терминов от документа к документу сильно изменяется (рисунок 5). Это обусловлено рядом причин: наполнение тем терминами неравномерно - разные темы содержат различное число терминов; объёмы статей также могут сильно различаться; статьи различаются и соотношением объёмов текста и математических выкладок; кроме того, текущая версия словаря пока не гарантирует полноты терминологии для конкретных тем онтологии.

При обработке данных тестирования статей рубрики «Теория линейных систем» были выделены кортежи тем с наиболее высокими значениями релевантности. Для них были вычислены суммарные значения по всем обработанным статьям (рисунок 6). Оказалось, что основной вклад - 73,5\% - в профили статей этой рубрики вносят термины трёх тем онтологии: «Теория автоматического управления», «Теория устойчивости управляемых систем» и «Теория оптимальных систем». На графе онтологии ПрО каждая из вершин, 
представляющих две последние тематики, является смежной с вершиной первой тематики «Теория автоматического управления».

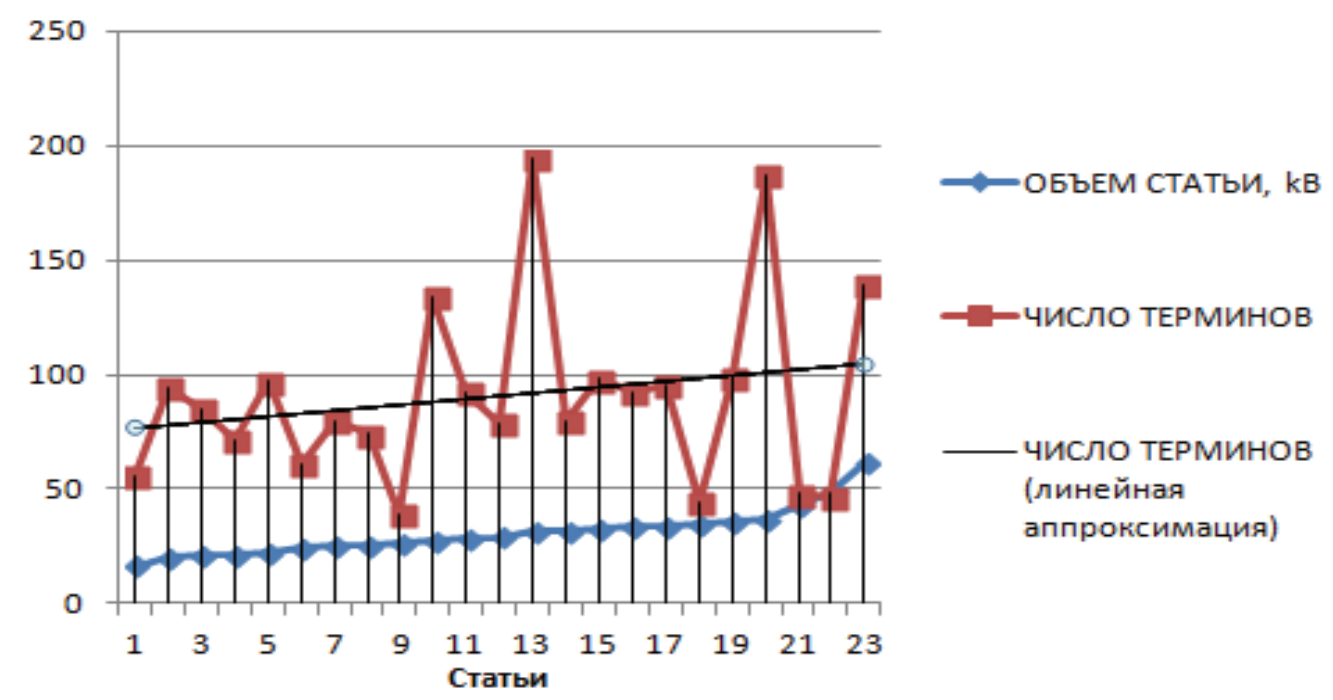

Рисунок 5 - Результаты тестирования рубрики «Теория линейных систем»

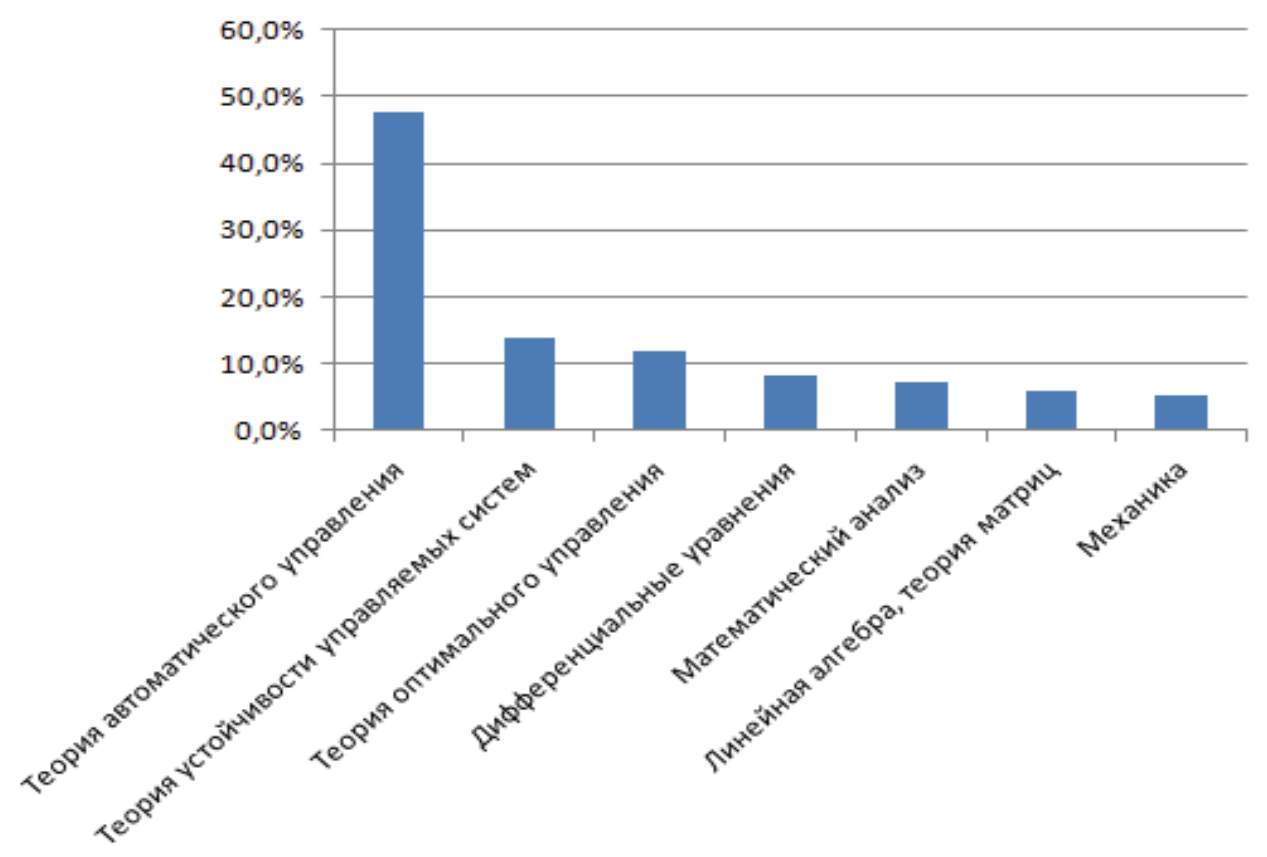

Рисунок 6 - Соотношение суммарных показателей релевантности статей из рубрики «Теория линейных систем» тематикам онтологии ПрО 


\title{
Заключение
}

Качество работы автоматизированной системы существенно зависит от корректности и полноты онтологии, полноты словаря и равномерности распределения терминов словаря по темам. Для текущей версии полнота словаря особенно актуальна. Для её обеспечения необходима серьёзная работа со специалистами в соответствующих областях.

Возможно развитие более сложных оценок профиля документа, учитывающих гипонимические отношения между тематиками в онтологии и весовые коэффициенты значимости терминов, установленные экспертами. Точности оценки профиля документа может способствовать привязка релевантностей документа к структурным разделам содержательной части текста и получение раздельных оценок по каждому из них.

Реально создание дополнительных программ для автоматизации преобразования терминов на естественном языке в регулярные выражения при составлении и пополнении словаря. В перспективе представляется интересным увеличение словаря за счёт регулярных выражений, представляющих собой лексические обороты, семантически соответствующие определённой теме. Отдельный интерес представляет накопление в ходе эксплуатации системы статистики встречаемости терминов и её использование для уточнения профиля документа.

\section{Список источников}

[1] Ильвовский, Д. Системы автоматической обработки текстов / Д. Ильвовский, Е. Черняк // Открытые системы. 2014, №1. - С. 51-53.

[2] Draganidis F., Mentzas G. Competency based management: a review of systems and approaches/ Information Management \& Computer Security, 2006, Vol. 14, No. 1, P. 51-64.

[3] Занина, Л.В., Меньшикова Н.П. Основы педагогического мастерства. - Ростов-на Дону: Феникс, 2003. $288 \mathrm{c}$.

[4] E uzenat J ., Shvaiko P. Ontology matching. - Springer-Verlag Berlin Heidelberg, 2007. - 332 p.

[5] Rogushina J ., Gladun A. Ontology-based competency analyses in new research domains / Journal of Computing and Information Technology. V.20, N. 4, 2012. - P.277-293.

[6] Крюков, К.В. О понятии формальной компетентности научных сотрудников / К.В. Крюков, О.П. Кузнецов, B.C. Суховеров // Материалы III-й международной научно-технической конференции (OSTIS-2013, Минск). Минск, УО "Белорусский государственный университет информатики и радиоэлектроники" (БГУИР), 2013. - С.159-162.

[7] Фридл Джс. Регулярные выражения, 3-е издание. - Пер. с англ. - СПб.: Символ_Плюс, 2008. - 608 с.

[8] Smith M.K., Welty C., McGuinness D.L. OWL Web Ontology Language Guide, 2004. https://www.w3.org/TR/2004/REC-owl-guide-20040210/

\section{A ONTOLOGICAL APPROACH TO DETERMINING THE SUBJECT MATTER OF SCIENTIFIC TEXT}

\author{
O.P. Kuznetsov ${ }^{1}$, V.S. Sukhoverov ${ }^{2}$ \\ Institute of C ontrol Sciences of Russian Academy of Sciences, M oscow, Russia \\ 1olpkuz@yandex.ru, ${ }^{2}$ suhoverv@ipu.ru
}

\begin{abstract}
The paper proposes an approach to determination the subject matter of scientific text, using the domain ontology. It presents the original principle of building applied sciences ontologies, in which the ontology tree contains three required branches: the "Fundamental theory", "Applied theory", "Applications". Topics are classes of the ontology and terms of the matching topics are instances of classes. We describe the structure of the control theory ontology and present
\end{abstract}


fragments of this ontology and its dictionary. It is assumed that the scientific text relevant to the topic, if it contains terms of this topic. A method is proposed for evaluating of the degree of scientific text relevance to different topics based on counting the number of the terms occurrences of these topics in the document. The result of this method is the "the document profile" - vector of document relevance to ontology topics. We describe the automatic system for analysis the subjects of scientific texts from the field of the control theory and practice developed on the basis of the proposed approach. The linguistic problems of the terms search are considered. We present some statistics after processing of thematic sections of the journal "Automation and Remote Control" and an example of building a profile for selected article. Possible directions to improve the estimates of relevance are noted.

Key words: ontology, competence, relevance, topic, term, document profile, control theory.

Citation: Kuznetsov O.P., Sukhoverov V.S. A ontological approach to determining the subject matter of scientific text. O ntology of designing. 2016; 6(1): 55-66. DOI: 10.18287/2223-9537-2016-6-1-55-66.

\section{References}

[1] II'vovskij D., Chernyak E . Sistemy avtomaticheskoi obrabotki tekstov [Systems of automatic processing of texts] //Otkrytye sistemy. 2014, №1: 51-53. (In Russian).

[2] Draganidis F., Mentzas G. Competency based management: a review of systems and approaches/ Information Management \& Computer Security, 2006, Vol. 14, No.1: 51-64.

[3] Zanina LV., Men'shikova NP. Osnovy' pedagogicheskogo masterstva. [Fundamentals of pedagogical skills] Rostov-na Donu: Feniks, 2003.

[4] E uzenat J ., Shvaiko P. Ontology matching. - Springer-Verlag Berlin Heidelberg, 2007. 332 p.

[5] Rogushina J ., Gladun A. Ontology-based competency analyses in new research domains / Journal of Computing and Information Technology. V.20, N. 4, 2012: 277-293.

[6] Kryukov KV., Kuznetsov OP., Sukhoverov VS. O ponyatii formal'noj kompetentnosti nauchnykh sotrudnikov [On the notion of formal competence of research staff] / Materialy III-j mezhdunarodnoj nauchno-tekhnicheskoj konferentsii (OSTIS-2013, Minsk). Minsk, UO "Belorusskij gosudarstvennyj universitet informatiki i radioelektroniki" (BGUIR), 2013: 159-162. (In Russian).

[7] F riedl J effrey E F . Mastering Regular Expressions, 3rd Edition - O'Reilly Media, 2006.

[8] Smith MK., Welty C., McGuinness DL. OWL Web Ontology Language Guide, 2004. https://www.w3.org/TR/2004/REC-owl-guide-20040210/

\section{Сведения об авторах}
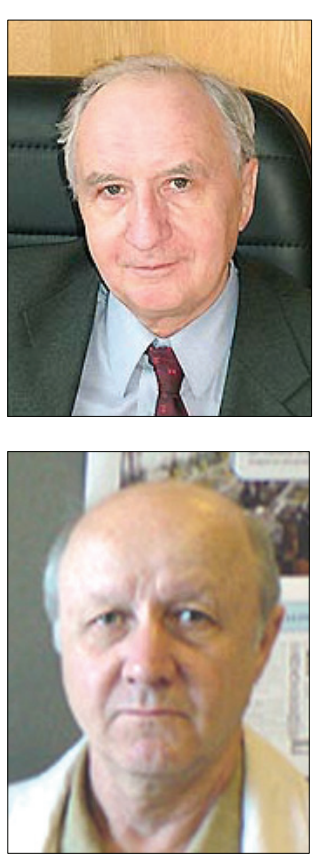

Кузнецов Олег Петрович. 1936 г. рождения. Окончил МГУ им. М.В.Ломоносова (1958 философский факультет, 1966 - механико-математический факультет). К.т.н. - 1965, д.т.н. -1983, проф. 1998. Заведующий лабораторией Института проблем управления им. В.А.Трапезникова РАН. Председатель Научного Совета Российской Ассоциации искусственного интеллекта. Член редколлегий журналов «Автоматика и телемеханика», «Проблемы управления», «Искусственный интеллект и принятие решений». Автор 143 статей и 3 монографий.

Kuznetsov Oleg Petrovich (b.1936) graduated from Moscow State University in 1958 (philosophy department) and 1966 (mathematics and mechanics department). Head of department at Institute of Control Sciences V.A.Trapeznikov Academy of Sciences. Chairman of Scientific Council of Russian Association of Artificial Intelligence. He is author 143 scientific articles and 3 monographies.

Суховеров Виктор Степанович. 1945 г. рождения. Окончил МЛТИ (1970 - факультет электроники и счетно-решающей техники). К.т.н. - 2004. Старший научный сотрудник лаборатории методов интеллектуализации дискретных процессов и систем управления Института проблем управления им. В.А.Трапезникова РАН. Автор более 50 статей.

Sukhoverov Victor Stepanovich (b. 1945) graduated from the Moscow State Forest University Faculty of Computer Sciences in 1970, PhD (2004). Senior researcher of Laboratory of Intellectualization Methods of Discrete Processes and Control Systems - V. A. Trapeznikov Institute of Control Sciences of Russian Academy of Sciences. He is author and co-author of more than 50 publications. 


\title{
УДК 557.97
}

\section{О КЛАССЕ, КЛАССИФИКАЦИИ И СИСТЕМАТИЗАЦИИ}

\author{
С.В. Микони \\ Санкт-Петербургский институт информатики и автоматизации Российской академии наук, \\ Санкт-Петербург, Россия \\ smikoni@mail.ru
}

\begin{abstract}
Аннотация
Рассмотрены определения понятия классификации в отечественных источниках. Обнаружены существенные различия в имеющихся трактовках, связанные с обозначением классификации, как процесса, так и его результата. Предложено именовать эти понятия разными терминами. Для устранения неточностей в определении классификации, её методов и связи с систематизацией знания предложено привлечь математические модели класса, классифицирования и системы. Рассматриваются модели формирования классов, используемые различными методами классифицирования объектов. Систематизированы свойства методов классифицирования и получаемых с их применением классификаций. Рассмотрен метод деления объёма понятий. На конкретном примере показана ошибка, допущенная в цитируемой работе за счёт неправильного выбора модели формирования класса. Рассмотрены индуктивные методы классифицирования объектов и метод архетипа. На основании анализа модели системы показывается соотношение классификации и систематизации, которое иллюстрируется на примере периодической системы химических элементов Д.И. Менделеева. Уточнены понятия классификации.
\end{abstract}

Ключевые слова: модель, класс, классифицирование, классификация, таблица Менделеева, система, систематизация, деление понятия, паксономия.

Цитирование: Микони, С.В. О классе, классификации и систематизации / С.В. Микони // Онтология проектирования. - 2016. - Т.6, №1(19). - С. 67-80. - DOI: 10.18287/2223-9537-2016-6-1-67-80.

\section{Введение}

В примечании к делению индивидов на категории в работе [1] редколлегия журнала отметила относительность «любой классификации» и пригласила читателей высказаться на эту тему. Эта тема действительно актуальна для формирования онтологии любой предметной области (ПрО), ибо согласно Ж.Б. Ламарку «всякая наука начинается с классификации».

Понятие «классификация (классифицирование)» нашло отражение в работах по философии и формальной логике [2-5], причём определение этого понятия в отмеченных источниках претерпевало изменения. Приведём его варианты в хронологическом порядке.

1) Классификация - это «раскрытие внутренней необходимой связи между группами (классами, родами и т.д.), по которым распределены классифицируемые предметы» [2].

2) Классификащия - это «система соподчинённых понятий (классов объектов) какой-либо области знания или деятельности человека, часто представляемая в виде различных по форме схем (таблиц) и используемая как средство для установления связей между этими понятиями или классами объектов, а также для ориентировки в многообразии понятий или соответствующих объектов» [3].

3) Классификащия - это «общенаучное и общеметодологическое понятие, означающее такую форму систематизации знания, когда вся область изучаемых объектов представлена 
в виде системы классов, или групп, по которым эти объекты распределены на основании их сходства в определённых свойствах» [4].

4) Классификация - это «многоступенчатое, разветвленное деление логического объёма понятия. Результатом классификации является система соподчиненных понятий (род, вид, подвид и т.д.)» [5].

Во всех определениях классификация представляется как система взаимосвязанных классов. Ключевыми словами системы классов являются «класс» и «связь». Первая часть четвёртого определения отражает процесс образования классов. Как процесс его правильнее назвать классифицированием, а его результат - классификацией, что соответствует паре аналогичных терминов: систематизация (процесс) и система (результат систематизации). Будем также называть классифицированием процесс отнесения объекта с известными свойствами к одному из классов.

Классификации во всех указанных источниках делятся на естественные и искусственные, причём в [2,3] они различаются по степени существенности оснований деления. В [2] им ставятся в соответствие содержательные и формальные классификации. К первым отнесены классификации, отражающие объективные законы природы, а ко вторым - классификации, получаемые логическим делением понятий. Естественные классификации в [2, 3] в отличие от искусственных классификаций именуют также научными по причине отражения ими законов природы.

Во всех источниках в качестве примера естественной (научной) классификации приводится периодическая система химических элементов Д.И. Менделеева, а в качестве примера искусственной классификации - универсальные десятичные классификации (УДК). Наряду с названными классификациями в [2] приводится метод архетипа, применяемый в биологической систематике.

Помимо своей разнородности приведённые определения классификации и пояснения к ним вызывают ряд вопросов. Только в определении [5] процесс классификации (классифицирование) отделён от его результата. Определение [2] не отражает процесс образования классов. Они считаются заранее известными. Определение [5] сводит классифицирование только к делению логического объёма понятия. Определение [4] рассматривает классификацию как форму систематизации знания (значит, одну из форм?), но во всех источниках классификация отождествляется с систематизацией на примере периодической системь химических элементов Д.И. Менделеева, что вызывает вопрос о соотношении этих понятий.

Определения классификации и пояснения к ним не охватывают все её методы, что отражается на используемой терминологии. Существенность признаков, используемых для деления классификаций на естественные и искусственные, никак не определена.

Надёжным фундаментом для ответов на эти вопросы могут служить только математические модели. Тем более, что в [2] отмечается, что «формально-логические правила классифицирования разработаны слабо». С этой целью в качестве объектов исследования рассмотрим класс, классификацию и систематизацию с привлечением их математических моделей. Применение этих моделей позволит уточнить перечисленные понятия и уточнить связи между ними. Это поможет, в том числе, аргументированно ответить на вопрос, заданный редколлегией журнала по поводу конкретного примера классификации.

\section{1 Модели класса}

Поскольку класс является ключевым понятием в классифицировании объектов, рассмотрим различные модели класса. Под классом понимается открытое множество [6]:

$$
A=\{x \mid \operatorname{Pr}(x)\} \text { или } A=\{x: \operatorname{Pr}(x)\} .
$$


Принадлежность элемента X множеству А определяется относительно свойства $\mathrm{Pr}$, присущего всем его элементам. Истинность одноместного предиката $\mathrm{Pr}$ ( $\mathrm{x}$ ) свидетельствует о том, что элемент $\mathrm{x}$ обладает заданным свойством $\mathrm{Pr}$. Таким образом, предикат $\mathrm{Pr}(\mathrm{x})$ представляет собой логическое правило формирования множества $A^{1}$. Оно характеризует факт принадлежности элемента $\mathrm{X}$ множеству $\mathrm{A}$ и на этой основе называется характеристической функцией множества $A: \operatorname{Pr}: A \rightarrow\{0,1\}$. Значение 0 (ложь) означает, что $\mathrm{X} \notin \mathrm{A}$, а значение 1 (истина) означает, что $x \in A$.

Oткрытым множество А называют потому, что его мощность (количество элементов) не фиксировано. По способу формирования множества его можно назвать разреши́мылм или рекурси́внылм, поскольку его характеристическая функция позволяет определить, принадлежит ли анализируемый элемент X множеству А с заданным свойством элементов.

Логическое правило формирования множества А усложняется, если его элементы должны обладать одновременно $\mathrm{n}>1$ свойствами:

$$
A=\left\{x: \wedge_{j=1}^{n} \operatorname{Prj}_{j}(x)\right\} \text {. }
$$

Фактически формула (2) предлагает выполнение $\mathrm{n}$ логических правил формирования множества А. Элементами класса «Отличник», например, являются только те ученики, которые получили оценку «Отлично» по всем $\mathrm{n}$ предметам. Класс «Троечник» предполагает наличие хотя бы одной удовлетворительной оценки:

$$
A=\left\{x: \bigvee_{j=1}^{n} \operatorname{Pr}_{j}(x)\right\} .
$$

Именованный класс представляет собой понятие. Мощность |А | множества А называется объёмом понятия, а совокупность признаков, по которым определяется объём - содержанием понятия [7].

Совокупность существенных признаков извлекается из определения понятия, выделяющего его из множества других понятий ПрО. Признаки являются существенными по отношению к той точке зрения, с которой определяется данное понятие. Например, по отношению к знанию, учёного можно охарактеризовать, как знающего, познающего и порождающего (новое знание). В силу фиксированного числа признаков содержание понятия «учёный» задаётся перечислительным способом:

Учёньй $(\mathrm{x})=\{$ Знающий $(\mathrm{x})$, Познающий $(\mathrm{x})$, Порождающий $(\mathrm{x})\}$.

Человек $\mathrm{x}$, удовлетворяющий этим требованиям, может считаться учёным. Объём понятия «учёный» не всегда удобно представлять перечислительным способом. Через разрешимое множество оно представляется подстановкой в формулу (2):

Учёный $(x)=\{x \mid$ Знающий $(x) \wedge$ Познающий $(x) \wedge$ Порождающий $(x)\}$.

Применение двоичных предикатов достаточно для выделения конкретного понятия из множества других понятий ПрО, но недостаточно для сопоставления порождённых из него видовых понятий. Например, как отличить молодого учёного от немолодого или зрелого от незрелого? Эта задача решается двухместным предикатом с целевым значением $c_{j}$ j-го свойства в роли базы сравнения. С учётом этого формула (2) принимает следующий вид:

$$
A=\left\{x: \operatorname{Pr}_{\succ}\left(f_{j}(x), c_{j}\right)\right\}
$$

Пусть учёный считается молодым в возрасте до сорока лет включительно. В соответствии с формулой (4) это условие представится следующим образом:

\footnotetext{
${ }^{1}$ Строго говоря, благодаря правилу отнесения к классу формула (1) представляет собой модель формирования класса.
} 
Молодой учёный $(\mathrm{x})=\{\mathrm{x} \mid \mathrm{Pr} \leq($ Возраст учёного $(\mathrm{x})), 40\}$.

Учёный, не удовлетворяющий этому правилу, считается немолодым. Здесь появляется искушение отождествить немолодого учёного со зрелым. Но зрелый учёный отличается от незрелого не возрастом, а своим вкладом в науку. А это уже другое основание деления. Человек, получивший учёную степень, может заняться другим видом деятельности и достигнуть зрелости в нём, а не в науке. Однако в общем случае зависимость зрелости учёного от его возраста исключать нельзя. Для её выявления используется статистика.

Формулу (4) так же, как и (1), можно обобщить на $\mathrm{n}$ свойств:

$$
A=\left\{x: \bigwedge_{j=1}^{n} \operatorname{Pr}_{\succ}\left(f_{j}(x), C_{j}\right)\right\} .
$$

Значение с н на шкале признака, принятого за основание деления, является пороговым между двумя классами, означающими наличие и отсутствие ј-го свойства. В теории принятия решений оно является основанием для отбора объектов в один из классов [8].

При наличии более одного класса шкала признака делится на m>1 диапазонов, a k-му классу, $k=\overline{1, m}$, ставится в соответствие диапазон [ $c_{k j, m i n,} c_{k j, m a x}$ значений j-го признака, $\mathrm{j}=\overline{1, \mathrm{n}}$. Отсюда число диапазонов значений признака, участвующего в классификации объектов, должно соответствовать числу классов m. Граница между k-м и I-м смежными классами на шкале ј-го признака называется нечёткой, если имеет место пересечение поставленных им в соответствие диапазонов значений:

$$
\left[\mathrm{C}_{\mathrm{kj}, \min }, \mathrm{C}_{\mathrm{kj}, \max }\right] \cap\left[\mathrm{C}_{\mathrm{lj}, \min }, \mathrm{C}_{\mathrm{lj}, \max }\right] \neq \varnothing .
$$

Принадлежность объекта X каждому из смежных классов в интервале [C $\left.\mathrm{C}_{\mathrm{j}, \min }, \mathrm{C}_{\mathrm{kj}, \max }\right]$ означает частичное обладание j-м свойством, что соответствует философии частичной истины [9]. Для её оценивания применяется функция принадлежности $\mu_{\mathrm{jk}}(\mathrm{x}) \mathrm{k}-\mathrm{y}$ классу по j-y свойству. Наличие общей шкалы у функций принадлежности разным классам позволяет классифицировать объект $\mathrm{X}$ на основании средневзвешенной аддитивной функции принадлежности k-y классу по n признакам [8]:

$$
\mu_{k}(x)=\sum_{j=1}^{n} w_{j} \cdot \mu_{j k}(x), \quad k=\overline{1, m} .
$$

В формуле (6) W ј означает вес (важность) j-го признака. Если все признаки имеют равную важность, их веса равны $\mathrm{W}_{\mathrm{j}}=1 / \mathrm{n}$.

Поскольку в общем случае имеет место частичная принадлежность объекта $\mathrm{x}$ k-му классу по $n$ признакам $\left(\mu_{k}(x) \in[0,1]\right), k=\overline{1, m}$, класс $h *$, которому объект $x$ принадлежит в большей степени, определяется по максимальной величине функции принадлежности:

$$
\mathrm{h}^{*}=\arg \left(\max _{\mathrm{k}} \mu_{\mathrm{k}}(\mathrm{x})\right) \text {. }
$$

Формула (7) представляет правило отнесения объекта $\mathrm{x}$ к одному из классов. Поскольку функция принадлежности $\mu_{\mathrm{k}}(\mathrm{x})$ измеряется в шкале $[0,1]$, для её отнесения к классу $\mathrm{h} *$ может также использоваться пороговое значение в этой же шкале, например, $\mu_{k}(x)>0,5$.

Правило (7) реализуется в модели выбора класса $h *$ :

$$
\mathrm{h}^{*}=\left\{\mathrm{x}: \arg \left(\max _{\mathrm{k}} \mu_{\mathrm{k}}(\mathrm{x})\right)\right\}
$$

Рассмотренные модели классификации изложены в порядке их усложнения, связанного с получением большего объёма информации о свойствах классифицируемых объектов - от наличия ј-го свойства до его количественного измерения, от одного до нескольких свойств. 
Иными словами, переход к каждой следующей модели предполагает более глубокое изучение ПрО.

При геометрической трактовке объектов точками в n-мерном пространстве их свойств существуют два способа задания класса: его границами и компактностью размещения точек.

Если границы класса задаются гиперповерхностью $\mathrm{F}\left(\mathrm{x}_{1}, \ldots, \mathrm{X}_{n}\right)$, условие принадлежности объекта $X$ классу А отражается нахождением его внутри границ класса:

$$
A=\left\{x: \operatorname{pr}_{\leq}\left(F\left(x_{1}, \ldots, x_{n}\right), 0\right)\right\} \text {. }
$$

В случае кусочно-линейного представления гиперповерхности $F\left(\mathrm{X}_{1}, \ldots, \mathrm{X}_{\mathrm{n}}\right)$ правило (9) преобразуется в конъюнкцию гиперплоскостей, представляющих границы класса $A$.

Условие компактности размещения точек в n-мерном пространстве свойств объекта представляется таксономической моделью класса:

$$
A_{k}=\left\{x: p r_{\leq}\left(d\left(x, c_{k}\right), d_{k, \max }\right)\right\} .
$$

В формуле (9) $C_{k}$ - это точка, принятая за центр (представитель) k-го класса, $d\left(x, c_{k}\right)-$ нормированное эвклидово расстояние в $n$-мерном пространстве между объектом $\mathrm{X}$ и центром k-го класса, $d_{k, \max }$ - максимальное расстояние до границы k-го класса. Модель (9) задаёт границы класса окружностью с центром $c_{k}$ и радиусом $d_{k, \max }$.

В основу нахождения таксонов более сложной конфигурации (рисунок 1) кладётся гипотеза $\lambda$-компактности [10]. Она опирается на понятие $\lambda$-расстояния, которое учитывает нормированное расстояние $d$ между элементами множества и локальную плотность $\tau$ множества в окрестностях этих элементов.

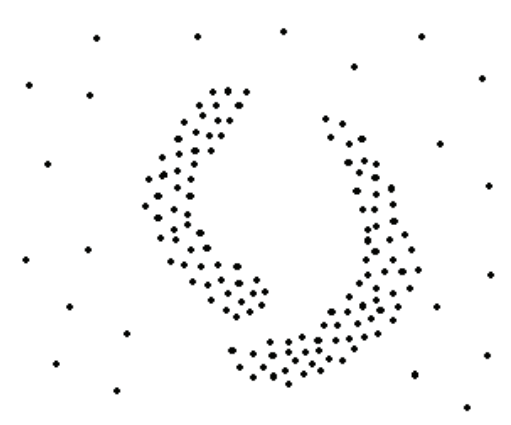

Рисунок 1 - Два таксона сложной конфигурации в двумерном пространстве свойств

Вычисленные $\lambda$-расстояния всех отрезков, соединяющих точки множества $A$, отображаются из евклидова в $\lambda$-пространство ${ }^{2}$. С применением алгоритма Крускала или Прима [6] находится минимальная стягивающая сеть (остов) полного $\lambda$-графа. Исходя из гипотезы $\lambda$ компактности, утверждается, что точки, близкие в $\lambda$-пространстве, образуют $\lambda$-компактные сгустки, представимые таксонами.

\section{2 Методы классифицирования объектов}

Разнообразию моделей класса соответствует разнообразие методов классифицирования объектов [2]. Эти методы характеризуются следующими признаками:

1) способом создания классификации

a. дедуктивные;

b. индуктивные;

\footnotetext{
${ }^{2}$ В формуле (10) $d$-расстояния заменяются на $\lambda$-расстояния.
} 
2) используемым математическим аппаратом

а. логические;

b. вычислительные;

3) наличием образца для классифицирования

a. методы, имеющие образец;

b. методы, не имеющие образца.

Как и любые методы проектирования, дедуктивный и индуктивный методы различаются направленностью создания классификации. Дедуктивный метод реализует нисходящий способ, а индуктивный метод - восходящий способ проектирования. Дедуктивный метод конкретизирует свойства классифицируемых объектов, а индуктивный метод обобщает их. Как и при решении других задач проектирования, эти методы, как правило, используются совместно, начиная с создания классификации от общего к частному или наоборот, и сменяя друг друга.

Как дедуктивный, так и индуктивный, методы могут использовать логические или вычислительные операции, либо и те, и другие, для разделения, либо обобщения классифицируемых объектов по их свойствам. Логическая операция оценивает наличие либо отсутствие у объекта рассматриваемого свойства. Вычислительные операции позволяют классифицировать объекты на основе количественного оценивания их свойств. Реализующие их методы называют параметрическими.

К методам, имеющим образец для создания классификации, относится разработанный в биологической систематике метод архетипа. Для каждого вида особей устанавливается типовой образец (архетип). При установлении места особи в систематике её признаки сравниваются с признаками архетипов различных видов, и делается вывод о принадлежности её к тому или иному виду.

Рассмотрим методы классифицирования объектов более подробно, уделив наибольшее внимание логическому методу деления объёма понятий, который имеет прямое отношение к вопросу, предложенному редколлегией журнала для обсуждения.

\section{3 Деление понятий}

В основе деления объёма понятий по свойствам лежит отношение общее-частное. Оно устанавливает родо-видовую связь между общим (родовым) и частным (видовым) понятиями за счёт расширения содержания общего понятия $A$ видовым отличием $B_{1}$ по основанию деления $^{3} B[11]$ :

$$
B_{1} A=A \cup B_{1}
$$

Получаемое таким образом понятие $B_{1} A$ называется видовыл. Поскольку все существенные признаки исходного понятия $A$ при его объединении с видовым отличием $B_{1}$ сохраняются, формула (11) отражает наследование признаков при порождении нового понятия.

Объём видового понятия сужается на основании формулы, двойственной формуле (11):
(12)
$\mathbf{B}_{1} \mathbf{A}=\mathbf{A} \cap \mathbf{B}_{1}$

Если основание деления $B$ имеет два значения $B_{1}$ и $B_{2}$, члены деления представляют собой несовместимые понятия, объёмы которых не пересекаются:

$$
\mathbf{B}_{1} \mathbf{A} \cap \mathbf{B}_{2} \mathbf{A}=\varnothing,
$$

а объединение объёмов даёт объём исходного понятия $A$ (правило соразмерности деления):

$$
\mathbf{B}_{1} \mathbf{A} \cup \mathbf{B}_{2} \mathbf{A}=\mathbf{A} \text {. }
$$

\footnotetext{
${ }^{3}$ В системном анализе основание деления называют системообразующим признаком. 
Например, если за основание деления понятия контроль принять его место в технологическом процессе изготовления изделий (на его входе и выходе), то объёмы полученных видовых понятий входной и выходной контроль не совпадают (пересечение их является пустым). Данный пример характеризует дихотомическое деление понятия контроль по выбранному основанию деления, так как последнее не порождает других членов деления, кроме приведённых выше: $\mathbf{B X} \mathbf{K} \cup \mathbf{B Ы \mathbf { X }} \mathbf{K}=\mathbf{K}$. При этом видовые понятия $B X K$ и $B Ы X K$ наследуют все признаки родового понятия контроль $(K)$.

Объект, оцененный правилом (2), включается в класс $A$, если он обладает всеми $\mathrm{n}$ свойствами этого класса. В противном случае, при дихотомическом делении понятия он включается в противоположный класс $\neg$ А.

Деление понятия по объёму не обязательно оказывается дихотомическим. Причиной тому является использование обобщённого основания деления. Если в приведённом выше примере место контроля не ограничивать входом и выходом технологического процесса, то результат деления понятия контроль будет включать три члена деления: $\mathbf{B X ~ K} \cup \mathbf{O П ~ К} \cup$ ВЫХ К = К, где ОП К означает пооперационный контроль.

Если обобщённое основание деления «место контроля в технологическом процессе» разделить на «оконечный контроль технологического процесса» и «вид оконечного контроля», то получим двухступенчатое дихотомическое деление. На первой ступени по ответу Да контроль разделится на оконечный и промежуточный, а по ответу Нет на второй ступени - на входной и выходной. Таким образом, расщепляя основание деления, можно N >2 членов деления свести к двум на каждом шаге за $\mathrm{k}=] \log _{2} \mathrm{~N}\left[\right.$ шагов $^{4}[8]$. При этом каждое последующее основание деления зависит от предыдущего, конкретизируя его.

Приведённый пример деления понятия контроль отражает последовательный способ деления, когда второе основание деления зависит от первого. В том случае, когда основания деления одного понятия независимы, реализуется параллельный способ деления объёма понятия. Получаемые по независимым основаниям дихотомического деления видовые понятия называют координатными [11].

Координатные понятия позволяют формировать межвидовые и смешанные понятия. Межвидовое понятие создаётся объединением координатных понятий, полученных по разнылм основаниям деления. В качестве примера приведём понятие входной производственный контроль. Видовое понятие производственный получено относительно деления технологического процесса на производственный и торговый. Смешанное понятие создаётся совмещением противоположных видовых понятий. Актуальным примером является появление в современных анкетах графы Другой при определении пола лица, принимаемого на работу. Человек, характеризуемый этим понятием, совмещает свойства мужчины и женщины.

Выбор признаков, принимаемых за основания деления, зависит от цели классификации. Здесь уместно провести аналогию с деревом целей в модели принятия решений [8]. Состав оснований деления, как и частных целей в дереве целей, определяется поставленной целью. Соответствие общей и частных целей регламентируется закономерностью целостности системного анализа [12].

Процессы конкретизации и обобщения связаны с поиском подходящих терминов для обозначения новых понятий. Здесь следует руководствоваться правилами терминологии [13, 14]. Установление взаимосвязи между известными понятиями выполняется на основе их определений. Существенные признаки, извлечённые из определений сопоставляемых понятий, позволяют установить, находятся ли они в отношении «общее-частное». Для решения этой задачи в [15] был предложен язык определения понятий (ЯОП).

\footnotetext{
${ }^{4}$ Символы ] [ означают ближайшее большее целое число.
} 
Относительность классификаций, отмеченная редколлегией журнала, объясняется неоднозначным подбором оснований деления понятий и их значений под заданную цель. Помимо относительности (условности) любой классификации следует оценивать её правильность. Она определяется выбором модели, соответствующей свойствам формируемого класса. Именно несоблюдение этого условия в [1] вызвало замечание редколлегии журнала.

При формировании понятия «трансцендентный человек» в работе [1] допущена ошибка в выборе модели класса, а именно, выбрана простейшая модель класса (1), не отвечающая поставленной задаче. Поясним эту мысль, отступив в терминах от высокого слога философии. Речь, на наш взгляд, идёт о целеустремлённом человеке (ЦУЧ). Ему недостаточно быть человеком, способным проектировать своё будущее (ПрЧ). Здесь нельзя не согласиться с мнением редколлегии журнала в том, что практически каждый человек, в той или иной мере, задумывается (философствует) о будущем. А поскольку измерить меру философствования каждого человека не представляется возможным, необходимо привлечь, как минимум, ещё один признак для выделения целеустремлённого человека из числа других людей. К таким признакам логично отнести настойчивость в достижении цели (настойчивый человек - НЧ). Тогда целеустремлённый человек характеризуется моделью (2), содержащей более одного признака:

$$
\text { ЦУЧ }(\mathrm{X})=\{\mathrm{x} \mid \text { ПрЧ }(\mathrm{x}) \wedge \text { НЧ }(\mathrm{x})\} .
$$

Этой формулой снимается возражение редколлегии в том, что практически все люди философствуют (проектируют будущее). Мало поставить цель (создать проект будущего). Нужно ещё иметь волю для достижения поставленной цели. В России человека, не имеющего этого качества, называют прожектёром. Такие люди могут, например, много говорить об импортозамещении, но не предпринимать конкретных шагов в этом направлении. Не претендуя на точный смысл терминов, выбранных для приведённого примера, хочется надеяться на то, что он доступно иллюстрирует идею правильного подбора модели класса для формирования нового понятия.

Более точным определением классифицирования по объёму понятий, чем в [5], на наш взгляд, является «многократное параллельное или/и последовательное деление объёма понятий по выбранным основаниям деления на виды в отношении общее-частное».

Принцип формирования видовых понятий путём деления объёма исходного понятия соответствует нисходящему способу проектирования - от общего к частному. По этому способу метод создания классификации понятий является дедуктивнылм, а по использованию логического аппарата - логическим.

\section{4 Другие методы классифицирования объектов}

Альтернативой дедуктивному логическому методу деления объёма понятий являются индуктивные методы создания классификаций, использующие модели класса (9) и (10) и статистические, либо экспериментальные данные.

Границы между сгустками точек (таксонами) в n-мерном пространстве признаков устанавливаются либо анализом расстояний между точками, либо обучением модели классифицирования на обучающей выборке.

Аналитический подход к формированию классов (таксонов) реализуется индуктивныли вычислительными методами на основе вычисления расстояний между точками в $\mathrm{n}$-мерном пространстве признаков [10]. Обучение модели классифицирования реализуется индуктивнылми логическими методами, формирующими границы класса на основе выборки с положительными и отрицательными примерами принадлежности классу. Для решения этой задачи успешно применяются нейросетевые модели. 
В классификационной системе с установленными опытным или экспертным способом нечёткими границами классов выбор класса осуществляется параметрическим методом по максимальной обобщённой принадлежности классу на основе модели (8). Здесь выбор класса осуществляется не только по совокупности отношения признаков к целевым значениям как на основе модели (5), но и по их обобщённым оценкам, например, с применением формулы (6), использующей нечёткие оценки свойств.

В биологической систематике успешно применяется метод классифицирования особей на основе составленного классификатором архетипа. Архетип отражает характерные свойства группируемых объектов. Например, архетипом птицы является объект живой природы, обладающий туловищем, головой, крыльями, хвостовым оперением и ногами. В силу разнообразия этих частей организма в живой природе при сопоставлении особей они анализируются по отдельности, чему соответствует членение системы в отношении «целое-часть».

Определение принадлежности рассматриваемой особи заданному архетипу осуществляется методами мерономии и таксономии [16]. Методы мерономии основаны на умозрительном анализе классифицируемых объектов, а методы таксономии - на экспериментальном подходе. Таксономия и мерономия находятся в отношении двойственности. Чем больше классификатор знает о реальной структуре таксонов, тем он лучше может определить архетип. И, наоборот, более точное определение архетипов позволяет гораздо точнее определить таксономическую структуру.

Части архетипа принимаются за мероны, играющие роль оснований деления в классифицировании понятий. В приведённом примере за мероны птицы принимаются все выделенные части тела. Относительно только одного мерона, такого как крыло, к птицам можно отнести и летучую мышь. Поэтому для определения принадлежности архетипу особи сопоставляются по всем меронам. Если же их не хватает для выявления сходства / различия особей, добавляются дополнительные мероны, либо детализируются уже выбранные мероны.

При отвлечении архетипа от живой природы он может использоваться и для классифицирования объектов искусственной природы. Например, архетип птицы можно обобщить в архетип «летательные объект», если голову птицы представить как орган управления, туловище, как корпус, ноги, как орган контактирования с земной (или водной) поверхностью. К этому архетипу относится и такой искусственный объект, как самолёт, имеющий наряду с крыльями и хвостовым оперением орган управления, конкретизированный кабиной пилота, корпус - фюзеляжем и орган контактирования с поверхностью - шасси. Такая аналогия с птицей и послужила идеей для изобретателей первых летательных аппаратов.

Идея архетипа, как обобщённого представителя класса, успешно используется в таких задачах распознавания образов, как распознавание рукописных символов (букв, цифр и пр.) и многих других.

\section{5 Характеристика классификаций}

Классификация, как результат классифицирования объектов ПрО, характеризуется некоторой совокупностью свойств, систематизированных следующим образом:

1) относительно подхода к целостности системы

а. внутренняя система;

b. внешняя система;

2) относительно природы классифицируемых объектов

a. естественная классификация;

b. искусственная классификация;

3) по числу классов 
a. известное;

b. неизвестное;

4) по форме представления

a. табличная;

b. графовая;

5) по структуре связей между классами

a. древообразная;

b. сетевая;

6) по степени обоснованности

a. научная;

b. эмпирическая.

Внутренний подход состоит в том, что исходная целостность мыслится как нерасчленённая, а присущая ей организация позволяет выделять в ней естественные членения на компоненты, которые сами могут рассматриваться как системы [12]. Примером внутренней системы является система понятий ПрО, полученная многократным делением выбранного родового понятия.

При внешнем подходе к выявлению целостности она мыслится не как возможность естественного членения на компоненты, но как возможность естественного объединения в классы заранее имеющихся объектов. Общность этих объектов состоит в наличии у них единой природы, позволяющей естественным образом сопоставлять между собой эти объекты и образовывать из них естественные классы. Примером внешней системы является биологическая систематика птиц.

Естественная классификация отражает объективные законы природы. Она может быть как внутренней (систематика химических элементов), так и внешней (систематика птиц). Искусственная классификация отражает системность объектов искусственной природы, создаваемых человеком. Искусственным происхождением объясняется и фиксированное (известное) число классов. Оно неизвестно при экспериментальном подходе к созданию классификации. Пример табличной классификации представлен в таблице 1.

Таблица 1 - Табличная классификации по двум основаниям деления

\begin{tabular}{|l|c|c|}
\hline Ф1 12 & Внутренняя & Внешняя \\
\hline Естественная & Е, Вн & Е, Вш \\
\hline Искусственная & И, Вн & И, Вш \\
\hline
\end{tabular}

В качестве оснований деления для формирования двух фасет с координатными понятиями выбраны: природа классифицируемых объектов (Естественная (Е)/ Искусственная (И)) и отношение к целостности ПрО (Внутренняя (Вн) / Внешняя (Вш)). В клетках таблиц приведены межвидовые понятия, сформированные объединением координатных понятий из разных фасет.

Табличная форма классификации может быть преобразована в ранжированный (иерархический) граф с корневой вершиной классификация, если принять межвидовые понятия за терминальные вершины графа, а координатные понятия - за вершины промежуточного уровня графа. Поскольку полустепени захода терминальных вершин равны двум, граф имеет сетевую структуру связей между понятиями. В графе типа дерево все промежуточные и терминальные (висячие) вершины имеют полустепень захода, равную единице.

К научным следует относить научно обоснованные классификации, отражающие закономерности ПрО. Не обладающие этими свойствами классификации имеют эмпирический характер. Надо отметить, что любая классификация, имеющая опытное или теоретическое начало, подвергается многократной доработке для того, чтобы отразить закономерности 
ПрО. Именно так обстояло дело и с периодической системой химических элементов, предложенной Д.И. Менделеевым и усовершенствованной его последователями.

\section{6 Классификация как разновидность системы}

Определённый парадокс заключается в различии терминов классификация и система при ссылке в качестве примера классификации на периодическую систему химических элементов Д.И. Менделеева, приводимой во всех источниках.

Для нахождения соотношения между классификацией и системой рассмотрим модель cucmeмbl. В [16] система определена как «целостность, определяемая некоторой организующей общностью». Система как совокупность элементов, находящихся в определенных отношениях друг с другом и со средой [17], может быть представлена реляционной системой [6]:

$$
\mathrm{M}_{\mathrm{str}}=\langle\mathrm{A}, \mathrm{R}\rangle \text {. }
$$

Здесь $A$ - множество компонентов (элементов) системы $A=A_{s} \cup A_{e}$,

$A_{s}-$ множество компонентов (элементов) системы, выделенных из их общей совокупности A,

$A_{e}$ - множество объектов, отнесённых к среде,

$R$ - множество отношений, отражающих внутренние $R_{s}$ и внешние $R_{e}$ связи системы: $\mathrm{R}=\mathrm{R}_{\mathrm{s}} \cup \mathrm{R}_{\mathrm{e}}$.

Согласно формуле (15) модель $\mathrm{M}_{\text {str }}$ отражает многообразие связей между элементами системы, отражая её структурный аспект. Многообразие связей является одним из признаков, характеризующих сложность системы.

Применительно к онтологии ПрО множество А представляет собой совокупность используемых в ней понятий. Множество отношений $R$ охватывает как общесистемные связи между понятиями (общее-частное (наследования), часть-целое (партитивную), причинноследственную (каузальную), функциональную, алфавитную и др.), так и связи, специфические для конкретной ПрО.

Поскольку для деления объёмов понятий используется отношение общее-частное между понятиями ПрО, классифицирование на основе одного отношения решает частную задачу систематизации понятий ПрО, и в этом смысле находится к ней в отношении «частноеобщее» [18]. В этом смысле классификационная система (классификация) представляет собой хотя и важнейшую, но только часть онтологии ПрО.

Почему же таблица Менделеева носит название $c$ стемел, а не классификации? Да потому, что на множестве свойств химических элементов устанавливается не только отношение общее-частное, но и отношение порядка на атомных массах (весах) элементов и периодах таблицы.

Номер столбца в таблице определяет квантовую структуру верхней оболочки атома, благодаря чему элементы этого столбца и обязаны сходством химических свойств, образуя относительно них класс. Номер строки в таблице определяет число электронных оболочек атома. В строке таблицы устанавливается разнонаправленное отношение порядка по атомному радиусу, энергии ионизации и электроотрицательности. Именно комплекс отношений на свойствах химических элементов обеспечил огромную роль периодической системы химических элементов Д.И. Менделеева в дальнейших исследованиях о строении материи.

\section{Заключение}

Во всех цитированных работах по классификации отмечается их важная роль в познавательной и предсказательной деятельности. По мнению Ж.Б. Ламарка «всякая наука начина- 
ется с классификации», а по мнению Д.И. Менделеева «наука начинается там, где начинают измерять». Кажущееся противоречие этих высказываний о начале науки исключается, если обобщить измерения на номинальную шкалу. Именно, в номинальной шкале, т.е. именами, и измеряются классифицируемые понятия. Это указывает на важнейшую роль терминологии в познавательной деятельности. В этом смысле плохую роль в понимании классификаций сыграла неоднозначность этого термина. Он трактуется и как процесс, и как результат процесса, т.е. порождает сам себя.

Предложенное в работе именование процесса создания классификации классифицированием позволило рассмотреть раздельно и систематизировать свойства методов классифицирования и самих классификаций.

Для правильного классифицирования объектов важно выбрать адекватную методу создания классификации модель формирования класса, что показано на конкретном примере. Предложенные в работе модели должны облегчить такой выбор.

Цитированные определения классификации отражают, по существу, только нисходящий подход к их созданию, не затрагивая восходящее проектирование классификаций на основе экспериментальных данных. Между тем, эти подходы равноправны и дополняют друг друга. Для восходящего проектирования классификаций предложены таксономические модели формирования класса.

Ключевой задачей в создании классификации является способ нахождения свойств классифицируемых объектов. Они могут выявляться умозрительным путём на основе умозаключений и доказательств их истинности, либо опытным путём на основе проведения экспериментов и их теоретических обобщений. По существу, эти подходы различаются лишь отправной точкой исследования - от теории или от практики. Использование архетипа оказалось эффективным средством выявления сходства / различия сложных объектов.

В цитированных источниках только естественные классификации рассматриваются как научные. Однако помимо законов природы существуют законы человеческого мышления, изучаемые философией, психологией и реализуемые системным анализом. Поэтому, на наш взгляд, к научным можно относить и те искусственные классификации, которые согласуются с этими законами. Непременными условиями научности следует также считать соответствие частных целей классификации её общей цели и подтверждение практикой. В отличие от научных эмпирические классификации не отвечают этим требованиям.

Классификации как системы, отражающие только отношение «общее-частное» на множестве свойств объектов, являются важным начальным этапом создания онтологии ПрО. Однако изучение функциональных, порядковых, причинно-следственных и других закономерностей ПрО требует применения соответствующих видов отношений. Применение дополнительных отношений и обеспечило успех периодической системы химических элементов Д.И. Менделеева в познании свойств материи.

\section{Благодарности}

Работа поддержана Программой фундаментальных исследований Отделения нанотехнологий и информационных технологий РАН (проект № 0073-2015-0007) в рамках бюджетной темы № 0073-2014-0009.

Автор благодарен редколлегии журнала за должное внимание к указанной проблеме и приглашение к дискуссии (том 5, № 4, 2015, с. 456). 


\title{
Список источников
}

[1] Резник, Ю.М. К феноменологии возможных миров человека: экзистенциальная онтология проектирования / Ю.М. Резник // Онтология проектирования. - 2015. - Т. 5, №4(18). - С. 450-462. doi: 10.18287/2223-95372015-5-4-450-462.

[2] Философская энциклопедия. Под редакцией Ф.В. Константинова. В 5-ти томах. - М.: Советская энциклопедия. 1960-1970.

[3] Философский энциклопедический словарь. Гл. редакция: Л.Ф. Ильичёв, П.Н. Федосеев, С.М. Ковалёв, В.Г. Панов. - М.: Советская энциклопедия. 1983.

[4] Новая философская энциклопедия. Под редакцией В. С. Стёпина. В 4-х томах. - М.: Мысль. 2001.

[5] Философия: Энциклопедический словарь. Под редакцией А.А. Ивина. - М.: Гардарики. 2004.

[6] Микони, C.B. Дискретная математика для бакалавра: множества, отношения, функции, графы. - СПб.: Лань, 2012. 192 с.

[7] Статья «Понятие». Большая Советская Энциклопедия. 3-е изд. т. 25. -М.: Изд-во БСЭ, 1976. - С. $473-474$.

[8] Микони, $\boldsymbol{C . \boldsymbol { B }}$. Теория принятия управленческих решений: Учебное пособие. - СПб.: Лань, 2015. - 448 с.

[9] Zadkh, L.A. Toward perseption-based theory of probabilistic reasoning with imprecise probabilities // Сборник докладов Междунар. конф. по мягким вычислениям и измерениям SCM'2003. -СПб.: Изд-во СПбГЭТУ «ЛЭТИ», 2003, С. 69-75.

[10] Загоруйко, Н.Г. Прикладные методы анализа данных и знаний. - Новосибирск: Изд-во института математики, 1999. - 270 с.

[11] Микони, С.B. Модели и базы знаний. Учебное пособие. - СПб.: ПГУПС, 2000. - 154 с.

[12] Микони, С.В., Ходаковский, В.А. Основы системного анализа: Учебное пособие. - СПб.: ПГУПС, 2011. $142 \mathrm{c}$.

[13] Лотmе,Д.С. Основы построения научно-технической терминологии. - М.: Изд-во АН СССР, $1961 .-157$ с.

[14] Сложеникина, Ю. В. Основы терминологии. - М.: Книжный дом «Либроком», 2013. 120 с.

[15] Микони C.B., Чахирева АЛ. Формализованный язык для определения понятий // Научно-техническая информация. Сер.2. 1987. № 1. - С. 23-27.

[16] Шрейдер, Ю.А., Шаров $\boldsymbol{A . A . ~ С и с т е м ы ~ и ~ м о д е л и . ~ - ~ М . : ~ Р а д и о ~ и ~ с в я з ь , ~ 1 9 8 2 . ~ - ~} 151$ с.

[17] Берталанфи,Л. Общая теория систем: Критический обзор // Исследования по общей теории систем. - М.: Прогресс, 1969. - С. 23-82.

[18] Микони, $\boldsymbol{C}$.B. Роль и место классификаций в системном анализе // Труды IV-й Международной конференции «Системный анализ и информационные технологии». - Челябинск: Изд-во ЧГУ, 2011, Том 2, - С.39-42.

\section{ABOUT THE CLASS, CLASSIFICATION AND SYSTEMATIZATION}

\section{S.V. Mikoni}

St. Petersburg Institute for Informatics and Automation of the Russian Academy of Sciences, St. Petersburg, Russia smikoni@mail.ru

\begin{abstract}
We consider a few classification definitions and explanations in domestic sources. It detected the ambiguity of the classification term. He refers to both the process and its result. It is proposed to call these concepts are different terms. In order to eliminate a number of uncertainties in the interpretation of classification, its methods and systematization of knowledge offered to attract mathematical models of class and system. The models of the formation of classes, used by different methods of classifying objects are considered. Classifying methods properties and classifications obtained on the basis of classifying methods are systematized. Mathematical model of dividing the volume of the concepts is discussed. Wrong choice of the class model is shown on a concrete example. Inductive methods of classifying objects and archetype method are considered. The system model is used to distinguish the processes of classification and systematization. It is illustrated by the example of the Mendeleev periodic system of chemical elements. Classification concepts are refined.
\end{abstract}

Keywords model, class, classification, periodic table, system, systematization, concept division, taxonomy.

Citation: M ikoni SV. About the class, classification and systematization. O ntology of designing. 2016; 6(1): 67-80. DOI: 10.18287/2223-9537-2016-6-1-67-80. 


\section{References}

[1] Rernik YM. To a phenomenology of possible human worlds. Ontology of designing. 2015; 5(4): 450-462. doi: 10.18287/2223-9537-2015-5-4-450-462. (In Russian).

[2] Filosofskaya Entsiklopediya Pod redaktsiyey F. V. Konstantinova. [Philosophical Encyclopedia. Edited by F.V. Konstantinov] V 5-ti tomakh. -M.: Sovetskaya entsiklopediya. 1960-1970. (In Russian).

[3] Filosofskiy entsiklopedicheskiy slovar'. Gl. redaktsiya: L. F. Il'ichov, P. N. Fedoseyev, S. M. Kovalev, V. G. Panov [Philosophical Encyclopedic Dictionary. Chief Editorial: L.F. Ilichev, P.N. Fedoseyev, S. Kovalev, V.G. Panov] M.: Sovetskaya entsiklopediya. 1983. (In Russian).

[4] Novaya filosofskaya entsiklopediya. Pod redaktsiyey V. S. Stepina [The New Encyclopedia of Philosophy. Edited by V.S. Stepin] V 4-kh tomakh. -M.: Mysl'. 2001. (In Russian).

[5] Filosofiya: Entsiklopedicheskiy slovar'. Pod redaktsiyey A.A. Ivina [Philosophy Encyclopedic Dictionary. Edited by A.A. Ivin] -M.: Gardariki. 2004. (In Russian).

[6] Mikoni SV. Diskretnaya matematika dlya bakalavra: mnozhestva, otnosheniya, funktsii, grafy. [Discrete Mathematics for Bachelor: sets, relations, functions, graphs]. SPb .: Lan, 2012. 192 p. (In Russian).

[7] Stat'ya «Ponyatie» [Article "Concept"]. Great Soviet Encyclopedia. 3rd ed. m. 25 - M .: Publishing House of the TSB, 1976: 473-474. (In Russian).

[8] Mikoni SV. Teoriya prinyatiya upravlencheskih reshenij: Uchebnoe posobie [Theory of administrative decision making: A Tutorial] -SPb.: Lan', 2015. - 448 p. (In Russian).

[9] Zadkh LA. Toward perseption-based theory of probabilistic reasoning with imprecise probabilities // Cbornik dokladov Mezhdunarodnoj konferencii po mjagkim vychislenijam i izmerenijam SCM'2003. - SPb.: Izd-vo SPbGEhTU «LEhTI», 2003: 69-75.

[10] Zagonuyko NG. Prikladnyye metody analiza dannykh i znaniy [Applied methods of data mining and knowledge analisys] -Novosibirsk: Izd-vo instituta matematiki, 1999. - 270 p. (In Russian).

[11] Mikoni SV. Modeli i bazy znanij. Uchebnoe posobie. [Model and Knowledge Bases. Tutorial]. - SPb.: PGUPS, 2000. -154 p. (In Russian).

[12] Mikoni SV, Khodkkouskijj VA. Osnovy sistemnogo analiza. Uchebnoe posobie. [Bases of the system analysis. Tutorial] - SPb.: PGUPS, 2011. -142 p.

[13] Lotte DS. Osnovy postroeniya nauchno-tehnicheskoj terminologii [Bases of creation of scientific and technical terminology] - M.: Izd-vo AN SSSR, 1961. - 157 p. (In Russian).

[14] Slozhenikina YV. Fundamentals of terminology. M.: Book House "LIBROKOM", 2013. 120 p. (In Russian).

[15] Mikoni SV, Chahireva AL. Formalizovannyi yazyk dlya opredeleniya ponyatii [The formalized language for definition of concepts] // Nauchno-tehnicheskaya informaciya. Ser. 2. 1987. № 1: 23-27. (In Russian).

[16] Shrejjder J uA, Sharov AA. Sistemy i modeli. [Systems and models]. -M.: Radio i svjaz', 1982. - 151 p. (In Russian).

[17] Bertalanffy L. Obshhaja teorija sistem: Kriticheskijj obzor [General Systems Theory: A Critical Review // Research on general systems theory.] // Issledovanija po obshhejj teorii sistem. - M.: Progress, 1969: 23-82. (In Russian).

[18] Mikoni SV. Rol' i mesto klassifikacijj v sistemnom analize [The role and place of classifications in the system analysis] // Trudy IV-j Mezhdunarodnoj konferencii «Sistemnyj analiz i informacionnye tekhnologii», Cheljabinsk: Izd-vo ChGU, 2011. Vol 2: 39-42. (In Russian).

\section{Сведения об авторах}

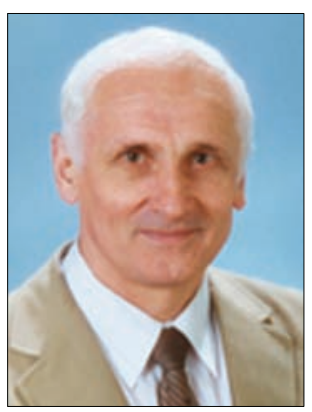

Микони Станислав Витальевич, 1936 г. рождения. Окончил Ленинградский институт инженеров железнодорожного транспорта им. Образцова в 1963 г., д.т.н. (1992), професcop (1994), ведущий научный сотрудник Санкт-Петербургского института информатики и автоматизации РАН. Член Российской ассоциации искусственного интеллекта. В списке публикаций более 270 работ, из них 2 монографии и 7 учебных пособий в области технической диагностики, дискретной математики, системного анализа, теории принятия решений, искусственного интеллекта.

Mikoni Stanisav Vitalievich (b. 1936) graduated from the Obraztsov Institute of Engineers of Railway Transport (Leningrad) in 1963, D. Sc. Eng. (1992). Professor (1994). He is Russian Association of Artificial Intelligence member. He is author and co-author of more than 270 publications in the field of technical diagnostic, discrete mathematic, system analyses, artificial intelligence, decision making theory. 


\title{
СОПОСТАВЛЕНИЕ ПОНЯТИЙ ПРОЕКТ, ПРОЕКТИРОВАНИЕ И ПРОЕКТИРОВОЧНАЯ ДЕЯТЕЛЬНОСТЬ: ИСТОРИЧЕСКИЙ, ЭТИМОЛОГИЧЕСКИЙ И ГНОСЕОЛОГИЧЕСКИЙ АСПЕКТЫ
}

\author{
Е.М. Кочнева \\ Нижегородский государственный педагогический университет им. Козьмы Минина \\ (Мининский университет), Нижний Новгород, Россия \\ e.m.kochneva@yandex.ru
}

\begin{abstract}
Аннотация
В статье сопоставляются понятия «проект», «проектирование» и «проектировочная деятельность» с целью обозначения их понятийного пространства, раскрытия сущности их использования разными науками. Приводятся подтверждения имплицитного присутствия структурных компонентов проектирования в различных философских и психолого-педагогических учениях о сущности психологической активности человека и видах его познавательно-деятельностной активности. На основе анализа работ философов разных исторических эпох обозначены онтологический и гносеологический аспекты предмета проектирования как опережающего отображения и порождения будущего. Выделены и определены основные терминологические дефиниции, необходимые для психологического анализа рассматриваемых понятий. На основе анализа историко-этимологической обусловленности использования понятий «проект» и «план» («проектирование» и «планирование») в русском языке выявлены сущностные различия в употреблении данных понятий и показано, что проектирование как процесс в рамках проектировочной деятельности является конкретной формой проявления прогностических функций человека. Приведены понятия, которые автор предложил включить в формируемый «словарь проектанта».
\end{abstract}

Ключевые слова: проект, проектирование, проектировочная деятельность, психологическая активность человека, образ, категориальный анализ.

Цитирование: Кочнева, E.M. Сопоставление понятий проект, проектирование и проектировочная деятельность: исторический, этимологический и гносеологический аспекты / Е.М. Кочнева // Онтология проектирования. - 2016. - Т.6, №1(19). - С. 81-94. - DOI: 10.18287/2223-9537-2016-6-1-8194.

\section{Введение}

«Категориальный аппарат - это сложно организованный инструмент исследовательского труда. Он существует только тогда, когда работает, добывая новое знание» [1]. На этапе становления научного направления задача разработки категориально-понятийного аппарата является первостепенной. Сложность решения этой задачи для «интегративной» научной дисциплины «Онтология проектирования» обусловлена тем, что нужно не только «определить область исследований», но и «обозначить её место в уже сложившейся и существующей дифференциации наук» [2, с. 7].

Разработка категориально-понятийного аппарата научного направления «Онтология проектирования» усложнена ещё и тем, что в настоящее время существуют проблемы, которые могут помешать «продуктивному диалогу» в процессе формирования «предметной области исследования». Вот некоторые из них.

- Проблема неправомерного использования иностранных терминов в русском языке и в научных работах отечественных авторов [3]. 
- Проблема качества научных исследований [4], проявляющаяся в низкой культуре представления результатов исследований и отсутствии описаний авторского понимания тех или иных терминов в научных публикациях.

- Проблема необдуманного заимствования терминов из разных научных направлений и отраслей, использования терминов при отсутствии категориального анализа, в результате чего могут возникнуть категориальные ошибки и смысловая неопределённость. Исследователям нужно помнить о том, что каждая научная категория, «подобно другим развивающимся формам, содержит в свёрнутом, «снятом» виде всё ценное, найденное в «муках творчества» теми, кто в былые эпохи отважился на поиск истин о психическом мире» [1]. Например, категория действия в исторической перспективе претерпела множество преобразований. В теоретическом плане это получило отображение в следующих понятиях: «интенциональный акт сознания (функциональная психология), отношение «стимул-реакция» (бихевиоризм), условный рефлекс (И.П. Павлов), компонент сенсомоторных структур (Ж. Пиаже), инструментальный семиотически опосредованный акт (Л.С. Выготский)» [1].

В этой связи представляет интерес сопоставление понятий «проект», «проектирование» и «проектировочная деятельность» с целью обозначения их понятийного пространства, раскрытия сущности их использования различными науками и обоснования необходимости рассмотрения в психологии особого самостоятельного конструкта «проектировочная деятельность». Для подтверждения имплицитного присутствия структурных компонентов проектирования в различных философских и психолого-педагогических учениях проведён анализ философских учений по двум направлениям:

- анализ работ, рассматривающих прогностическую функцию сознания и сущность психологической активности человека;

- анализ работ, рассматривающих категорию «образ» как форму отображения объектов в сознании человека.

\section{1 Историко-философское понимание сущности психологической активности человека}

В Упанишадах (философские воззрения Древней Индии), обсуждались фундаментальные проблемы: место и назначение человека в системе окружающего бытия, природа внешнего мира и человека, характер его жизни и психики, границы и возможности его познавательных способностей, нормы его поведения и признавалась ответственность человека за происходящее с ним. Среди многих вопросов о природе, человеке и познании в Упанишадах упоминалось о познании искусства предсказания (развитие прогностических способностей человека). «Поистине познанием познают ... правила почитания предков, науку чисел, искусство предсказаний, хронологию, логику, этимологию» [5].

В Китайской философии - Лао-Цзы, Конфуций, Ван Чун и др. - провозглашали созерцательное отношение к действительности, влияние фатализма («судьбы») на индивидуальную и общественную деятельность людей. Мо-Цзы и поздние моисты (IV-III вв. до н.э.), наоборот, влияние «судьбы» не признавали [5].

Аристотель обосновал целенаправленность человеческой деятельности и её причинное объяснение [6].

Анализ взглядов философов Средневековья на природу человека, его активность и ответственность за свою жизнь показал, что:

- человек не ответственен за происходящее с ним; «Бог всемогущ и всё в мире предопределено, и действия, и судьбы людей» (Августин) [5, с. 581-605]; разум подчинён вере, 
вера направляет движения разума (Фома Аквинский) [5, с. 823-862]; и, наоборот, подчёркивалась ценность и роль человека (И.С. Эриуген) [5, с. 787-794]; независимость веры от разума (У. Оккам) [5, с. 890-907];

- признавая Бога началом и причиной всего сущего, некоторые философы (Езник Кохбаци [5, с. 631-633]; И. Дамаскин [5, с. 621-626]) выступали против фатализма и отстаивали учение о свободе воли, выделяли волевой акт, оказывающий влияние на жизненную перспективу человека;

- некоторые философы признавали опыт (опытность) человека в контексте познания (Д. Анахт [5, с. 634-639]; Р. Бэкон [5, с. 862-877]).

В эпоху Возрождения философская мысль снова обратилась к человеку и широко использовала наследие Античного мира. На первый план вышла проблема человека, определившая гуманистическую направленность философии. Важнейшей ценностью признавалась земная жизнь человека, его всестороннее развитие, человеческое счастье, любовь. Достижение гармонии в земной жизни становилось смыслом жизни человека (Данте Алигьери, Дж. Бруно, Н. Кузанский, М. Монтень, Ф. Патрици, Ф. Петрарка, Э. Роттердамский, Д. Юм и др.) [7].

Человек, опираясь на свободную волю, мог стать своим собственным «скульптором и творцом». Так Т. Мор в «Утопии» провозглашал право человека на выббор любого ремесла, к которому он «питает склонность от природы» [7, с. 97-112]. Человек благоразумен, если умеет «предвидеть выгодное для себя и избегать невыгодного» (Л. Балла) [7, с. 77-84]. А в «Городе солнца» Т. Компанеллы [7, с. 184] можно найти должностное лицо «перспективист». Э. Роттердамский [8] мечтал пробудить человеческое в человеке, М. Монтень [7, с. 137-141] призывал высоко иченить самостоятельность и не идти слепо за авторитетами, а И.С. Пересветов [7, с. 135137] писал о свободе и справедливости.

Анализ воззрений философов эпохи Просвещения на проблему человека и человека в мире, показал, что:

- одним из первых провозгласил, что история - дело самих людей, и целиком на них лежит ответственность за неё, был М.Ф. Аруэ (Вольтер), именно ему принадлежит призыв «Осмельтесь мыслить самостоятельно» [7, с. 545-558];

- о влиянии личностной позиции человека, его активности, самостоятельности, ответственности за его жизнь писали Дж. Беркли [7, с. 507-530], П.А. Гольбах [7, с. 665-685], Д. Юм [7, с. 574-609];

- К.А. Гельвеций признавал сознание и ценностно-смысловое объяснение природы существования человека главной движущей силой общественного развития [7, с. 621-635];

- о важности побудительных мотивов деятельности, потребностей и самопознания в жизни человека писали П.А. Гольбах [7, с. 665-685], Ж.О. де Ламетри [7, с. 609-621], Ш.Л. Монтескье [7, с. 536-545].

Сущность психологической активности человека в работах философов конца XVIII - ceредины XIX вв. обнаружилась в следующих идеях и положениях.

- Человек свободен от каких бы то ни было ограничений и имеет право на самоопределение (Г.В.Ф. Гегель, Э. Дембовский, Г. Каменский, А. Руге, Л.А. Фейербах, И.К. Фихте, А. Цешковский, Ф.В.Й. Шеллинг, М. Штирнер и другие) [9].

- Человек должен стремиться к совершенствованию активно и целенаправленно действуя (А. Руге, И.К. Фихте, Ф.В.Й. Шеллинг). В частности А. Руге писал: «Самоцели нельзя достигнуть абстрактно, а можно только в связи с уже достигнутой внешней действительностью» [9, с. 414].

- Положено начало обсуждению содержания системы «человек - мир» (Л.А. Фейербах) [9, c. $440-490]$. 
- Обосновано влияние творчества, инициативности и активности на способность и возможность человека творить своё будущее (Г. Каменский, Э. Дембовский) [9, с. 428-440].

Главная цель философии, по мнению западных философов периода со второй половины XIX в. до XX в., представлявших множество школ, направлений и концепций, заключалась в том, чтобы помочь человеку в потоке опыта двигаться по направлению к поставленной цели и достигать её [10].

Таким образом, обобщая воззрения философов разных исторических эпох на понимание сущности психологической активности человека, его взаимоотношения с миром, следует констатировать, что события будущего в разные исторические периоды ставились в зависимость от:

- уровня моральности человека («Упанишады», Древняя Индия);

- влияния Бога, «всё в мире предопределено» (Средневековье);

- индивидуальных особенностей человека, таких как благоразумие, самостоятельность, право на выбор и личной позиции человека (Эпоха Возрождения и Эпоха Просвещения);

- осознания свободы и права на самоопределение (философия конца XVIII - середины XIX вв.);

- личностно-исторического характера времени и его связи с человеческой деятельностью (экзистенциализм второй половины XIX и до XX в.).

\section{2 Образ как форма отображения объектов в сознании человека}

Первые упоминания о восприятии предметов окружающего мира и их образов можно найти в работах философов Древней Индии (IX-VI века до н.э.) и Древнего Китая (IV-III вв. до н. э.). «Подобно тому... как по одному комку глины узнаётся всё сделанное из глины, [ибо всякое] видоизменение - лишь имя, основанное на словах, действительное же - глина; ...(Чханд. VI. 1.4-6)»; «[Все] это было тогда неразличимо. Он стал различим по имени и образу... Ведь поныне [все] различимо по имени и образу (Брихад. I. 4. 7.).» [5, с. 89]. «Познающий, обладая способностью к знанию и сталкиваясь с вещами, может представлять себе их образ, как будто он сейчас видит эти вещи (гл. «Пояснение к Канону», ч. I)» [5].

Первой «теорией отражения» человеческим сознанием внешнего мира или первой целостной концепцией психического образа, как отмечает С.Д. Смирнов, можно назвать теорию имитирующей репрезентации Эмпедокла, Демокрита и Эпикура [11].

Аристотель ввёл представление об образе и воображении для объяснения связи между мышлением и чувствами, истинными знаниями и ощущениями [1].

Проблема восприятия и отражения предметов окружающего мира продолжала интересовать философов и в эпоху Средневековья (Ф. Аквинский, Авиценна, Д. Динанский, У. Оккам и др.). «Образ - интуитивное знание» (У. Оккам) [5, с. 899].

Познанием окружающего мира посредством восприятия, ощущений, памяти, разума, опыта занимались философы эпохи Возрождения (Т. Кампанелла, Леонардо да Винчи, Н. Кузанский, Т. Мор и др.).

В эпоху Просвещения Д. Юм определял идеи как результат чувственных впечатлений, копии, схваченные умом, которые остаются после того, как прекратятся впечатления. Согласно этому подходу, образ - это не только икона, но и отпечаток, вызываемый оригинальным объектом [7, с. 574-609].

И. Кант использовал образ, трансцендентальные схемы и продуктивное воображение для объяснения существования двух основных стволов человеческого познания, «вырастающие, быть может, из одного общего, но неизвестного нам корня, а именно чувственность и рассу- 
док» и понимал (трактовал) образ как: «непосредственный образ некоего сущего»; «наличный отображающий вид некоего сущего»; «вид чего-то вообще» [9, с. 124].

Таким образом, категория образа являлась «формой и инструментом» работы исследователя во все времена. Но данная категория «не работает вне системы других. За явленным сознанию предметным образом скрыты предметные действия, мотив, к нему побуждающий, отношение субъекта к другим людям, а также личная значимость и переживание информации, свернутой в образе - чувственном и умственном» [1].

Однако обозначение Г.В.Ф. Гегелем прототипа (образа) схемы проектировочной деятельности, т.е. выделение элементов (создание образа результата; влияние образа результата на субъекта, реализующего деятельность; оценка внутренних возможностей) [9, с. 282-394]; раскрытие У.Х. Килпатриком понятия проект как результата деятельности [12]; использование Д. Дьюи и У.Х. Килпатриком проектирования как особого вида профессиональной деятельности позволили выделить гносеологический аспект предмета проектирования, т.е. описать отношение проектирования к объективной действительности.

\section{3 Сопоставление понятий «проектировочная деятельность» и «проектирование»}

Сопоставление понятий «проектировочная деятельность» и «проектирование» в контексте психологического изучения роли проектирования в профессиональной деятельности человека, проведено на основе:

- анализа научных публикащий отечественных педагогов и психологов, в трудах которых использовалось понятие «проектирование»:

- проектирование психологического образования педагогов и труда учителя (Е.И. Исаев [13], В.И. Стрелков [15]);

- проектирование образовательного процесса в средней и высшей школе (С.А. Жемулин [14, с.63-89], Н.Г. Зверева [14, с. 151-182], И.Н. Кроткова [14, с. 118-150], А.А. Михайлов [14, с. 37-62], Г.Е. Муравьева [14, с. 7-36] и др.);

- социально-психологическое проектирование в педагогике (Ю.Н. Емельянов [16]);

- экспертиза, проектирование и мониторинг образовательной среды (В.А. Ясвин [17]);

- психологическое проектирование производственной организации (А.А. Грачев [18]) и др.;

- определения семантического пространства понятия «проектирование» (планирование, моделирование), выделения сходства и различия между родственными понятиями;

- дефиниций, относящихся к категории «деятельность» (субъект, потребности, мотивы, цели, ценности, антиципация, вероятностное прогнозирование, готовность субъекта к профессиональной деятельности), которые позволили осуществить категориальный анализ понятий «проектировочная деятельность» и «проектирование», определить уровень их теоретической и практической разработанности в психологической науке и практике.

В контексте исследования важным научным положением явилось то, что в философии базовая категория, как «родовое понятие», может быть конкретизирована посредством видовых характеристик. В психологии общественно-историческая категория деятельности, к которой отечественные учёные обратились одними из первых, конкретизирована посредством обозначения видов деятельности человека (игровая, учебная, трудовая и т.д.), выделения структуры деятельности: мотивы (побудительные силы); иели (образы результатов); средства и сам процесс деятельности, в котором выделяют целенаправленные действия обеспечивающие достижение необходимого результата [19, с. 166-169]. 
Чтобы избежать категориальных ошибок отнесения фактов, соответствующих одной категории к некоторой другой, в нашем случае категории «деятельность» и категории «процесс», анализировались принципиальные сходства и принципиальные различия понятия «проектировочная деятельность» и понятия «проектирование».

Проектировочная деятельность и проектирование имеют во многом сходство по структурным составляющим (цель, мотивы, средства, способы, действия, результаты).

На основе анализа определений, представленных в различных словарях, сходство понятий «проектирование» и «проектировочная деятельность» обусловлено, возможно, тем, что:

- образ конечного результата и там, и там будет носить вероятностно-прогностический характер;

- отмечается некоторая общность в завершающем этапе (рефлексивно-оценочном), поскольку и там, и там рефлексируются результаты, позволяющие выстраивать последующую активность субъекта [20].

Различаются данные понятия по степени (уровню) максимальной осознаваемости в категории «проектировочная деятельность» и наличие недостаточно осознаваемых компонентов в проектировании как одной из форм психической активности [21-23]. Отличительной особенностью понятий «проектировочная деятельность» и «проектирование» является ещё и полнота технологического обеспечения. Любая деятельность требует высокого уровня технологического обеспечения, так как она протекает в пространственно-временной протяжённости «здесь и сейчас».

\section{4 История использования терминов «проект» и «проектирование» в русском языке}

Слово проект впервые появилось в русском языке во времена Петра I, его можно встретить в документах конца XVII - начала XVIII века в значении предложение, намерение. В эпоху правления Екатерины II использовался глагол проектировать в значении план, намерение, замысел осуществления, проведения в жизнь какого-либо нововведения, предприятия. В конце XVIII - начале XIX вв. термин проект используется в значении «главное, определяющее положение в системе взглядов, воззрений, основной существенный принцип мировоззрения», а с конца XIX - начала XX вв. - как «принцип устройства чеголибо» $[24$, с. 70$]$.

В толковом словаре русского языка [25, с. 628] даётся три значения термина проект:

- разработанный план сооружения, какого-нибудь механизма, устройства, включающий в себя описание, чертежи, макеты и т.п.;

- предварительный текст какого-нибудь документа, представляемый на обсуждение, утверждение;

- замысел, план.

В современной научной литературе понятия «проект» и «проектирование» имеют многоаспектное и многофункциональное толкование, которое, с одной стороны, указывает на многообразие подходов к данным понятиям, с другой - подчёркивается, что очертить границы целостной проектировочной деятельности достаточно сложно, поскольку она лежит в плоскости новой «самоопределяющейся» и труднопредсказуемой действительности [26].

В инженерно-технической и архитектурно-строительной сферах проектирование рассматривается как разработка комплексной технической документации (проекта), содержащей технико-экономическое обоснование, расчёты, чертежи, макеты, сметы, пояснительную записку и другие материалы, необходимые для строительства (реконструкции) каких-либо объектов. Проект - совокупность конструкторских документов, содержащих принципиаль- 
ное (эскизный проект) или окончательное (технический проект) решение, дающее необходимое представление об устройстве создаваемого сооружения (изделия) и исходные данные для последующей разработки рабочей документации. Следовательно, в проектировании отмечается два варианта: первый - создание какого-либо объекта, второй - разработка процесса, т.е. совокупность действий для достижения результата. Многообразие методов проектирования обуславливается разнообразием целей, объектов и средств проектирования [27].

В отличие от инженерно-технической и архитектурно-строительной сфер, в которых данные понятия трактуются с большой степенью определённости и предполагают более чёткие и конкретные дефиниции, в гуманитарных областях знаний представлено общее, нестрогое понимание данных понятий. Так в социологическом энциклопедическом словаре проектирование понимается как «одна из форм опережающего отражения действительности; процесс создания прообраза (прототипа) предполагаемого объекта, явления или процесса посредством специфических методов. Социальное проектирование - научно-обоснованное конструирование системы параметров будущего социального объекта или качественно нового состояния существующего объекта; одна из форм социального управления» [28].

По своей сущности проектирование охватывает практически все сферы деятельности человека и общества, тесно взаимодействуя, с одной стороны, с предвидением и прогнозированием, с другой - с планированием, конструированием и др. функциями управления деятельностью человека. В современных условиях всё более насущной проблемой становится проектирование социальных систем, которое в принципе сводится к директивному определению будущего состояния конкретного социального объекта, процесса, явления в рамках определённой программы и плана.

\section{5 Сходства и различия понятий «проектирование», «моделирование» и «планирование»}

Определение понятийно-категориального аппарата раскрывающего сущность предмета исследования, неизбежно приводит к выявлению сходств и различий между понятиями, которые можно отнести в семантическое пространство исследуемого понятия. В частности в семантическое пространство понятия «проектирование» автор включил понятия «моделирование» и «планирование», между которыми в психологии отсутствуют чёткие демаркационные линии [29].

При первом приближенном сравнении понятий «планирование» и «проектирование» имеется общность в характере целеполагания и мотивационной основы. Они допускают вероятность технологического спектра. Синонимическое использование понятий «планирование» и «проектирование» объясняется в первую очередь словарными определениями понятий «проект» и «план». В словаре русского языка при определении понятия «проект» используется термин «план» [25].

Такое толкование слова «проект» ограничивает содержание данного понятия и не раскрывает его сущности, поэтому автор обратился к историко-этимологическому словарю современного русского языка (П.Я. Черных) [24, с.38;70]. Сравнивая историческую обусловленность использования понятий «план» и «проект», было установлено.

- Слова «план» и «проект» известны в русском языке с самого начала XVIII века. В «Архиве» Куракина слово «проект» встречается с 1710 г. («учиняя проект, подал тайному совету»), а слово «план» (также в форме «плян») встречается с 1713 г.

- С 1765 г. в бумагах Екатерины II встречается слово «проектировать».

- С 1847 г. появились прилагательные «проектный» и «плановый». 
Первоисточниками слова «проект» явились латинские слова «projectus» - вытягивание, вытянутое положение; «projacio» - держу впереди, протягиваю, вытягиваю, бросаю. Первоисточник слова «план» есть латинское слово «planum»- «плоскость», «равнина», от прилагательного «planus» - «плоский», «ровный» [30, с. 471; 495].

Следовательно, в контексте сравнения историко-этимологической сущности понятий «проект» и «план», понятие «проектирование» включает планирование в качестве составного элемента.

Сопоставление понятий «проектирование» и «моделирование» свидетельствует о том, что в толковании этих понятий есть сходства и различия.

«Модель» (в переводе с латинского modulus - мера, образец) имеет достаточно много значений. Модель в широком смысле - любой образ, аналог, изображение, описание, схема, чертеж, график, план, карта и т.д. какого-либо объекта, процесса или явления (оригинала), используемого в качестве его «заместителя», «представителя» [30, с. 392].

Модель как изображение существенных элементов исследуемого предмета или процесса, которое характеризуется однозначной связью соответствующих знаков с этими элементами. Модель наглядна, если в сочетании элементов и пространственно-временные отношения учитываются таким образом, что возникает определённая похожесть, позволяющая по модели узнать оригинал [31,с. 278]. Понятие «модель» используется и в практической деятельности, и областях научного знания.

Анализ литературы показал, что существует много различных классификаций моделей в зависимости от выделяемого основания:

- по форме представления моделей (логические, механические, математические, физические и т.д.);

- по природе моделируемых явлений (социальные, психологические, физиологические, педагогические и т.д.);

- по задаче моделирования (эвристические, прогностические и т.д.);

- по степени точности (точные, приближенные, достоверные, вероятные)

- по другим основаниям.

Неоднозначность толкования термина «модель» повлекла за собой и неоднозначное толкование термина «моделирование». Наиболее плодотворным для нашего исследования можно считать логико-математическое моделирование, которое предложил Д.Н. Хорафакс, и оно используется в следующих ситуациях [32]:

- для предсказания последствий изменения образа действий, условий или методов в ситуации, когда осуществление такого изменения в реальности связано с каким-либо риском или затратами средств;

- как средство изучения сложных систем с целью их совершенствования и более эффективного использования;

- $\quad$ как средство ознакомления с системами или условиями, которые, возможно, пока ещё не существуют в реальной действительности;

- для проверки или демонстрации новой идеи, системы или метода;

- как средство предсказания будущего и обеспечения основы для планирования, прогнозирования и проектирования.

В.А. Ясвин указывал, что принципиальной особенностью метода моделирования, отличающей его от других методов научного познания, следует считать опосредованное изучение объекта, проводимое с помощью исследования другого объекта, аналогичного первому. «Смысл моделирования заключается в возможности получать информацию о явлениях, происходящих в оригинале, путём переноса на него определённых знаний, полученных при изучении соответствующей модели» [17, с. 33]. 
Автор разделяет точку зрения Г.Е. Муравьевой о том, что проектирование отличается от моделирования тем, чем проект отличается от модели: целями их создания. Проект служит для воплощения проектируемого явления в реальность; модель - для исследования объекта, получения информации. Моделирование является составной частью проектирования и широко использоваться в проектировании для представления и преобразования объектов, явлений и процессов, которых ещё нет в реальности или они по каким-то причинам недоступны. Модель позволяет оперировать с ними, определяя устойчивые свойства, выделять отдельные сущностные аспекты проектируемых объектов, явлений и процессов и подвергать их более скрупулезному логическому анализу [14, с. 7-36].

Таким образом, проектирование как процесс в рамках проектировочной деятельности является конкретной формой проявления прогностических функций человека, когда им создаётся возможный образ будущей материальной или идеальной реальности [26]. Проектирование целенаправленно и его целью является такое преобразование действительности, в процессе которого создаются (или предполагается создание) объекты, явления или процессы, отвечающие желаемым свойствам.

\section{6 Дополнение «словаря проектанта»}

Автор предлагает включить в разрабатываемый «словарь проектанта» [33] ряд понятий, которые могут дополнить предметную область исследования.

Антиципация [лат. anticipatio] - 1) предвосхищение событий; заранее составленное представление о чём-либо; 2) преждевременное наступление какого-либо события [30, с. 52]. Анатомо-физиологической основой антиципации является механизм акцептора действия, описанный П.К. Анохиным в теории функциональных систем [19, с. 40].

Мотивационная готовность - это феномен, который характеризует уровень активности индивида в развитии потребностей в чём-либо, в частности потребности в профессиональной деятельности. Мотивационная готовность имеет уровневую организацию.

Ориентировочно-поисковый уровень характеризуется отсутствием у индивида сознательной направленности на достижение отдалённой по времени цели, неумением планировать действия и направлять усилия на стимулирование активности для достижения целей.

Операционно-потребностный уровень характеризуется наличием активности, направленной на достижение цели, которая может быть нейтрализована усилиями индивида, препятствующими их достижению.

Операционно-целевой уровень характеризуется умением ставить цели и задачи, стремлением к достижению результатов и частичным принятием ответственности за результат.

Операционно-содержательный уровень характеризуется сознательной направленностью индивида, планомерностью осуществления деятельности, сосредоточенностью на достижении результата.

Операционно-действенный уровень характеризуется доминированием сознательной направленности индивида на достижение отдалённой по времени цели; высоким уровнем целеустремлённости; способностью быстро принимать решения; точным пониманием того, что необходимо сделать в ситуации достижения целей; умением выбрать наиболее адекватное ситуации решение [34, с. 58].

Проектирование профессиональной деятельности - особая форма интеллектуальной активности человека, направленная на осуществление целеполагания, осознание личностных ресурсов для достижения целей обозримого профессионального будущего, нахождение путей восполнения необходимых ресурсов, конструирование образа ожидаемого результата в соответствии с обозначенными временными континуумами [29, с. 111]. 
Рефлексия [англ.reflexion] - мыслительный (рациональный) процесс, направленный на анализ, понимание, осознание себя, собственных действий и т.д. [19, с. 569].

Прорефлексия - это самоанализ из будущего, который позволяет критически посмотреть на себя из будущего. Как правило, он реализуется посредством вопросов, например: «В каком случае (наименование будущего события) вы будете считать его (событие) успешным?», «По поводу чего из того что вы не делаете сейчас вы будете сожалеть в будущем?» $[35,36]$.

\section{Заключение}

Необходимость рассмотрения особого самостоятельного конструкта «проектировочная деятельность», продиктована запросами высшей школы и задачами, которые данная деятельность решает, в частности:

- проектирование имплицитно присутствует в Федеральных государственных образовательных стандартах высшего образования по направлениям подготовки 37.03.01; 44.03.01; 44.03 .02 и др.;

- проектирование выполняет важную роль в «теории развивающего обучения», являясь генетико-моделирующим экспериментом, основным методом изучения учебной деятельности и развивающего обучения, а также «тонким инструментом», обусловливающим развитие самой теории деятельности [37];

- проектирование является обязательной составной частью всех видов профессиональной деятельности педагога, практического психолога и других специалистов;

- в научных изданиях отмечается недостаточная подготовленность выпускников к профессиональной деятельности $[38,39]$ и важность подготовки молодёжи к проектированию своего будущего [40].

Полученные автором данные опроса студентов свидетельствуют о том, что большинство выпускников (85\%) считают себя не совсем готовыми к профессиональной деятельности. Особенно остро этот вопрос встал сегодня, в связи с переходом на уровневую систему обучения.

С методом проектирования внутренне связан «деятельностный подход к совершенствованию всех сфер социальной практики». Кроме того, «в последние столетия была абсолютизирована роль научного исследования в изучении действительности и оттеснено в этой функции проектирование... Характерной особенностью проектирования является не изучение того, что существует, а создание новых продуктов и одновременно познание того, что лишь может возникнуть» [37, с. 506].

Проектирование в рамках проектировочной деятельности позволяет субъектам (обучающимся):

- формировать и развивать профессиональное пространство;

- преодолевать неопределённость в профессиональном пространстве;

- создавать целостный образ профессиональной деятельности, т.е. находить ответы на многие вопросы, получать ожидаемый результат и просчитывать профессиональные риски;

- планировать свою профессиональную деятельность и преодолевать стихийность профессионального становления;

- планировать своё личностное и профессиональное развитие.

\section{Список источников}

[1] Петровский, А.В. Основы теоретической психологии / А.В. Петровский, М.Г. Ярошевский / PSYLIB «Самопознание и саморазвитие» - http://goo.gl/DMvlDK (Дата обращения 10.03.16). 
[2] Боргест, Н.M. Научный базис онтологии проектирования / Н.М. Боргест // Онтология проектирования. 2013. - №1 (7). - С. 7-25.

[3] Микони, C.B. Проблема современной русской терминологии / С.В. Микони // Онтология проектирования. 2015. - Т.5, №4 (18). - С. 472-484. doi: 10.18287/2223-9537-2015-5-4-472-484

[4] Фельдштейн, Д.И. Проблемы качества психолого-педагогических диссертационных исследований, их соответствие современным научным знаниям и потребностям общества: Аналитический доклад на заседании Экспертного совета ВАК Минобрнауки России - http://goo.gl/EK0Dgm (Дата обращения 11.03.16).

[5] Антология мировой философии в 4-х томах: Т.1, ч.1-2. Философия древности и средневековья // Электронная библиотека «Koob.ru» - http://www.koob.ru. (Дата обращения 11.03.16).

[6] Аристотель Метафизика // Электронная библиотека «Библиотекарь.Ру» - http://goo.gl/WnnHJF.

[7] Антология мировой философии в 4-х томах: Т.2 Европейская философия от эпохи Возрождения по эпоху Просвещения. // Электронная библиотека «Koob.ru» - http://www.koob.ru. (Дата обращения 10.03.16).

[8] Свободная энциклопедия «Википедия» - https://goo.gl/kZaTFo. (Дата обращения 11.03.16).

[9] Антология мировой философии в 4-х томах: Т.3. Буржуазная философия конца XVIII в. — первых двух третей XIX в. // Электронная библиотека «Koob.ru» - http://www.koob.ru (Дата обращения 10.03.16).

[10] Спиркин, А.Г. Философия: Учебник / А.Г. Спиркин - М.: Гардарики, 2006. - 736 с.

[11] Смирнов, С.Д. Психология образа: проблема активности психического отражения: монография/ С.Д. Смирнов - М.: Изд-во МГУ, 1985. - 232 с.

[12] Килпатрик, Уильям Херд / Свободная энциклопедия «Википедия» - https://goo.gl/1yF46А. (Дата обращения 10.03.16).

[13] Исаев, Е.И. Проблемы проектирования психологического образования педагога / Е.И. Исаев // Вопросы психологии. - 1997. - №6. - c. 48-57.

[14] Проектирование образовательного процесса в средней и высшей школе: коллективная монография / под ред. Г.Е. Муравьевой - Шуя: Изд-во ГОУ ВПО «ШГПУ», 2009. - 229 с.

[15] Стрелков, В.И. Профильное проектирование личности учителя / В.И. Стрелков // Сборник научных трудов. - М.: Московский университет МВД. Выпуск 2, часть 2. - 2006, с. 110-117.

[16] Емельянов, Ю.Н. Социально-психологическое проектирование в педагогике / Ю.Н. Емельянов // Вопросы психологии. - 1988. - №1. - с. 26-32.

[17] Ясвин, В.A. Образовательная среда: от моделирования к проектированию / В.А. Ясвин - М.: Смысл. 2001. $356 \mathrm{c.}$

[18] Грачев, $\boldsymbol{A}$ A. Психологическое проектирование вуза как социальной организации / А.А. Грачев // Известия РГПУ им. А.И. Герцена, 2002. - с. 5-16.

[19] Большой психологический словарь. 4-е изд. / Сост. и общ.ред. Б.Г. Мещеряков, В.П. Зинченко. - М.: АСТ: АСТ МОСКВА; СПб.: Прайм-ЕВРОЗНАК, 2009. - 811с.

[20] Кочнева, E.M. Теоретический анализ сущностного понимания и использования проектирования в педагогике и психологии: сходства и различия / Е.М. Кочнева // Актуальные проблемы психологического знания (теоретические и практические проблемы психологии). 2013, №4 (29) - с. 45-52.

[21]Леонтьев, А.Н. Лекции по общей психологии / А.Н. Леонтьев // Электронная библиотека «Кооb.ru»http://www.koob.ru (дата обращения 08.01.2016).

[22] Щедровицкий, Г.П. Избранные труды / Г.П. Щедровицкий; составители А. Пископпель, Л.Щедровицкий. М.: Школа Культурной Политики, 1995. - 800 с.

[23] Юдин, Э.Г. Системный подход и принцип деятельности. Методологические проблемы современной науки: Монография / Э.Г. Юдин; составители А.П. Огурцов, Б.Г. Юдин. - М.: Наука, 1978. - 384 с.

[24] Черных, П.Я. Историко-этимологический словарь современного русского языка: в 2т., 9-е изд. / Черных П.Я. - М.: Рус.яз. Медиа; Дрофа, 2009. - Т.1. 623 с.; - Т.2. 559 с.

[25] Ожегов, С.И. Толковый словарь русского языка. / С.И. Ожегов, Н.Ю. Шведова - М.: АЗЬ, 1993. - 960 с.

[26] Новиков, А.М. Методология / А.М. Новиков, Д.А. Новиков - М.: СИНТЕГ, 2007. - 668c.

[27] Новый политехнический словарь / главный редактор А.Ю. Ишлинский. М.: «Большая Российская энциклопедия». 2000. - 672 с.

[28] Социологический словарь / Редактор Г.В. Осипов - ИСПИ РАН, М.: НОРМА, 2008. - 608 с.

[29] Кочнева, E.M. Концептуальные основы подготовки студентов к проектированию будущей профессиональной деятельности: монография / Е.М. Кочнева - Н.Новгород, НГПУ им. К. Минина, 2012 - 186 с.

[30] Словарь иностранных слов и выражений / Авт. сост. Е.С. Зенович. - М.: ООО Агентство КРПА «Олимп»: ООО «Изд-во АСТ», 2003. - 778 с.

[31] Философский словарь / под ред. Г. Шишкоффа. - М.: «Республика», 2003. - 576 с.

[32] Хорафакс, Д.Н. Системы и моделирование / Д.Н. Хорафакс - М.: Наука, 1967. - 420 с.

[33] Боргест, Н.M. Ключевые термины онтологии проектирования: обзор, анализ, обобщения / Н.М. Боргест // Онтология проектирования - №3 (9), 2013. - с. 9-31. 
[34] Кочнева, E.M. Мотивационная готовность студентов к профессиональной деятельности: монография / Е.М. Кочнева, Л.Ю. Пахомова - Н.Новгород, НГПУ им. К. Минина, 2011 - 140 с.

[35] Пригожин, А.И. Ценности и цели. Новые методы работы с будущим / А.И. Пригожин - М.: Издательство «Дело» АНХ. 2010. - 432 с.

[36] Кочнева, E.M. Психодидактика в содержании подготовки студентов к проектированию будущей профессиональной деятельности / Е.М. Кочнева // European Social Science Journal - 2014, №4, том 2. - c. 59-63.

[37] Давыдов, В.В. Теория развивающего обучения / В.В. Давыдов - М.: ИНТОР, 1996. - 544 с.

[38] Забродин, Ю.M. Проблема развития личностного и творческого потенциала практических психологов в контексте современного состояния их подготовки и переподготовки / Ю.М. Забродин, В.Э. Пахальян // Сборник материалов конференции «Пихология образования: Психологическое обеспечение Новой школы»- М., 2010. - с. 91- 92.

[39] Рубцов, В.В. Осуществление психолого-педагогической подготовки учителя для новой школы / В.В. Рубцов // Проблемы современного образования, 2010., №6, c. 3-9. - http://www.pmedu.ru

[40] Маралов, В.Г. Основы самопознания и саморазвития / В.Г. Маралов - М. ИЦ «Академия, 2004. - 256 с.

\title{
COMPARISON OF CONCEPT DESIGN, DESIGNING AND PROJECT ACTIVITY: HISTORICAL, ETYMOLOGICAL AND EPISTEMOLOGICAL ASPECTS
}

\section{E.M. Kochneva}

Nizhny Novgorod State Pedagogical U niversity Kozma M inin (M ininsky U niversity), Nizhny Novgorod, Russia e.m.kochneva@yandex.ru

\begin{abstract}
The article compares the concept of «project», «design» and «designing activity» to refer to their conceptual space, the disclosure of their use in different sciences; it is implicit confirmation of the presence of the structural components of the design in a variety of philosophical and psycho-pedagogical teachings about the nature of mental activity of the person and type of his cognitive activity-activity. Based on analysis of the works of philosophers from different historical periods in the article marked an ontological and epistemological aspects of the subject as an advanced display design and future generation; identify and define the basic terminology necessary for the definition of the concepts of psychological analysis. Based on the analysis of historical and etymological conditioning using the terms «project» and «plan» («design» and «planning») in the Russian language are designated essential differences in the use of these concepts and show that the design of the process within the planning activity is a specific form of manifestation prognostic human functions. The article presents the concepts that the author proposed to include in the «Dictionary designer».
\end{abstract}

Key words: project, design, designing activity, psychological activity of man, image, category analysis.

Citation: Kochneva EM. Comparison of concept design, designing and project activity: historical, etymological and epistemological aspects. O ntology of designing. 2016; 6(1): 81-94. DOI: 10.18287/2223-9537-2016-6-1-81-94.

\section{References}

[1] Petrovsky AV. Osnovy teoreticheskoy psychology [Basics theoretical psychology] / A.V. Petrovsky, M.G. Yaroshevsky / PSYLIB «Samopoznanie i camorazvitie» - http://goo.gl/DMvlDK (In Russian).

[2] B orgest N M. Scientific basis for the ontology of designing. O ntology of designing. 2013. №1(7): 7-25 (In Russian).

[3] M ikoni SV. Problems of modern Russian terminology. O ntology of designing. 2015. V. 5, №4(18): 472-484 DOI: 10.18287/2223-9537-2015-5-4-472-484. (In Russian).

[4] Pheldshteyn DI. Problemy kachestva psichologo-pedogogicheskih dissertacionnuh issledovaniy, ih sootvetsvie sovremennym nauchnym znaniyam i potrebnostyam obshestva: Analiticheskiy doklad na zasedanii Expertnogo soveta VAK [Quality problems of psycho-pedagogical dissertation research, their conformity with current scientific knowledge and the needs of society] - http://goo.gl/EK0Dgm. (In Russian). 
[5] Antologiya mirovoy philosophii [Anthology of world philosophy: The philosophy of antiquity and the Middle Ages] v 4-h tomah: T.1, ch. 1-2. Philosophiya drevnosti i srednevekovya // Elektronnaya biblioteka «Koob.ru»http://www.koob.ru. (In Russian).

[6] A ristotel Metapsizika [Metaphysics] / «Bibliotekar.ru»-http://goo.gl/WnnHJF. (In Russian).

[7] Antologiya mirovoy philosophii v 4-h tomah : T.2. Evropeyskaya philosophiya ot epochi Vozrojdeniya po epochu Prosvesheniya [Anthology of world philosophy: European philosophy from the Renaissance to the enlightenment] // «Koob.ru» - http://www.koob.ru.

[8] Svobodnaya enciklopediya «Vikipediya» [Free Encyclopedia] - https://goo.gl/kZaTFo. (In Russian).

[9] Antologiya mirovoy philosophii v 4-h tomah: T.3. Burzhuyaznaya philosophiya konca XVIII v.- pervoy chetveretey XIX v. [Anthology of world philosophy: Bourgeois philosophy of the end of the XVIII century] // «Koob.ru»- http://www.koob.ru. (In Russian).

[10] Spirkin AG. Philosophiya: uchebnik [Philosophy: Textbook] - M.: Gardariki, 2006. - 736 p. (In Russian).

[11] Smirnov SD. Psihologiya obraza: problema aktivnosti psihicheskogo otrazjeniya: Monographiya [Image Psychology: the problem of mental reflection of activity: Monograph] - M.: Izd-vo MGU, 1985. - 232 p. (In Russian).

[12] Kilpatrik UH / Svobodnaya enciklopediya «Vikipediya» - https://goo.gl/1yF46A. (In Russian).

[13] Isaev E I. Problemy proektirovaniya psihologicheskogo obrazovaniya pedagoga [Design problems of psychological education teacher] / Voprosy psichologii - 1997. - №6: 48-57. (In Russian).

[14] Proektirovanie obrazovatelnogo processa v sredney i vysshey shkole: kollektivnaya monographiya [Design of the educational process in the middle and high school: collective monograph] / Edit. G.E. Muravyevoy - Shuya: Izdvo «SHGPU», 2009. - 229 p. (In Russian).

[15] Strelkov VI. Profilnoe proektirovaniya lichnosti uchitelya [Mold projecting teacher's personality] / Sbornik nauchnyh trudov - M.: Moskovskiy universitet MVD. Vypusk 2. - 2006: 110-117 (In Russian).

[16] Emelyanov YN. Socialno-psihologicheskoe proektirovanie v pedagogike [Socio-psychological design in pedagogy] / Voprosy psihologii. - 1988. №1: 26-32. (In Russian).

[17] Yasvin VA. Obrazovatelnaya sreda: ot modelirovaniya k proektirovaniy [Educational environment: from modeling to design] - M.: Smysl. 2001. - 356 p. (In Russian).

[18] Grachev AA. Psihologicheskoe proektirovanie vuza kak socialnoy organizacii [Psychological designing the university as a social organization] / Izvestiay RGPU im. A.I. Gercena, 2002: 5-16 (In Russian).

[19] Bolshoy psihologicheskiy slovar. [Significant psychological dictionary] 4-e izd. / Edit. B.G. Mesheryakova, V.P. Zinchenko. - M.: AST: AST MOSKVA; SPb.:Praym-EVROZNAK, 2009. - 811 p. (In Russian).

[20] Kochneva EM. Teoriticheskiy analiz sushnostnogo ponimaniya i ispolzovaniya proektirovaniya $\mathrm{v}$ pedagogike $\mathrm{i}$ psihologii: shodstva i razlichiya [Theoretical analysis of the essential understanding and use of design in pedagogy and psychology: similarities and differences] / Aktyalnye problem psihologicheskogo znaniya (teoreticheskie i prakticheskie problem psihologii). 2013, №4 (29): 45-52. (In Russian).

[21] Leontyev AN. Lekcii po obshey psihologii [Lectures on general psychology] // Elektronnaya biblioteka «Koob.ru» - http://www.koob.ru. (In Russian).

[22] Shedrovickiy G P. Izbrannye Trudy [Selected works] - M.: Shkola kulturnoy politiki. 1995. - 800 p. (In Russian).

[23] Yudin EG. Sistemnyj podhod i princip deyatelnosti. Metodologicheskie problemy sovremennoy nauki: Monographiya [System approach and the principle of action. Methodological problems of modern science: Monograph] / E.G. Yudin; sostaviteli A.P. Ogurcov, B.G. Yudin. - M.: Nauka, 1978. - 384 p. (In Russian).

[24] Chernyh PY. Istoriko-etimologicheskiy slovar russkogo yazyka: v 2 t., 9-e izd. [Historical and etymological dictionary of modern Russian language] / - M.: Rus. yaz. Media; Drofa/ 2009. - T.1-623 p.; T.2-559 p. (In Russian).

[25] Ozjegov SI, Shvedova NY. Tolkovyj slovar russkogo yazyka [Dictionary of Russian language] - M.: AZ, 1993. 960 p. (In Russian).

[26] Novikov AM, Novikov D A. Metodologiya [Methodology] - M.: SINTEG, 2007. - 668 p. (In Russian).

[27] Novyj politehnicheskiy slovar [The New Polytechnic Dictionary] / Edit. A.Y. Ishlinskiy. - M.: Bolshaya Rossiyskaya enciklopediya. 2000. - 672 p. (In Russian).

[28] Sociologicheskiy slovar [Opinion Dictionary] / Edit. G.V. Osipov - ISPI RAN, NORMA, 2008. - 608 p. (In Russian).

[29] Kochneva EM. Konceptualnye osnovy podgotovki studentov k proektirovaniy budushey prophessionalnoy deyatelnosti: Monographiya [Conceptual bases of preparation of students to design their future professional activity: Monograph] - N.Novgorod, NGPU im. K. Minina. 2012. - 186 p. (In Russian).

[30] Slovar inostrannyh slov i vyrazjeniy [Dictionary of Foreign Words and expressions] / Edit. E.S. Zenovich. - M.: OOO Agentstvo KRPA «Olimp»: OOO «Izd-vo AST», 2003. - 778 p. (In Russian).

[31] Philosophskiy slovar [Philosophical Dictionary] / Edit. G. Shishkophpha. - M.: «Respublika», 2003. - 576 p. (In Russian).

[32] H oraphaks DN. Sistemy i modelirovanie [Systems and simulation] - M.: Nauka, 1967. - 420 p. (In Russian). 
[33] B orgest NM. Keywords of ontology of designing: review, analysis, generalization. Ontology of designing. 2013. №3 (9): 9-31. (In Russian).

[34] Kochneva EM, Pahomova LY. Motivacionnaya gotovnost studentov $k$ prophessionalnoy deyatelnosti: monographiya [Motivational readiness of students to professional work: monograph] - N.Novgorod, NGPU im. K. Minina. 2011. - 140 p. (In Russian).

[35] Prigozjin Al. Cennosti i celi. Novye metody raboty s budushim [The values and goals. New ways of working with the future] - M.: izd-vo«Delo». 2010. - 432p. (In Russian).

[36] Kochneva EM. Psihodidaktika v soderzjanii podgotovki studentov k proektirovaniy budushey prophessionalnoy deyatelnosti [Psihodidaktika in preparing students to design the content of their future professional activity] / Evropeyskiy zhurnal socialnuh nauk - 2014, №4, v. 2: 59-63. (In Russian).

[37] Davydov VV. Teoriya razvivayushego obucheniya [The theory of developmental education] - M.: INTOR, 1996. 544 p. (In Russian).

[38] Zabrodin YM, Pahalyan VE. Problema razvitiya lichnostnogo i tvorcheskogo potenciala prakticheskih psihologov $\mathrm{v}$ kontekste sovremennogo sostoyaniya ih podgotovki i perepodgotovki [The problem of personal and creative potential of practical psychologists in the context of the current state of their training and retraining] / Sbornik materialov konferencii «Psihologiya obrazovaniya: Psihologicheskoe obespechenie Novoy shkoly» - M., 2010: 91-92. (In Russian).

[39] Rubcov VV. Osushestvlenie psihologo-pedagogicheskoy podgotovki uchitelya dlya novoy shkoly [Implementation of psycho-pedagogical training of teachers for the new school] / Problemy sovremennogo obrazovaniya. 2010. №6: 3-9 - http://www.pmedu.ru. (In Russian).

[40] Maralov VG. Osnovy samopoznaniya i samorazvitiya [Basics of self-knowledge and self-development] - M.: Akademiya. 2004. - 256 p. (In Russian).

\section{Сведения об авторе}

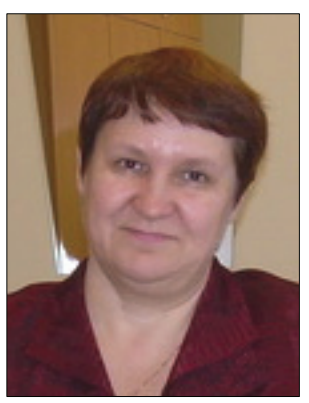

Кочнева Елена Михайловна , 1958 г. рождения. Окончила Горьковский государственный педагогический институт им. М. Горького (ГГПИ, ныне Нижегородский государственный педагогический университет им. К. Минина - НГПУ им. К. Минина), факультет математики в 1981 г., факультет практической психологии в 1989 г.; к.психол.н. (2004). Доцент кафедры социальной и организационной психологии НГПУ им. К. Минина. В списке научных трудов более 80 работ в области психологии профессионального самоопределения и проектирования профессиональной деятельности.

Kochneva E lena Mikhaylovna (b. 1958) graduated from the Gorky State Pedagogical Institute in 1981, PhD (2004). She is associate professor of social and organizational psychology in the Nizhny Novgorod State Pedagogical University named Kozma Minin (Mininsky University). She is the author of over 80 publications in the field of psychology of professional self-determination and design of professional activity. 


\title{
УДК 72.01:72.025.4
}

\section{ДВИЖЕНИЕ КАК КАТЕГОРИЯ АРХИТЕКТУРЫ}

\author{
И.С. Заяц \\ Санкт-Петербургский государственный архитектурно-строительный университет, \\ Санкт-Петербург, Россия \\ i.vvv0302@gmail.com
}

\begin{abstract}
Аннотация
В статье впервые предлагается и раскрывается определение «движение» как категория архитектуры на фоне традиционно принятых, таких как форма, масса, пространство и образ. Движение как философское понятие находит непосредственное отражение в архитектурном творчестве, как результат исторического процесса изменения общества, технического прогресса и развития строительных технологий. В зависимости от различных характеристик движения в архитектуре, вводятся и описываются виды движения: глобальное - движение времени и исторического процесса; объективное - движение стихий природы в природной и архитектурной среде; субъективное - функциональное движение, отражающее целесообразность архитектуры; относительное движение, основанное на специфике зрительных образов; и ассоциативное движение в архитектурной композиции. Каждый вид движения влияет на формирование архитектурного образа среды и сооружения, выявляет закономерности формообразования во взаимосвязи с временем, движением природных стихий, функцией архитектурного пространства и физиологией человеческого восприятия.
\end{abstract}

Ключевые слова: теория архитектуры, категории архитектуры, формообразование, виды и характеристики движения в архитектуре.

Цитирование: Заяц, И.С. Движение как категория архитектуры / И.С. Заяц // Онтология проектирования. - 2016. - Т.6, №1(19). - C. 95-105. - DOI: 10.18287/2223-9537-2016-6-1-95-105.

\section{Введение}

Теория формообразования в архитектуре традиционно опирается на такие категории, как масса, пространство, оболочка, плоскость, поверхность [1] и рассматривается с точки зрения организации классических архитектурных форм. Исторический опыт мировой архитектуры в рамках стиля и разнообразных формальных характеристик трактуется как мироощущенческая модель человечества на разных этапах его развития [2, с. 49]. Но теоретическое осмысление архитектурной формы, её исторических трансформаций, должно быть основано на исследовании условий её возникновения, причин и целей её создания, ограничений и правил окружающей среды, уровня развития общества и наук, производительных сил, строительных технологий.

Архитектура возникла, прежде всего, как защита человека от природных стихий, но их влияние на формообразующие процессы обычно выходит за пределы теоретических исследований. Окружающая среда должна рассматриваться не только как категория пространства, но и как категория движения стихий природы: водных и воздушных потоков, солнечных лучей, изменяющих своё направление и интенсивность в течение дня. Обобщение теоретических и практических знаний об этих стихиях и их влиянии на архитектуру ведёт к выявлению закономерностей экологического формообразования, которые необходимы для логики и оптимизации архитектурного творческого процесса в современном, не совсем устойчивом мире. 
Изучение философских, теоретических и прикладных основ ведёт к некоторому переосмыслению взаимосвязи основных категорий и принципов онтологии и стратегии архитектурного проектирования.

Категории архитектуры складывались исторически, как руководство к архитектурному творчеству, и были известны уже во времена античности [3]. Тексты Витрувия интерпретировались и комментировались в различные эпохи и разными авторами. Достаточно подробно описывает категории по Витрувию А.Ф. Лосев [4]. В философских рассуждениях Лукреция, как и у его предшественников, философов-материалистов, ясно прослеживается идея познания мира, основанная на наблюдении невидимых сил природы, обладающих огромной силой, процессов их движения и влияния на среду, в которой существует человек. Определение бесконечного пространства, сохранение и движение материи, олицетворение природы находит отражение и в описании исторических процессов, проходящих также в движении пространства и времени [5, с. 34, 45, 53].

«В самом же деле в морях, на земле и в небесных высотах

Много различным путём совершается много движений

Перед глазами у нас; а не будь пустоты, то не только

Вещи никак не могли б пребывать в непрестанном движеньи,

Но и на свет никогда появиться ничто не могло бы,

Ибо лежала б всегда материя стиснутой всюду.

Кроме того, и при всей своей видимой плотности, вещи

Всё ж, как увидишь сейчас, всегда будут пористы телом:

Так, сквозь каменья пещер сочится текучая влага

Вод, и слезятся они обильными каплями всюду;

Всюду по телу живых созданий расходится пища;

Да и деревья растут, и плоды в своё время приносят,

Так как от самых корней растекается пища повсюду,

Вверх по стволу проходя и по веткам везде пробегая;

Звуки идут через стены домов и замкнутые двери,

Внутрь пролетая; мороз до костей проникает жестокий» [5, с. 36].

Большое внимание законам и правилам архитектуры уделяли теоретики Ренессанса [6]. Например, Альберти определял здание, как «своего рода тело, которое, как и другие тела состоят из очертаний и материи, причём первые создаются умом, а вторая берётся из природы. Для первых нужны ум и мысль, для второй - подготовка и выбор» [7]. Участие опытного художника необходимо для оформления материи очертаниями. Уже в этом коротком высказывании определяются категории архитектуры, такие как пространство, масса, форма и образ, в соединении которых и возникает архитектурный объект или архитектурно-пространственная композиция ансамбля, комплекса, городского квартала и пр. Архитектурная композиция определяет взаимодействие форм архитектурных объёмов между собой и в контексте окружающей среды на основании законов науки и искусства, и в соответствии с функциональным, технико-экономическим и идейно-эстетическим содержанием [8]. Композиция считается гармоничной, когда достигнуто органическое единство, и все части и целое связаны и согласованы [9]. Здесь же могут быть рассмотрены взаимоотношения структуры, т. е. внутреннего устройства объекта, его архитектоники, а также функциональной технологии, оборудования, инженерного обеспечения. Композиция зависит от основных двух положений: закономерностей и правил построения, логики использования элементов и деталей, их пропорциональных взаимоотношений - с одной стороны; с другой - от индивидуального творческого процесса. К первому следует отнести и 
правила, диктуемые природными условиями, спецификой воздействия природных стихий в том или ином климатическом поясе.

\section{1 Движение как категория архитектуры}

Теоретические исследования касаются обычно лишь движения в архитектурной композиции [10] и в архитектурной форме $[11,12]$, либо движения как фактора взаимодействия человека и пространства, человека и архитектурного объекта [13]. Но при рассмотрении различных аспектов влияния движения в архитектурном формообразовании выявляется более общее и основополагающее этого явления и понятия, присущее категориям, составляющим суть архитектуры и её онтологии, её объёмно-планировочной структуры и принципов формообразования.

Если говорить о движении как категории архитектуры, необходимо рассмотреть критерии и характеристики для её определения. Прежде всего, это понятия движения и времени, которые, в свою очередь, связаны между собой. Движение в широком философском смысле - это любое изменение, заключённое в универсальном принципе Гераклита «всё течет, всё меняется» [14]; в более узком - изменение положения тел в пространстве. «Я утверждаю, что видов движения два: изменение и перемещение», - разделяя различия между качественным изменением и движением относительно определенного места, писал Платон [15].

Первое относится к диалектике изменения жизни, а в контексте архитектуры - к течению исторического процесса, эволюции технологий, развитию производительных сил, смене стилей и предпочтений и т.д. Второе относится к любому перемещению, но в нашем случае возможно рассмотрение движения человека в пространстве, созерцание движения и движение в процессах жизнеобеспечения. Движение как перемещение - «...это намерение вообще» [16], то есть любое перемещение определяется не только в контексте движения и его взаимосвязи с пространством, временем и материей, но и в цели любого действия.

\section{2 Виды движения и его характеристики}

\section{1 Глобальное движение}

Противоречивость движения, заключённая в изменчивости и устойчивости [17], также наблюдается в архитектуре, и в первую очередь это относится к архитектурному наследию. Понятие подлинности как основной ценности памятника обязательно характеризуется патиной времени. Можно легко определить здание старое или новое, не только идентифицируя его стилевую особенность, но и по состоянию материала и формы, так называемой степени деградации. В этом заключается и двойственность нашего отношения ко времени. С одной стороны, время ${ }^{1}-$ это необратимое течение, мы говорим: время неизбежно движется вперёд, нельзя дважды вступить в одну и ту же реку [14], течение времени ассоциируя время с речным потоком. С другой - пытаясь сохранить памятник, мы неизбежно

\footnotetext{
${ }^{1}$ Философ и математик Черняков А.Г. в своей монографии «Онтология времени. Бытие и время в философии Аристотеля, Гуссерля и Хайдеггера» (2001) привёл слова Хайдеггера об онтологии: «Мы называем эту науку ... темпоральной наукой... Все положения онтологии суть темпоральные положения. Её истины - это выявленные структуры и возможности бытия в свете темпоральности. Все онтологические положения имеют характер Veritas temporalis». Для нас время - важнейший и определяющий атрибут как в обыденной жизни, так и в проектировании, именно поэтому редакция приглашает авторов для публикации содержательных работ в области исследования темпоральности и жизненных циклов в онтологии проектирования. Прим.ред.
} 
стремимся остановить время, «законсервировать» его в прямом и переносном смыслах, сохранить подлинность всех элементов, конструкций, материала или любой другой информации.

Интересна концепция субъективного времени Августина, средневекового философа, где оно становится психическим феноменом смены восприятий и делится на три части: настоящее, прошлое и будущее (рисунок 1). Прошлое дано в памяти, будущее в ожидании, но в душе каждого человека и в человеческой истории в целом время однонаправлено и линейно, и метрическое его измерение связано с вращением Земли вокруг Солнца, а также с биением человеческого пульса [18].

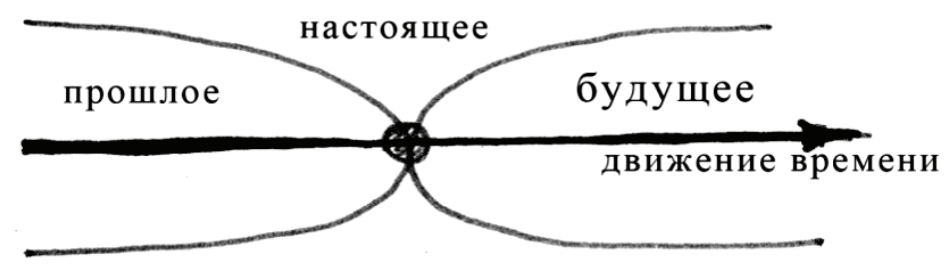

Рисунок 1 - Схема концепции движения субъективного времени

Таким образом, определяется первая форма движения - глобальная, которую мы не можем изменить. Это движение времени, необратимое течение событий в одном направлении, из прошлого через настоящее в будущее - технический прогресс, историческое развитие, преобразование общества и мира, что непосредственно влияет на архитектуру, на не повторяемость её стилей или их интерпретаций. Так, рисунок 2 наглядно иллюстрирует пример изменения форм в процессе движения времени. Изобретение турбинного (III век до н.э. в Греции) и вертикального колеса (I век до н.э. в Риме) для использования энергии воды повлекло в дальнейшем строительство довольно стабильной формы водяных мельниц, являвшихся на протяжении 20 столетий основными объектами промышленной архитектуры. В отличие от архитектурной формы водяной мельницы, использование ветровой энергии, начавшееся около VII века, как непостоянной и трудно управляемой, формы ветряных мельниц на протяжении многих веков изменялись в процессе изучения аэродинамических законов и поиска их эффективности. Так, в VII веке башенная мельница использует силу сквозняка; с IX века козловая, столбовка, немецкая - поворачивается на вертикальном столбе; а с XVII века шатровая, голландская - получила обтекаемые формы с вращающейся «шапкой».

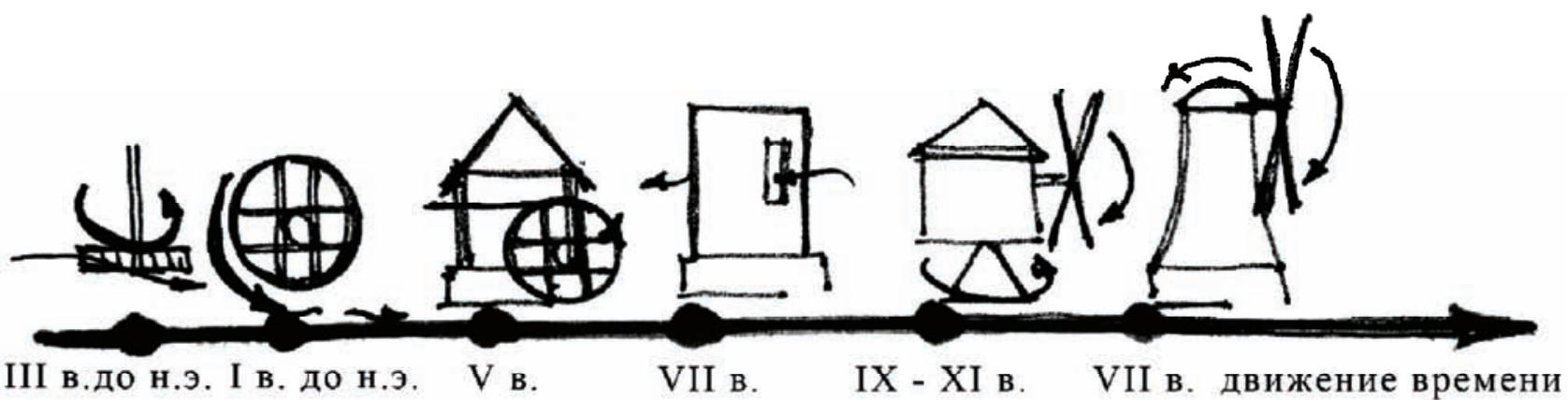

Рисунок 2 - Изменение форм в процессе движения времени на примере исторических энергоактивных сооружений

Мерами движения времени являются эры, эпохи, века, периоды. Это движение превращает Неархитектуру в Архитектуру. В его процессе мы выявляем истинные ценности, 
принадлежащие разным этапам. Мельницы и акведуки, амфитеатры и пещерные города, средневековые храмы и жилые дома наряду с шедеврами архитектуры определяют пласт культуры, опираясь на который мы находим новые пути творческого самовыражения.

\section{2 Объективное движение}

В процессе творческого поиска архитектор не освобождается от законов природы и от объективного движения стихий: потока ветра, бега воды, направления лучей солнца, которое влияет также и на рост растений. Понятие движения в архитектуре и в смысловом, и в семантическом смысле, берёт начало от движения в природе, которое влияет на структуру и содержание здания, диктует определённые правила и преобразует пространство в соответствии со своими объективными законами (рисунок 3). Законы движения воды, ветра и солнца в природе преобразуются в законы организации движения воды, потоков воздуха (естественной вентиляции) и света (инсоляции и естественного освещения) в любом здании.

Любое из перечисленных природных явлений характеризуется определённым направлением или направлениями движения и активно воздействует на формообразование города и отдельного здания. Расположение улиц и площадей, устройство дорог и тротуаров, систем дренажей и водоотводящих лотков, ориентация зданий, организация в них проёмов, уклонов крыш с определённым качеством применяемых материалов, предпочитаемых для того или иного климатического пояса, - далеко не полный список элементов, которые зависят от природных стихий и, в свою очередь, являются неотъемлемой частью архитектуры.

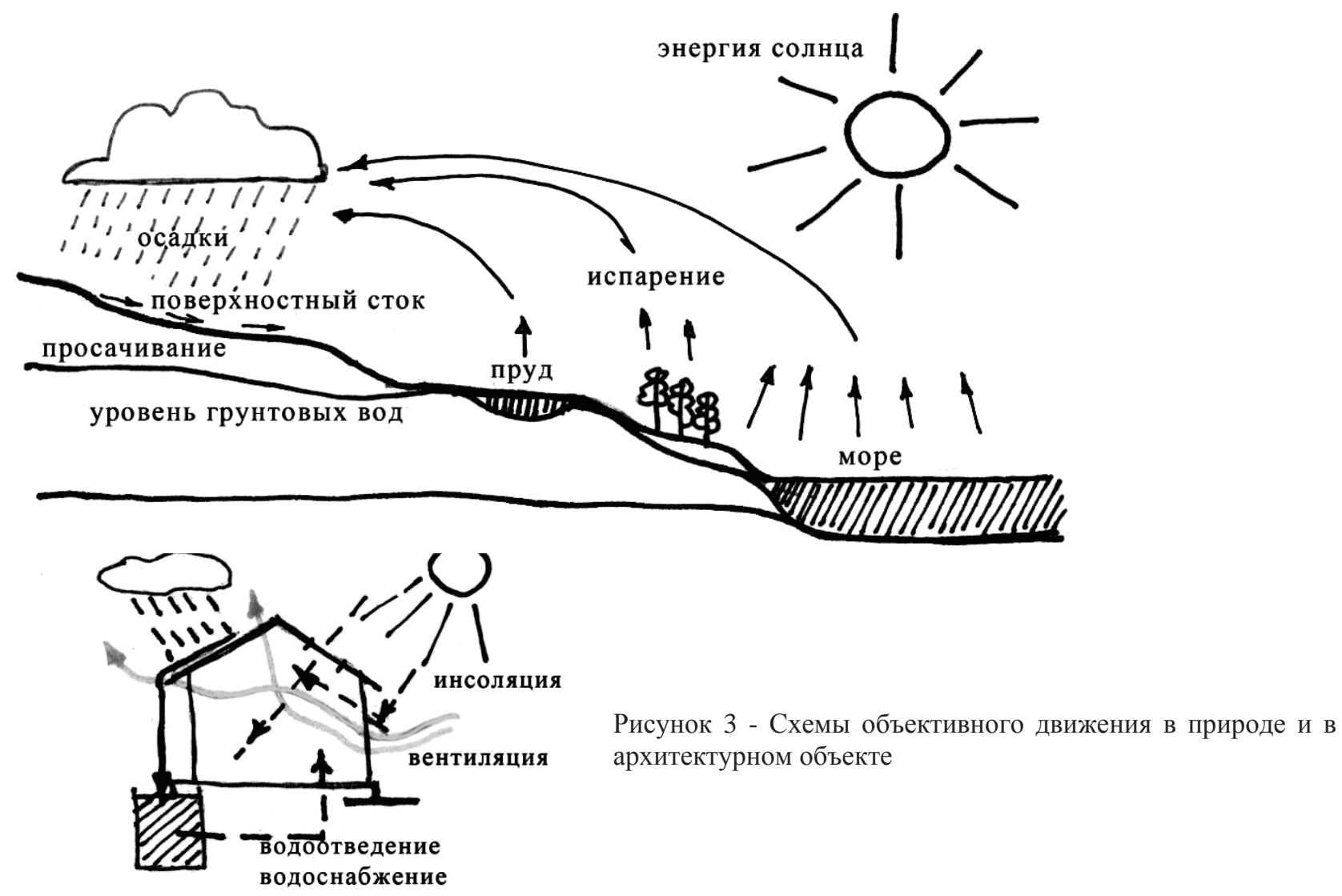


В этом же списке объективного движения - стихии природы, которые являются возобновляемыми источниками энергии, и человек, научившись управлять ими непосредственно, преобразуя движение стихии в энергию движения машин, влияет на ландшафт и ищет в соответствии с функцией оптимальную форму здания.

\section{3 Субъективное движение}

Понятие функции [19] определяет ещё одну форму движения - субъективную. Это движение человека в пространстве, которое связывает в единое целое архитектурный объект, его внутреннюю объёмно-пространственную структуру и внешнее пространство, природное и рукотворное. В этом движении определяются последовательность восприятия форм, функциональное взаимодействие элементов среды во времени. И в процессе создания архитектурного пространства немаловажную роль играет сценарий этого движения, которое непосредственно определяет взаимосвязи этого пространства с человеческим телом, которое выражается, прежде всего, в принципах масштабности и пропорциональности. «...Мир нашего тела и мир нашего жилища находятся в вечно изменчивом взаимодействии. Мы обустраиваем свои места, выражая наш опыт и знания, которые мы черпаем из мест, уже созданных нами прежде. Сознаем мы это или нет, наши тела и движения ведут постоянный диалог с нашими сооружениями» [13, с. 253].

Фрэнсис Д. Чинь предлагает довольно структурированную систему сценария движения человека в пространстве, включая подход с дальних точек, проход снаружи внутрь, конфигурацию прохода с организацией последовательных пространств и согласований элементов функциональных зон и формы миграционных пространств, таких как коридоры, вестибюли, холлы, галереи и лестницы [13, с. 255].

Подходы к зданию могут быть фронтальные, боковые, спиральные, живописно ассиметричными или организованно геометричными, цель которых обозначается порталом или воротами. По-разному могут быть оформлены входы в здание, включая навесы, балконы, портики, выступающие из плоскости стены, регулируя поведение человека, направляя его действия, давая возможность отдыха или укрытия. Лестницы и пандусы вводят вертикальное измерение, вносят определённый ритм в членения архитектурного сооружения или в масштаб среды. От этих архитектурных элементов, от их масштаба и форм также зависят функциональные и символические составляющие. Улицы, дороги, проходы в здании, для чего бы они ни предназначались, по своей природе целенаправленны, но насколько разнообразны их траектории, пересечения, принципы организации. Ф. Чинь подразделяет их конфигурации на линейные, радиальные, спиральные, решётчатые, сетчатые и смешанные $[13$, c. 279$]$.

Инертность, статичность пространства преодолевается только через движение, которое имеет в архитектуре различные и многообразные пространственные выражения [2, с. 98]. Понятие функции приближает к пониманию объективных и субъективных законов движения, которые подразумевают также и цель, целесообразность действия (рисунок 4).

\section{4 Относительное движение}

Относительное движение - это созерцание движения, направленность восприятия, движение архитектурной композиции и пространства вокруг человека, влияние визуальных связей и смена визуального ряда, линия горизонта, ритм вертикалей и горизонталей, создающих иллюзию движения, контур архитектурной композиции, вертикальные движения доминант, эффект движения пространства вокруг человека в транспорте. Вполне вероятно, что идея расстояния, а вслед и за ним понятие движения, возникла у человека как 
осмысление того, близко или далеко тот объект или вещь, которые ему нужны. «Понимание «вращения» вещей вокруг человека есть уже момент объединения пространства и отправная точка для зарождения сознания того, что единое пространство может произвольно уходить от него во все стороны» [2, с. 52].

Подход, вход
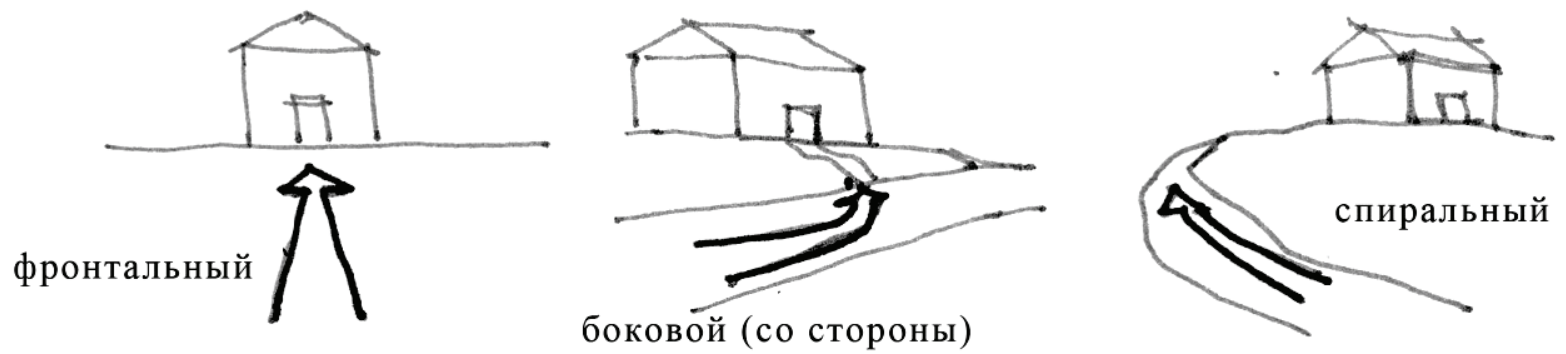

Коммуникационные пространства
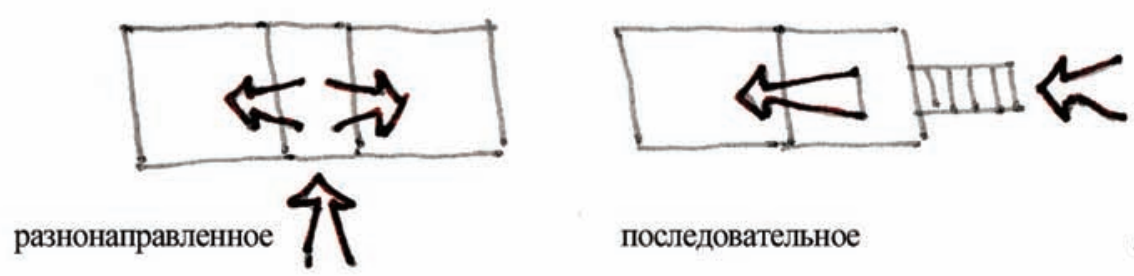

последовательное дифференцированное
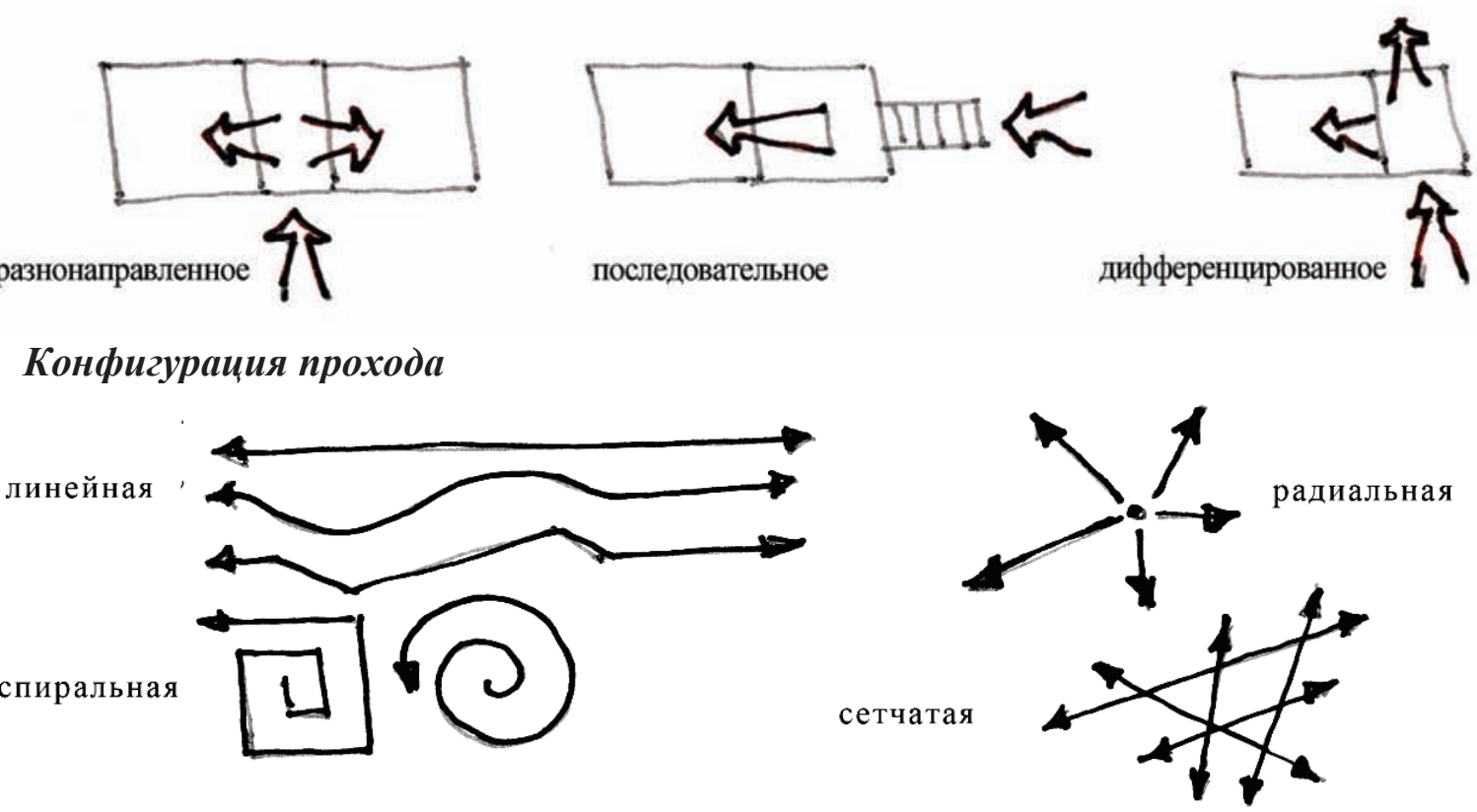

Рисунок 4 - Графические схемы субъективного движения

Свойство человеческого зрения, прежде всего направленное вперёд, также определяет направленность и движение пространства. «...Всякая трёхмерность в архитектуре лучше всего воспринимается при рассматривании под углом. Вместе с тем объёмность здания есть сумма представлений с точки зрения нашего движения при приближении к зданию и обходе вокруг него; исходя из понятия предела, мы имеем дело с суммированием бесконечного числа точек зрения или бесконечного числа картин» [2, с. 416].

Смена этих картин создаёт эффект движения, превращает пространство вокруг в систему движущихся линий, как начерченный контур города или перспективы улицы, или линия реки c абрисом постройки на её берегу. Это движение непосредственно влияет на регламентирование городских и сельских застроек, определяя высотность, ритмичность и масштаб архитектурной среды (рисунок 5). 


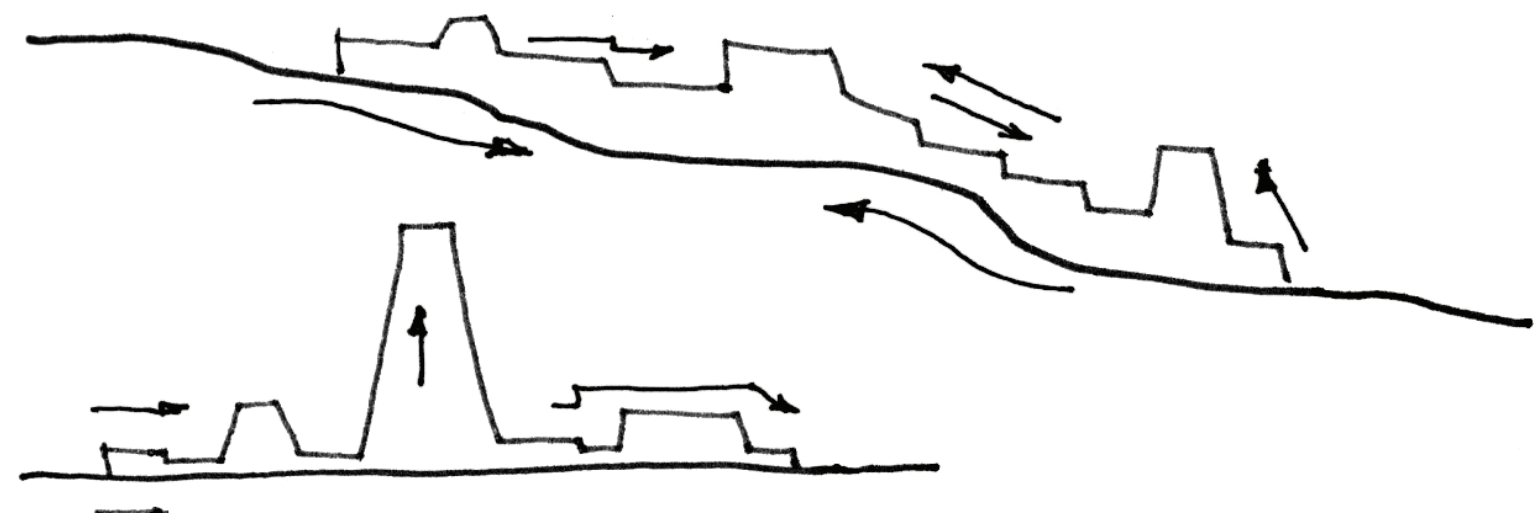

Рисунок 5 - Графические схемы относительного движения

\section{5 Ассоциативное движение}

Любое здание как архитектурная форма также заключает в себе момент движения, оно и не подвижно, и обладает иллюзией движения. Это ассоциативное движение, которое присутствует в любой архитектурной композиции, и прежде всего, также связано со спецификой зрения, о которой уже говорилось выше, а также с законами построения образа, такими как членения, ритм, пропорции, линейность, пластика и прочее [20]. Мы говорим о беге колонн или о вращении лестниц, или о разворотах фасадов, подразумевая некоторые метафоричные ассоциации. Можно определить различные виды этого движения: прямолинейное, изогнутое, циркульное, спиралевидное, которые достигаются использованием в архитектурных композициях ритмических или свободных изменений качеств, разнообразных соотношений, форм, материалов, световых и цветовых нюансов [21]. Природа иллюзий подвижности, в общем, довольно инертной массы лежит не только в физиологии восприятия, которое заставляет для изучения предмета водить по нему взглядом, но и в аналогиях окружающей нас жизни. Законы цикличности и ритмичности природы, разнообразие её форм, находят отражение в любом произведении искусства и архитектуры, которая на основе различных способов организует целостность ритмического построения, определяет главное и второстепенное [2]. Эффект движения достигается с помощью изменений пропорций и масштаба, включения акцентов, вертикальных и горизонтальных элементов, асимметрии и динамического равновесия, использования геометрического подобия, спиралевидных структур, криволинейных напряженных форм, с обязательной ритмической организацией, которая является универсальным средством гармонического единства композиции (рисунок 6).
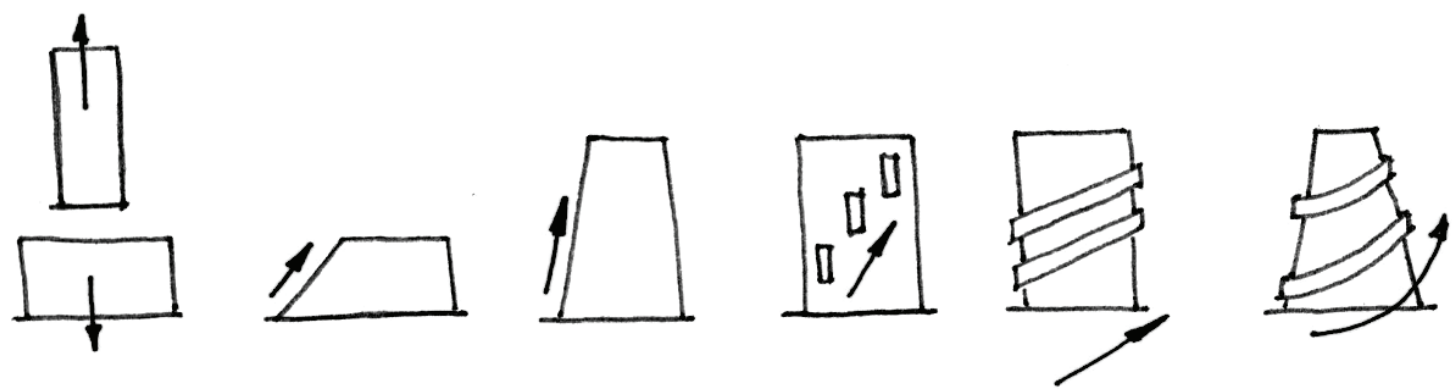

Рисунок 6 - Графические схемы ассоциативного движения 


\section{Заключение}

Онтология как философское учение о сущем включает и рассматривает свойства и условия бытия - пространство, время, движение и форму. В архитектурной онтологии пользуются лишь категориями пространства, формы, массы, образа или стиля. Архитектура, таким образом, традиционно воспринимается как некое застывшее творение. Тем не менее, архитектура движется и эволюционирует во времени и пространстве, она подчиняется законам ритма, метра, масштаба и пропорций. Таким образом, движение может рассматриваться как онтологическая составляющая и предельно общее понятие в архитектуре, поскольку является неотьемлемой частью архитектурного формообразования. Синтез рассматриваемых формообразующих категорий выявляет систему и взаимодействие функции - формы - пространства - движения - образа.

Движение как категория архитектуры имеет свои законы, принципы и приёмы. Оно является необходимой составляющей онтологии архитектурного проектирования, начиная с расчёта инсоляции, ветровых нагрузок, организации водоотводов, разработки функционального движения людей и транспорта в организуемом архитектурном пространстве. Различные характеристики движения заключаются в различных стилях и образах архитектуры, отражая время.

\section{Список источников}

[1] Габричевский, А.Г. Морфология искусства. - М.: Аграф, 2002. - 864 с.

[2] Некрасов, $\boldsymbol{A}$. Теория архитектуры. - М.: Стройиздат, 1994. - 480 с.

[3] Витрувий. Десять книг об архитектуре. - М.: «Архитектура-С», 2006. - 328 с.

[4] Лосев, $\boldsymbol{A}$. Ф. История античной эстетики. Ранний эллинизм. / История античной эстетики. - Том V. - М.: «Искусство», 1979. - 494 с.

[5] Лукреций. О природе вещей. / Пер. с лат. Ф. Петровского. - М.: Худож. лит. 1983. - 383 с.

[6] Очерки истории теории архитектуры Нового и Новейшего времени. / Антология. - Ред. Азизян И.А. СПб.: Издательство Коло, 2009. - 656 с.

[7] Альберти, Леон-Баттиста. Десять книг о зодчестве. / в 2-х т. - под общ. ред. А. Г. Габричевского. Пер. В.П. Зубова, фрагмент анонимной биографии - пер. Ф.А. Петровского. - М.: изд. Всесоюзной Академии Архитектуры, - 1935-1937. - Т.1. - 427 с.

[8] Сом⿰в, Г.Ю. Природа средств архитектурной композиции. / Теория композиции в советской архитектуре. Под научной редакцией Л. И. Кирилловой. - Глава 3. Принципы и средства композиции в современной архитектуре. - М.: Стройиздат, 1986. - с. 44-56.

[9] Гликин, Я.Д. Методы архитектурной гармонии / Я.Д. Гликин. - Л.: Стройиздат, 1979. - 96 с.

[10] Леденева, Г. Л. Теория архитектурной композиции: курс лекций. - Тамбов: Изд-во Тамб. гос. техн. ун-та, 2008. - $80 \mathrm{c}$.

[11] Хан-Магомедов, Селим. Архитектура советского авангарда. // Книга первая. Проблемы формообразования. Мастера и течения. Глава 4. Ранний этап поисков нового художественного образа. 7. И. Голосов - теория построения архитектурных организмов и теория движения в архитектуре. http://alyoshin.ru/Files/publika/khan_archi/khan_archi_1_049.html - (дата обращения 30.04.2015).

[12] Арнхейм, P. Динамика архитектурных форм / Пер. с англ. В.Л. Глазычева. - М.: Стройиздат, $1984 .-192$ с.

[13] Чинь, Фрэнсис Д. К. Архитектура: форма, пространство, композиция. / Пер. с англ. Е. Нетесовой. - М.: АСТ: Астрель, - 2010. - 432 с.

[14] Словари и энциклопедии на Академике. Философская энциклопедия. Гераклит. http://dic.academic.ru/dic.nsf/enc_philosophy/251 (дата обращения 30.05.2015).

[15] Платон. Диалоги. Теэтет - 181. - http://www.psylib.org.ua/books/plato01/22teate.htm (дата обращения 20.06.2015).

[16] Маркс, К., Энгельс, Ф. Сочинения / в 50 т. - М.: Государственное издательство политической литературы, - 1955-1981 гг. - т. 20, 563 с.

[17] Философия. Эни̧иклопедический словарь. / Под ред. А.А. Ивина. - М.: Гардарики, 2004. - 1072 с.

[18] Время. Википедия. - https://ru.wikipedia.org/wiki (дата обращения 30.05.2015).

[19] Иконников, $\boldsymbol{A}$. В. Функция, форма, образ в архитектуре. - М.: Стройиздат, 1986. - 288 с. 
[20] Ибрагимов, И.А. Характеристики визуальной динамики в архитектуре. / Вестник Челябинского государственного университета. - 2013. № 35 (326). - Филология. Искусствоведение. - Вып. 85. С. $143-148$.

[21] Арнхейм, Р. Искусство и визуальное восприятие. / Пер. с англ. В. Н. Самохина; под общ. ред. В.П. Шестакова. - М.: Стройиздат, 1974. - 386 с.

\title{
MOVEMENT AS A CATEGORY OF ARCHITECTURE
}

\author{
I.S. Zayats \\ Saint P eter sburg State U niversity of Architecture and Civil Engineering, Saint Petersburg, R ussia \\ i.vvv0302@gmail.com
}

\begin{abstract}
This article will introduce and provide a definition of "movement" as a category of architecture in the context of these traditionally accepted: form, mass, space and character. The philosophical concept of movement is directly reflected in architectural creation, as the result of historical changes in society, technological progress and the development of building technologies. Depending on the different characteristics of movement in architecture, various types of movement are introduced and described: global movement of time and historical processes; objective movement of natural elements both in nature and architectural space; subjective or functional movement, reflecting the practicability of architecture; relative movement based on the specifics of visual characters and associative movement in architectural composition. Each type affects the formation of the architectural character of the space or building and identifies the function of patterns in shaping the relationship with time, movement of natural elements, architectural space and human perception.
\end{abstract}

Key words: the architectural theory, categories of architecture, morphogenesis, the types and characteristics of movement in architecture.

Citation: Zayats IS. Movement as a category of architecture. Ontology of designing. 2016; 6(1): 95-105. DOI: 10.18287/2223-9537-2016-6-1-95-105.

\section{References}

[1] Gabrichevski AG. Morfologiya iskusstva. [Art Morphology]. - M.: Agraf, 2002. - 864 p. (In Russian).

[2] N ekrasov A. Teoriya arkhitekturi. [The theory of architecture]. - M. : Stroiizdat, 1994. - 480 p. (In Russian).

[3] Vitruvi. Desyat knig ob arkhitekture. [The ten books of architecture]. - M.: «Arkhitectura-S», 2006. - 328 p. (In Russian).

[4] L osev AF . Istoriya antichnoi estetiki. Ranni ellinizm. [The antique aesthetic history]. / Istoriya antichnoi estetiki. Tом V. - M.: «Iskusstvo», 1979. - 494 p. (In Russian).

[5] L ukretsi. O prirode veshchei. [On the Nature of Things]. / Per. S latin. F. Petrovskogo. - M.: Hudozh. lit., 1983. 383 p. (In Russian).

[6] Ocherki istorii teorii arkhitekturi Novogo I Noveishego vremeni. [The History essays of Architectural Theory of New and Contemporary time] / Antologiya. - Red. Azizyan I. A. - SPb.: Izdatelstvo Kolo, 2009. - 656 p. (In Russian).

[7] Alberti Leon Battista. On the Art of Building in Ten Books (MIT Press) Revised ed. Edition. ISBN-13: 9780262510608

[8] Somov GYu. Priroda sredstv arkhitekturnoi kompozitcii. [Nature of architectural composition] / Teoriya kompozitcii v sovetskou arkhitekture. Pod nauchnoi red. L. I. Kirillovoi. - Glava 3. Printcipi I sredstva kompozitcii v sovremennoi arkhitekture. - M.: Stroiizdat, 1986: 44-56. (In Russian).

[9] Glikin YaD. Metodi arkhitekturnoi garmonii. [Methods of architectural harmony]. - L.: Stroiizdat, 1979. - 96 p. (In Russian).

[10] Ledeneva GL. Teoriya arkhitekturnoi kompozitcii: kurs lektcii. [The architectural composition theory: lectures course]. - Tambov : Izd-vo Tamb. gos. tekhn. Un-ta, 2008. - 80 p. (In Russian).

[11] Khan-Magomedov Selim. Arkhitektura sovetskogo avangarda. [The Soviet avant-garde architecture] // Kniga pervaya. Problemi formoobrazovaniya. Mastera I techeniya. Glava 4. Rannii etap piskov novogo 
hudozhestvennogo obraza. - 7. I. Golosov - teoriya postroeniya arkhitekturnikh organizmov I teoriya dvizheniya v arkhitekture. - http://alyoshin.ru/Files/publika/khan_archi/ - (valid on 30.04.2015). (In Russian).

[12] Arnheim R.The dynamics of architectural form. 30th Anniversary Edition. ISBN-13: 978-0520261259.

[13] F ransis DK Chin. Architecture. Form, Space and Order. 3rd Edition. ISBN-13: 978-0471752165.

[14] Slovari I entciklopedii na Akademike. Filosofskaya entciklopediya. Geraklit. http://dic.academic.ru/dic.nsf/enc_philosophy/251 (valid on 20.06.2015). (In Russian).

[15] Platon. Dialogi. Teetet - 181. - http://www.psylib.org.ua/books/plato01/22teate.htm (valid on 20.06.2015). (In Russian).

[16] Marks K, E ngels F. Sochineniya. / v 50 t. - M. : Gosudarstvennoe izdatelstvo politicheskoi literaturi, - 1955-1981. - t. 20, 563 p. (In Russian).

[17] Filosofiya. Entciklopedicheski slovar. [Philosophy. Encyclopedia]. / Pod red. A.A. Ivina. - M.: Gardariki, 2004. 1072 p. (In Russian).

[18] Time. Vikipediya. - https://ru.wikipedia.org/wiki (valid on 30.05.2015). (In Russian).

[19] I konnikov AV. Funktciya, forma, obraz v arkhitekture. [Function, form, character in architecture]. - M.: Stroiizdat, 1986. - 288 p. (In Russian).

[20] Ibragimov IA. Kharakteristiki vizualnoi dinamiki v arkhitekture. [Characteristics of visual dynamic in architecture]. / Vestnik Chelyabinskogo gosudarstvennogo universiteta. - 2013. № 35 (326). -Filologiya. Iskusstvovedenie. - Vip. 85: 143-148. (In Russian).

[21] Arnheim R. Art and Visual Perception: A Psychology of the Creative Eye. University of California Press, Berkeley, CA 94720, U.S.A., 1974. New version; expanded and revised edition of the 1954 original. 508 p.

\section{Сведения об авторе}

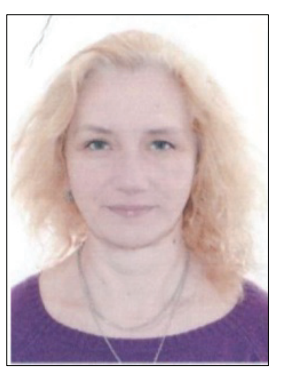

Заяц Инна Сергеевна, 1961 г. рождения. Окончила Ленинградский политехнический институт им. М. Калинина (1984 г.), Академию реставрации (г. Москва, 1994 г.). Кандидат архитектуры (2007 г.). Доцент кафедры архитектурно-строительных конструкций СанктПетербургского государственного архитектурно-строительного университета. Докторант, архитектор-реставратор, член Союза архитекторов России. Научные интересы: теория, история и методика реставрации, теория архитектуры, исторические аспекты жизнеспособной архитектуры. Автор 40 статей, монографии и более 30 реставрационных исследований и проектов.

Zayats Inna Sergeevna, (b. 1961). Graduated the Leningrad's Polytechnic Institute n. M. Kalinin (1984), Academy of Restoration (Moscow, 1994). PhD in Architecture, Associate Professor at the Saint Petersburg State University of Architecture and Civil Engineering, doctoral candidate, an architect-restorer, the member of the Union of Architects of Russia. Scientific interests: the theory, history and methods of restoration, the theory of architecture, historical aspects of sustainable architecture. The author of 40 papers, a monograph and more than 30 restoration researches and projects. 


\title{
УДК 332.1
}

\section{ЭВЕРГЕТИКА И ОНТОЛОГИИ УПРАВЛЕНИЯ ${ }^{1}$}

\author{
М.Р. Арпентьева \\ Калужский государственный педагогический институт им. К.Э. Циолковского, Калуга, Россия \\ mariam-rav@yandex.ru
}

\begin{abstract}
Аннотация
Усложнение сообществ и процессов их развития, умножение разнообразия проблем управления этими сообществами и их развитие актуализируют необходимость разработки теоретических моделей, позволяющих не только оптимизировать способы управления, но и ответить на вопрос о том, что такое управление и какое именно управление необходимо для развития сообществ как сложных, развивающихся систем. Одной такой моделью является эвергетика В.А. Виттиха, как пример трансдисциплинарного и трансдискурсивного подхода к осмыслению сути и технологий управления, позволяющая выделить стратегии, гармонично реализующие ценности и цели управления как компонента развития сообществ. Сравнительный анализ стратегий управления позволяет выделить эвергетические, псевдоэвергетические и антиэвергетические стратегии, их особенности и возможности в управлении развитием сообществ. Выделенные стратегии феноменологически сходны с различными подходами к изучению управления, отражающими те или иные его аспекты. В исследовании представлен новый взгляд на сущность, компоненты и процессы управления, предполагающего возможности оптимизации как самого управления, так и обучения управлению социальным развитием. В статье сделана попытка развития теории эвергетики как инновационного метатеоретического, трансдискурсивного подхода к осмыслению управления сложными социальными системами.
\end{abstract}

Ключевые слова: онтологии управления, управление, идеология, эвергетика, интерсубъективные технологии, эвергетические стратегии, социальное служение.

Цитирование: Арпентьева, М.Р. Эвергетика и онтологии управления / М.Р. Арпентьева // Онтология проектирования. - 2016. - Т.6, №1(19). - С. 106-124. - DOI: 10.18287/2223-9537-2016-6-1106-124.

\section{Введение}

Понятие онтологии управления может рассматриваться как «набор определений фрагмента декларативных знаний, ориентированный на совместное многократное использование практиками и теоретиками управления» [1- 5]. В современной науке и практике можно говорить о нескольких онтологиях как системах идеологий и теорий управления, реализующих их технологий и отражающих их особенности системах понятий. С одной стороны, онтология как система понятий выступает как инструмент достижения взаимопонимания в науке и

\footnotetext{
1 Эвергетика, как субъектно - и ценностно-ориентированная постнеклассическая наука о процессах управления в обществе, нуждается в разработке соответствующего онтологического основания, связанного с поисками ответов на вопросы, подобные следующим: «на каких принципах следует организовывать процессы управления в современном обществе?», «как эти принципы будут изменяться при переходе от одной общественной формации к другой?», «кто должен определять, ради чего стоит управлять?», «какие движущие мотивы могут определять стремление людей к коммуникации и достижению взаимопонимания?» и т.п. Созданию такого онтологического основания и посвящены статьи М.Р.Арпентьевой. Публикуемая статья, равно как и подобные работы, имеющие явно выраженный гуманитарный характер, представляет интерес для журнала «Онтология проектирования» и его читателей. Особое внимание следовало бы уделить публикациям, посвящённым «слиянию» человека с бытием и его участию в переменах бытия, в которых переносится акцент с научного отображения бытия на обыденное, повседневное его переживание; тем самым будет стимулироваться разработка «обыденной» онтологии, повседневного мировоззрения. Прим.ред.
} 
практике, и здесь «важна конвенция относительно факта, требующего объяснения» и управления. Как отмечают Н.М. Боргест и другие исследователи онтологий проектирования, эта конвенция важна для того, чтобы пересматривать объяснение и управление, находить новые решения и создавать новые онтологии [6-10]. С другой стороны, традиционное представлений об онтологии как науки о бытии позволяет выделить в существующих практиках и теориях управления их «технологические» и «онтологические» аспекты.

\section{1 Проблемы и задачи управления}

На сегодняшний день классическая модель управления во многом устарела, поскольку разработанный ею язык (система понятий) весьма ограничен, а бытийный аспект управления, по сути, элиминирован. Современная эвергетическая модель управления ставит перед собой вопросы о том, что есть управление и какими способами (технологиями) оно может быть реализовано, а также создаёт новую систему понятий описания процессов управления, включающую как классические, так и новые термины и взаимосвязи. Таким образом, эвергетика выступает как онтология управления в целом. Её развитие связано с тем, что усложнение сообществ и процессов их развития, умножение разнообразия проблем управления этими сообществами и их развитие актуализируют необходимость разработки подходов, интегрирующих практическое многообразие этих проблем и разрабатывающих единые, теоретические модели и мета-модели. Такие модели позволяют ответить на вопрос о том, что такое управление и какое именно управление необходимо для развития сообществ как примеров сложных, развивающихся систем. Особенно важно решение этого вопроса в отношении масштабных, трансординарных ситуаций, возникающих в результате рассогласования общественного функционирования и развития управления ими.

Возможности продуктивного осмысления постоянно меняющихся социальных отношений ограничены многочисленными нарушениями, заложенными в теории и практике экономики «дикого капитализма» или «дикого рынка», сложившихся в России на рубеже XX XXI веков. Одна из важнейших групп проблем и, соответственно, задач теории и практики управления, связана с регуляцией современного профессионального рынка труда и необходимостью делиберализации отношений государства и общества к той части предпринимательской и иных сфер активности людей, в которых отмечаются нарушения нравственных норм и прав людей. Другая - с решением вопросов прекаризации профессионального труда на фоне огромного и всё нарастающего социального неравенства, организации взаимодействия центральных и периферийных структур, защищающих права трудящихся и потребителей, наряду с правами и интересами государства и производителей. Третья проблема связана с регулированием соотношения меритократических и бюрократических («криптократических») «лифтов», необходимостью развития профессиональной и человеческой культуры граждан, в том числе предпринимателей, с целью внедрения продуктивных технологий предотвращения и коррекции профессиональных деформаций и профессионального выгорания, безработицы и дауншифтинга, профилактики иных кризисов индивидуального и организационного развития. Четвертая проблема - деформализации и десимуляции бюрократическими и иными структурами мер поддержки гражданского общества и бизнеса, а также создание механизмов участия и поддержки государства и социально ответственного и необходимого государству и обществу бизнеса гражданами. Пятая проблема - поиск новой онтологии управления как системы её идеологических, теоретических и технологических основ. Такая онтология, по мнению современных исследователей, может быть сформирована на основе феноменологической парадигмы исследования процессов управления организациями. 
Она предполагает особое внимание связи «целевой рациональности» с «рациональностями» и «иррациональностями» ценностно-смысловыми.

\section{2 Эвергетика В.А. Виттиха}

Одним из примеров реализации этой парадигмы является эвергетика В.А. Виттиха, являющаяся иллюстрацией трансдисциплинарного и трансдискурсивного, онтологического подхода к осмыслению сути и технологий управления. Эвергетика позволяет выделить стратегии управления, более или менее гармонично реализующие его ценности и цели, а также разработать новые и дать новое осмысление традиционным технологиям управления как компонента развития сообществ. Эвергетика развивается как попытка развернутой многоуровневой рефлексии сути управления, его ценностно-целевых основ, взаимосвязи теории и практики управления, из развития в исторической и диахронической перспективах. Рефлексия как основание трансдискурсивности и трансдисциплинарности позволяет, особенно в изучении сложных феноменов, включая феномен управления - человеком, организацией, сообществом - интегрировать имеющиеся модели и практики управления, сопоставляя их как феноменологически сходные стратегии управления [11, 12].

Концепция эвергетики возникла как ответ на вопросы продолжающихся реформ в России: страны, стремящейся стать социальным государством. Эти реформы все больше меняют характер профессионального и непрофессионального труда, включая организационную и нормативно-ценностную составляющую деятельности бизнеса (предпринимателей). Изменяется общий характер отношений общества и бизнеса, бизнеса и государства, государства и общества ${ }^{2}$. Происходят изменения, связанные с переосмыслением роли значимости человеческого и, в том числе, социального капитала, в развитии центральных и периферийных территорий. Эти изменения связаны с осознанием значимости отношений социального партнерства и сотрудничества «центра» и периферии, предпринимателей и потребителей, профессионалов и непрофессионалов, постижением совместной жизни в контексте представлений о социальном служении и взаимопомощи.

Концепция эвергетики развивается в работах В.А. Виттиха и его школы на пересечении теоретического осмысления процессов управления сложными системами и практического опыта внедрения принципов эвергетики в деятельность самых разных «примеров» этих сложных систем [12]. По мнению В.А. Виттиха современные теория и практика управления сложными системами обращены к осмыслению роли социальных коммуникаций в формировании, функционировании и развитии (инноватике) организаций и сообществ. Разделение функций управления, жёсткая иерархия, вертикальность и моносубъектность коммуникаций традиционных организационных структур в современном, инновационном, интерсубъектном творчески ориентированном бизнесе и менеджменте всё больше заменяются социальным партнёрством, консенсусом, горизонтальными коммуникациями, эвергетикой. Стратегия «изолированного руководства», стоящего над людьми, и стратегия соавторства - это, по сути, дискурсивный и трансдискурсивный методы осмысления происходящего в организации и сообществе. Трансдискурсивным является подход и/или управление, субъект которого находится в центре дискурса, обозначая круг проблем, которыми живёт данный дискурс [11]. Дискурсивным - подход, который не предполагает возможности выхода за рамки сложившихся отношений, рефлексии и изменений. Трансдискурсивность неразрывно связана с

\footnotetext{
${ }^{2}$ Указанные сущности общество, государство, бизнес и атомарная их сущность человек интуитивно понятные, но онтологически не определены, что не позволило автору на этом этапе предложить и построить саму онтологию управления, обозначив лишь принципы её формирования без обсуждения адекватного бытию механизма их реализации. Редакция приглашает восполнить этот пробел и предложить своё видение онтологии проектирования общественных институтов. Прим.ред.
} 
функциями рефлексии, управления и прогнозирования. Необходимость трансдискурсивного подхода в осмыслении феноменов управления - результат умножения его концепций и моделей, приводящая к необходимости построения нового, мета-аналитического уровня осмысления феноменов управления, их интеграции в единое поле. Основой такого поля может стать эвергетика.

Кроме того, в теории управления сложными системами В.А. Виттиха ставится основной вопрос о сущности современного управления: дело не в том - как, а в том - для чего, ради чего - управлять [13]. Важно не просто думать о том, как повысить эффективность управления человеческими ресурсами и общественным развитием, а о том, каковы цели управления как такового. Эвергетика есть попытка осмыслить глубинную суть управления, в отличие от традиционных попыток исследования его феноменов. В отличие от классических теорий управления она позволяет ответить не только на вопрос о том, чем отличается плохое управление от хорошего, но и о том, что в некоторых случаях называемая «управлением» совокупность действий субъекта не просто не является управлением, но и может рассматриваться как «антиуправление». Она позволяет отличить ситуации, в которых можно говорить об управлении и в которых можно говорить лишь о попытках его имитации.

\section{3 Модели общества}

Целью традиционных рационалистических, прагматических моделей в классических исследованиях и исследованиях «мальтузианских» представителей постмодерна, для которых «нравственно то, что выгодно», является достижение такого уровня руководства (разработка таких его технологий), которые позволяли бы достигать $100 \%$ успешности и результативности управления. Эти технологии в основном включают способы манипуляции обществом и его членами, направленные на формирование единообразных, предсказуемых, лишённых попыток осмысления реакций людей-рабов, предполагают, по сути, уничтожение противников рабства и геноцида. Они ориентированы на уничтожение оппозиции, препятствующей разрушению традиционных нравственных ценностей (духовно-нравственное разложение, отчуждение и дезориентацию населения), а также основанных на них «социальных связей», «организационных мостов» и «семейных уз», на создание препятствий доверию и взаимопомощи, в том числе - средствами пропаганды примитивизма, вседозволенности и «квалифицированного» потребления. Они нацелены на создание препятствий развитию человека как личности, профессионала и партнера, - конкурента в сражении за власть и за жизнь в целом, и вырождаются в социальный каннибализм. Последний в своём предельном развитии включает отказ от технологического прогресса и инноваций или их существенное ограничение. Это позволяет удерживать иллюзию контроля процессов социального функционирования и развития, предотвращать и пресекать «несанкционированные» формы реагирования: совершая выбор между рабом и роботом, своим комфортом и выживанием и выживанием и развитием других людей, общества, представители власти однозначно выбирают собственный комфорт и успех.

Они видят общество однородным и безликим. Как отмечал Р.Л. Акофф [14], классическое представление об однородности, гомогенности общества как функционирующего по определённым правилам, не учитывающее «наложения» и взаимодействия вертикальных и горизонтальных коммуникаций, особенностей их ценностно-целевого и смыслового содержания в организациях разных типов и уровней развития, как относительно простого феномена, используемое в традиционном менеджменте, представляет «человека вообще». Этот «плоский человек» (a man) предназначен для того, чтобы смотреть на себя «со стороны», в том числе - со стороны общества или государства, со стороны менеджера как «хозяина по- 
ложения», который редуцирует социальные связи, организационные мосты и даже семейные «узы» к предписанным им (субъектом) устойчивым правилам, опирающимся на соответствующие идеологии (например, иерархическим, отчуждённым, ролевым отношениям между «начальниками» и «подчинёнными»). Даже в семье и наедине с собой «плоский человек»- не более, чем лишённая внутренней сущности совокупность общественных отношений. С точки зрения гомогенной модели общества человек - «винтик», «раб», функция коллективного производства. Само общество и организация состоят в отношениях «потребления», обратные связи между ними сведены к функционально необходимому минимуму. Иначе - в феноменологических, эвергетических моделях социальной сложности, общества как системы, основанной на принципах многостороннего и многоуровневого социального партнерства. В этой системе социальные связи, организационные мосты и семейный узы людей - компоненты социального капитала, который может отличаться по своему качеству, но в целом служат развитию людей, организаций, общества. Гомогенная модель общества изначально служит превращению людей в «однородную массу», это - псевдоэвергетическая стратегия классического рационализма, часто маскирующаяся «многообразием» постмодерна.

В современных моделях общество выступает как сложная, гетерогенная развивающаяся система. Каждый человек - с его субъективными представлениями о мире (the man) - oсмысляет себя в диалоге с другими, само общество - «калейдоскоп ситуаций» и «гетерогенных акторов». Интерсубъективность сознания и жизнедеятельности побуждает людей коммуницировать, совместно искать выход из сложившейся ситуации, создавая «интеграционную платформу» знаний, умений, идеологий, используемых для принятия управленческих и эвергетических решений. Иерархию заменяет лоурархия как социальное служение, взаимопомощь и социальное партнерство, которые дают обществу возможность сохранять гибкость и выживаемость [14]. Организация перестает игнорировать общество, включает его в свою жизнедеятельность как партнёра и приоритет. Гетерогенное представление об обществе, обращённое на конкретных индивидов и групп, являющихся одновременно и субъектами, и объектами управления, учитывает их ценностно-смысловые ориентиры и в процессах принятия решений об урегулировании и развитии проблемной ситуации (Таблица 1).

\section{4 Человек культуры и поиск «третьего пути»}

Постнеклассическая рациональность отражается в эвергетике, её теории интерсубъективного управления, управления «человеком культуры» «человека культуры», их сотворчества культуры и, в том числе, идеологии общества. Этим она отличается от вынужденного работать на общество «экономического человека» в классической рациональной теории управления. Каждый человек и каждая группа этого общества заинтересованы в преумножении культурного наследия, включая увеличение доли управленческих решений, направленных на благо с помощью благих действий: опирающихся на идеологию социального служения (взаимопомощи и партнерства).

Эвергетика есть попытка нахождения альтернативы безликому хаосу «демократической» толпы и столь же безликой автократии бюрократической системы. Она опирается на работы критиков демократии. Так, К. Поланьи ${ }^{3}$, ставивший целью «поиск «третьего пути», отличного от единоличной автократии и демократической бюрократии, создание теоретической основы идеального общественного устройства, где человек является главной ценностью», исходил из того, что люди в любом обществе коммуницируют на основе принципов дарообмена (то есть взаимности, реципрокности), централизованного перераспределения (отчужден-

\footnotetext{
${ }^{3}$ Карл Поланьи (1886-1964) — американский экономист, антрополог, социолог и политический философ венгерского происхождения, один из основоположников экономической антропологии. Прим.ред. 
ной редистрибуции) и рынка (аномичного обмена). Однако, соотношение этих принципов в жизни каждой страны и региона индивидуально. Характер развития страны есть «результирующая» выделенных К. Поланьи векторов социальных коммуникаций [15].

Таблица 1 - Модели общества и эвергетические стратегии

\begin{tabular}{|c|c|c|c|}
\hline$\stackrel{5}{\stackrel{5}{0}}$ & $\begin{array}{l}\text { пассическая, рационали- } \\
\text { ическая модель (разви- } \\
\text { я) общества }\end{array}$ & $\begin{array}{l}\text { ическая модель } \\
\text { я ) общества }\end{array}$ & $\begin{array}{l}\text { Постнеклассическая } \\
\text { (развития) общества }\end{array}$ \\
\hline 兽 & $\begin{array}{l}\text { Рациональность, гомоген- } \\
\text { ность, универсальность, одно- } \\
\text { типность, простота, отноше- } \\
\text { ния хозяев и рабов, «челове- } \\
\text { ческий материал», «рабочая } \\
\text { сила» }\end{array}$ & $\begin{array}{l}\text { Иррациональность, внеш- } \\
\text { няя гетерогенность, хаотич- } \\
\text { ность, разнотипность, } \\
\text { сложность, отчужденность, } \\
\text { человеческие «ресурсы», } \\
\text { «человеческий фактор» } \\
\end{array}$ & $\begin{array}{l}\text { Гармоничность, гетерогенность, } \\
\text { мультистратегичность, } \\
\text { сложность, социальное парт- } \\
\text { нерство, социальный и челове- } \\
\text { ческий капитал }\end{array}$ \\
\hline 总 & $\begin{array}{l}\text { Антиуправление, псевдоцен- } \\
\text { ности и псевдотехнологии } \\
\text { управления, достижение соб- } \\
\text { ственных целей за счет орга- } \\
\text { низации (общества) }\end{array}$ & $\begin{array}{l}\text { Рамочное или делегирую- } \\
\text { щее управление «по ситуа- } \\
\text { ции», псевдоуправление, } \\
\text { отказ от управления, } \\
\text { технологии, замещающие } \\
\text { управление }\end{array}$ & $\begin{array}{l}\text { Партисипативное, «управление } \\
\text { по целям» ценностно-целевое, } \\
\text { сотрудничество и взаимопо- } \\
\text { мощь в развитии как ведущая } \\
\text { технология управления }\end{array}$ \\
\hline 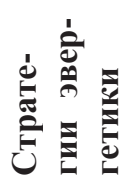 & $\begin{array}{l}\text { Социальный каннибализм и } \\
\text { взаимное потребление, ре- } \\
\text { прессии и принудительная } \\
\text { редистрибуция }\end{array}$ & $\begin{array}{l}\text { Ільная аномия и от- } \\
\text { ние, имитации отно- } \\
\text { í и «дикий» рынок }\end{array}$ & $\begin{array}{l}\text { Социальное служение и взаи- } \\
\text { мопомощь, дароообмен и мило- } \\
\text { сердие, антиконсюмеризм }\end{array}$ \\
\hline 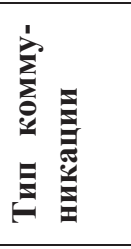 & $\begin{array}{l}\text { Фатическая коммуникация, } \\
\text { игнорирование мира как } \\
\text { «среды» существования субъ- } \\
\text { екта управления (потребле- } \\
\text { ния), вертикальные обезли- } \\
\text { ченные коммуникации }\end{array}$ & $\begin{array}{l}\text { Монолог субъекта управле- } \\
\text { ния, вертикальные комму- } \\
\text { никации субъектны, гори- } \\
\text { зонтальные коммуникации } \\
\text { обезличены и пресекаются }\end{array}$ & $\begin{array}{l}\text { Полилог, многоуровневая и } \\
\text { многоаспектная коммуникация } \\
\text { субъектов с собой и миром, вер- } \\
\text { тикальные и горизонтальные } \\
\text { коммуникации субъектны }\end{array}$ \\
\hline
\end{tabular}

Рыночные отношения, которые предполагают более или менее взаимную калькуляцию выгод и издержек, также разрушают человеческие отношения и признаки культуры, нравственность. В мире «ситуативных» знаний, «дигитальной нравственности» и «технического родства», вызревающего в «плюрализме» социальной аномии, личность с рождения усваивает идеологию обмана и подавления. «Сайентифицированная» и «мифологизированная» «массовая культура» стран, забывших о необходимости уважительного отношения к сакральным и нравственным ценностям, превращается в тотальное бескультурье, субъект и сообщество приучаются к фамильярно-потребительскому отношению к себе и миру. Рынок ведёт к дестабилизации общества и более или менее явно выраженному централизованному перераспределению власти бюрократией и криптократией («теневым правительством», олигархами). Таким образом, вновь возникает редистрибуция как одна из форм уравнительного распределения, которая направляет развитие сообществ и стран в отношения всё нарастающей, многоуровневой и полиморфной эксплуатации. Как её антипод, обмен дарами осуществляется свободно, без гарантий и требований возмещения затрат. Он также может стать асимметричным, вырождаясь в редистрибуцию или консюмеризм (потребительство). Однако этому противостоит система нравственных и иных ценностей обменивающихся [15].

Исследованиями социального и человеческого капитала показана интерсубъектность и интерсубъективность управления, его эвергетичность: наиболее прибыльным является вложение в людей, а не в их «использование» и уничтожение. Однако опирающаяся на классический подход доминирующая в современном мире мальтузианская модель управления (свя- 
зывающая нищету и бесправность народных масс не с общественным строем, а с быстрым ростом населения и медленным увеличением средств существования) об этом предпочитает умалчивать. Мальтузианская модель «ножниц» продолжает настаивать на важности глобализации, мондиализации и дистрибуции ресурсов и прав, включая право на жизнь. Она поддерживает антиэвергетический дискурс, в рамках которого люди - не более чем «расходный материал» производства. Нарастающее замалчивание репрессивно-карательной сути общества «всеобщего потребления» становится следующим этапом «точки невозврата»: в нарастании проявлений социального коллапса. Интерсубъективность всё более сворачивается, «монолит» бюрократической системы - всё более фрагментируется и распадается. Таким образом, современный мир живёт в условиях отсутствия справедливой и сбалансированной, этически насыщенной рыночной среды хозяйствования, дееспособных государственных политик в отношении промышленности и предпринимательства в целом. К этому добавляется поддержка государствами разных стран почти исключительно наиболее крупных и экономически эффективных предприятий, монополизирующих рынок стратегий. Их судьба и выживание - вопрос времени и идеологии: служат ли они чему-либо и, если да, то кому. Для остальных игроков рынка и, тем более, отдельных граждан, пытающихся просто выжить и сохранить домохозяйство и самого себя как таковых, именно коммуникационные, «мультиакторные» или интерсубъективные технологии являются стратегическим резервом выживания и развития [16-18]. Общество, малый и средний бизнес, граждане и гражданское общество могут найти много нового и полезного в сотрудничестве. Государство и большой бизнес получают в этом случае информацию о том, насколько важны отношения взаимной поддержки и партнерства. Они могут на практике понять, насколько важно действительно нравственное отношение друг к другу, а не просто использование «человеческого и социального материала» в целях бизнеса.

\section{5 Эвергетические стратегии}

В управлении государством, организацией, человеком можно выделить эвергетические стратегии - способы управления, опирающиеся на социальные идеологии как системы ценностно-смысловых представлении субъектов о социальном мире и его компонентах. Параллельно, можно выделить разные дискурсивные стратегии изучения управления как:

- манипулирования «хозяином» своими «рабами» - превращения субъектов производства в «объекты»;

- руководства «человеческими ресурсами», чей «человеческий капитал» составляют, прежде всего, профессиональные и связанные с ним ресурсы, а социальный капитал «облегчает, «фасилитирует» производственные процессы;

- полилогического сотворчества, социального партнерства, взаимопомощи и взаимообучения, в процессе которого реализуется и развивается, накапливается и воспроизводится человеческий и социальный капитал - общество $[19,20]$.

Данные стратегии реализуются с помощью специфического набора технологий: онтологические модели управления (его цели и средства) во всех трёх случаях различны.

Эвергетика как онтология утверждает продуктивность и эффективность гуманитарных социальных технологий управления, подчеркивая их направленность на активизацию и привлечение граждан к участию в деятельности производственных организаций, предпринимательства, государственных и общественных структур [21-23].

В региональном и государственном управлении обычно нет возможности использовать знания огромного количества людей, всех, кто не смог попасть на встречи или «достучаться» до лиц, принимающих решения. Участие множества людей с использованием методов сете- 
вого, «крауд-» и/или интерсубъективного управления, позволяет начать решать данную проблему [21-23]. Однако идеология толпократии страдает многими ограничениями: «умная толпа» очевидно не так умна и однородна, как это представляется сторонникам краудтехнологий. Напротив, сознание большинства становится всё более фрагментированным и неразвитым.

Эвергетика помогает уйти, с одной стороны, от спонтанности (хаотичности) взаимодействия граждан с органами управления и самими бизнес-структурами, a, с другой, избежать жёстких, некорректных и малопродуктивных решений. В этом случае процесс согласования интересов выходит на новый уровень, который характеризуется осознанностью отношений и конструктивностью взаимодействия. Глубинный источник эвергетики - идеология социального служения. Стимулируемые ею взаимопомощь и социальное партнёрство обеспечивают, кроме прочего, социально-политическую мобильность и лояльность общества и правящей «элиты». Именно поэтому концепция энергетики приобретает статус онтологии, причём не только онтологии управления, но онтологии общественного бытия в целом: интерсубъективность управления - другое название качественно новой ступени общественных взаимоотношений. На основе концепции интерсубъективного управления В.А. Виттиха могут быть и должны быть созданы интерсубъективные технологии, позволяющие людям реально участвовать в процессах управления собственной жизнью, а также не просто удовлетворять собственные желания и потреблять, а служить себе и обществу, реализуя истинные нужды.

\section{6 Общество социального служения}

Важнейшими, сущностными моментами отношений человека, общества и государства, предпринимателей и потребителей являются отношения «социального служения»: взаимной помощи индивидов, общественных организаций и государства. В прошедшие под знаком «буржуазной морали» столетия идеология «нравственно то, что выгодно» практически себя изжила. Производство ради накопления власти и финансовых капиталов не удовлетворяет ни общество, ни государство, ни сам бизнес. Аналогичным образом, гротескно выраженный и всё усиливающийся контроль государством так и неразвившегося в России гражданского общества и почти полное отсутствие контроля коррупционных государственных и бизнесструктур продемонстрировали, что игнорирование и подавление не могут быть способом решения проблем. Нужны иные способы, в том числе, способы предотвращения и коррекции состояний, подобных «майданам». Это способы, обращённые к уважению человеческого достоинства и нравственности, к мнению и жизни «маленького человека», в том числе безотносительно к их непосредственной, сиюминутной экономической выгоде. Социальное служение как антипод «административного восторга» и «экономического гангстерства» властей, как сотрудничество и паритетность государства и граждан, потребителей и предпринимателей, предполагает, что социальное служение становится специфической сферой или ведущей идеей жизнедеятельности общества, государства и предпринимательства [24-26]. Оно имеет общие задачи восстановления, оптимизации и развития человеческих сообществ и нравственных основ их функционирования, ориентируясь на долгосрочные «выгоды» и развитие.

Социальное служение в современной России в основном понимается как совокупность организованных форм социальной деятельности религиозных организаций, в меньшей степени - коммерческих и иных организаций и индивидов. Оно является неотъемлемой частью практической реализации нравственных основ человеческого бытия, той идеологии служения, которая объединяет эти законы и задаёт смысл государства, бизнеса, частной жизни. Служение включает как акты милосердия и благотворительности, так и акты совместной деятельности, поиска и внедрения нравственных форм управления жизнью человека, организа- 
ции, государства. Людей, занимающимся социальным служением, принято называть благотворителям или добровольцами. Понятие доброй воли является, по-видимому, ключевым: чтобы избежать закономерного коллапса, необходимо кардинально изменить системы отношений.

Основа служения - нравственность (чувство долга, сострадание к ближнему) и стремление к развитию (стремление к постоянному личностному и социальному росту, совершенствованию). Поэтому оно, по своей сути проективно, направлено на то, чтобы средствами социального участия строить и реализовывать гармоничные с точки зрения внутренней и внешней структуры проекты социального развития центральных и периферийных территорий, поддержки развития организаций и индивидов. Однако на пути к нему руководство регионов часто выбирает не прямые, а обходные пути: модели и идеологии управления, сложившиеся в эпоху классического рационализма, довлеют над организациями. Вместе с тем, правительство и бизнес в России всегда уделял внимание благотворительности. В будущем эта тенденция, очевидно, будет усиливаться, поскольку социальный и человеческий капиталы в современном мире, как показали исследования экономистов XX века, должен учитываться, по крайней мере, наравне с финансовым и материальным. Если же речь идёт о навёрстывании упущенного Россией в контексте «смены технологических укладов», перехода к технологиям всё более высокого уровня, то забота о социальном и человеческом капиталах становится приоритетной.

Сопротивление «поддержке» кадров в организации и людей вне неё, типичное для современного российского бизнеса и государства, практикуется потому, что «деловые» отношения в России в массе своей изначально основаны на нарушении нравственных норм и представляют не что иное, как более или менее замаскированную форму социального каннибализма: идеологии потребления, при котором потребляющие готовы ради прибыли на всё, включая уничтожение «несогласных» потребителей, работорговлю и отказ от прогресса. Кадровый менеджмент и управление во многих организациях и регионах России часто организованы так, что стимулируют, а не препятствуют текучести кадров, депрофессионализации и дауншифтингу. Отношение же к потребителям хорошо отражает понятие «одноразовый»: производство одноразовых и/или заведомо вредных для человека, его душевного и физического здоровья товаров, вытеснение с рынка добросовестных производителей и эксплуатация низменных инстинктов «толпы» - последствия идеализации ценностей «цивилизованного мира» (демократии, потребления, успеха и т.д.).

\section{7 Коллапс консюмеристских сообществ}

Поскольку коллапс консюмеристских сообществ - неизбежность, постольку нужно говорить о перспективах и альтернативах. В качестве ведущей альтернативы обществу потребления можно назвать лишь общество социального служения. Конечно, реформы не идут непрерывным потоком: каждый шаг делается после длительных согласований и т.д.; даже такой очевидный вопрос как «выгоды» социального и человеческого капитала, несмотря ни на что, продолжает оспариваться. Одна из причин хорошо иллюстрируется трудами Дж. Коулмана, который полагает, что индивид обращает внимание на важность других людей в своей жизни, отношений с ними вынужденно [27]. Он вынужден считаться с тем, что, как и другие формы капитала, социальный и человеческий капиталы приносят дивиденды лишь в случае их использования: и просто «вклады», «размещение под проценты» малоэффективно, капитал должен работать, участвовать в процессе производства. Поэтому в концепции «кредита добрых дел» отношения людей и групп строятся по принципу «ты мне - я тебе». Чем больше в группе невыплаченных кредитов (взаимных обязательств помочь), тем выше социальный 
капитал: люди не могут выйти из системы, они поставлены в столь тесную взаимную зависимость, что выход одного звена рушит всю цепь. Напротив, пользуясь социальным капиталом, человек обычно его истощает (даже оказывается «в долгах»). Но, чтобы быть полезными, людям и организациям всё же приходится использовать свои связи, и цикл замыкается: служение и взаимопомощь носят вынужденный характер или выступают как способы «зарабатывания» капитала, манипуляции партнерами и т.д. [27]. Речь идёт об управлении, построенном на основе зависимости членов друг от друга и вынужденных «кредитов доверия»«доверительных расписок». Что же касается человеческого капитала, при таком «вынужденном» отношении к обменам ресурсами с другими людьми нельзя ожидать, что руководитель будет заинтересован в поддержке и развитии подчинённых. Напротив, выгодно довольствующееся полуфабрикатами, «усилителями вкуса», слепое и глухое ко всему, кроме собственных инстинктов, «болото». Именно с этим можно связать пропагандистскую кампанию в отношении крауд-технологий: утверждать «ум» толпы можно лишь имея на то какие-то основания, теоретические и эмпирические исследования. Ни тех, ни других на рубеже прошлого и нынешнего веков не проводилось, а опыт «голосований» демократических стран показывает, что демократическим можно с успехом называть и государство с выраженными фашистскими ориентациями.

На практике люди обычно соглашаются с тем, что решения принимаются за них и вместо них, однако, также обычно отвечают на них «протестными» формами деятельности, например, «протестным голосованием» как отказом выражать свою волю вообще, а также постоянной «усталостью» и поиском не связанного с внешними мотивами труда. Периодические все более масштабные коррупционные скандалы вызывают у граждан сомнения в своей способности оказывать влияние на процесс принятия в стране политических решений, на свою жизнь вообще. Возникают состояния постоянной усталости и готовности к взрыву [28, c.233]. При этом даже «поддержка» государства, направленная, например, на конкретное предприятие и людей, работающих на нём, от банкротства и т.д., протестность не отменяет: самостоятельный выбор продолжает оставаться недоступным. Государство как «монолит» не даёт возможность участвовать в принятии решений, решая всё «за человека». Человек пассивно соглашается и перенимает репрессивную идеологию до той поры, пока не возникает коллапс. Во время коллапса он либо погибает вместе с государством, либо переходит на иные формы жизнедеятельности.

\section{8 Меритократия и бюрократия}

В другой модели - общественного ресурса, - социальный капитал есть имманентная характеристика структуры человеческих отношений: будучи связанным с другими людьми, человек получает множество преимуществ [29]. Более того, если человека окружают талантливые, профессиональные люди, это положительно сказывается на его жизни и развитии. Однако в этой концепции вводится важное разграничение и выделяется важное представление о феномене, названном нами «антикапитал»: сплочённость группы делает её более закрытой для новичков. Группа может помешать одному из её членов достичь успеха: имея определённые обязательства и общие паттерны поведения в группе, человек не может легко и без больших потерь из неё выйти. Кроме того, внутри групп с высоким уровнем социального капитала социальный контроль подчас настолько высок, что существенно ограничивает свободу людей, а значит и их развитие (развитие человеческого капитала). Это особенно характерно для бюрократических - «монолитных структур», с высокой степенью иерархизированности отношений. Чрезмерно развитый человеческий капитал, даже в форме меритократии, не свободен от опасности всех бюрократических систем: дальнейшей иерархизации и самоудо- 
влетворения вплоть до полного коллапса, самоуничтожения. Всё это - чрезмерно выраженное и лишённое нравственной основы, направленности власти на социальное служение, может привести к замедлению развития группы, организации или региона, конфликтам и бунтам, коллапсам на уровнях государства, бизнеса и общества. Формирование и развитие, инволюция и разрушение компонентов социального капитала, глубина его продуктивной и негативной трансформации (реформации или деформации) различаются в группах с высоким и низким уровнем принятия социальных нормативов. Здесь важны показатели индивидуальной ответственности, интеллектуальной независимости и уважения к праву, а также ориентации на инновационное, творческое отношение к жизни, не только на получение вкладов и инвестиций сообществ в жизнь его членов, но и на отдачу, служение членов сообщества друг другу и обществу в целом. Что касается антикапитала, это, прежде всего, капитал «спаянных одной цепью»: моноакторное управление с высокой степенью иерархизации приводит к интенсивной бюрократизации (и коррупции) управления и выхолащиванию его сути. Бюрократия начинает жить «наряду с обществом», по своим собственным законам, потребляя общество по мере необходимости как жизненный ресурс, аналогичный ресурсам материальным.

\section{9 Социальное партнёрство и антикапитал}

В третьей модели - социального развития - использование капитала означает его автоматическое развитие: чем больше тратится, используется капитал, тем быстрее и больше он развивается, увеличивается. В этой концепции социальный капитал, как и капитал человеческий, - социальное богатство личности и общества, которое выражается в совокупности межличностных связей, предоставляет доступ к личностным и профессиональным ресурсам партнёров и даёт возможность партнёрам пользоваться её ресурсами [29]. При этом человеческий капитал не сводится к выработанным способностям человека, не является просто знаниями и умениями, подобно обычному пониманию человеческого капитала, не запечатлевается в человеке в виде «инкорпорированных навыков». Социальный капитал не существует вне людей, но и не является атрибутом какого-то отдельного человека: это капитал межличностный, партнёрский. Эта модель наиболее близка развиваемой самарскими учёными эвергетике. Становление партнёром - важный этап развития человека, с которым, с одной стороны, связано становление личностью и профессионалом, то есть - человеческий капитал, а с другой - партнёром. В современном обществе становление партнёром далеко не всегда происходит автоматически и просто [30, 31]. Быть партнёром, сотрудником - вторая ступень развития человека. Быть партнёром предполагает «три открытости»:

- открытость отношениям и установка на причастность: отношения - это работа; она «осуществляется как ради своего, так и ради взаимного удовлетворения»;

- открытость пониманию как готовность рисковать, пытаясь передать ценности и смыслы партнёру и осмыслить принимаемое от него, готовность принять риск быть отвергнутым, непонятым, а может быть и наказанным, вызвать агрессию и враждебность;

- открытость изменениям и неприятие лжи как попыток жить в соответствии с частичным и амбивалентным принятием нормативов, которые навязываются друг другу - без осмысления и обсуждений, даже - без компромисса.

Эти открытости «грозят» конфликтами, но и открывают дорогу диалогу и прогрессу личностному, межличностному, организационному и государственному согласованию потоков развития партнёров. «Закрытости» загоняют проблемы внутрь, в репрессии и взаимное уничтожение, ведут к деградации, к дауншифтингу как разрыву партнёрских и иных отношений в целом. Открытость как основа партнёрства базируется на уважении и доверии: при- 
водит к накоплению и развитию социального и человеческого капиталов, закрытость - к разрушению имеющегося и накоплению антикапиталов.

Как и социальный капитал, человеческий капитал также может быть отрицательным, антикапиталом. Отрицательный человеческий капитал или, в наших терминах, антикапитал, — часть накопленного капитала, не дающая полезной обществу и человеку отдачи от инвестиций в него, но, напротив, препятствующая росту качества жизни населения, развитию общества и личности. Так, преступники, наркоманы и просто бездельники могут быть оценены как потерянные для общества, организаций и семей субъекты, как потерянные инвестиции. Сюда же можно отнести, по сути, и всю бюрократию, со свойственным ей игнорированием нужд населения, коррупционной направленностью, склонностью к мародёрским и компрадорским формам жизнедеятельности («освоению» государственных и общественных ресурсов в целях собственного обогащения, «административный восторг» и «реформы» как программы, направленные на развал правоохранительной, здравоохранительной, научнообразовательной и иных сфер).

Накопленный отрицательный человеческий капитал (антикапитал) активно проявляет себя в периоды бифуркаций и революций, смены поколений - в условиях неравновесных состояний капитал может быстро изменить свои «знак» и иные качественные и структурные характеристики. Отрицательный человеческий капитал формируется на базе негативных сторон функционирования нации, страны, на низкой культуре отношений к себе и миру значительной части населения. Кроме того, можно выделить пассивно-нейтральный человеческий капитал - человеческий капитал, не вносящий вклада в процессы развития страны, в инновационную экономику, направленный человеком на собственное потребление и комфорт. В положительную часть капитала входят трудолюбивые профессионалы, люди, занимающиеся благотворительностью и разделяющие идеалы служения обществу, взаимопомощи: идеологию социального служения. Положительный человеческий капитал - это креативный или инновационный капитал. Его определяют как обеспечивающий полезную отдачу от инвестиций в него в процессы развития: в повышение и поддержание качества жизни населения, в рост инновационного и институционального потенциалов.

Таким образом, в первых теориях социального капитала предполагалось, что чем крепче взаимосвязи и взаимозависимость людей, тем больше их социальный капитал и меньше необходимость в нормативном регулировании отношений. Однако данный постулат должен быть уточнён: социальный капитал тем больше, чем крепче продуктивные взаимосвязи между людьми, чем прочнее не столько взаимозависимость, сколько прочнее и многообразнее функционально-ролевые и интимно-личностные взаимосвязи, чем выше уровень развития сообщества как субъекта жизнедеятельности, включая его характеристики как носителя идеологии и включённых в неё духовно-нравственных ориентиров, способов взаимоотношений.

Антикапитал, как и капитал, может накапливаться, приводя к разрушению сообщества, его производительных ресурсов, коллапсу государств и смерти людей. В этом смысле социальный антикапитал (недоверие и конфликтность, стереотипные и обыденные представления о себе и мире, эгоизм как консюмеризм, властно-репрессивные и отчуждённые, лишённые экзистенциальной наполненности, смысла отношения и т.д.), является фактором, оказывающим негативное воздействие на накопление и использование материального и других видов капитала. В основе доверия, как ведущего компонента социального капитала людей и сообществ, лежит вера во взаимность, в действенность взаимных связей - взаимопомощи, взаимная толерантность и сплочённость (поддержка друг друга). В основе профессионализма - как ведущего компонента человеческого капитала - лежат духовно-нравственные ценности, а также личностная зрелость и зрелость отношений. 
Формирование и развитие, инволюция и разрушение компонентов социального капитала, глубина его продуктивной и негативной трансформации (реформации или деформации) различаются в группах с высоким и низким уровнем принятия социальных нормативов, включая показатели индивидуальной ответственности, интеллектуальной независимости и уважения к праву, а также ориентации на инновационное, творческое отношение к жизни, не только на получение вкладов и инвестиций сообществ в жизнь его членов, но и на отдачу, служение членов сообщества друг другу и обществу в целом. Таким образом, организация перестаёт игнорировать общество, но, напротив включает его в свою жизнедеятельность как партнёра: начиная с типичного для классической модели этапа «потребления» и моноакторного, «моносубъективного» управления до крауд-технологий и далее - интерсубъективного управления, реального участия людей в разработке и производстве потребляемого обществом организационного «продукта».

\section{0 Продуктивная конкуренция и вложение в людей}

Для эффективного функционирования и накопления социального и человеческого капитала необходимо конкурентоспособное качество жизни, включая безопасность, относительно комфортные условия жизни, а также свобода изучения себя и мира при наличии прочной идеологической основы, направленной на развитие человека и общества, сформированных духовно-нравственных ориентиров жизнедеятельности. Основными «драйверами» его развития являются продуктивная конкуренция, осмысленные инвестиции, системные инновации и - наличие нравственно определённых целей производства и жизни в целом. Развитие человеческого капитала связано с развитием общественного и, при наличии гуманных отношений в сообществе, активно развивается и служит развитию сообщества. Развитие человеческого капитала опирается на инвестиции в подготовку и переподготовку, рабочее состояние социальных лифтов, высокопрофессиональный коллектив, наличие нравственно определенных целей производства и жизни. В ситуации доминирования потребительских отношений человеческий и социальный капитал в должной мере не используются и не развиваются, превращаются в элемент манипуляции отношениями и жизнями людей и организаций.

Однако вопреки исследованиям в парадигме социального и человеческого капитала, отражающим интерсубъектность управления, его эвергетичность, показывающих, что наиболее прибыльным является вложение в людей и отношения между людьми и организациями, а не в их уничтожение, мальтузианская модель об этом целенаправленно умалчивает. Современное управление ищет пути, которые могут дать ему больше власти и контроля: последние видятся необходимыми перед лицом нарастающих сопротивлений и конфликтов власти и общества, бизнеса и власти, общества и бизнеса и т.д. Даже игра в демократию и всеобщее участие в управлении миром сторонникам мондиализации кажется опасной и экономически невыгодной. Напротив, активно поддерживаются «судебные реформы» и «приватизации»: усиление репрессивно-карательных режимов, подающих под видом «порядка» насилие над личностью и обществом, коррупция как «освоение» ресурсов, поддержка социального расслоения [26-29]. Поддержка негосударственных институтов и организаций во многих отношениях воспринимается как невыгодная. На этих путях социальный и человеческий капитал ценится лишь постольку, поскольку речь идёт о самой структуре управления: управляемые в разряд «капитала» не включаются или, если включаются, то так, чтобы включение в процесс управления работало против них.

Такова толпократия с её идеями гласности и крауд-технологиями. Поскольку бюрократия привыкла манипулировать общественностью, постольку она склонна выбирать технологии, лишь внешне похожие на технологии социального служения. Учёные и практики неред- 
ко идут на поводу, поскольку сообществ и людей, способных, в том числе в силу наличия реального опыта, строить отношения служения и взаимопомощи, очень мало. Они изучают достоинства толпократии и крауд-технологий, уповая на самоорганизацию и саморегуляцию «свободного рынка» труда, товаров и услуг, работодателей и т.д. Однако иллюзия самоорганизации не срабатывает: пока основой жизни человека и группы остаётся идеология социального превосходства, накопительства и власти, человек и группа будут трансформировать любые, самые «лучшие» технологии, опираясь на привычные способы решения проблем и принятия решений, будут выбирать пути, позволяющие имитировать «заботу о ближнем».

В практике стратегии управления в значительной степени перемешаны. Негативным моментом является преобладание тенденций моноакторного управления или отказа (имитаций) управления. Позитивным моментом являются продолжающиеся научные и практические эксперименты в сфере управления, разработка эвергетики и, на её основе, разработка и внедрение интерсубъективных технологий, предполагающих мультиакторные формы управления, привлечения граждан к процессам принятия решений в управлении территориями. Применение мультиакторных или интерсубъективных технологий участия граждан в управлении позволяет уйти, с одной стороны, от спонтанности их взаимодействия с органами власти и управления, а, с другой, избежать жёстких, административных решений и выводят процесс согласования интересов на новый уровень, который характеризуется рационализацией отношений и конструктивностью взаимодействия. Без технологий интерсубъективного управления и трансформации отношений государства, общества и бизнеса в отношении служения и взаимопомощи, без превращения стран в государства-церкви, функционирующие на основе нравственных, а не только юридических законов, развитие не возможно. Люди нуждаются в сознании возможностей лоурархии и социального служения, а также реализующих их эвергетические, интерсубъективные технологии управления сообществом, позволяющие создать государство-церковь и активизировать личностное развитие граждан, развивать и накапливать социальный и человеческий капитал.

\section{Заключение}

Таким образом, одно из наиболее важных измерений исследований развития управления в рамках общества, организации и жизни человека связано с выбором между:

- социальным служением, альтруизмом, помощью другим людям, служению обществу в целях его совершенствования и гармонизации, эвергетической стратегией социального участия и партнёрства, взаимопомощи и благодарения в лоурархическом, глубинно демократическом сообществе, развивающемся по принципам интерсубъектного, инновационного управления и со-управления, полилога;

- социальной аномией и равнодушным «присутствием» в обществе как реальности, не требующей и не нуждающейся в развитии и преобразовании, анархическом и псевдодемократическом сообществе рынка и бюрократии, псевдоэвергетической стратегией, сворачивающих диалогичность, интерсубъектность управления к нормам подчинения и исполнения, купли и продажи власти и привилегий;

- социальным каннибализмом, связанным с потребительской ориентацией в отношении общества и его членов, нацеленностью на получение бесконечных персональных выгод, подавление слабых; типичны антиэвергетическая стратегия мондиалистической редистрибуции, криптократический стиль управления «хозяев» «рабами» в неорабовладельческом обществе, не нуждающемся и не допускающем коммуникацию: управляемые - не люди, а рабы. 
Подводя итог, подчеркнём, что концепция эвергетики В.А. Виттиха, при внешней очевидности вопроса о ценностях и целях управления, обладает огромным потенциалом, связанным с ревизией традиционных и современных моделей управления, самого понятия управление. Вводя в научное исследование представление о тесной связи ценностей и целей управления с его сущностными характеристиками, В.А. Виттих формулирует новый поворот в осмыслении управления как такового. Этот поворот, интегрирующий классические и неклассические концепции и модели управления в единую, трансдициплинарную и трансдискурсивную модель, - значим и теоретически, и практически. Не имеет смысла говорить о механизмах управления, об эффективности и продуктивности управления, тем более - управления развитием, - там, где не определена сама суть управления, не отрефлексированы его образующие - процессы и компоненты. В эвергетике как «постнеклассической науке о процессах управления в обществе», которая исходит из «суперпозиции» субъекта и объекта управления, «неоднородности» сообществ и акторов, выступающих и как исследователи, и как субъекты, участвующие в принятии решений, исследующий управление также является актором. Исследователь утрачивает «привилегированную позицию абсолютного наблюдателя, выступая лишь как участник социальной жизни наравне с другими» [32-35].

Субъект и творит, и познает мир: актор находится «внутри» объекта (общества) и коммуницирует с другими акторами в общей для них проблемной жизненной ситуации [36-38]. В стремлении найти выход, решение проблемы акторы вырабатывают соглашения как интерсубъективные знания, систематизируют их для принятия коллегиального решения. В традиционной модели вынесение человека «за скобки» не позволяет использовать его индивидуальные возможности в процессах управления, они просто игнорируются. При этом человеческий или субъективный фактор отражает «помехи» и «трудности» управления. Поиск смысла ситуации её участниками - всего лишь артефакт, а не центральный аспект управления. Однако понимание смысла раскрывает и путь изменений, управления.

Феномен управления - один из трансдициплинарных и трансдирскусивных объектов современных исследований, который в контексте трансдисциплинарного и трансдискурсивного подхода, обрёл своё новое название - эвергетика как одна из «кибернетик третьего порядка» [39-42].

\section{Список источников}

[1] Агафонов, А.Ю. Наука о сознании: нерешённые проблемы / А.Ю. Агафонов // Онтология проектирования. 2014. - №2(12). - C.8-18.

[2] Боргест, Н.M. Ключевые термины онтологии проектирования: обзор, анализ, обобщения / Н.М. Боргест // Онтология проектирования. 2013. - №3(9). - С.9-32.

[3] Боргест, Н.M. Научный базис онтологии проектирования / Н.М. Боргест // Онтология проектирования. 2013. - №1(7). - C.7-25.

[4] Боргест, Н.M. Онтологии: современное состояние, краткий обзор / Н.М. Боргест, М.Д. Коровин // Онтология проектирования. 2013. - №2(8). С.49-55.

[5] Bummux B.A. Принятие решений на основе консенсуса с применением мультиагентных технологий / В.А. Виттих, Т.В. Моисеева, П.О. Скобелев // Онтология проектирования. - 2013. - №2(8). С.20-25.

[6] Витmих, B.A. Пролегомены к эвергетике / В.А. Виттих // Онтология проектирования. 2015. - №2 (5). C.135-148.

[7] Скобелев, П.О. Онтологии деятельности для ситуационного управления предприятиями в реальном времени / П.О. Скобелев // Онтология проектирования. 2012. - №1(3). - С.6-38.

[8] Смирнов, C.B. Онтологии как смысловые модели / С.В. Смирнов // Онтология проектирования. 2013. №2(8). - C.12-19.

[9] Guarino, N. Formal ontology, conceptual analysis and knowledge representation / N. Guarino // Int. J. of Human Computer Studies. 1995. V. 43. № 5/6. - P. 625-640.

[10] Киндлер, E. Языки моделирования: Пер. с чеш. / Е. Киндлер - М.: Энергоатомиздат, 1985. - 288 с. 
[11] Vittikh, V.A. Introduction to the Theory of Intersubjective Management // Group Decision and Negotiation. - January 2015. - V. 24, issue 1. - P. 67-95.

[12] Витmих, В.A. Проблемы эвергетики / В.А. Виттих // Проблемы управления. 2014. - №4. - С. 69-71.

[13] Vittikh, V.A. Evolution of ideas on management processes in the society: from cybernetics to evergetics // Group Decision and Negotiation. - September 2015- V. 24, issue 5. - P. 825-832.

[14] Акофф, P.Л. За пределами социализма и капитализма: развивающееся общество / Р.Л. Акофф // Проблемы управления в социальных системах. - 2009. Т.1. - С. 112-140.

[15] Розинская, Н.А. Введение. «Великая трансформация» Карла Поланьи / Н.А. Розинская, Ю.В Латов / Под ред. Р.М. Нуреева. М.: ВШЭ, 2007. - С.11-21.

[16] B eni, G. Swarm Intelligence in Cellular Robotic Systems, Proceed / G.Beni, J. Wang // NATO Advanced Workshop on Robots and Biological Systems. Tuscany, Italy, June 26-30, 1989. - N.Y.: NATO, 1989.

[17] Rzevski, G., Skobelev, P. Emergent Intelligence in Large Scale Multi-Agent Systems// international journal of education and information technologies. - 2007. Issue 2, Volume 1. - P.64-71.

[18] Wooldridge, M. An Introduction to MultiAgent Systems. N.Y.: John Wiley \& Sons Ltd, 2002. - 366 p.

[19] Арпентьева, M.P. Эвергетические стратегии и управление развитием сообществ / М.Р. Арпентьева // Материалы XVII Международной конференции «Проблемы управления и моделирования в сложных системах» 22-25 июня 2015 г., Самара. - Самара: ИПУСС РАН, 2015. - С.174-180.

[20] Aрпентьева, M.P. Эвергетические стратегии в управлении человеческими ресурсами и социальным развитием / М.Р. Арпентьева // Нефть и газ Западной Сибири: материалы междун. научно-технической конф., посв. 90-лет. со дня рожд. А.Н. Косухина 15-16 октября 2015 г. / Отв. ред. П.В. Евтин. - Тюмень: ТГНГУ, 2015. - T.6. - С.27-32.

[21] Рейнгольд, Г. Умная толпа/ Г.Рейнольд. М.: ФАИР ПРЕСС, 2006. - 416 с.

[22] Стэндинг, Г. Прекариат: новый опасный класс / Г. Стэндинг. - М.: Ад Маргинем Пресс, 2014. - 328c.

[23] Xay, Джс. Краудсорсинг. Коллективный разум как инструмент развития бизнеса / Дж. Хау. — М.: Альпина Паблишер, 2012. - 288 с.

[24] Ладягин Ю.С. Русский административный восторг / Ю.С. Ладягин // Проблемы теории и практики управления. - 2005. - №3. - С.8-15.

[25] Фисман, Р. Экономические гангстеры / Р.Фисман, Э. Мигель. М.: ООО «Юнайтед Пресс», 2012. - 302 с.

[26] Валлерстайн И. После либерализма / И. Валлерстайн. - М.: Едиториал УРСС, 2003. - 256 с.

[27] Коулман, Джс. Капитал социальный и человеческий /Дж. Коулман // Общественные науки и современность, 2001. № 3. - С. 121-139.

[28] Бодрийяр, Ж. Усталость / Ж. Бодрийяр // Бодрийяр, Ж. Общество потребления. Его мифы и структуры. М.: Культурная революция; Республика, 2006. - С. 230-234.

[29] Putnam, R. The Prosperous Community. The American Prospec. 1993. - Vol.4. №13. - P.1-8.

[30] Арпентьева, М.P. Социально-психологическая компетентность: статьи и эссе / М.Р. Арпентьева, И.В. Карпенкова, Н.П. Ничипоренко / Под ред. М.Р. Арпентьевой. - Калуга: КГУ им. К.Э. Циолковского, 2016. $-650 \mathrm{c}$.

[31] Allport, G.W. The Nature of Prejudice. — N.Y.: Addison-Wesley Publishing Company, 1979. — 537 c.

[32] Витmux, B.A. Инструментальная и коммуникативная рациональности акторов / В.А. Виттих // Проблемы управления и моделирования в сложных системах: Труды XV международной конференции. - Самара, Самарский научный центр РАН, 2013, - с.267-273.

[33] Vittikh, V.A. Heterogeneous Actor and Everyday Life as Key Concepts of Evergetics // Group Decision and Negotiation, November 2015. - V. 24, issue 6. - P. 949-956.

[34] Bummux, B.A. Феноменологический подход к построению теории управления обществом / В.А. Виттих // Сборник трудов XII Всероссийского совещания по проблемам управления. Москва, ИПУ РАН, 16-19 июня 2014 г. - С. 6182-6186.

[35] Витmих, B.A. Ситуационное управление с позиций постнеклассической науки / В.А. Виттих // Онтология проектирования, №2 (4), 2012. - С. 7-15.

[36] Лепский B.E. Философия и методология управления в контексте развития научной рациональности / В.Е. Лепский // Труды ХІІ Всероссийского совещания по проблемам управления. - М.: ИПУСС РАН, 2014. C. 7785-7796.

[37] Новиков, Д.А. Кибернетика: Навигатор: История кибернетики, современное состояние, перспективы развития / Д.А. Новиков. - М.: ЛЕНАНД, 2016. - 160 с.

[38] Харитонов, В.A. Концепция субъектно-ориентированного управления в социальных и экономических системах / В.А.Харитонов, А.О. Алексеев // Политематический сетевой электронный научный журнал Кубанского государственного аграрного университета (Научный журнал КубГАУ). - Краснодар: КубГАУ, 2015. - №05(109). - IDA [article ID]: 1091505043. - http://ej.kubagro.ru/2015/05/pdf/43.pdf 
[39] M ancilla, R. Introduction to Sociocybernetics (Part 1): Third Order Cybernetics and a Basic Framework for Society / R. Mancilla // Journal of Sociocybernetics. 2011. Vol. 42. No 9. - P.35-56.

[40] Kenny, V. There's Nothing Like the Real Thing. Revisiting the Need for a Third-Order Cybernetics / V. Kenny // Constructivist Foundations. 2009. No 4(2). - P.100-111.

[41] Umpleby, S.A Brief History of Cybernetics in the United States / S.A Umpleby // Austrian Journal of Contemporary History. 2008. Vol. 19. No 4. - P.28-40.

[42] U mpleby, S.A The Science of Cybernetics and the Cybernetics of Science / S.A Umpleby // Cybernetics and Systems. 1990. Vol. 21. No. 1. - P.109-121.

\title{
EVERGETIC AND ONTOLOGIES OF MANAGEMENT
}

\section{M.R. Arpentieva}

Kaluga State U niversity named after K.E. Tsiolkovsky, Kaluga, Russia

mariam-rav@yandex.ru

\begin{abstract}
The article is devoted to the analysis of the three evergetical strategies in sciences searches and management of the community development. The study develops regulations based on postnonclassical scientific rationality evergetics from V.A. Vittikh, discusses evergetical strategies, it's differences in managing theory and practice. The complexity of communities and the process of their development, the proliferation of diversity management issues these communities and their development suggest the need for developing approaches that integrate a variety of these practical problems and develop a single, theoretical model and meta-model. These models allow not only to optimize the control method, but to answer the question about what management is and what management is necessary for the development of communities as examples of complex, developed systems. Evergetics, proposed by V.A. The Vittikh, becomes one of such approaches It is an example of transdisciplinary and transdiscursive approach to comprehend the essence and technologies of management. It allows to select the strategy, harmoniously implementing the values and management objectives as a component of community development. Comparative analysis of management strategies allows to select evergetical, pseudoevergetical and unevergetical strategies, their characteristics and capabilities in managing the development of their communities. Selected strategies phenomenologically similar to various under-moves to the study of management, reflect certain aspects of it. Practical significance of the research connected with the development of a new perspective on the nature, components and processes that involves the possibility of optimizing the management and training management of social development. Theoretical significance of the research is connected with the development of the evergetics theory by V.A. Vittikh as an innovative metatheoretic, transdimensional approach to understanding the control of complex systems aimed at understanding the essence of society and its development.
\end{abstract}

Key words: management ontologies management, technology, ideology, evergetics, multi-agent technology, evergetical strategy, social service.

Citation: Arpentieva M R. Eevergetic and ontologies of management. O ntology of designing. 2016; 6(1): 106-124. DOI: 10.18287/2223-9537-2016-6-1-106-124.

\section{References}

[1] Agafonov AYu. Science of consciousness: unsolved problems. Ontology of designing. 2014. - №2(12): 8-18 (In Russian).

[2] Borgest NM. Key terms ontology of designing: a review, analysis, synthesis. Ontology of designing. 2013. №3(9): 9-32 (In Russian).

[3] Borgest N M. The scientific basis of ontology of designing. Ontology of designing. 2013. - №1(7): 7-25 (In Russian).

[4] B orgest N M, Korovin M D. Ontologies: current status, an overview. Ontology of designing. 2013. - №2(8): 49-55 (In Russian). 
[5] Vittikh VA, M oiseeva TV, Skobelev PO. A decision on the basis of consensus with the use of multiagent technologies. Ontology of designing. - 2013. - №2(8): 20-25 (In Russian).

[6] Vittikh VA. Prolegomena to evergetics. Ontology of designing. 2015. - №2 (5): 135-148 (In Russian).

[7] Skobelev PO. Ontology of activities for the situational management of enterprises in real time. Ontology of designing. 2012. - №1(3): 6-38 (In Russian).

[8] Smirnov SV. Ontology as a semantic model. Ontology of designing. 2013. - №2(8): 12-19. (In Russian).

[9] Guarino N. Formal ontology, conceptual analysis and knowledge representation / Int. J. of Human Computer Studies. 1995. V. 43. № 5/6: 625-640.

[10] Kindler E. Yazyki modelirovaniya [Modeling languages]: Translated from Czech. - Moscow: Energoatomizdat, 1985. - 288 p. (In Russian).

[11] Vittikh VA. Introduction to the Theory of Intersubjective Management // Group Decision and Negotiation. - January 2015. - V. 24, issue 1: 67-95.

[12] Vittikh VA. Problemy evergetiki [Evergetics Problems] / Problemy upravleniya [Problems of management]. 2014. - №4: 69-71 (In Russian).

[13] Vittikh VA. Evolution of ideas on management processes in the society: from cybernetics to evergetics // Group Decision and Negotiation. - September 2015- V. 24, issue 5: 825-832.

[14] A koff RL. Za predelami sotsializma i kapitalizma. Problemy upravleniya v sotsial'nykh sistemakh [Beyond socialism and capitalism. Management problems in social systems]. T.1., 2009: 112-140 (In Russian).

[15] R ozinskaya N A, Latov YV. Vvedenie. «Velikaya transformatsiya» Karla Polan'i [Introduction. The «great transformation» of Karl Polanyi] / Pod red. R.M. Nureeva. M.: VShE, 2007: 11-21. (In Russian).

[16] B eni G, Wang J. Swarm Intelligence in Cellular Robotic Systems, Proceed / NATO Advanced Workshop on Robots and Biological Systems. Tuscany, Italy, June 26-30, 1989. - N.Y.: NATO, 1989.

[17] Rzevski G, Skobelev P. Emergent Intelligence in Large Scale Multi-Agent Systems// International journal of education and information technologies. - 2007. Issue 2, Volume 1: 64-71.

[18] Wooldridge M. An Introduction to MultiAgent Systems. N.Y.: John Wiley \& Sons Ltd, 2002. - 366 p.

[19] Arpent'eva MR. Evergeticheskie strategii i upravlenie razvitiem soobshchestv [Evergetical strategy and management community development] / Materialy XVII Mezhdunarodnoy konferentsii «Problemy upravleniya i modelirovaniya v slozhnykh sistemakh» [Proceedings of the XVII International conference «Problems of control and modeling in complex systems»] 22-25 July 2015, - Samara: IPUSS RAN, 2015: 174-180. (In Russian).

[20] Arpent'eva MR. Evergeticheskie strategii v upravlenii chelovecheskimi resursami i sotsial'nym razvitiem [Evergetical strategies in the management of human resources and social development] / Neft' i gaz Zapadnoy Sibiri: materialy mezhdun. nauchno-tekhnicheskoy konf., posv. 90-let. so dnya rozhd. A.N. Kosukhina [Oil and gas of West Siberia: materials of the int. scientific-technical conf. arr. 90-years. from the day born. A. N. Kosuhina] 1516 October 2015. / Edit. P.V. Evtin. - Tyumen': TGNGU, 2015. - T.6: 27-32. (In Russian).

[21] R eyngold G. Umnaya tolpa [Smart crowd]. M.: FAIR PRESS, 2006. - 416 p. (In Russian).

[22] Stending G. Prekariat: novyy opasnyy klass [Precariat: the new dangerous class]. — M.: Ad Marginem Press, 2014. - 328 p. (In Russian).

[23] Khau J . Kraudsorsing. Kollektivnyy razum kak instrument razvitiya biznesa [Crowdsourcing. Collective intelligence as a tool of business development]. — M.: Alpina Publisher, 2012. — 288 p. (In Russian).

[24] L adyagin YP. Russkiy administrativnyy vostorg [Russian administrative delight] / Problemy teorii i praktiki upravleniya [Problems of theory and management practice]. - 2005. - №3: 8-15. (In Russian).

[25] F isman R, M igel E . Economic Gangsters: Corruption, Violence, and the Poverty of Nations, 2009. - 264 p. ISBN13: 9780691144696.

[26] Wallerstein I. After liberalism. The New Press (1995-11-01). - 288 p. ISBN-13: 9781565843042.

[27] Coleman J S. Social Capital in the Creation of Human Capital. American Journal of Sociology. Vol. 94, Supplement: Organizations and Institutions: Sociological and Economic Approaches to the Analysis of Social Structure (1988): S95-S120.

[28] B audrillard J. The Consumer Society: Myths and Structures (Published in association with Theory, Culture \& Society). SAGE Publikation. 2004. - 208 p. ISBN-13: 978-0761956921.

[29] Putnam R. The Prosperous Community. The American Prospect. 1993. - Vol.4.№13.P. 1-8.

[30] Arpent'eva MR, Karpenkova IV, Nichiporenko NP. Sotsial'no-psikhologicheskaya kompetentnost': stat'i i esse [Socio-psychological competence: articles and essays] / Edit. M.R. Arpent'eva. - Kaluga: KGU im. K.E. Tsiolkovskogo, 2016. - 650 p. (In Russian).

[31] Allport GW. The Nature of Prejudice. - N.Y.: Addison-Wesley Publishing Company, 1979. — 537 p.

[32] Vittikh VA. Instrumental'naya i kommunikativnaya ratsional'nosti aktorov [Instrumental and communicative rationality of actors] / Problemy upravleniya i modelirovaniya v slozhnykh sistemakh: Trudy XV mezhdunarodnoy konferentsii [Problems of control and modeling in complex systems: Proceedings of the XV international conference]. - Samara, Samarskiy nauchnyy tsentr RAN, 2013: 267-273. (In Russian). 
[33] Vittikh VA. Heterogeneous Actor and Everyday Life as Key Concepts of Evergetics // Group Decision and Negotiation, November 2015. - V. 24, issue 6: 949-956.

[34] Vittikh VA. Fenomenologicheskiy podkhod k postroeniyu teorii upravleniya obshchestvom [Phenomenological approach to the theory of management of society] / Sbornik trudov XII Vserossiyskogo soveshchaniya po problemam upravleniya [Proceedings of XII All-Russian conference on management problems]. Russia, Moscow, ICS RAS, 16-19 July 2014: 6182-6186 (In Russian).

[35] Vittikh VA. Situational management from the perspective of postnonclassical science. Ontology of designing. 2012. - №2 (4): 7-15 (In Russian).

[36] Lepskiy VE . Filosofiya i metodologiya upravleniya v kontekste razvitiya nauchnoy ratsional'nosti [Philosophy and methodology of management in the context of the development of scientific rationality] / Trudy XII Vserossiyskogo soveshchaniya po problemam upravleniya [Proceedings of XII All-Russian conference on management problems]. - M.: ICCS RAS, 2014: 7785-7796 (In Russian).

[37] Novikov DA. Kibernetika: Navigator: Istoriya kibernetiki, sovremennoe sostoyanie, perspektivy razvitiya [Cybernetics: the Navigator: a History of Cybernetics, the current state and prospects] — M.: LENAND, 2016. — 160 p. (In Russian).

[38] Kharitonov VA, Alekseev AO. Kontseptsiya sub'ektno-orientirovannogo upravleniya v sotsial'nykh i ekonomicheskikh sistemakh [The Concept of subject - oriented management in social and economic systems] / Politematicheskiy setevoy elektronnyy nauchnyy zhurnal Kubanskogo gosudarstvennogo agrarnogo universiteta (Nauchnyy zhurnal KubGAU) [Polythematic network electronic scientific journal of the Kuban state agrarian University (Journal KubGAU)]. - Krasnodar: KubGAU, 2015. - №05(109). - IDA [article ID]: 1091505043. http://ej.kubagro.ru/2015/05/pdf/43.pdf (In Russian).

[39] M ancilla R. Introduction to Sociocybernetics (Part 1): Third Order Cybernetics and a Basic Framework for Society / Journal of Sociocybernetics. 2011. Vol. 42. N 9: 35-56.

[40] Mancilla R. Introduction to Sociocybernetics (Part 3): Fourth Order Cybernetics / Journal of Sociocybernetics. 2013. Vol. 44. No 11: 47-73.

[41] Umpleby PA. Brief History of Cybernetics in the United States / Austrian Journal of Contemporary History. 2008. Vol. 19. N4: 28-40.

[42] Umpleby PA. The Science of Cybernetics and the Cybernetics of Science / Cybernetics and Systems. 1990. Vol. 21. No.1: 109-121.

\section{Сведения об авторе}

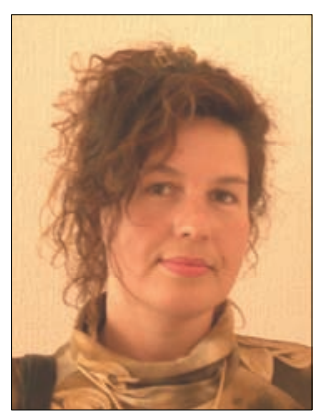

Арпентьева Мариям Равильевна, 1972 г.рождения. Окончила Калужский государственный педагогический институт им. К.Э. Циолковского в 1994 г., аспирантуру Московского государственного университета им. М.В. Ломоносова в 1999 г. В 1999 г. защитила кандидатскую и в 2015 г. докторскую диссертации. Д.пс.н., старший научный сотрудник кафедры психологии развития и образования Калужского государственного университета им. К.Э. Циолковского. В списке научных трудов более 350 работ в области социальной психологии и философии, посвященных проблемам изучения понимания и взаимопонимания в отношениях социальных субъектов как сложных социальных систем.

Arpentieva Mariam Ravilievna (b.1972) graduated from the Kaluga State Pedagogical Institute in 1994. Graduated from postgraduate course of Moscow M. V. Lomonosov State University in 1999. He defended his candidate thesis in 1999 and doctoral thesis in 2015, doctor of psychological sciences. She is Senior researcher at Kaluga K. E. Tsiolkovsky State University, Department of psychology of development and education. She is author more than 350 scientific articles and monographs in the field of social psychology and philosophy: understanding and comprehension in social interaction. 


\title{
РЕКОМЕНДАЦИИ АВТОРАМ
} Recommendations for authors of journal

\author{
«Работа не имеет никакой ценности, \\ если никто её не прочитал, \\ не использовал и не процитировал» \\ Якшонок Г.П., \\ руководитель партнерских программ \\ Elsevier в России и Беларуси
}

Требования к оформлению материала для журнала «Онтология проектирования» по мере необходимости совершенствуются и публикуются на сайте журнала в разделе ния $^{1} »$, где в формате шаблона-образца размещена Инструкция по подготовки статей. Обязанности авторов статей указаны также на сайте в разделе «Этика ${ }^{2} »$. Однако опыт работы редакции показывает, что многие присылаемые статьи, к сожалению, не соответствуют установленным правилам как по оформлению и выдерживанию стилевых решений, так и по содержанию и этическим нормам самой научной статьи. Ориентируясь в своей деятельности на лучшие отечественные и мировые практики ${ }^{3,4,5}$, редакция считает своим долгом ещё раз напомнить основные и очевидные требования к присылаемым в редакцию научным статьям.

Авторы предоставляют статью, являющуюся оригинальным самостоятельным результатом исследования, не публиковавшимся ранее, где освещаются актуальность поставленной проблемы и научная новизна. Все рукописи авторских статей проходят в редакции процедуру рецензирования и редактирования. Хорошая статья:

- понятно написана, представлена и выстроена логически (рецензенты, редакторы легко «схватывают» научный смысл работы);

- полезна (её результаты могут использовать другие авторы в своей работе);

- вызывает научный интерес;

- позволяет другим учёным воспроизвести её результаты.

Но для начала определитесь - соответствует ли Ваша статья тематике журнала, и если да, то какому разделу больше всего соответствуют результаты Ваших исследований. Не забудьте об этом сообщить редакции, сделав в конце статьи приписку с указанием тематического раздела журнала, к которому, по Вашему мнению, относится предложенный материал.

- Прикладные онтологии проектирования.

- Инжиниринг онтологий.

- Методы и технологии принятия решений.

- Философские, лингвистические и психологические аспекты проектирования.

\section{Рекомендуемые параметры статьи (для ориентира)}

Объём статьи 10-25 страниц.

Название - краткое, но точное; определяет основную проблему статьи; начинается с предмета работы. Хорошее заглавие должно содержать наименьшее по возможности количество слов, которые максимально точно описывают содержание статьи.

\footnotetext{
${ }^{1}$ http://agora.guru.ru/display.php?conf=scientific_journal\&page=item001\&PHPSESSID=9c8ub514t4da0rmbmfs17ieur1 ${ }^{2} \mathrm{http}: / /$ agora.guru.ru/display.php? conf $=$ scientific_journal\&page $=\mathrm{item} 009 \& P H P S E S S I D=h 7 \mathrm{k} 85 \mathrm{u} 7 \mathrm{igh} 88 \mathrm{ik} 1 \mathrm{~s} 22 \mathrm{ra} 3$ eqet6 ${ }^{3}$ Guide for Authors. - https://www.elsevier.com/journals/engineering-fracture-mechanics/0013-7944/guide-for-authors; http://health.elsevier.ru/for-authors/

${ }^{4}$ Рекомендации авторам ПТЭ по подготовке статей к печати. - http://www.maik.ru/journals/p/pribory/rus/recom.pdf

${ }^{5}$ Якшонок Г.П. Рекомендации авторам по подготовке публикации в международном рейтинговом журнале с использованием доступных информационных ресурсов Elsevier. - http://lib.ifmo.ru/file/news/92/2.pdf
} 
Ключевые слова (5-8 слов) - являются метками статьи, используются индексирующими и реферирующими сервисами и базами данных. Не используйте слова слишком широкого значения, избегайте многословные термины, допустимы только общепринятые сокращения.

Аннотация (120-250 слов) - краткое изложение проблемы, методов исследования, результатов и заключения. Аннотация - это фактически реклама статьи, поэтому должна быть точной и конкретной, интересной и простой для понимания, так как напрямую влияет на то, будет ли в дальнейшем Ваша статья читаться и анализироваться или нет.

В содержательном отношении редакция ориентируется на отечественный стандарт представления научно-исследовательских материалов ${ }^{6}$, приветствует и IMRAD-структуризацию статьи (ориентированная в большей степени на публикацию материалов эмпирического исследования). В любом случае структуризация статьи - введение, разделы (возможно, тоже структурированные), заключение - обязательна.

Текст должен состоять из осмысленных, осваиваемых читателем частей. Структурированный текст - это признак глубокой работы автора, уважения и заботы о читателе. Именно для читателя предназначена статья, именно ему предстоит разобраться в написанном и использовать или нет в своей работе материал статьи. Слабо структурированная статья затрудняет её прочтение. Мысль не должна растекаться на несколько страниц (это не литературное произведение), а быть содержательной, конкретной и понятной читателю. В каждом структурированном фрагменте текста читатель смог бы найти для себя полезную законченную мысль, идею, суждение. Большие «куски мысли» автора трудны для читателя. Фактически работа автора перекладывается в таком случае на плечи читателя.

Во введении (1-2 страницы) следует убедить читателей в том, что работа полезна, объяснить мотивы выполненного исследования. Представьте суть возникшей проблемы, укажите, есть ли её решение и в чём его ограниченность. Сформулируйте цель исследования, придерживаясь направленности журнала.

В основной части работы, представленной разделами статьи (рекомендуемый размер раздела не более 3-х страниц), опишите Ваши достижения: разработанные подходы, концепции, модели, методы и результаты, полученные с их помощью; результаты исследования значимости и эффективности сделанных предложений, решений. Рисунки и таблицы будут хорошо представлять результаты, если подписи их достаточно подробны, а в тексте на них имеются ссылки и комментарии!

В заключении (до 1 страницы) сопоставьте цели и задачи работы с полученными результатами. Обсудите, как ваша работа улучшает/расширяет знания в исследуемой области, что конкретно достигнуто в работе; отразите её связь с тенденциями развития направления и т.п.

В список источников включайте работы из разных стран и только те, на которых действительно основывалось Ваше исследование. Не «раздувайте» список, не допускайте излишнего самоцитирования (возьмите за ориентир не более $20 \%$ ) и строго соблюдайте предложенный редакцией стиль!

Благодарность. Проверьте, что вы поблагодарили, отдали должное тем, кто помог вам в подготовке вашей работы, включая спонсоров, помощников, консультантов; тех, кто предоставлял вам дополнительный материал, давал советы и т.п.

\section{Окончательная проверка}

Проверьте Вашу работу, прежде чем направлять её в редакцию! Попросите коллег или руководителя просмотреть её. УДАЧИ!

\footnotetext{
${ }^{6}$ ГОСТ 7.32-2001. Отчет о научно-исследовательской работе: Структура и правила оформления / Система стандартов по информации, библиотечному и издательскому делу. - Минск: Межгосударственный совет по стандартизации, метрологии и сертификации, 2001. - 19 с.
} 


\section{Рекомендуемые конференции - 2016 - Recommended Conference}

\begin{tabular}{|c|c|c|}
\hline $\begin{array}{c}\text { Название } \\
\text { конференции }\end{array}$ & $\begin{array}{l}\text { Дата и место } \\
\text { проведения }\end{array}$ & $\begin{array}{c}\text { Сроки приёма } \\
\text { и рассмотрения докладов }\end{array}$ \\
\hline $\begin{array}{l}\text { International Conference on Communication, } \\
\text { Management and Information Technology } \\
\text { (ICCMIT2016)_www.iccmit.net }\end{array}$ & $\begin{array}{l}\text { April 26-29 } \\
\text { University } \\
\text { of Calabria, } \\
\text { Cosenza, Italy }\end{array}$ & $\begin{array}{l}\text { Submission deadline - March } 1 \\
\text { Notification of acceptance - March } 14 \\
\text { Conference registration - March } 30 \\
\text { Final paper submission - April } 10 \\
\end{array}$ \\
\hline $\begin{array}{l}\text { 14th International Design Conference } \\
\text { http://www.designconference.org/ }\end{array}$ & $\begin{array}{c}\text { May 16-19 } \\
\text { Cavtat, Dubrovnik, } \\
\text { Croatia }\end{array}$ & $\begin{array}{l}\text { Final acceptance of papers - February } 26 \\
\text { Publish-ready papers - March } 21 \\
\text { Final Conference programme - April }\end{array}$ \\
\hline $\begin{array}{l}\text { XVI международная научная конференция } \\
\text { «Интеллектуальный анализ информации - } \\
\text { 2016» им. Т.А. Таран (ИАИ-2016) }\end{array}$ & $\begin{array}{l}\text { 18-20 мая } \\
\text { Киев, } \\
\text { Украина } \\
\end{array}$ & $\begin{array}{l}\text { Прием заявок - } 25 \text { марта } \\
\text { Извещение авторов о решении } \\
\text { Программного комитета - } 10 \text { апреля } \\
\end{array}$ \\
\hline $\begin{array}{l}\text { 22-я международная конференция по } \\
\text { компьютерной лингвистике и } \\
\text { интеллектуальным технологиям «Диалог» } \\
\text { http://www.dialog-21.ru/dialog2016/ }\end{array}$ & $\begin{array}{l}\text { 1-4 июня } \\
\text { Москва, } \\
\text { Россия }\end{array}$ & $\begin{array}{l}\text { Результаты рецензирования } \\
\text { с } 22 \text { марта по } 10 \text { апреля } \\
\text { Итоговые варианты статей } \\
\text { с } 28 \text { марта по } 17 \text { апреля }\end{array}$ \\
\hline $\begin{array}{l}\text { XXI Всероссийская Байкальская } \\
\text { конференция «Информационные и } \\
\text { математические технологии в науке и } \\
\text { управлении» www.imt.isem.irk.ru }\end{array}$ & $\begin{array}{c}29 \text { июня - } 8 \text { июля } \\
\text { Иркутск - Байкал, } \\
\text { Россия }\end{array}$ & $\begin{array}{l}\text { Прием докладов с публикацией } \\
\text { до конференции - } 25 \text { марта } \\
\text { Прием докладов с публикацией после } \\
\text { конференции - } 25 \text { июня }\end{array}$ \\
\hline $\begin{array}{l}\text { SEKE 2016: The 28th International } \\
\text { Conference on Software Engineering \& } \\
\text { Knowledge Engineering } \\
\text { http://ksiresearchorg.ipage.com/seke/seke16.ht } \\
\underline{\mathrm{ml}}\end{array}$ & $\begin{array}{c}\text { July } 1 \text { - 3 } \\
\text { Redwood City, } \\
\text { San Francisco Bay, } \\
\text { California, USA }\end{array}$ & $\begin{array}{l}\text { Paper submission due - March } 1 \\
\text { Notification of acceptance - April } 20 \\
\text { Early registration deadline - May } 10 \\
\text { Camera-ready copy - May } 10\end{array}$ \\
\hline $\begin{array}{l}\text { 9th International Conference on Formal } \\
\text { Ontology in Information Systems } \\
\text { (FOIS 2016) } \\
\text { http://www.iaoa.org/fois2016/ }\end{array}$ & $\begin{array}{c}\text { July 6-9 } \\
\text { University of } \\
\text { Savoie, Annecy, } \\
\text { France } \\
\end{array}$ & $\begin{array}{l}\text { FOIS Paper Submission Deadline - } \\
\text { February } 15 \\
\text { FOIS Notification - April } 15\end{array}$ \\
\hline $\begin{array}{l}\text { ECAI 2016: 22nd European Conference on } \\
\text { Artificial Intelligence } \\
\text { http://www.ecai2016.org/ }\end{array}$ & $\begin{array}{l}\text { August 29- } \\
\text { September } 2 \\
\text { World Forum } \\
\text { The Hague }\end{array}$ & $\begin{array}{l}\text { Paper Submission - April } 15 \\
\text { Paper Notification - June } 7 \\
\text { Early Registration Deadline - July } 5\end{array}$ \\
\hline $\begin{array}{l}\text { AIMSA } 2016 \text { : The } 17 \text { th International } \\
\text { Conference on Artificial Intelligence: } \\
\text { Methodology, Systems, Applications } \\
\text { http://www.aimsaconference.org/ }\end{array}$ & $\begin{array}{l}\text { September 7-9 } \\
\text { Varna, } \\
\text { Bulgaria, }\end{array}$ & $\begin{array}{l}\text { Submission deadline - April } 30 \\
\text { Notification of acceptance - June } 1 \\
\text { Deadline for camera-ready - June } 24\end{array}$ \\
\hline $\begin{array}{l}\text { AIAI 2016: The 12th IFIP International } \\
\text { Conference on Artificial Intelligence } \\
\text { Applications and Innovations } \\
\text { http://conferences.cwa.gr/aiai2016/ }\end{array}$ & $\begin{array}{c}\text { September 16-18 } \\
\text { Thessaloniki, } \\
\text { Greece }\end{array}$ & $\begin{array}{l}\text { Submission Deadline - April } 20 \\
\text { Notification Due - May } 20 \\
\text { Final Version Due - Jun } 10\end{array}$ \\
\hline $\begin{array}{l}\text { Пятнадцатая национальная конференция } \\
\text { по искусственному интеллекту } \\
\text { с международным участием (КИИ-2016) } \\
\text { http://www.raai.org/ }\end{array}$ & $\begin{array}{l}\text { 3-7 октября } \\
\text { Смоленск, } \\
\text { Россия }\end{array}$ & $\begin{array}{l}\text { Представление докладов - } 30 \text { апреля } \\
\text { Извещение авторов о решении } \\
\text { Программного комитета - } 15 \text { июня } \\
\text { Получение докладов - } 10 \text { июля } \\
\end{array}$ \\
\hline $\begin{array}{l}\text { Информационные технологии } \\
\text { в управлении ИТУ-2016 } \\
\text { (с секцией «Онтологическое } \\
\text { моделирование в управлении») } \\
\text { http://www.spiiras.nw.ru/conf/itu2016/ }\end{array}$ & $\begin{array}{c}\text { 4-6 октября } \\
\text { Санкт-Петербург, } \\
\text { Россия }\end{array}$ & $\begin{array}{l}\text { Регистрация рефератов - } 25 \text { апреля } \\
\text { Уведомление о принятии } \\
\text { доклада - } 5 \text { июня } \\
\text { Представление докладов - } 11 \text { августа }\end{array}$ \\
\hline $\begin{array}{l}\text { Twentieth International Multi-Conference On } \\
\text { Advanced Computer Systems (ACS 2016) } \\
\text { http://acs.wi.zut.edu.pl/ }\end{array}$ & $\begin{array}{l}\text { October } 19 \text { - } 21 \\
\text { Międzyzdroje, } \\
\text { Poland }\end{array}$ & $\begin{array}{l}\text { Submission of the full paper - May } 8 \\
\text { Notification of the paper acceptance } \\
\text { /rejection after review - June } 12 \\
\text { Camera-ready - June } 26\end{array}$ \\
\hline
\end{tabular}




\title{
XVIII Международная конференция ПРОБЛЕМЫ УПРАВЛЕНИЯ И МОДЕЛИРОВАНИЯ В СЛОЖНЫХ СИСТЕМАХ (ПУМСС-2016)
}

\author{
20-25 сентября 2016 г., Самара, Россия
}

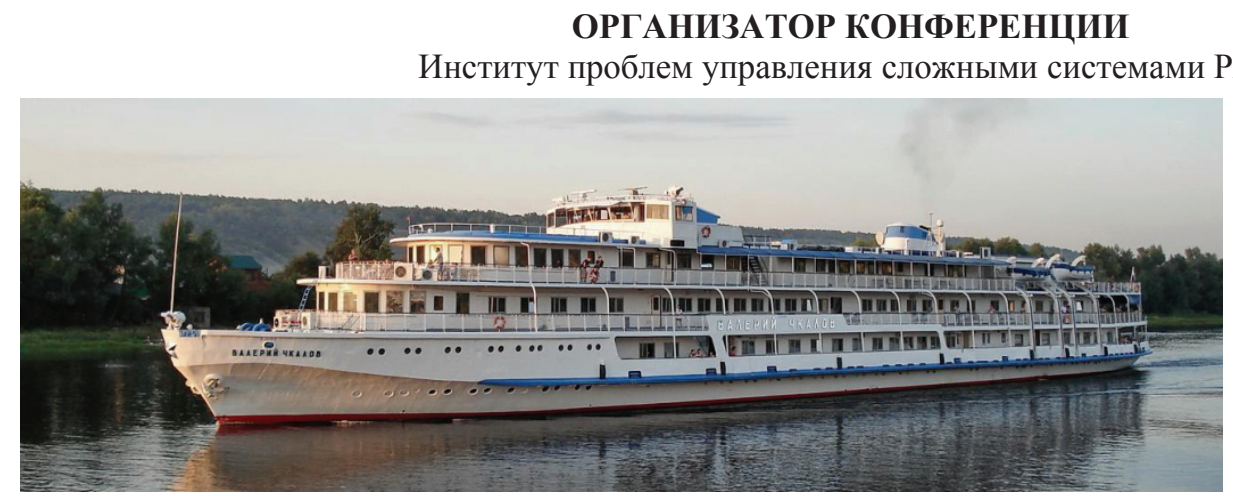

Конференция проводится на борту комфортабельного трёхпалубного теплохода «Валерий Чкалов», следующего по маршруту Самара-ЧебоксарыНижний НовгородКазань-Самара.

\section{ОСНОВНЫЕ НАПРАВЛЕНИЯ РАБОТЫ КОНФЕРЕНЦИИ}

- Интеллектуальные системы управления предприятиями

- Интеллектуальные системы управления группировками роботов

- Управление космическими полётами

- Процессы управления в обществе (в социиальных, экономических и политических системах)

- Информационные технологии в управлении

- Теория оптимального управления и её приложения

- Управление в сложных технических системах

- Измерения, контроль и диагностика в экстремальных условиях

Председатель программного комитета - Федосов Е.А. академик РАН, ФГУП ГосНИИАС, г. Москва Заместитель председателя программного комитета - Виттих В.А. д.Т.Н., ИПУСС РАН, г. Самара Учёный секретарь программного комитета - Моисеева Т.В. к.э.Н., ИПУСС РАН, г. Самара

\section{КОНТАКТНАЯ ИНФОРМАЦИЯ}

443020, Самара, ул. Садовая, 61, ИПУСС РАН. http://www.iccs.ru, E-mail: cscmp@iccs.ru, тел. (846) 333-27-70 - Моисеева Татьяна Владимировна, ученый секретарь Программного комитета. тел. (917) 161-24-35 - Шустова Дина Владимировна, технический секретарь конференции.

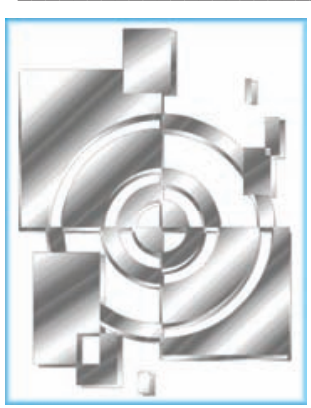

\section{9 марта 2016 г. исполнилось 20 лет со дня образования Института проблем управления сложными системами Российской академии наук (ИПУСС РАН)}

От имени редколлегии поздравляем сотрудников Института! Желаем дружному коллективу ИПУСС РАН оптимизма и новых творческих успехов на благо Отечества и науки!

Участвуя во второй половине 90-х в программе создания Системы компьютерной интеграции знаний в Научнотехническом центре ОАО АВТОВАЗ, коллектив лаборатории анализа и моделирования сложных систем ИПУСС РАН (тогда ею заведовал директор-основатель Института д.т.н. В.А. Виттих) впервые обратил внимание на полезность онтологической метафоры. Занимаясь разработкой прикладных интеллектуальных систем для поддержки инженерной деятельности и инструментальным обеспечением этой работы, коллеги всё больше убеждались, что давно говорят «прозой» - языком онтологического инжиниринга. Спустя пять лет была подготовлена одна из первых в России докторских диссертаций на эту тему: «онологический анализ в системах компьютерного моделирования» (Смирнов С.В., 2002). 


\section{Индекс 29151}

В конце 2015 года вышли в свет издания по онтологии проектирования, подготовленные сотрудниками СГАУ и ориентированные на магистрантов и аспирантов инженерных специиальностей университетов

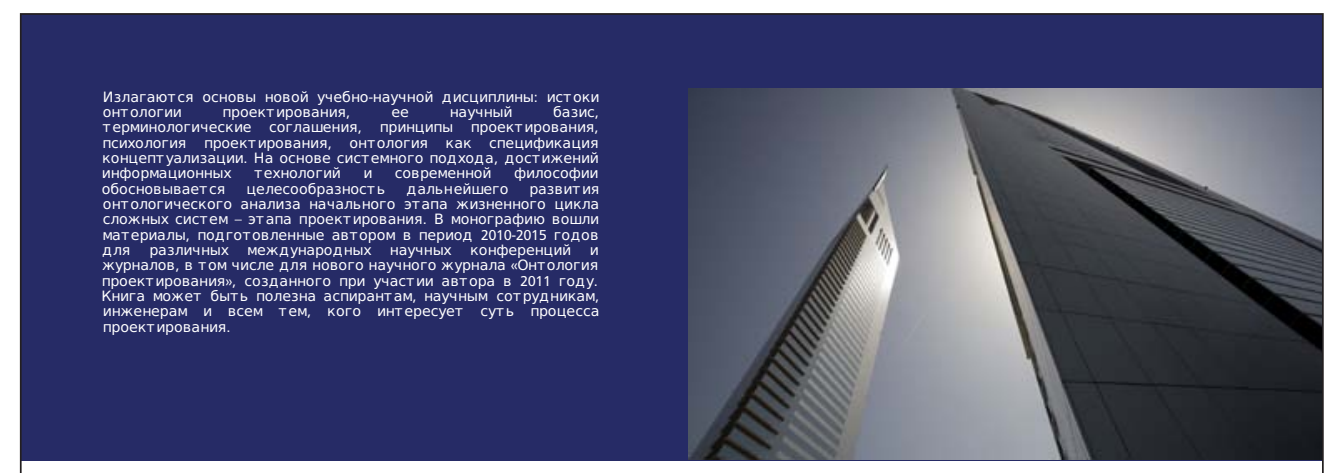

Николай Боргест

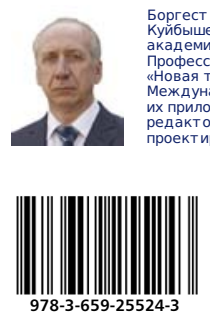

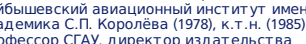

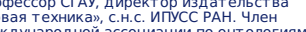

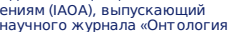

\section{Введение в онтологию
проектирования \\ Введение в онтологию
проектирования}
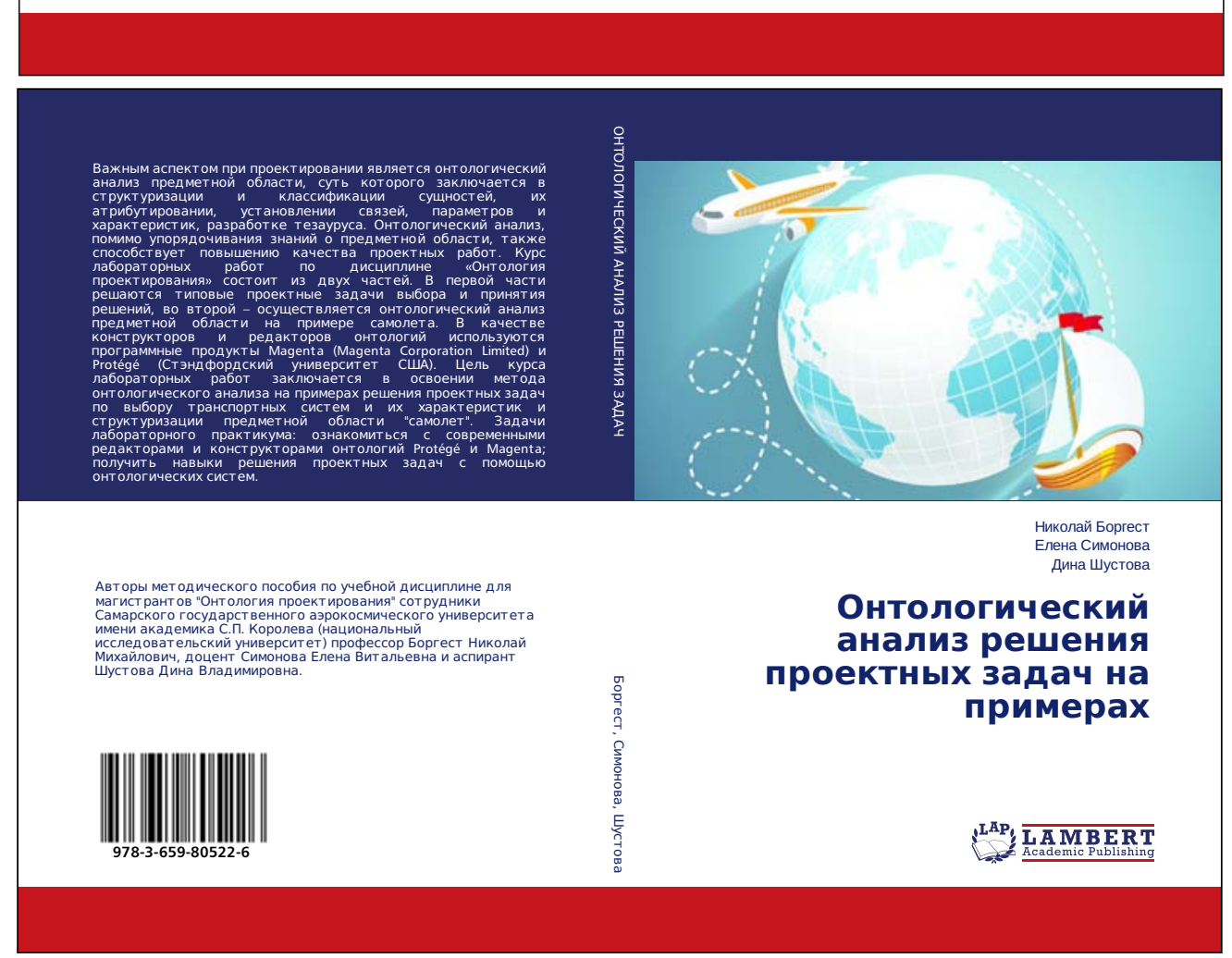

Ontologists and designers of all countries and subject areas, join us!

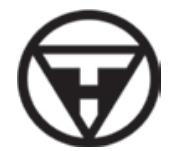

Издательство "Новая техника" - Publisher «New Engineering» Ltd Россия, 443010, Самара, ул.Фрунзе 145 - 145, Frunze Str., Samara, 443010, Russia 